August 2003 - NREL/SR-560-34389

\title{
DUIT: Distributed Utility Integration Test
}

Distributed Utility Associates

Livermore, California

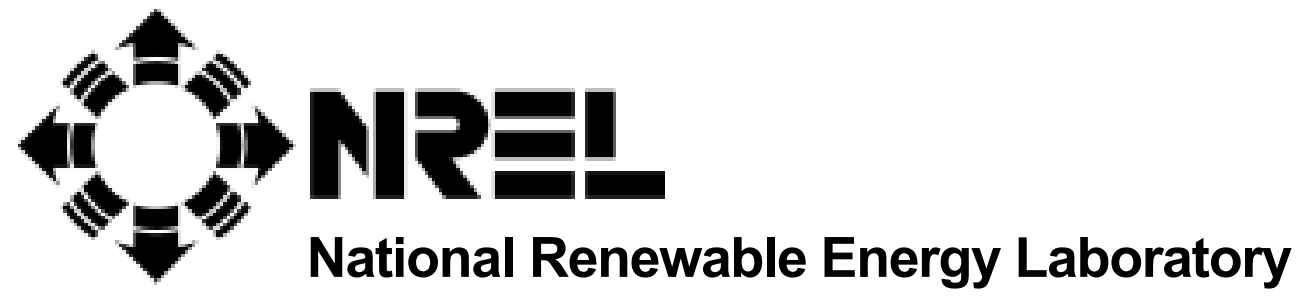

1617 Cole Boulevard

Golden, Colorado 80401-3393

NREL is a U.S. Department of Energy Laboratory

Operated by Midwest Research Institute • Battelle • Bechtel

Contract No. DE-AC36-99-G010337 


\section{DUIT: Distributed Utility Integration Test}

Distributed Utility Associates

Livermore, California

NREL Technical Monitor: Ben Kroposki

Prepared under Subcontract No. AAD-0-30605-05

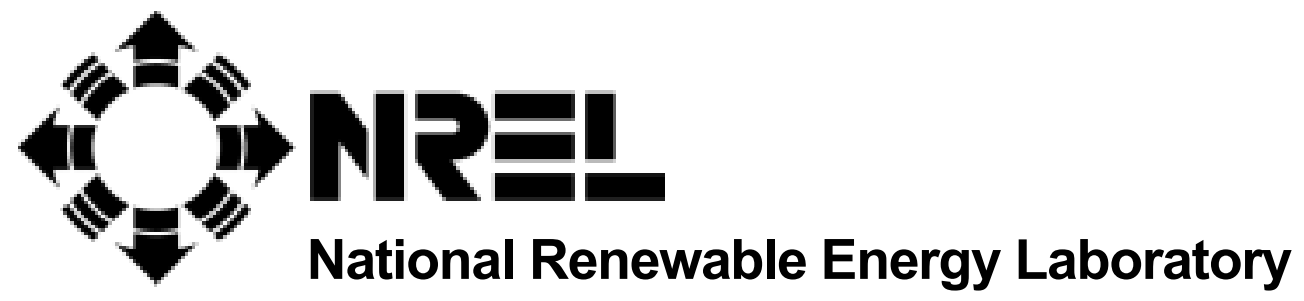

1617 Cole Boulevard

Golden, Colorado 80401-3393

NREL is a U.S. Department of Energy Laboratory

Operated by Midwest Research Institute • Battelle • Bechtel

Contract No. DE-AC36-99-G010337 


\section{NOTICE}

This report was prepared as an account of work sponsored by an agency of the United States government. Neither the United States government nor any agency thereof, nor any of their employees, makes any warranty, express or implied, or assumes any legal liability or responsibility for the accuracy, completeness, or usefulness of any information, apparatus, product, or process disclosed, or represents that its use would not infringe privately owned rights. Reference herein to any specific commercial product, process, or service by trade name, trademark, manufacturer, or otherwise does not necessarily constitute or imply its endorsement, recommendation, or favoring by the United States government or any agency thereof. The views and opinions of authors expressed herein do not necessarily state or reflect those of the United States government or any agency thereof.

Available electronically at http://www.osti.gov/bridge

Available for a processing fee to U.S. Department of Energy and its contractors, in paper, from:

U.S. Department of Energy

Office of Scientific and Technical Information

P.O. Box 62

Oak Ridge, TN 37831-0062

phone: 865.576 .8401

fax: 865.576.5728

email: reports@adonis.osti.gov

Available for sale to the public, in paper, from:

U.S. Department of Commerce

National Technical Information Service

5285 Port Royal Road

Springfield, VA 22161

phone: 800.553.6847

fax: 703.605.6900

email: orders@ntis.fedworld.gov

online ordering: http://www.ntis.gov/ordering.htm 


\section{Acronyms}

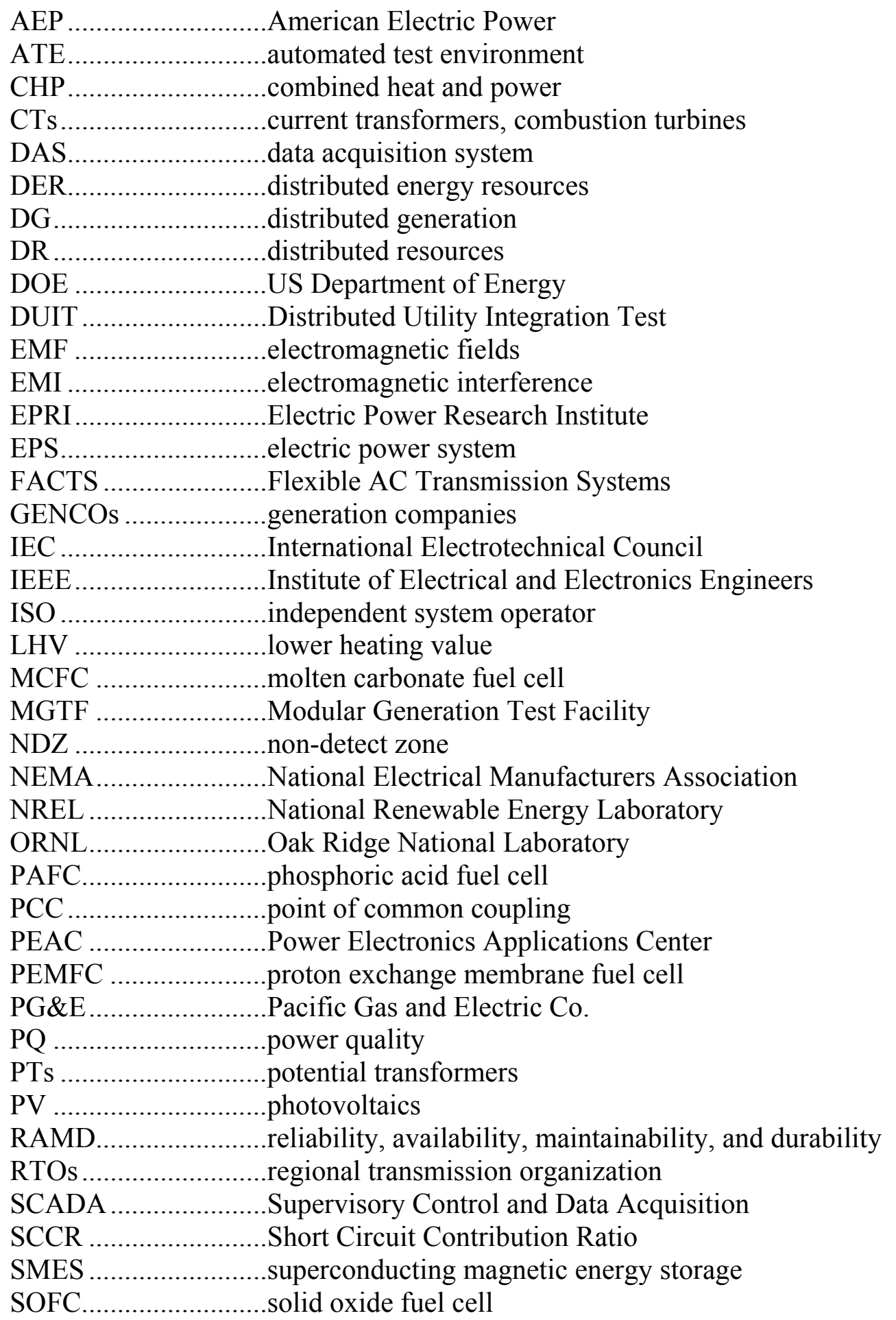


TES ............................Technical and Ecological Services

THD .........................total harmonic distortion

$\mathrm{T} \& \mathrm{D}$...........................transmission and distribution, transmission and distribution utility

TRANSCOs ...............transmitting utilities

UCI...........................University of California at Irvine

UL .............................Underwriters Laboratories

VOS.........................value of service 


\section{Table of Contents}

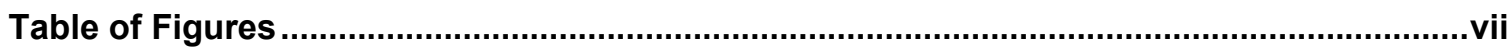

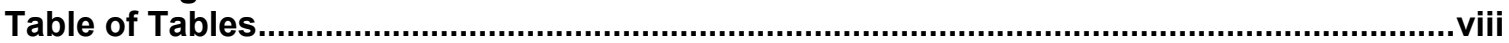

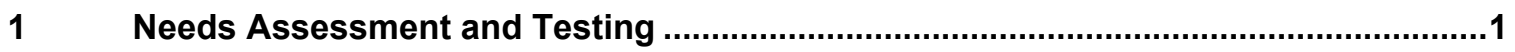

1.1 Introduction and Overall Project Description ......................................................

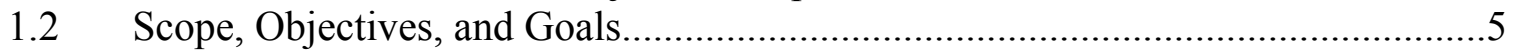

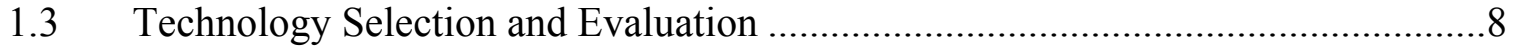

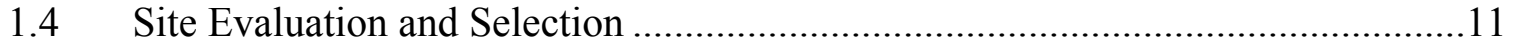

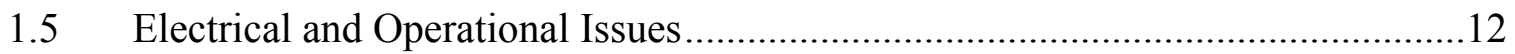

1.6 DUIT's Potential Results and Policy Implications ............................................15

$2 \quad$ Assessment of Test Sites

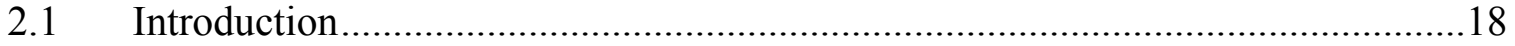

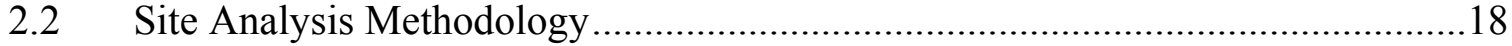

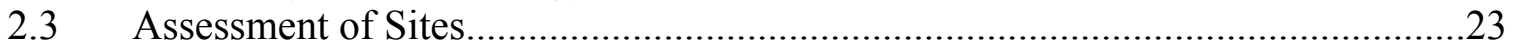

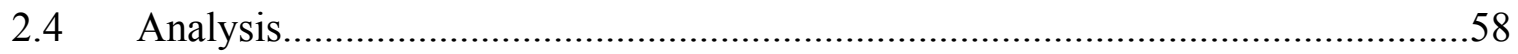

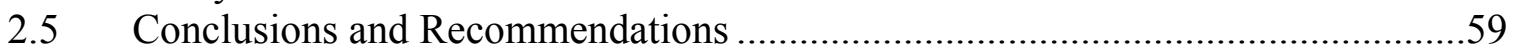

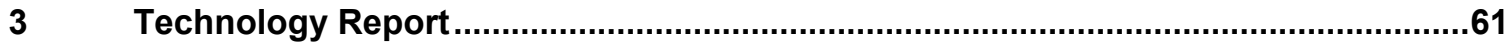

3.1 Introduction: Selection and Evaluation of Technologies for the DUIT................61

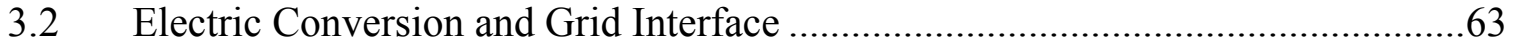

3.3 Inverters and Inverter-Based Technologies .....................................................68

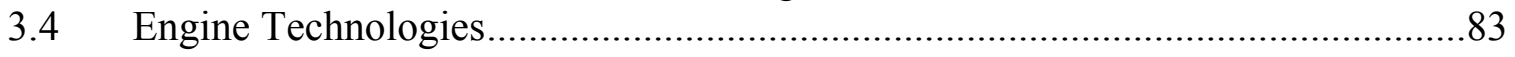

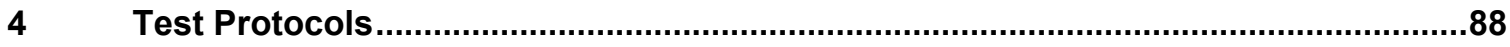

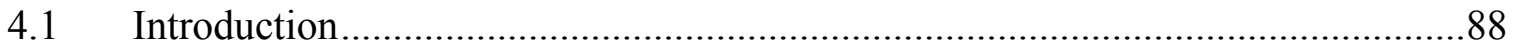

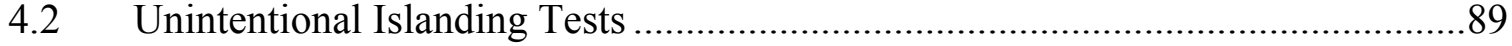

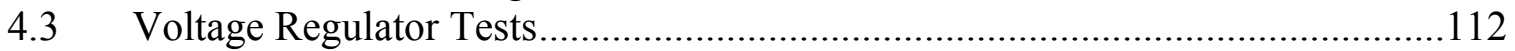

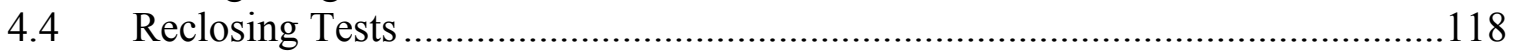

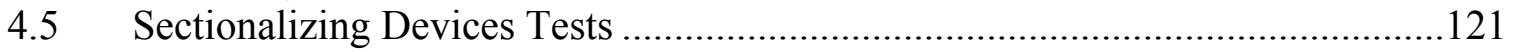

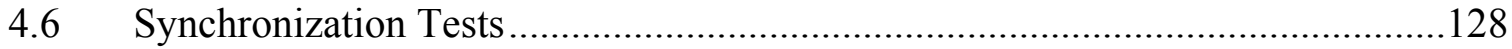

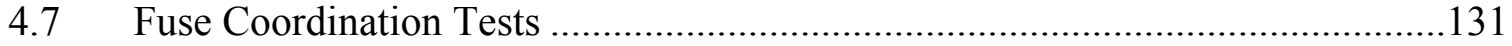

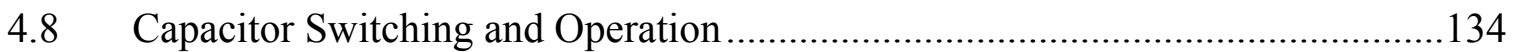

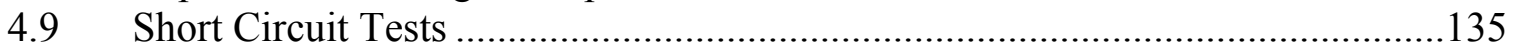

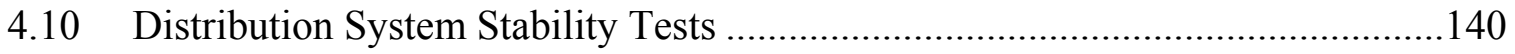

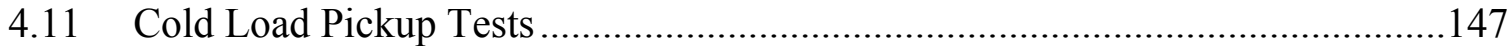

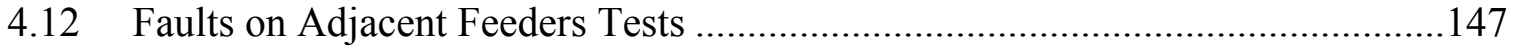

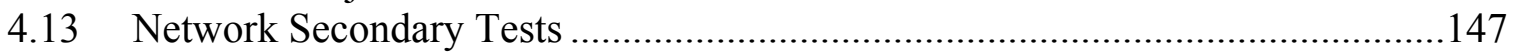

4.14 Substation Backfeed Tests .......................................................................... 148

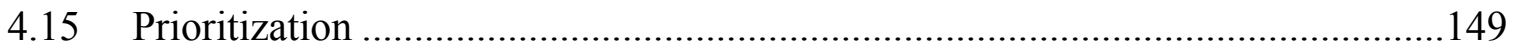




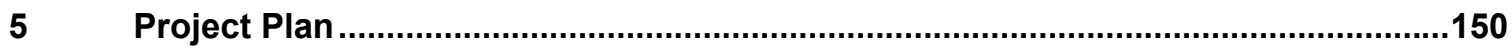

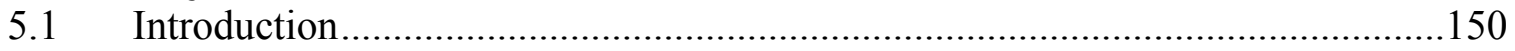

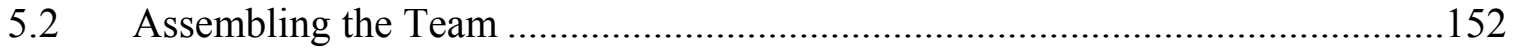

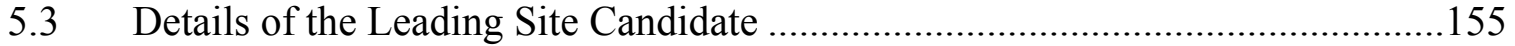

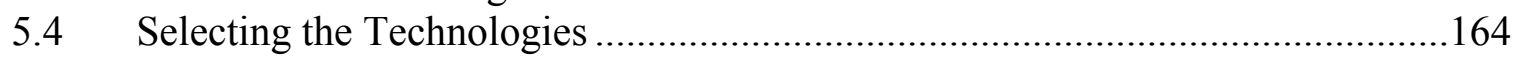

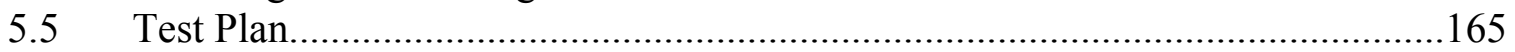

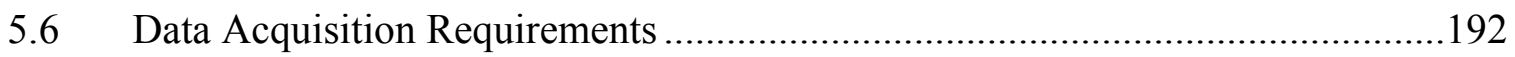

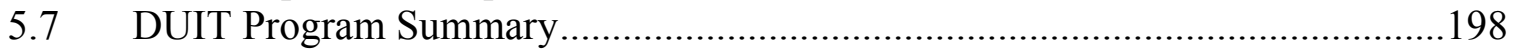

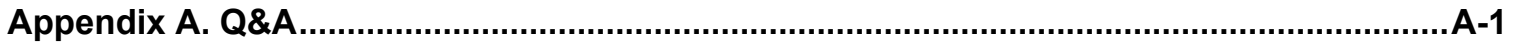

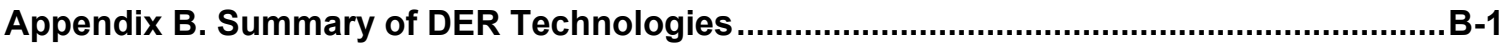

B.1 Internal Combustion/Reciprocating Engine Generators …..............................

B.2 Combustion Turbines..........................................................................

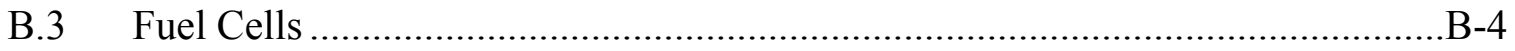

B.4 Energy Storage Systems ..........................................................................

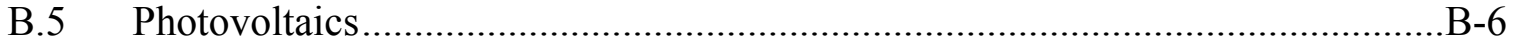

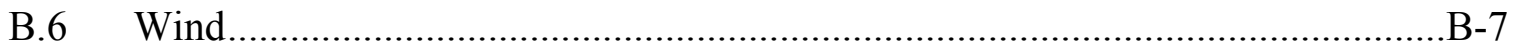

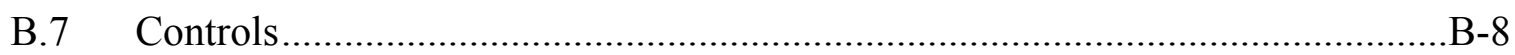

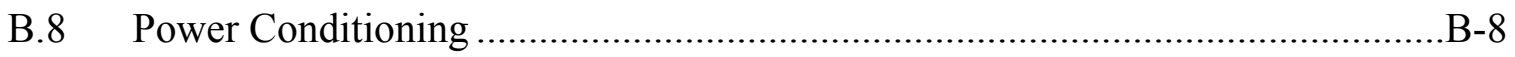

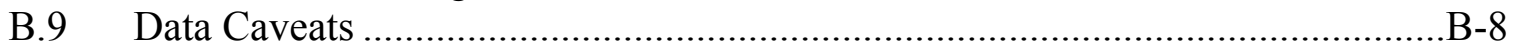

Appendix C. Transmission and Distribution Cost/Benefits .................................................

C.1 Deferral of Capital Expenditures ....................................................................

C.2 Utilization of Existing Transmission and Distribution Assets............................

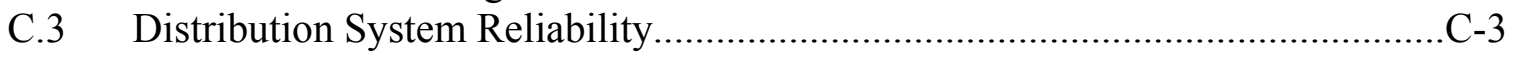

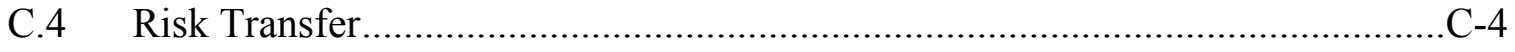

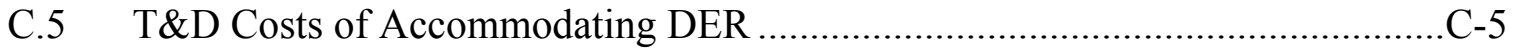

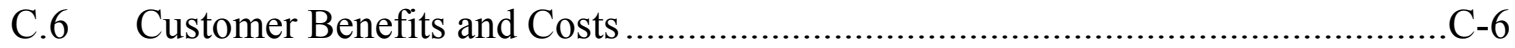

C.7 Other Benefits and Costs .....................................................................

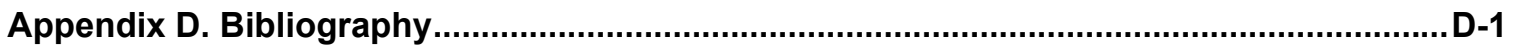

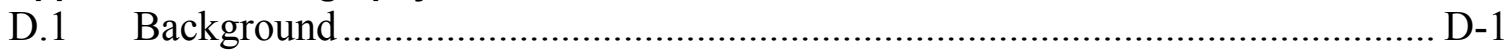

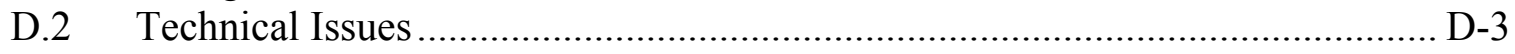

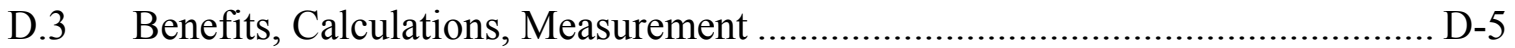

D.4 Codes and Standards .......................................................................... D-10

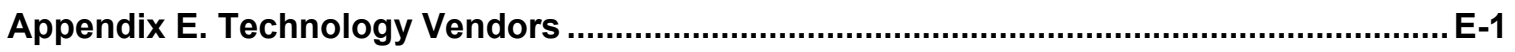




\section{Table of Figures}

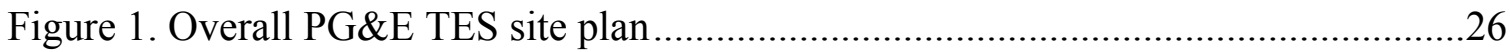

Figure 2. PG\&E TES electrical test facilities ……………...........................................29

Figure 3. MGTF/Smart Substation single line diagram................................................30

Figure 4. Single line diagram for TES High Current Yard.................................................31

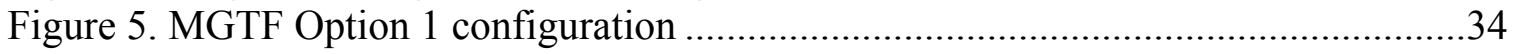

Figure 6. MGTF Option 2 configuration .....................................................................

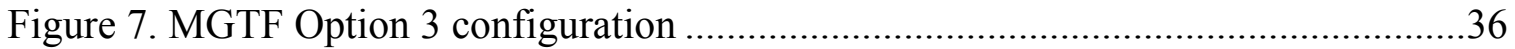

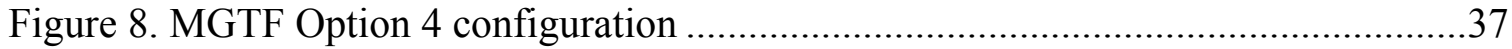

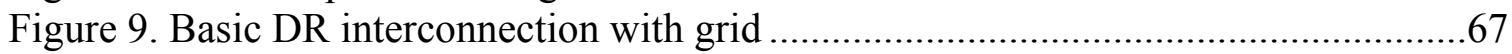

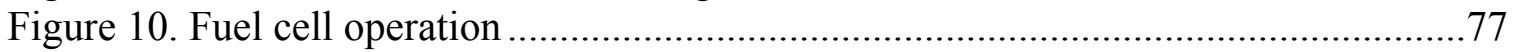

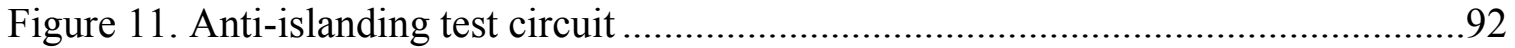

Figure 12. Anti-islanding test circuit with multiple DR …….......................................95

Figure 13. Results of islanding tests showing trip times of L:G...................................97

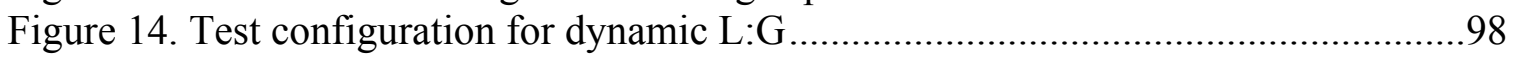

Figure 15. Test configuration with rotating loads.........................................................101

Figure 16. Test configuration for DR count test...........................................................104

Figure 17. Test configuration for current distortion measurements ................................106

Figure 18. Test configuration of nonlinear anti-islanding tests .....................................109

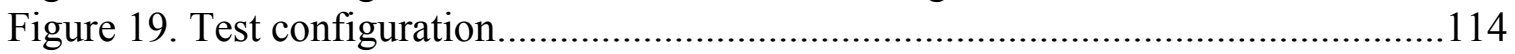

Figure 20. Reverse power flow voltage-regulating test................................................116

Figure 21. Schematic for basic sectionalizer test........................................................123

Figure 22. Schematic for basic sectionalizer test with DR fuse protection .....................127

Figure 23. Resynchronization after a momentary island ..............................................129

Figure 24. Momentary island test waveform .............................................................130

Figure 25. Schematic for fuse coordination tests ......................................................133

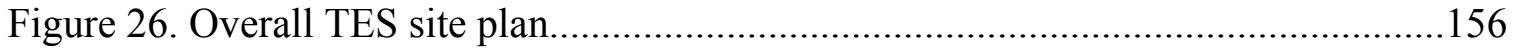

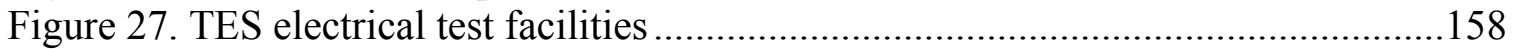

Figure 28. MGTF/Smart Substation single line diagram...............................................159

Figure 29. Schematic of PG\&E TES research facility .....................................................160

Figure 30. Thevenin equivalent circuit for a distribution system fault............................183

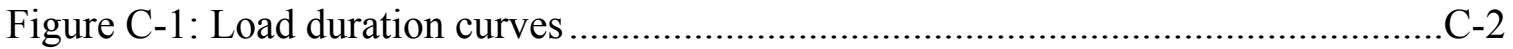




\section{Table of Tables}

Table 1. Summary of Capabilities: PG\&E Modular Generation Test Facility and

Technical and Ecological Services Department .......................................25

Table 2. MGTF/Smart Substation/High Current Yard Components ....................................32

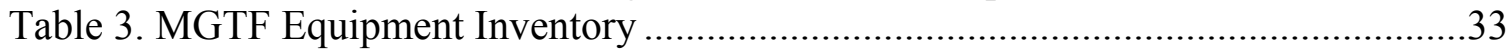

Table 4. Summary of Capabilities - University of California at Irvine...............................41

Table 5. Summary of Capabilities - Dolan Test Center ....................................................43

Table 6. Summary of Capabilities - Southwest Research Institute ....................................45

Table 7. Summary of Capabilities - Power Electronics Applications Center ....................46

Table 8. Summary of Capabilities - Sandia National Laboratories.....................................48

Table 9. Summary of Capabilities - National Renewable Energy Laboratory....................50

Table 10. Summary of Capabilities - University of Wisconsin-Madison .........................52

Table 11. Summary of Capabilities - Pacific Northwest National Laboratory ..................53

Table 12. Summary of Capabilities - Solar Test and Research Center ..............................54

Table 13. Summary of Capabilities - Oak Ridge National Laboratory..............................55

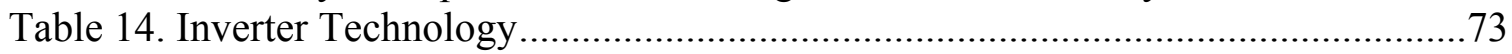

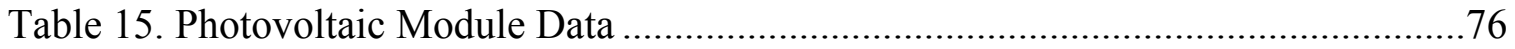

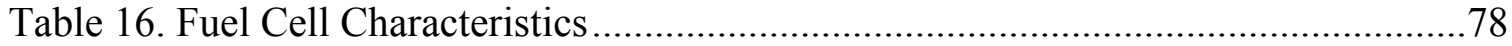

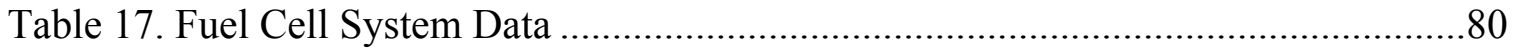

Table 18. Energy Storage System Data ………………….............................................

Table 19. Rotating and Microturbine Technology Data ……………………….................8

Table 20. Basic Anti-Islanding Test Data Acquisition Requirements ..............................94

Table 21. Anti-Islanding With Multiple DR Types Data Acquisition Requirements........96

Table 22. Anti-Islanding With Dynamic L:G Data Acquisition Requirements.................99

Table 23. Anti-Islanding With Dynamic L:G DR Requirements .....................................99

Table 24. DR Anti-Islanding Test Using Rotating Loads Data Acquisition

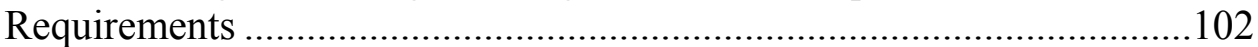

Table 25. DR Anti-Islanding Test Using Rotating Loads DR Requirements..................102

Table 26. DR Count Test DR Requirements ....................................................................104

Table 27. High Penetration DR Harmonic Content and Nuisance Tripping

Because of Active Anti-Islanding Schemes Data Acquisition

Requirements ......................................................................................107

Table 28. High Penetration DR Harmonic Content and Nuisance Tripping

Because of Active Anti-Islanding Schemes DR Requirements................107

Table 29. Anti-Islanding Testing Using Nonlinear Loads Data Acquisition

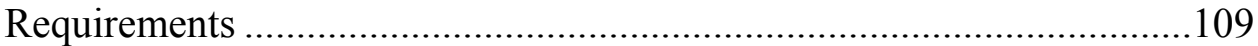

Table 30. Anti-Islanding Testing Using Nonlinear Loads DR Requirements ..................110

Table 31. Anti-Islanding With Reduced Undervoltage and Underfrequency Trip

Settings Data Acquisition Requirements

Table 32. Feeder and Automatic Voltage Regulating Device Characterization Data

Acquisition Requirements....................................................................113

Table 33. Feeder and Automatic Voltage Regulating Device Characterization DR

Requirements

Table 34. Performance of Voltage-Regulating Device With Reverse Power Flow Data

Acquisition Requirements. 
Table 35. Performance of Voltage-Regulating Device With Reverse Power Flow DR Requirements

Table 36. Islanding Detection Timing Data Acquisition Requirements..........................119

Table 37. Islanding Detection Timing DR Requirements ...............................................119

Table 38. Sectionalizer-Recloser Coordination Test Data Acquisition

Requirements …….........................................................................124

Table 39. Sectionalizer-Recloser Coordination Test Facility Requirements....................124

Table 40. Sectionalizer-Recloser Coordination Test DR Requirements ..........................125

Table 41. Sectionalizer, Recloser, and Fuse Coordination Test Data Acquisition

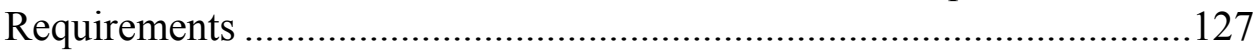

Table 42. Sectionalizer, Recloser, and Fuse Coordination Test Facility

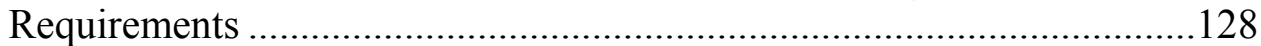

Table 43. Sectionalizer, Recloser, and Fuse Coordination Test DR Requirements ........128

Table 44. Transition From Momentary Island Data Acquisition Requirements .............131

Table 45. Fuse Desensitization Test Data Acquisition Requirements .............................133

Table 46. Fuse Desensitization Test Facility Requirements .............................................134

Table 47. Fuse Desensitization Test DR Requirements..................................................134

Table 48. DR Short Circuit Characteristics Test Data Acquisition Requirements ..........136

Table 49. DR Short Circuit Characteristics Test Facility Requirements ..........................137

Table 50. DR Short Circuit Characteristics DR Requirements........................................137

Table 51. Multiple DR Short Circuit Test Data Acquisition Requirements ....................139

Table 52. Multiple DR Short Circuit Test Facility Requirements ...................................139

Table 53. Multiple DR Short Circuit Test DR Requirements...........................................140

Table 54. DR Stability Characterization Test Data Acquisition Requirements................142

Table 55. DR Stability Characterization Test Facility Requirements...............................143

Table 56. DR Stability Characterization Test DR Requirements .....................................143

Table 57. DR-to-DR Stability Test Data Acquisition Requirements.................................146

Table 58. DR-to-DR Stability Test Facility Requirements..............................................146

Table 59. DR-to-DR Stability Test DR Requirements ....................................................147

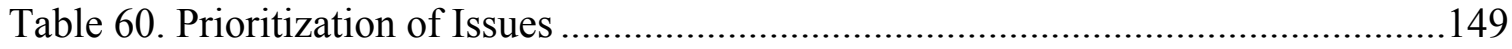

Table 61. Smart Substation and High Current Yard Components...................................161

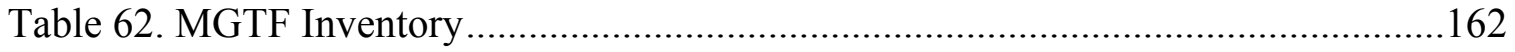

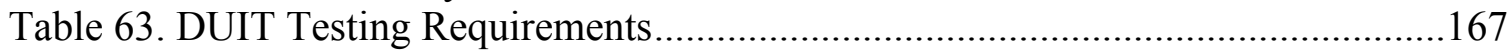

Table 64. Interconnection System Response to Abnormal Voltages.................................176

Table 65. Potential Transformers Required for DUIT Data Acquisition System.............193

Table 66. Current Transformers Required for DUIT Data Acquisition System...............193

Table 67. Other DUIT Data Acquisition System Requirements........................................194 


\section{Needs Assessment and Testing}

\subsection{Introduction and Overall Project Description}

\subsubsection{Project Rationale}

This report on the Distributed Utility Integration Test (DUIT) describes a proposed test of the electrical implications of deep and diverse penetration of distributed energy resources (DER) into distribution systems. As distributed power becomes more commonplace, its electrical interactions will become more important to understand and more challenging to manage. This testing program attempts to anticipate electrical interactions and discover the problems and benefits that will result from the extensive use of DER.

In general, not enough is known about how distributed resources (DR) might perform with regard to safety, health, economics, availability, and reliability-especially over time. Knowledge about the interconnection or interface of DR with a distribution grid or customer facility is also limited. Their operation must be interactive if the highest-value benefits are to be obtained and safety and reliability problems are to be avoided. Energy market players such as utilities and customers are traditionally risk-adverse and will defer decisions to install DR until performance is better known.

Without accurate and demonstrated performance knowledge, early adopters are more likely to encounter failures that will further discourage risk-adverse would-be adopters.

Policymakers such as lawmakers, regulators, and public-good funds managers need test information to develop, implement, and enforce policy decisions that result in improved laws, regulations, codes and standards, and technologies.

Even now, as the Institute of Electrical and Electronics Engineers (IEEE) P1547 committee is developing proposed interconnection standards for distributed power, the issue of the allowable penetration level of DER on a feeder is controversial. Diverse opinions (but little data) abound. DER penetration levels may not even be as important as the types and numbers of technologies in a given locality.

Once the IEEE has approved a set of interconnection standards, individual states and utilities will evaluate whether it should be adopted in whole or in part. Utilities might still be circumspect about the applicability of these standards to their typical distribution conditions. Thus, an early integration test tailored to address state and utility concerns will lead to a more uniform national set of standards by reducing the difficulty of embracing the IEEE standards. This will help make policy more uniform at state and utility levels.

To resolve, or at least shed light on, these interconnection issues, the US Department of Energy (DOE) asked Distributed Utility Associates and its DUIT team members to propose a testing plan for its consideration. This report defines the technical needs for such a test, its objectives, success criteria, and siting and technology options. 
The DER market appears ready to expand dramatically because of the emergence of new technologies, uncertain central power supply and delivery costs, and a need for more reliable, high-quality power service to critical customers.

As this industry expands and the power system becomes more dependent on distributed power, the efficiency, grid and facility compatibility, and reliability of DER and up-to-date, appropriate rules and regulations become more pressing public issues.

Although it is impossible to accurately anticipate the results of such a comprehensive and complicated set of tests, it is nonetheless useful to suggest possibilities:

- The concepts of electrical proximity factor and DER diversity quotient are new parameters that are key to understanding the results of DUIT and, hence, the integration issues in a broader context.

- The use of sophisticated control systems allows for the capture of maximum benefits that accrue to not only the end-user but also the distribution utility. The control system is also capable of capturing the ancillary benefits touted by DER proponents.

- Network systems have a different set of interconnection issues from radial systems. However, DUIT testing is expected to show that many of the protection and interconnection issues can be dealt with in a similar manner. There will be issues that remain unique to network systems and that will have to be addressed separately, but the breadth of these issues can be reduced.

- DER operate reliably enough to warrant consideration as an alternative to distribution system upgrades. Generation, transmission, and distribution benefits appear to be substantial. Ancillary benefits are possible with the use of a sophisticated control system, but quantifying and especially metering is problematic.

- A subset of the results from DUIT is scalable to other problems, but a subset remains that requires computer modeling for accurate prediction and future use. DUIT is useful in both sets of problems. For non-scalable problems, DUIT testing and modeling groups will identify validation tests early in the project. The results of these tests will be compared against modeling results for accuracy.

\subsubsection{History and Status of DER}

The distributed utility concept involves the use of modular electric technologies that provide electric capacity or energy when and where they are needed within an electricity distribution system. Such technologies, collectively referred to as distributed energy resources or distributed resources, include both distributed generation (DG) and distributed storage. DER may be either interconnected with a large grid or isolated from the grid, but their locational value is high enough that their distributed value is important to their economics and operation. Modular electric technologies (e.g., photovoltaics [PV], fuel cells, microturbines, cogeneration, or small battery storage systems) are common examples of DER and have historically been sized to maximize local advantages, usually from the customer perspective. This has led to matching DER to local loads and dispatching for substantial customer 
benefits. Dispatch and control by the utility, for the utility's benefit, has, for the most part, not been a major consideration in the design of these systems.

Utilities can use modular electric technologies to delay, reduce, or eliminate the need for additional generation, transmission, and distribution infrastructure and to avoid some expenses while firming up voltage and local reliability. If the DER can serve the load effectively, the utility avoids incurring costs associated with its traditional "central generation and wires" solution.

Customers can apply the Distributed Utility concept two ways: to manage their bills and reliability by augmenting their service with DR or to provide power completely independent of the grid (either by choice or out of necessity). If the customer system is grid-connected, interconnection procedures and contractual relationships with the utility must be addressed.

Although the Distributed Utility concept makes economic sense for the vertically integrated utility of the present, how will the envisioned electric utility industry restructuring affect opportunities for distributed generation or storage and targeted demand management? The potential benefits of using DER include reduced capital expenditures for generation, transmission, and distribution equipment; increased component life; reduced line losses; improved reliability and power quality; and expanded customer service. The development of an accepted methodology for evaluating these benefits is only beginning, but considerable work has been done in this area over the past 10 years.

The benefits of applying the Distributed Utility concept — whatever they are in a given instance - can be internalized by vertically integrated utilities as part of their regulated business practices. A utility's generation, transmission, and distribution planners and operators can determine just the right place and time to install DR for maximum advantage.

DER is in its infancy as a utility solution for cost reduction, improved use of T\&D resources, and enhanced system reliability (e.g., ancillary services such as operating reserves and voltage support). Nevertheless, end-use customers have been using on-site power in various forms for many years to achieve benefits such as improved reliability (standby/emergency power), reduced demand charges (peak shaving, interruptible rates, power factor improvement), and reduced energy costs (cogeneration, prime power in areas with high electric rates or no electric service). Traditional technologies such as reciprocating engines and steam and gas turbines have outstanding track records of providing end-use customers with these and other benefits. Emerging technologies such as microturbines, fuel cells, PV, and energy storage systems hold promise to provide customers with these same benefits and other desirable enhancements (e.g., improved power quality and uninterruptible supply) at higher efficiencies and reduced emissions. 
What is missing from the customer side of the equation is proof that traditional and emerging technologies can work together seamlessly to provide the desired mixture of benefits. What is missing from the utility side of the equation is proof that any of these technologies can be used as reliable DER to improve system operation and lower the cost of electric service for all customers. Questions that must be answered before either utilities or customers will widely adopt DER as a means of achieving these benefits include:

- Will there be significant systems integration and interoperability problems when installing and using different kinds of equipment from different manufacturers (e.g., conflicting modes of operation, inability to "load share" between multiple units, inability to communicate with units for maintenance and tracking purposes)?

- Can "islanded" operation as a "microgrid" be automated to best use the features and characteristics of different DER technologies to serve base load, intermediate load, and peak load requirements at a facility?

- How will multiple DER technologies at a facility interact with the grid when interconnected, and can these resources be managed safely and cost effectively with other utility resources?

- Can DER be integrated cost effectively into other utility systems such as substation automation, distribution automation, and customer billing systems?

- What benefits, if any, do DER provide with regard to voltage regulation, power factor improvement, or other ancillary services?

- Do we need DER standards for issues such as metering and billing, protective relays for safe interconnection with the grid, emissions and other permitting requirements, communication protocols for proper fault recovery and system coordination, and management?

- Will there be adverse interactions among different types and brands of DER technologies that could actually create power quality problems rather than alleviate them (e.g., harmonics from inverters)?

- What economic and reliability benefits can the utility really expect to achieve with automated dispatch capabilities?

- Can DER participate cost effectively in independent system operator (ISO)/power exchange bidding procedures for generation supply or customer load on an aggregated basis?

- Is there a DER technology demonstration project available in the public domain to help utilities, manufacturers, and customers make informed decisions with regard to the claims surrounding DER?

Distributed Utility Associates expects to perform one or more integration tests at or near utility substations that allow the generation and storage components to work together, facilitated by a flexible yet powerful control and information infrastructure. These tests will be designed to address the above questions. 


\subsection{Scope, Objectives, and Goals}

\subsubsection{Project Scope}

The DUIT project would result in the first full-scale integration test of distributed generation and storage technologies in the United States. The DUIT will have a broad test plan that will include a detailed exercising of variously configured systems with sophisticated monitoring to document the interaction of the components both within the system and on the electric utility grid. The DUIT plan is to focus on DER integration and aggregation issues, not on DER technology itself. Grid interaction problems and benefits will both be evaluated.

The DUIT project will seek to establish one or more integration test sites at or near utility substations that will allow small generation, storage, and distribution control components to operate under the management of a communication and control system. Multiple test sites may be required to minimize the cost of simulating a broad variety of distribution and technology circumstances to meet national needs.

A key aspect of the DUIT project is a thorough test of the feasibility and value of collocation and integration of diverse distributed generation and storage technologies into the electric distribution system. Ideally, several distributed generation and storage technologies would be installed within electrical interaction proximity of one another to allow aggregate benefits and operational issues to become evident.

This local collection of distributed generation and storage technologies will be managed by a state-of-the-art control system, demonstrating feasibility of remote operation, monitoring, and dispatch.

The units will be instrumented to measure the potential electric distribution system advantages and challenges of substantial penetration (significantly greater than $10 \%$ of local load) of distributed generation and storage at distribution voltage levels. The data will be gathered and analyzed to characterize the actual value of distributed generation and storage to ratepayers and utilities (e.g., avoided costs, distribution cost savings, lower energy costs).

\subsubsection{Project Objectives}

The primary objective of the DUIT project is to advance the state of the art in distributed generation and storage integration practices and strategies. This will accelerate the market entry of advantageous modular technologies, leading to lower ratepayer cost of service and improved service quality and reliability.

The goals of this project are to prove the feasibility and quantify the benefits of integrating diverse distributed generation and storage technologies with a distribution system and to provide a testing ground for observing and measuring the beneficial or detrimental interactions among the distributed technologies on the distribution system. Achieving these goals will entail full-scale multi-megawatt implementation, testing, and demonstration of DG technologies in an actual utility installation. 
From the customer's perspective, proof is needed that traditional and emerging technologies can work together seamlessly to provide the desired mixture of benefits.

Utilities seek evidence that any of these technologies can be used as reliable DER to improve system operation and lower the cost of electric service for all customers.

Technology development stockholders have a significant interest in DUIT because it provides a vehicle for demonstrating the benefits of their equipment to customers, utilities, and regulators. Confidence by these bodies removes significant barriers to the wide-scale adoption and implementation of DER technologies. Large-scale adoption also creates the opportunity for new business initiatives, such as the development of privately held, independent DR generation and storage projects.

From a policy standpoint, federal, state, and utility regulators will be more confident as they consider standardization of interconnection procedures.

The increasing potential of DR in emerging utility markets has focused attention on two critical issues: interconnection of DR with the electric distribution system and the unknown nature of potential interactions between multiple distributed devices. Interconnection is a critical issue because of the diversity of distributed technologies and the variability of interconnection standards and practices from state to state and utility to utility. Interactions among multiple DER are largely unpredictable because of limited operating experience to date; this uncertainty contributes to the inhibition of market acceptance of DER.

By examining current and emerging technologies and operational concepts to properly integrate diverse DR, this project will provide insights into grid support issues and suggest innovative system protection design concepts. The DUIT will illuminate these DOE issues:

- Universal distributed and electric power system interconnection technology, including current and advanced/future designs; requirements and tests for interconnection

- Interconnection equipment performance and functional characterization and installation test method design, development, validation, and documentation

- Command, control, communication, monitoring, and remote and on-site intelligent controls for interconnection

- Interconnection equipment/technology tests and procedures

- Design and development requirements for the establishment of an industry-wide third party for interconnection equipment as well as for on-site interconnection approval.

\subsubsection{Technology and Distribution System Selection}

Ideally, a range of modular generation and storage technologies will be investigated. The possible portfolio of DG technologies includes natural gas or dual-fueled engines, small gas turbines, microturbines, PV, and fuel cells. Energy storage DER could incorporate 
technologies such as state-of-the-art and advanced electrochemical battery systems, flywheels, and superconducting magnetic energy storage (SMES).

The selection of specific DER units will be based on several rank-ordered criteria: DER technology diversity, diversity of electrical generation hardware (i.e., rotating and DC output), "clean" technologies (minimal emissions and permitting requirements), DER electrical rating, total electrical rating of all DER, consistency with host utility needs/objectives, cost (purchase, lease, or rental), installation, fuel supply, fuel system(s), commercial availability, and "transportability."

A review of distribution system types across the country will guide the selection of the DUIT distribution system configuration(s) (radial, network, etc.) so that the test results will have the largest possible direct effect. Where different configurations exist, the data collected at DUIT will provide technical guidance and modeling validity to integrated DER performance on those dissimilar configurations.

\subsubsection{Controls}

The DUIT collection of local DER will be managed by a state-of-the-art communication and control system. The system aggregates DER and presents them to the system operator as one resource. Available capacity, capacity that is scheduled or committed, and current aggregate output is presented to the operator through the system's graphical interface. Available capacity may be scheduled by start date, time, and duration or requested at once. Resources may be grouped by defined characteristics (e.g., location, emissions, heat rate), and groups of DER may be scheduled or dispatched individually.

Tests will reveal needs related to the monitoring, controlling, and beneficial dispatch of DER. DER and the power distribution system to which they are connected will be instrumented to measure parameters that provide meaningful indications of the potential advantages and drawbacks associated with substantial DER penetration at distribution voltage levels.

\subsubsection{Documentation}

The detailed documentation of the integration testing will be made available to those considering the development or installation of a DG system. By providing the results of the DUIT to electric utilities, customers, developers, and equipment suppliers, fewer barriers will hinder intelligently designed DG components and installations.

\subsubsection{Federal Role}

A "natural" federal role in the sponsoring and administration of DUIT results from:

- Regulatory changes in the vertical utilities of the past

- The new role of customer stakeholders as energy providers and selectors

- The proliferation of new and diverse technologies and technology companies that have emerged over the past 5 to 10 years. 
Federally sponsored DUIT testing will provide objective, real-world test conditions for DER. Because of its complexity and the broad set of stakeholders, this testing would not likely be performed by any individual stakeholder. Federal agency sponsorship will ensure widespread and uniform dissemination of test results and documentation that could not be guaranteed with other sponsoring bodies. This is critically important as state and local regulatory agencies move to adopt national standards such as IEEE 1547 or generate their own standards. The more uniform those standards, the higher the likelihood that all of the purported benefits of DER can be realized.

Historically, the vertically integrated utility selected the technologies that made the most economic sense to install from its perspective. Testing was largely performed by the utility and the technology manufacturers. When the utility had complete control over the technology selection and there was no technology "stretch" involved, the utility could be confident of its own decisions and its own protection coordination practices. The advent of DER places much of this selection and operation responsibility on the energy end-users, most of whom have no test capability prior to installation or during operation. The end-user is also usually limited in his concern about issues such as grid interactions because his objectives tend to be focused on cost containment and backup power availability.

One could argue that the role of testing in this new DER environment would then fall to the DER manufacturer, but relying solely on this stakeholder also has its drawbacks. Most testing performed by manufacturers is done under highly controlled conditions with the intention of developing a data specification sheet for potential customers. At times, this information can be incomplete, and equitable comparisons with other technologies can be difficult. If performed in an accredited laboratory, testing of a manufacturer's production units will logically result in certification testing, in which the parameters of a particular make and model are credibly established and warranted by the manufacturer. The result is that a utility (or other end-user) need not require testing of every such unit proposed for interconnection. Although this is important testing, it can be self-serving and focused on technology with little interest in utility or grid integration issues.

This is why multi-stakeholder integration testing such as DUIT is being proposed and why it is unlikely that such testing would take place in the absence of federal sponsorship. DUIT will be a technology- and utility-neutral test facility with a strong team of organizations and individuals that have been active in DER concept and integration development over many years. This unique test facility is necessary to fully realize the diverse economic and environmental benefits of DER.

\subsection{Technology Selection and Evaluation}

\subsubsection{Technology Selection}

The purchase of distributed generation and storage hardware is beyond the budget and scope of this project. Commercial or near-commercial DER will instead be rented, leased, or borrowed. Ownership of equipment is not necessary to meet project goals and objectives. Therefore, rented or leased equipment will minimize system engineering and procurement costs and lead times. 
Team members have already approached several DER suppliers about the possible loan of equipment for such a test. Some DER technology developers may be eager to include their systems in a world-class, groundbreaking project such as the DUIT.

The project is meant to measure and analyze the interactions among units rather than to prove the operation of any single DG technology or storage component; thus, rental, lease, or loan of "off the shelf" distributed generation and storage units is preferable from both test design and budgetary standpoints.

The team will make the final selection of which distributed generation and storage technologies to include based on the following criteria, which will be prioritized by the project team:

- Diversity of technologies (more than one type of distributed generation and storage variety is mandatory; three or more types is preferred)

- Diversity of electrical generation hardware (both rotating and power electronic conversion types are highly desired)

- Pre-existing, on-site distributed generation and storage technologies

- Clean technologies with minimal emissions or permitting problems

- Individual DER unit electrical rating size (10 kW to $2 \mathrm{MW}$ would be ideal)

- Total electrical rating size (1 MW to $3 \mathrm{MW}$ would be ideal)

- Host utility objectives such as compatibility with site physical limitations

- Budgetary considerations such as lease costs, installation costs, and fuel supply hardware

- Proven, off-the-shelf (i.e., reliable, tested, trouble-free) distributed generation and storage technologies to separate integration factors from new technology issues during operation and testing

- Technologies whose development was supported by one of the project participants

Also, because many of the technologies are relocatable (e.g., batteries, small gensets, and flywheels), the project may be able to allow some units to be in place for only relatively short duration tests, perhaps lasting a month or more.

Some of these criteria may conflict with one another, making the technology and site selection efforts critically important to the success of the project. 


\subsubsection{Technology Evaluation}

Each of the prospective technologies will be evaluated based on the criteria presented below:

Physical Characteristics

- Size, weight, venting, fuel requirements

- Indoor/outdoor requirements

- Enclosure temperature control

Electrical

- Rated parameters

- Fault duty

- Short-circuit current capacity

- Maximum current inrush

- Included protective devises

Mechanical

- Mounting and other mechanical requirements

- Manual shut-off

Environmental and permitting

- Emissions

- Air

- Water

- Other permitting needs

Length of Use

- Cost, rent, lease, buy? Special discounts?

- Availability

- Operation and maintenance requirements

- Certified to what standards?

\subsubsection{Applications of DER}

DG systems may be composed of one or more primary technologies, such as internal combustion engines, combustion turbines (CTs), PV, and batteries. Innumerable combinations of DER technology-fuel options are possible to take advantage of synergies between individual technologies and make them as robust or cost-effective as possible.

Most DER systems operate on gaseous or liquid hydrocarbon fuel to produce electricity as needed; natural gas fuel is piped in, and diesel fuel is stored on site. Battery systems store electric energy from the grid for use when needed. Renewable energy DER use solar or wind energy as fuel.

One important DER characteristic is the duty cycle. For "peaking" duty cycle applications, DER only operate a small portion of the year, usually 50 to 600 hours annually. For "base load" duty cycles, DER operate many hours each year. 
Peaking duty DG tends to have relatively low installed cost and can take on load in just a few minutes (or less). It tends to be relatively inefficient and have significant air emissions per hour operated. Peak duty cycle DER usually operate for just a few hundred hours between overhauls. Typical installed costs range from $\$ 200 / \mathrm{kW}$ to $\$ 500 / \mathrm{kW}$, and nonfuel operating costs range from $\$ 0.01 / \mathrm{kWh}$ to $\$ 0.05 / \mathrm{kWh}$.

Primary DG technologies used for base load duty cycle tend to be fuel-efficient, reliable, and cleaner-burning combustion-based options. Typical installed costs range from $\$ 400 / \mathrm{kW}$ to $\$ 800 / \mathrm{kW}$, and nonfuel operating costs range from $\$ 0.005 / \mathrm{kWh}$ to $\$ 0.03 / \mathrm{kWh}$.

Most types of DG can provide useful and valuable thermal energy. To do so, additional equipment (e.g., pipes and pumps) is added to the generation system so that, during electricity generation, otherwise wasted heat energy is captured and used to heat water or air or for industrial processes. This concept is often referred to as combined heat and power (CHP) or cogeneration. Depending on the generator used, the existing thermal energy infrastructure of the facility, and other project-specific factors, equipment for CHP can add $25 \%$ to $100 \%$ to the installed cost for a generation-only system.

Important "enabling” subsystems include:

- Power conditioning equipment such as an electricity generator, a transformer, and inverters

- Controls

- Communications

- Fuel handling and fuel storage

- Emission controls

- Sound attenuation enclosures.

\subsection{Site Evaluation and Selection}

\section{Site Assessment Criteria}

The goal of the DUIT is to test how distributed generation and storage technologies might interact with the electric grid, with one another, and with adjacent customers and loads on a distribution feeder. In particular, the DUIT is designed to illuminate specific issues of penetration of DR into the electric distribution system. These include:

- Interconnection technologies and practices

- Interconnection equipment performance and functional characterization

- Instrumentation, monitoring, and control technologies

- Methods of controlling DG remotely, whether in a utility/regional hierarchical scheme or in a local/independent mode.

It is envisioned that multiple distributed generators, storage devices, load banks, capacitors, and other components would be installed at the test site and operated in a variety of configurations by means of state of-the-art control, communications, and data-logging systems. Monitoring and data recording of key parameters would be carried out to evaluate 
the performance of DER and determine potential problems or issues that may arise. This knowledge would then be used to draw conclusions about how the DER may perform in "real world" distribution systems.

The DUIT will require a laboratory test site (or combination of sites) that is capable of accommodating the installation and simultaneous operation of multiple DER along with monitoring and instrumentation systems, data logging hardware, and the requisite support facilities, such as fuel supply and storage.

Given the foregoing, the criteria in the following list were developed and used in the assessment of each site.

- Available space - number of test cells or bays, their sizes, and limitations

- Megawatt rating - largest single DER allowed, total allowed DER for facility

- Existing/permanent DER on site

- Existing equipment - control, monitoring, and instrumentation; switching; load banks

- Ability to test in both radial and network circuit configurations

- Grid supply - voltage, megavolt amperes, switching arrangements, and limitations

- Fuel supply and storage - natural gas line size, pressure, and flow rate; diesel, hydrogen, gasoline, and liquefied petroleum gas availability and/or storage capability

- Limitations - noise, emissions, other

- Ability to test multiple DER at once in interactive modes

- Number and expertise of testing staff

- Testing history/experience relevant to DUIT.

\subsection{Electrical and Operational Issues}

\subsubsection{Why Distribution and Not Transmission?}

Generators that connect at the transmission level are usually much larger than DER ( $>50$ MW) and are designed to export power to the utility grid. For this type of situation, existing utility tariffs and interconnection procedures are known and well defined, providing precise information to a generator developer. In addition, utility planning engineers will perform the requisite impact studies by modeling the addition of the generator to the grid and running power flow and stability programs to verify that the generator will not negatively affect the system. These practices are well known to all participants in the process.

DG can be connected to the distribution system. However, most utility distribution systems were not designed with generation in mind. The idea has historically been to take power from the transmission system and distribute it to customers. The majority of distribution in the US is radial, not networked, and the effects of generation can be more pronounced on a networked system. Given that the penetration level of DER in the distribution system to date has been small, more must be known about their effects on the system and other customersespecially about the potential for interactions among DER on the same feeder. 


\subsubsection{Extensibility of DUIT Results}

In the selection of a DER and distribution system configuration (or configurations) for DUIT, every effort will be made to maximize the value of the results by testing what is determined to be the most likely system configuration(s). It is not possible, however, to test every possible combination of DER and distribution system. The question then arises: is it possible to extend the results from the DUIT to these dissimilar configurations? The short, but not simple, answer to this question is that a subset of classical problems and analysis is relatively straightforward to extend, but another subset of problems is much more difficult to extend. The DUIT has an important role in dealing with both of these situations.

First, the subset of classical problems that are scalable needs to be defined and classified from those that are not. The DUIT will aid in this classification process. Second, protection and load flow problems that do not scale effectively out of the DUIT can be addressed by computer modeling. Here, the importance of the DUIT is that a significant number of these problems will be identified for testing and modeling early in the project. Validation of models for these types of problems will be performed. To obtain maximum benefit from the models, there will be close coordination and planning of validation tests between modeling and testing teams.

\subsubsection{Identification of Test Issues}

A non-exhaustive list of electrical and operational issues to be considered for the DUIT is shown below. These items will be prioritized by DUIT team members and external reviewers. The emphasis of the DUIT is on integration issues, and items that fit into this category will naturally receive high priority.

Design and Manufacturing (UL 1741)

- Surge withstand capability

- Immunity protection

- Field-adjustable trip points

- DC isolation

- Dielectric voltage withstand test

- Power factor

- Harmonic distortion

- DC injection

- Utility voltage and frequency variation

- Reset delay

- Loss of control

- Short circuit contribution

- Load transfer synchronization 
Installation and Commissioning

- Metering and instrumentation

- Grounding

- Pre-parallel inspection

- Protective function

- Verification of final protective settings

- Trip testing

- In-service

- Flicker

Grid Effects

- Load following

- Parallel-standalone transition

- Power quality

- Harmonics

- Power factor

- Flicker

- DC injection

- Electromagnetic interference (EMI)/electromagnetic fields (EMF)

System Protection

- Abnormal conditions: voltage/frequency trip points, reverse-power/under-power trip points, fault detection, loss of synchronism

- Islanding

- Synchronization

Distribution System Impact/Interaction

- Network systems

- Fuse protection

- Recloser coordination

- Short circuit current contribution

- Capacitor switching

- Stability

- Cold-load pickup

- Sectionalizer operation

- Voltage regulation

- Substation backfeed

- Single-phase faults

- Faults on adjacent feeders

DER-to-DER Interaction

- Islanding

- Centralized control 


\subsection{DUIT's Potential Results and Policy Implications}

\subsubsection{Electrical Results}

The two factors that will ultimately help the widespread acceptance of DER are overcoming existing electrical concerns about large-scale DER operation on distribution systems and confirming that the benefits of such generation can, in fact, be realized in real-world settings. Broadly, the results obtained from DUIT will be targeted at answering these questions.

The installation and operation of DUIT will be focused on testing the integration and interaction of multiple, diverse DER with one another and with the distribution system. This testing will provide a thorough real-world attempt to confirm the applicability, usability, and limitations of the IEEE P1547 standard and other interconnection rules.

In addition, it is expected that unforeseen obstacles will arise from the installation and operation of DER for the DUIT. These events are viewed as a benefit of doing the testing, and, if possible, solutions to these problems will be developed, documented, and implemented quickly in the DUIT environment.

Section 1.5 presented a partial list of test issues. These issues will be prioritized and modified to fully investigate the interaction of the DER with the grid. It is expected that the DUIT will confirm and identify necessary modifications and potential enhancements to existing standards, and, through this process, the results and documentation should be persuasive in overcoming existing concerns of utilities and regulatory bodies.

Although it is impossible to accurately anticipate the results of such a comprehensive and complicated set of tests, it is nonetheless useful to state the questions the DUIT team will be working to answer.

- Will diverse DER be electrically compatible with one another?

- Which DER are capable of load following, and which are better suited to base load?

- Can the stiffness ratio and short circuit current contribution be effectively applied to those issues identified by IEEE 1547 by using a variable distribution length feeder of 10,20 , and 30 miles?

- Do diverse DER permit adequate grounding?

- How will the new parameters concepts of "electrical proximity factor" and "DER diversity quotient" add to our understanding of the results of DUIT and integration issues in a broader context?

- Will IEEE 1547 provide adequate interconnection guidance, or will much more sophisticated standards be needed as DER penetration of UL 1741-compliant inverter-based technologies exceeds a certain level?

- Too fully realize the value of DER, both from an end-user point of view and a distribution company perspective, are sophisticated control systems required? Is this control system also required to maximize ancillary benefits? 
- Network systems are different from radial systems. However, many of the protection issues may be the same. Are there fewer differences than originally thought?

- Will network protectors react the same way to DER as they do to existing regenerative loads?

- Do DER operate reliably enough to warrant consideration as an alternative to distribution system upgrades? Generation, transmission, and distribution benefits appear to be substantial; ancillary benefits are possible, but quantifying and especially metering them is problematic. Dispatching the ancillary benefits is possible by use of the DER control system.

- Does the use of computer modeling and a set of validation tests at the DUIT, together with the set of scalable DUIT results, allow accurate prediction of a large set of future DER installation issues?

\subsubsection{End-User and Utility Potential Benefits}

The realization of conceived benefits is another expected result from DUIT. The economic benefits of location and dispatchability as well as ancillary benefits will be validated through demonstration. A complete list of potential benefits, both utility side and customer side, is presented in Appendix C.

\subsubsection{Policy Implications}

The list of potential results illustrates the types of issues that will be resolved, raised, or illuminated by the DUIT. The effect of having these technical answers will differ depending on the stakeholder.

- Regulators will be able to make more informed decisions regarding the adoption of IEEE 1547 or other proposed interconnection standards.

- Deeper DR penetration of the distribution system will be better understood and accepted by utilities.

- Utilities will be able to see firsthand the protection afforded by standards and better understand the remaining issues.

- Utilities/distribution companies will have more substantial proof and confidence in the use of DR for their own purposes.

- ISOs, regional transmission organizations (RTOs), generation companies (GENCOs), transmitting utilities (TRANSCOs), and energy brokers will have more confidence in the operation and benefits of grid-connected DG.

- DG installations will be less likely to have excessive costs because of interconnection fears.

- Customers will have more surety that their DR will be interconnected safely, smoothly, and with minimum cost.

- Customers will be less likely to be adversely affected by their neighbor's DR. 
- Manufacturers will be better able to anticipate the types of protection devices required for the most beneficial incorporation of DG into utility systems or at customer sites.

- Standards-setting bodies such as IEEE will feel more (or less) comfortable about aspects of the current standards, leading them to refine, reconsider, or expand subsequent versions.

- Some stakeholders will consider the DUIT as a good first step but still inadequate to resolve some of their most important issues. 


\section{Assessment of Test Sites}

\subsection{Introduction}

\subsubsection{Objective}

The objective of this task is to evaluate potential test locations and recommend the optimum site (or combination of sites) for the installation, operation, and testing of DG technologies. As part of the analysis, and to the extent possible with the available data, an assessment of each site will determine the upgrades needed at each facility and the additional equipment required to accommodate the DUIT.

\subsubsection{Background}

The DUIT project would result in the first full-scale integration test of multiple distributed generation and storage technologies in the United States. The DUIT will have a broad test plan that will include a detailed exercising of the system with sophisticated monitoring to document the interaction of the various components both within the system and with the electric utility grid. Both grid interaction problems and benefits arising from penetration of DG into the distribution system will be evaluated.

A key aspect of the DUIT project is a thorough test of the feasibility and value of collocation of diverse distributed generation and storage technologies in the electric distribution system and the integration of those technologies into the distribution system. Ideally, several distributed generation and storage technologies would be installed within electrical interaction proximity of one another to allow their aggregate benefits and compounding operational issues to become evident.

The DG units will be instrumented and monitored to measure the potential electric distribution system advantages and challenges of substantial penetration (significantly greater than $10 \%$ of local load) of distributed generation and storage at distribution voltage levels. The data will be gathered and analyzed to characterize the actual value of distributed generation and storage to ratepayers and utilities (e.g., avoided costs, distribution cost savings, and lower energy cost).

The DUIT project will seek to establish one or more integration test sites at or near utility substations that will allow small generation, storage, and distribution control components to operate under the management of a communication and control system. Multiple test sites may be required to minimize the cost of simulating a broad variety of distribution and technology circumstances.

\subsection{Site Analysis Methodology}

\subsubsection{Overview}

The goal of the DUIT project is to perform testing to determine how distributed generation and storage technologies might interact with the electric grid, with one another, and with adjacent customers and loads on the distribution system. In particular, the DUIT is designed to illuminate other specific issues related to penetration of DR into 
the electric distribution system. These include interconnection technologies and practices; interconnection equipment performance and functional characterization; instrumentation, monitoring, and control technologies; and methods of controlling DG remotely, whether in a utility/regional hierarchical scheme or in a local/independent mode.

It is envisioned that multiple distributed generators, storage devices, load banks, capacitors, and other components would be installed at the test site and operated in a variety of configurations by means of state-of-the-art control, communications, and datalogging systems. Monitoring and data recording of key parameters would be carried out to evaluate the performance of DG and determine potential problems or issues that may arise. This knowledge would then be used to draw conclusions about how the DG may perform in "real world" distribution systems.

In the interest of minimizing effects on the DUIT project budget, sites that are most likely to be considered candidates for DUIT have existing DG technologies, testing and monitoring infrastructure, and the collaboration and support of the host utility. Also, a staff experienced in the DG field, flexible loads, and a reconfigurable distribution system are positive factors. Because it is expected that no single site will be able to accommodate all DUIT testing and some infrastructure upgrades may be required, the cost to accomplish the needed upgrades may be a key factor in the selection of sites.

\subsubsection{Technologies}

Because a primary objective of the DUIT is to test the interactions among DG and between DG and the electric system, it is desirable to test as many distributed generation and storage technologies as is practical. Inverter-based systems, synchronous and induction generators mated to engines and turbines, and storage technologies should all be considered. For the DUIT, every effort will be made to use existing DG at the testing sites to minimize the funds expended for purchase or lease of equipment. Indeed, sites with existing DG suitable for the DUIT will be given extra credit in the evaluation process, and those sites with existing test configurations will be given even more credit.

The DG technology types considered for DUIT will include:

1. Microturbines

2. Combustion turbines

3. Diesel engines

4. Dual-fuel engines

5. Spark engines

6. Stirling engines

7. Fuel cells

8. Photovoltaics

9. Storage technologies

- Flywheels

- Batteries

- Capacitors

- Superconducting magnetic energy storage. 


\subsubsection{DUIT Testing Requirements}

Preliminary discussions led to the development of a general list of test requirements to address utility concerns with DG interconnection. These discussions were necessary to develop the test facility requirements. Following is a preliminary outline of DG-related testing categories from the draft DUIT Test Plan. Not all of these will necessarily be addressed as part of the DUIT project, but their requirements were taken into account when assessing the capabilities of candidate sites.

\section{DUIT Test Requirements}

1. Commissioning tests

2. Performance

$2.1 \quad$ Load following

2.2 Parallel-standalone transition

3. Grid impact

3.1 Power quality

3.1.1 Harmonics

3.1.2 Power factor

3.1.3 Flicker

3.1.3.1 Flicker meter

3.1.3.2 In-rush

3.1.4 DC injection

3.1.5 EMI/EMF

3.2 System protection

3.2.1 Abnormal conditions

3.2.1.1 Voltage trip points

3.2.1.2 Frequency trip points

3.2.1.3 Reverse power/under power trip points

3.2.1.4 Fault detection

3.2.1.5 Loss of synchronism

3.2.2 Unintentional islanding

3.2.3 Intentional islanding

3.2.4 Synchronization

3.3 Distribution system impact/interaction

3.3.1 Network system

3.3.2 Fuse protection

3.3.3 Recloser coordination

3.3.4 Short circuit current contribution

3.3.5 Capacitor switching and operation

3.3.6 Stability

3.3.6.1 DG type testing

3.3.6.2 Interaction between DG

3.3.6.3 Islanding 
3.3.7 Cold load pick-up

3.3.8 Sectionalizing devices

3.3.8.1 Automatic circuit reconfiguration

3.3.8.2 Misoperation because of DG voltage

3.3.9 Voltage regulation

3.3.10 Substation backfeed

3.3.10.1 Adjoining feeders

3.3.10.2 Transmission system

3.3.11 Single-phase faults

3.3.12 Faults on adjacent feeders

3.4 DG interaction

4. Data

4.1 Measurements

4.1.1 Voltages

4.1.2 Currents

4.1.3 Power

4.1.4 Power factor

4.1.5 Harmonics

4.1.6 Impedance

4.1.7 EMI/EMF

4.2 Sampling rates

4.3 Averaging rates

5. Test Equipment

$5.1 \quad$ Monitoring

5.2 Control

5.3 Loads

$5.4 \quad$ Faults

6. Issues

6.1 Legacy versus future systems

6.2 Export versus non-export

6.3 Control aggregation

6.4 Scalability

6.5 Long-term versus short-term

6.6 Low versus high penetration

6.7 DER as nuisance versus DER as utility resources

6.8 Start-up versus steady-state operation

6.9 Single-phase versus three-phase

6.10 Three-wire versus four-wire

6.11 DR type

6.11.1 Inverter-based

6.11.2 Synchronous

6.11.3 Induction 
6.12 Prime mover

6.12.1 Fuel cell

6.12.2 Photovoltaics

6.12.3 Microturbine

6.12.4 Combustion turbine

6.12.5 Reciprocating engines

6.13 Storage

6.13.1 Batteries

6.13.2 Flywheels

6.13.3 Capacitors

6.13.4 Superconducting magnetic energy storage

6.14 Controls

6.14.1 DG unit control

6.14.2 Area control

7. Benefits

7.1 Asset utilization

7.2 Voltage and stability support

7.3 Ancillary services

7.4 Reliability/power quality

7.5 Demand reduction

7.6 Energy efficiency/CHP

7.7 Emissions trading/offsets

7.8 Transmission and distribution congestion

7.9 Risk reduction/sharing

7.10 Emergency/backup power

\subsubsection{Site Assessment Criteria}

Given the foregoing, the criteria in the following list were developed and used in the assessment of each site.

- Available space - number of test cells or bays, their sizes, and limitations

- Megawatt rating - largest single DG allowable; total allowed DG for facility

- Existing/permanent DG on site - potential for reducing acquisition costs of new equipment

- Existing testing equipment - controls, monitoring and instrumentation, switching load banks, etc.

- Host utility's level of interest, support, and involvement, both financial and in terms of personnel time and expertise

- Ability to test in both radial and network circuit configurations

- Grid supply - voltage, megavolt amperes, switching arrangements, and limitations 
- Fuel supply and storage - natural gas line size, pressure, and flow rate; diesel, hydrogen, gasoline, liquefied petroleum gas availability and/or storage capability

- Flexibility of facility to evolve or adapt to future/unforeseen testing needs

- Limitations - noise, emissions, other

- Ability to test multiple DG at once in interactive modes

- Number and expertise of testing staff

- Testing history/experience relevant to DUIT

- Costs - for required facility upgrades to accommodate DUIT testing as well as for the testing itself. Factors to consider:

- Cost of DER technologies (purchase, rental, lease, operation and maintenance, fuel, etc.)

- Number of DER installations and removals

- Duration of tests

- Fuel costs

- Analysis and reporting requirements

- Requirements of host utility (meetings, trips, etc.)

- Special installation equipment required

- Control equipment for multiple DER.

\subsubsection{Cost Estimates}

An important criterion in assessing sites for DUIT is cost. Aside from the anticipated project costs for labor and materials associated with testing, some costs will be associated with upgrading sites to accommodate testing. These "start up" costs must be estimated based on the specific equipment and infrastructure required to achieve the desired level of functionality.

Pacific Gas and Electric Co. (PG\&E) has developed cost estimates for four levels of upgrade options for the Modular Generation Test Facility in San Ramon, California. These estimates serve as a general guide of what it would take to modify a research facility with above-average testing facilities to levels required by DUIT. Other sites may require lesser or greater upgrades depending on equipment already installed.

\subsection{Assessment of Sites}

The goal of this task is to assess the existing state of each potential testing site. That is, an inventory is compiled of the physical and human resources at the given facility. Comparative evaluation of all sites, and preliminary conclusions concerning the ranking of the sites, will follow. 


\subsubsection{Modular Generation Test Facility - San Ramon, California}

PG\&E's Department of Technical and Ecological Services (TES) is located in San Ramon, California. This facility comprises a number of laboratories, both indoor and outdoor, for testing, calibration, analysis, and research in numerous aspects of utility operations. Several of these facilities could be used for the types of tests envisioned for the DUIT project.

One of these is the Modular Generation Test Facility (MGTF), which was constructed more than 10 years ago for research and demonstration of new generation technologies. The facility is designed for testing grid-connected and off-grid power generation and storage technologies. Although it has not been used for this purpose for several years, much of the necessary hardware and infrastructure is still in place.

Another facility is an outdoor area, adjacent to the MGTF, called the Smart Substation. This facility contains additional capabilities for DG testing and is electrically connected to the MGTF and the utility grid.

The third facility of interest is another outdoor area adjacent to the MGTF called the High Current Yard. This facility has a separate utility grid connection and has been used for high-current testing, primarily of distribution equipment. Concrete bays are designed to contain debris should components fail under testing.

TES has unique capabilities for testing and evaluating DG equipment and their interactions with a utility grid. Its engineering and technical staff has worked on R\&D projects extensively with PG\&E's Research and Development Department (which no longer exists), including advanced generation and storage, substation automation, transmission design, and other projects. The staff is highly skilled and knowledgeable in instrumentation and monitoring - both in the field and in the lab - and management of research projects. Chemical, metallurgical, and mechanical laboratories are also located here and could be called on if needed.

In addition, TES works closely with PG\&E's transmission and distribution personnel on related utility operations and engineering design issues. One of these issues is the effect of DG technologies on the PG\&E grid. TES personnel have expressed great enthusiasm for the prospect of hosting a DUIT site, as have personnel in the transmission and distribution departments.

An overall site plan for the TES facility is shown in Figure 1. The MGTF, Smart Substation, and High Current Yard are listed in bold, with circles as their label symbols.

A PV array that tracked the position of the sun (upper left corner of Figure 1) no longer exists. At one time, there was also a large number of PV systems installed on the roof of the Thermal Flow Test Facility undergoing long-term performance testing. 
Table 1. Summary of Capabilities:

PG\&E Modular Generation Test Facility and Technical and Ecological Services Department

\begin{tabular}{|c|c|}
\hline Parameter & Capabilities \\
\hline Number of test cells or bays & $\begin{array}{l}\text { Three indoor (in MGTF), one outdoor (in Smart } \\
\text { Substation), } 8-\mathrm{ft} \times 13-\mathrm{ft} \text { sound enclosure }\end{array}$ \\
\hline Natural gas? & Yes \\
\hline Natural gas pressure (psia) & $\begin{array}{l}\text { 1-in. line @ } 50 \mathrm{psi}, \sim 150 \mathrm{cfm} \\
\text { 1-in. line @ 3,100 psi, } 5 \mathrm{cfm} \\
\text { Storage tanks: 8,000 } \mathrm{ft}^{3} @ 3,100 \mathrm{psi}, \sim 10 \mathrm{cfm}\end{array}$ \\
\hline Natural gas flow rate (Btu/hr) & \\
\hline $\begin{array}{l}\text { Other fuels? Diesel, hydrogen, } \\
\text { gasoline, LPG, other }\end{array}$ & Would require permits \\
\hline $\begin{array}{l}\text { Any permanent DG units on site, type, } \\
\text { megawatts }\end{array}$ & $\begin{array}{l}\text { 192-kW PV simulator, 396-V battery system, } \\
\text { PQ2000 AC battery system ( } 2 \text { MW @ } 10 \text { s) }\end{array}$ \\
\hline Load banks? Resistive? & 400-kW resistive, 300-kVAR reactive in MGTF; \\
\hline Reactive? Rotating? & $\begin{array}{l}\text { impedance loop in Smart Substation has three } 2.5 \% \\
\text { segments, simulates up to } 30 \text { miles of feeder; High } \\
\text { Current Yard has various reactors and adjustable } \\
\text { resistive loads }\end{array}$ \\
\hline Live loads? & $\begin{array}{l}\text { 100-hp variable frequency drive motor; two } 50-\mathrm{kW} \\
\text { motors; can also pick up some nearby building load }\end{array}$ \\
\hline $\begin{array}{l}\text { Grid connectivity? Island, } \\
\text { connected, either }\end{array}$ & Either \\
\hline Max single megawatts & 0.25 \\
\hline Max total megawatts & 0.5 (upgradable to $1.5 \mathrm{MW}$ ) \\
\hline Multiple DG interacting & Yes \\
\hline Site limitation? Noise & No \\
\hline Site limitation? Footprint & No \\
\hline Site limitation? Height & No \\
\hline Site limitation? Width & No \\
\hline Site limitation? Weight & No \\
\hline Site limitation? Technology type & No \\
\hline Site limitation? Emissions & No \\
\hline \multicolumn{2}{|l|}{ Site limitation? Other } \\
\hline Usual purpose of testing & $\begin{array}{l}\text { Standards, calibration, chemical, metallurgical, } \\
\text { mechanical, HV and LV electrical testing and } \\
\text { analysis }\end{array}$ \\
\hline Strengths of facility & $\begin{array}{l}\text { Wide variety of physical facilities; extensive track } \\
\text { record in all types of testing; strong R\&D history; } \\
\text { involvement and support of host utility }\end{array}$ \\
\hline Weaknesses of facility & $\begin{array}{l}\text { Limit of } 250 \mathrm{~kW} \text { per DG because of internal wiring } \\
\text { and switchgear constraints within MGTF; } \\
\text { limit of three DG simultaneously operating }\end{array}$ \\
\hline Describe major test equipment & $\begin{array}{l}\text { Power meters, power quality meter, JEM-1 meter, } \\
\text { THD meter, inverter, spectrum analyzer, CTs, } \\
\text { potential transformers, infrared, EMF, numerous } \\
\text { computers and data loggers, Helox connectors }\end{array}$ \\
\hline Number of test staff & $\sim 140$ \\
\hline $\begin{array}{l}\text { Total person-years of relevant DG test } \\
\text { experience }\end{array}$ & $200+$ \\
\hline
\end{tabular}




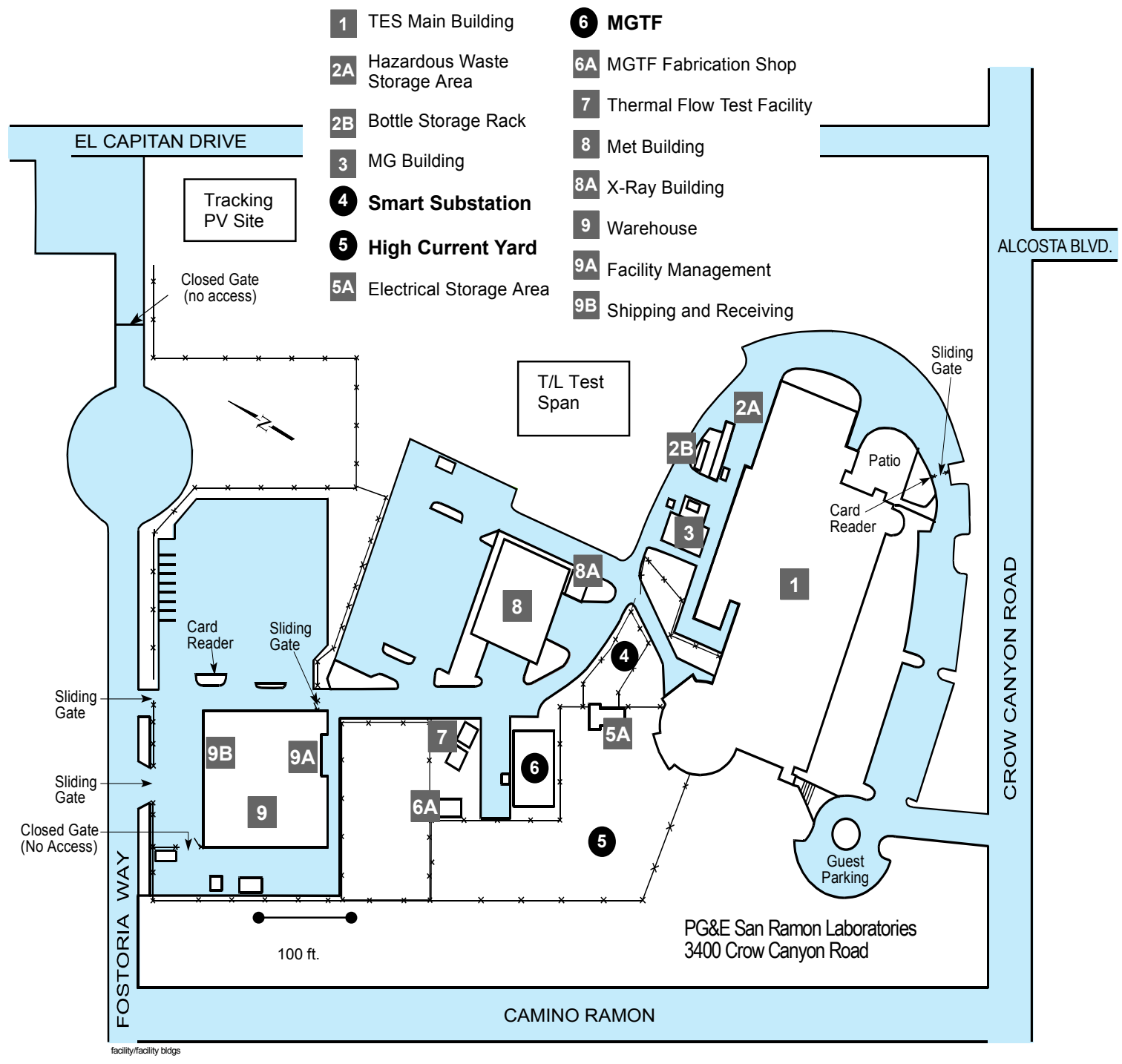

Figure 1. Overall PG\&E TES site plan

\subsubsection{Existing Test Facilities (MGTF, Smart Substation, High Current Yard)}

An overall, simple diagram of the three facilities, which shows how they are connected to one another and to the utility grid, is given in Figure 2. A single line diagram of the MGTF and Smart Substation is shown in Figure 3, and Figure 4 shows a single line diagram for the High Current Yard. Table 2 gives a summary of the features of these three facilities. Table 3 gives some additional details for the MGTF. 
In summary, the MGTF and Smart Substation have the following characteristics:

- A 70-foot by 40-foot building designed for DG testing (MGTF)

- An additional outdoor area available for DG testing (Smart Substation)

- Up to a 1.5-MW grid connection

- Three-phase, 480-V wye service

- Multiple bus configurations for islanding capability

- Protection for under/overfrequency, under/overvoltage, and ground fault current

- 400-kW variable resistive load controllable in 5-kW increments, which can be used for single-phase and unbalanced connections

- 300-kVAR variable inductive load controllable in 3.75-kVAR increments, which can be used for single-phase and unbalanced connections

- Additional capacitance, resistance, and inductance that can be added as required

- Up to 30 miles of simulated distribution line

- $\quad$ 1-in., 50-psi natural gas supply

- 8 -ft by $13-\mathrm{ft}$ acoustic isolation enclosure for engine tests.

The High Current Yard is a large area that is adjacent to the MGTF and connected to a $230-\mathrm{kV}$ transmission line. It has the potential to connect larger generating units to the grid and operate at various distribution voltage levels (i.e., 2.4-34.5 kV). However, the existing $230-\mathrm{kV}$ transformers represent a serious limitation; core overheating problems prevent them from being continuously energized for more than a couple of hours, regardless of ambient temperature. It would be very expensive to replace these transformers, so use of the High Current Yard grid connection for DG testing would be limited to short-duration testing. Alternatively, it may be practical to use some of the physical space in the High Current Yard by locating DG there and connecting directly to the MGTF/Smart Substation facility.

\subsubsection{PG\&E Facility Modification Options}

Several testing configuration options have been identified for cost-estimating purposes. These options are listed in order of anticipated cost, from least to most expensive:

Option 1: Use Existing Capabilities; Three Units (in MGTF Only) - Figure 5

- $500 \mathrm{~kW}$ total grid-connected load

- Maximum load of $250 \mathrm{~kW}$ on any individual unit

- Central 500-kW internal load bank (400-kW variable resistive load, 300-kVAR variable inductive load)

- Three units at same time, with isolation transformers

- 480-V radial distribution 
Option 2: Three Units With Individual Loads (in MGTF Only) - Figure 6

- $500 \mathrm{~kW}$ total grid-connected load

- Maximum load of $250 \mathrm{~kW}$ on any individual unit

- Variable resistive load banks; fixed inductive load on each DG unit

- Three units at same time, with isolation transformers

- $480-\mathrm{V}$ radial distribution

Option 3: Six Units (in MGTF and Smart Substation) - Figure 7

- $1.5 \mathrm{MW}$ total grid-connected load

- Maximum load of $500 \mathrm{~kW}$ on any individual unit

- Variable resistive load banks; fixed inductive load on each DG unit

- Six units at same time, with isolation transformers

- 10 mi simulated impedance on three units

- $480-\mathrm{V}$ radial distribution

Option 4: Add Network Distribution Capability to Option 3 - Figure 8

- $1.5 \mathrm{MW}$ total grid-connected load

- Maximum load of $500 \mathrm{~kW}$ on any individual unit

- Variable resistive load banks; fixed inductive load on each DG unit

- Six units at same time, with isolation transformers

- 10 mi simulated impedance on three units

- 480-V radial and network distribution

Other Options: High Current Yard

- $>1.5 \mathrm{MW}$

- At least six units at the same time

- Different distribution voltage levels (2.4-34.5 kV)

- Radial and network systems

- Very expensive because of transformer replacement 


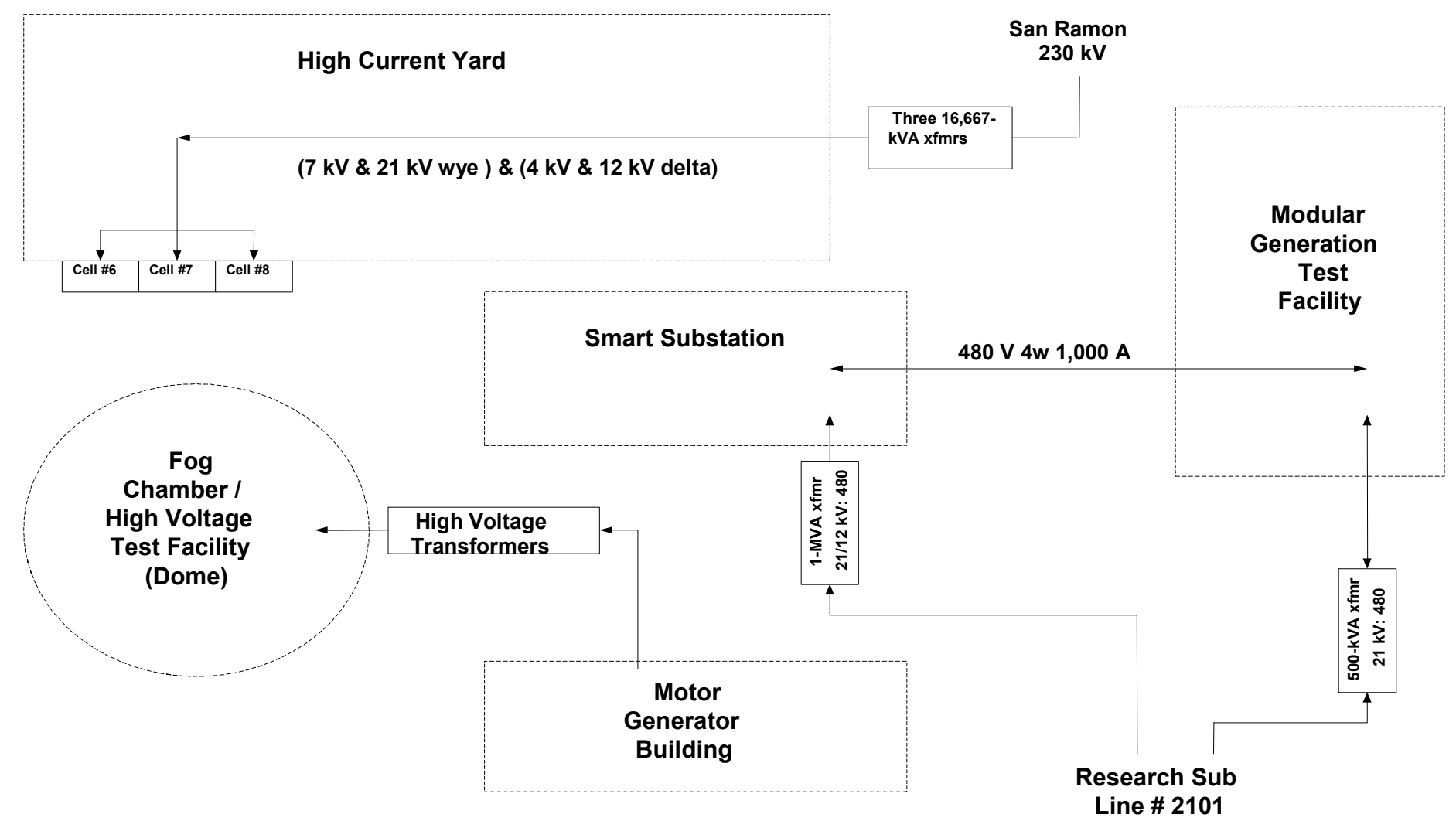

Figure 2. PG\&E TES electrical test facilities 


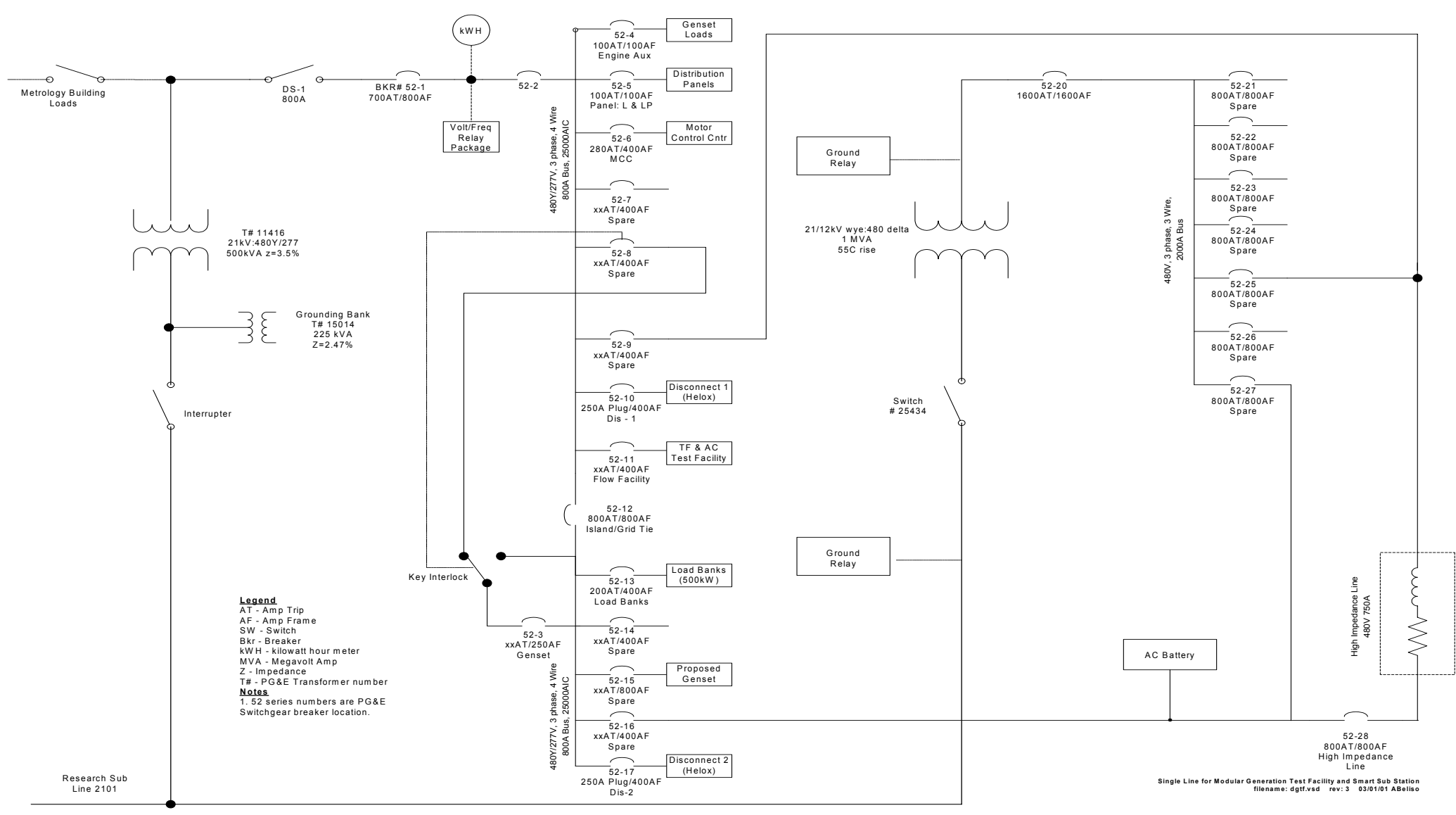

Figure 3. MGTF/Smart Substation single line diagram 


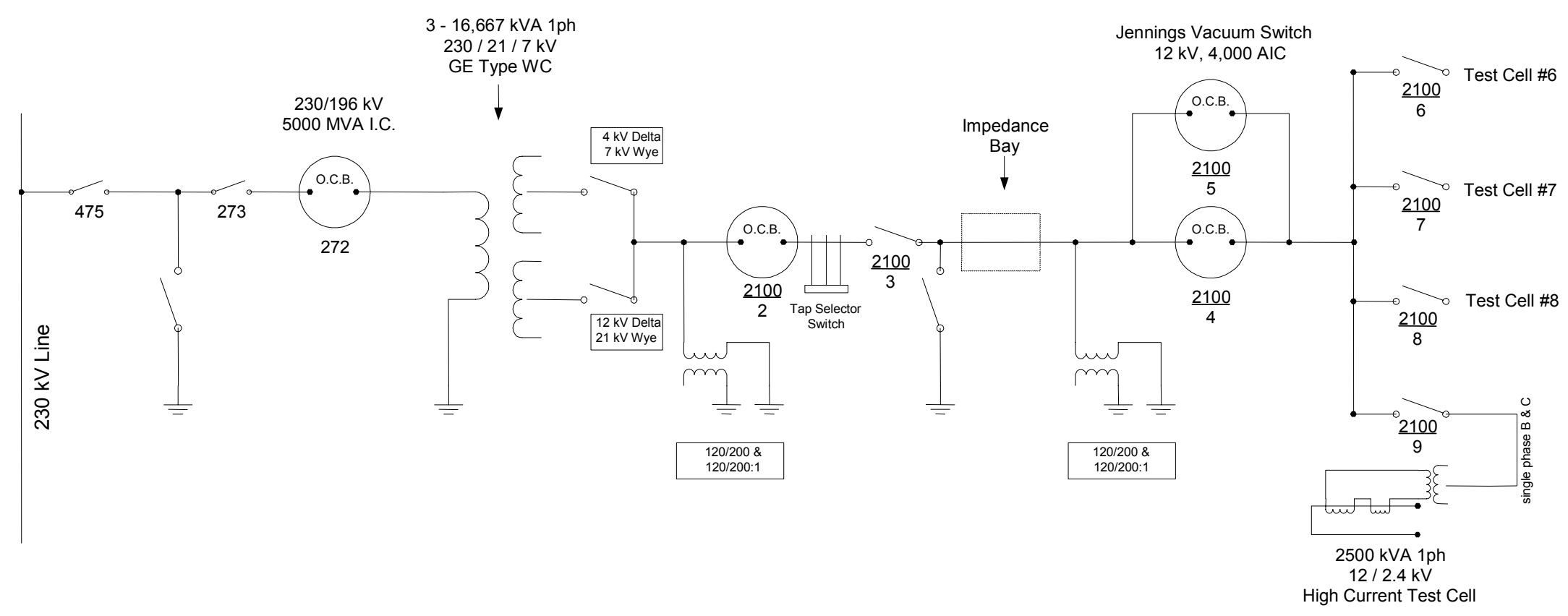

Figure 4. Single line diagram for TES High Current Yard 
Table 2. MGTF/Smart Substation/High Current Yard Components

DUIT Site Assessment

Pacific Gas and Electric Co.

Technical and Ecological Services Dept.

\begin{tabular}{|c|c|c|c|c|c|c|c|c|c|c|c|c|c|c|c|}
\hline & $\begin{array}{l}\text { Space } \\
\text { (sq ft) }\end{array}$ & Drawings & Wye & Delta & Controls & Circuits & $\begin{array}{l}\text { Switch- } \\
\text { gear }\end{array}$ & Protection & $\begin{array}{l}\text { Load } \\
\text { Banks }\end{array}$ & Xfrmrs & $\begin{array}{c}\text { Grid } \\
\text { Connect }\end{array}$ & $\begin{array}{c}\text { Equipment } \\
\text { Instrumentation, } \\
\text { DAS }\end{array}$ & Existing & Gas & Permits \\
\hline MGTF & $2,800 / 2,000$ & Visio & 480 & 480 & Synch & $\begin{array}{l}\text { Grid } \\
\text { and/or } \\
\text { island }\end{array}$ & & Relay/fuse & $\begin{array}{c}500 \mathrm{~kW} \\
(400 \mathrm{res}) \\
\text { (300 reac) }\end{array}$ & $\begin{array}{c}15,30 \\
75,1 \\
12.5\end{array}$ & $\begin{array}{c}\text { Research } \\
2101\end{array}$ & $\begin{array}{l}\text { Various power } \\
\text { meters, } \\
\text { yokogawa, bmi, } \\
\text { wavebook, spec } \\
\text { analyzer, rpm, ct, } \\
\text { pt, infrared temp, } \\
\text { emf, and others }\end{array}$ & $\begin{array}{c}\text { Flow } \\
\text { facility } \\
\text { motor } \\
(100 \mathrm{hp}, \\
\text { var freq } \\
\text { drive), } 2 \\
50-k W \\
\text { motors, } \\
\text { PV } \\
\text { simulator } \\
(192 \mathrm{~kW})\end{array}$ & $\begin{array}{l}\text { Natural } \\
\text { gas @ } \\
50 \mathrm{psi}\end{array}$ & $\begin{array}{l}\text { Other } \\
\text { fuel } \\
\text { requires } \\
\text { permit, } \\
\text { zinc } \\
\text { bomine } \\
\text { (notify } \\
\text { fire and } \\
\text { city) }\end{array}$ \\
\hline $\begin{array}{l}\text { High } \\
\text { Current }\end{array}$ & $\begin{array}{l}\text { Outdoor } \\
\text { NA/6,000+ }\end{array}$ & Visio & $\begin{array}{c}7 \\
\text { kVA, } \\
21 \\
\text { kVA }\end{array}$ & $\begin{array}{c}4 \\
\text { kVA, } \\
12 \\
\text { kVA }\end{array}$ & $\begin{array}{c}2,100 / 2 \\
\text { auto, } \\
\text { manual } \\
\text { (air } \\
\text { breakers) }\end{array}$ & $\begin{array}{c}\text { Grid } \\
\text { (see } \\
\text { drawings) }\end{array}$ & $\begin{array}{c}\text { Test } \\
\text { cells } \\
6,7,8 \\
2,100 \\
\text { A }\end{array}$ & Relay & $\begin{array}{l}\text { Various } \\
\text { reactors, } \\
\text { adjustable } \\
\text { resistive } \\
\text { loads }\end{array}$ & $\begin{array}{c}230 \\
\text { kVA: } \\
2.4- \\
34.5 \\
\text { kV }\end{array}$ & $\begin{array}{l}\text { San } \\
\text { Ramon } \\
\text { sub }\end{array}$ & Same as above & Capacitors & None & $\begin{array}{l}\text { Same } \\
\text { as } \\
\text { above }\end{array}$ \\
\hline $\begin{array}{l}\text { Smart } \\
\text { Sub }\end{array}$ & $\begin{array}{l}\text { Outdoor } \\
\text { limited }\end{array}$ & Visio & & 480 & $\begin{array}{l}\text { Impedance } \\
\text { loop }\end{array}$ & $\begin{array}{l}\text { Grid or } \\
\text { island }\end{array}$ & $\begin{array}{c}2,000 \mathrm{~A} \\
\text { bus }\end{array}$ & Relay & $\begin{array}{l}\text { Same as } \\
\text { MGTF }\end{array}$ & $\begin{array}{l}21 \mathrm{kV} \\
\text { to } 480\end{array}$ & $\begin{array}{c}\text { Research } \\
2101\end{array}$ & Same as above & $\begin{array}{l}\text { PQ2000 } \\
\text { battery } \\
(2 \mathrm{MW} \text { for } \\
10 \mathrm{~s})\end{array}$ & NA & $\begin{array}{l}\text { Same } \\
\text { as } \\
\text { above }\end{array}$ \\
\hline
\end{tabular}


Table 3. MGTF Equipment Inventory

\begin{tabular}{|c|c|c|c|c|}
\hline Item & Description & Power Rating & Voltage & Notes \\
\hline Building & $70 \mathrm{ft}$ by $40 \mathrm{ft}$ & $500 \mathrm{kVA}$ & 480 4-wire & Natural gas \\
\hline Working area & $1,800 \mathrm{ft}^{2}$ & & & Floor space \\
\hline SS switchgear & 9 ckt brkr cell & 1,600 A (main) & 480 4-wire & \\
\hline MGTF switchgear & 10 ckt brkr cell & 800 A (main) & 480 4-wire & \\
\hline PV simulator & DC power supply & $192 \mathrm{~kW}$ & 480 3-wire & \\
\hline Wavedriver & Inverter & $60 \mathrm{~kW}$ & 208 & \\
\hline Load bank & Simplex (resistive) & $400 \mathrm{~kW}$ & 480 3-wire & \\
\hline Load bank & Simplex (reactive) & 300 kVAR & 480 3-wire & \\
\hline Sound enclosure & $8 \mathrm{ft}$ by $13 \mathrm{ft}$ by $8 \mathrm{ft}$ & & & \\
\hline DC supply & Batteries & & 12-396 VDC & (Can be increased) \\
\hline Impedance loop & (3) $2-1 / 2 \%$ Z steps & $\begin{array}{l}750 \mathrm{~A} \\
\text { continuous }\end{array}$ & 480 3-wire & Variable \\
\hline Island bus & & 500 kVA & 480 3-wire & Grid or island \\
\hline Helox connector 1 & Quick test & $250 \mathrm{kVA}$ & 480 4-wire & Grid \\
\hline Helox connector 2 & Quick test & $250 \mathrm{kVA}$ & 480 3-wire & Island \\
\hline Helox connector 3 & Quick test & $112.5 \mathrm{kVA}$ & 208 4-wire & Grid \\
\hline Amp connector 1 & Quick test & $112.5 \mathrm{kVA}$ & 208 or 120 & 208 or $1203 p h$ \\
\hline $\begin{array}{l}\text { Trace inverters } \\
\text { (12) }\end{array}$ & 24 VDC & $4 \mathrm{~kW}$ & 1201 -phase & SW4024 \\
\hline MCC-1 & $\begin{array}{l}\text { Motor control } \\
\text { center }\end{array}$ & & 480 4-wire & \\
\hline Power meters & Yokogawa & & $600 / 600$ & $A C / D C$ \\
\hline $\begin{array}{l}\text { Power quality } \\
\text { meter }\end{array}$ & $\begin{array}{l}\text { Power quality } \\
\text { nodes }\end{array}$ & & & \\
\hline $\begin{array}{l}\text { Power quality THD } \\
\text { meters }\end{array}$ & RPM & & $600 / 1,000$ & $24-000-1650$ \\
\hline Spectrum analyzer & $\mathrm{HP}$ & & & $1.5 \mathrm{GHz}$ \\
\hline JEM-1 metering & Main utility meter & $\begin{array}{l}\text { Transformer } \\
\text { rated }\end{array}$ & 480 4-wire & \\
\hline Fuel supply 1 & Natural gas & & & 1 in. @ 50 psi \\
\hline Fuel supply 2 & Natural gas & & & $8,000 \mathrm{ft}^{3} 3,100 \mathrm{psi}$ \\
\hline Fuel supply 3 & Natural gas & & & 5 cfm @ 3,100 psi \\
\hline
\end{tabular}




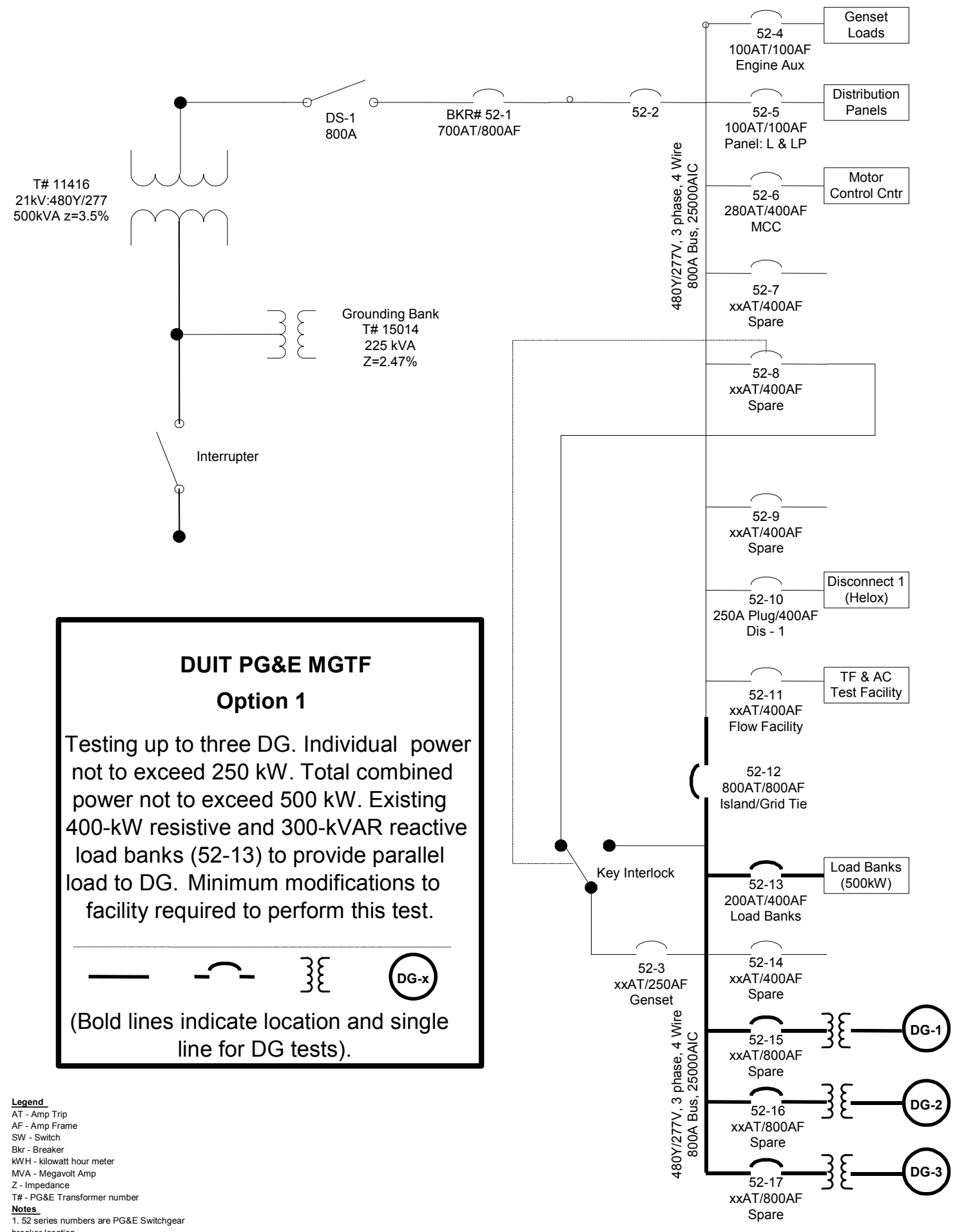

Figure 5. MGTF Option 1 configuration 


DUIT PG\&E MGTF
Option 2
Testing up to three DG units with individual variable
resistive and reactive loads. Individual power
not to exceed $250 \mathrm{~kW}$. Total combined power
not to exceed $500 \mathrm{~kW}$.

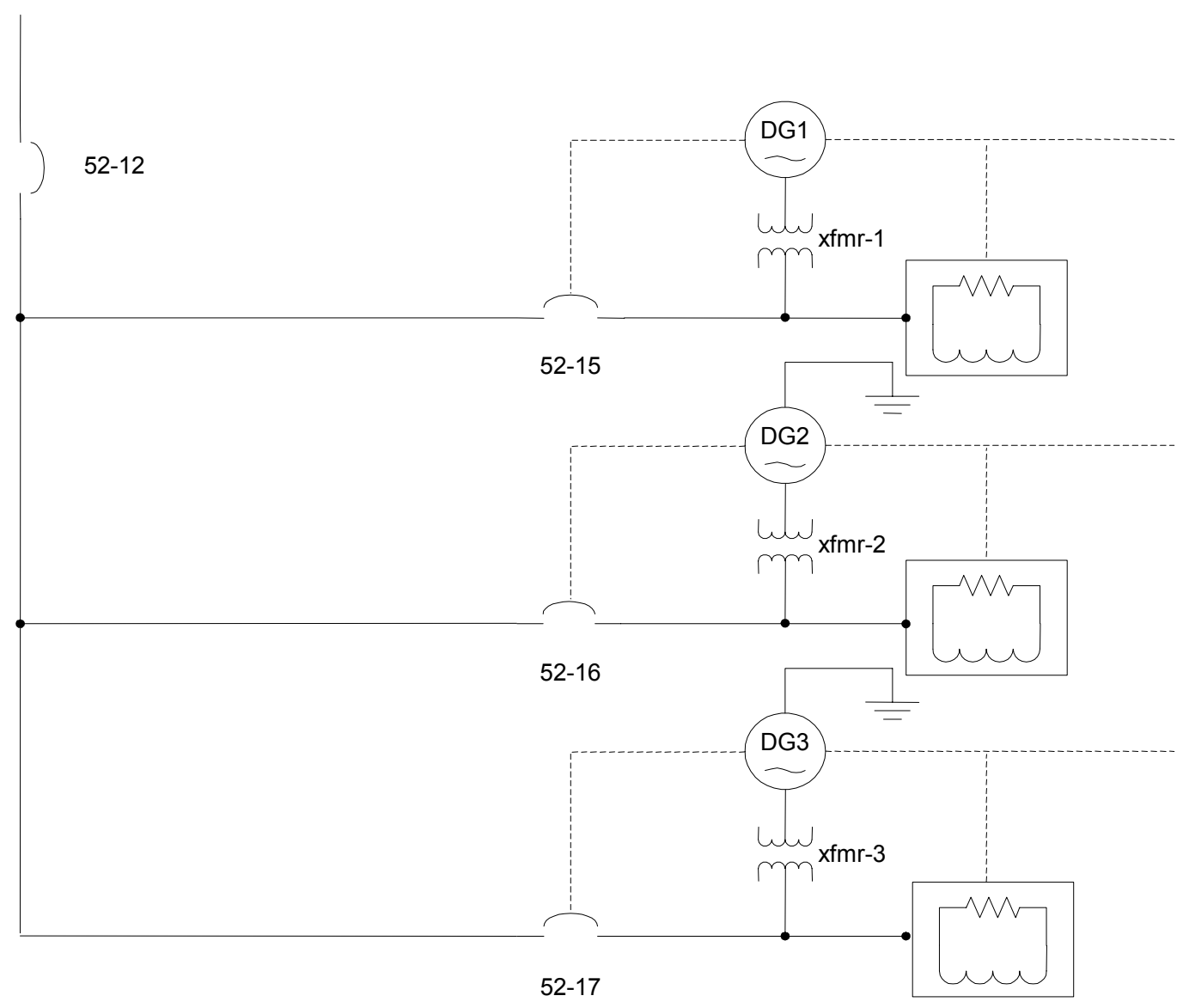

Figure 6. MGTF Option 2 configuration 


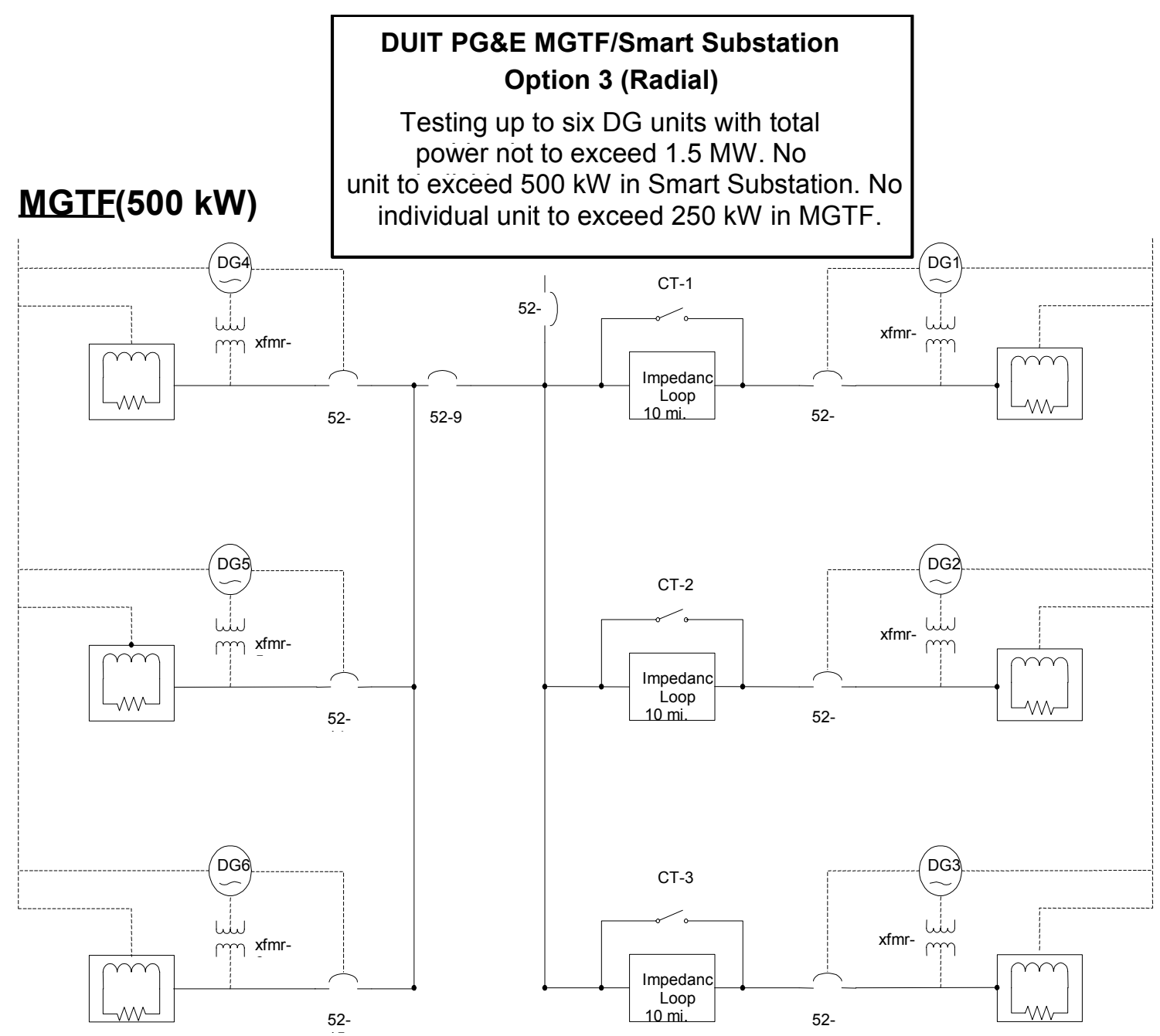

Figure 7. MGTF Option 3 configuration 


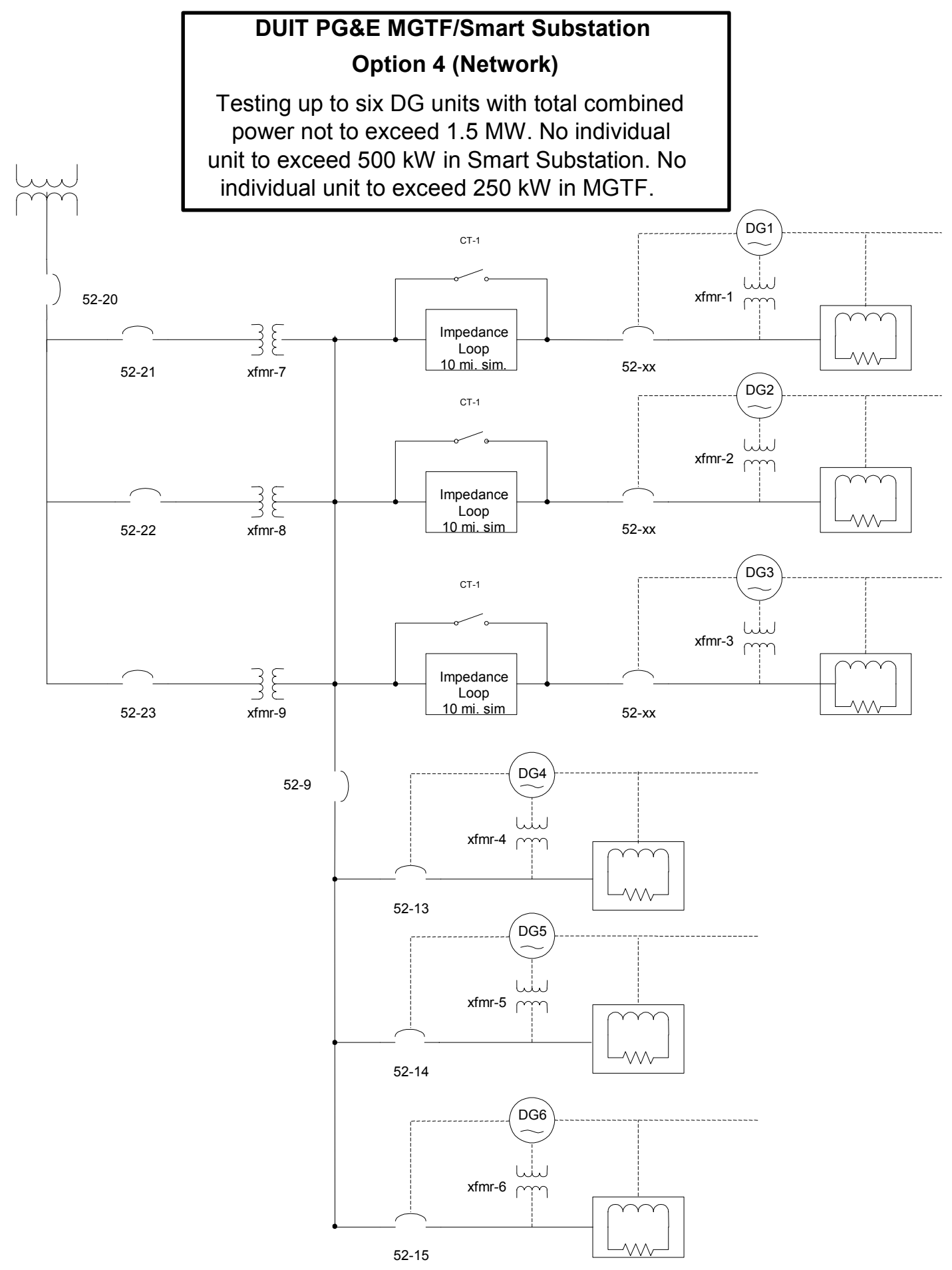

Figure 8. MGTF Option 4 configuration 


\subsubsection{Additional Capabilities}

PG\&E's TES Department provides a full range of testing, analytical, and environmental services at its 13-acre site and at field locations throughout the PG\&E system. TES has more than 140 engineers, scientists, and technicians who work in various areas, including:

- Failure analysis and service life enhancement

- Performance assessment and optimization

- Evaluation and development of measurement methods and test equipment

- Environmental assessment and compliance monitoring

- Meteorological measurement and forecasting

- In-service inspection

- Instrument calibration and repair

- Material and product evaluation

- Welding and machine shop.

In regard to DG technology evaluation, capabilities currently exist for additional testing related to:

1. Emissions

2. Noise

3. EMF

4. Efficiency

5. Vibration.

\subsubsection{Cost Estimates}

Cost estimates for the first four options were prepared by breaking the work into three areas:

1. Facility Preparation

This is an overall cost based on project planning; modifications and materials needed in the facility; general instrumentation, data acquisition, and control setup and calibration; and teardown at the conclusion of the test.

2. DG Unit Installation, Start-Up, and Commissioning

This cost was estimated on a per-DG unit basis and then multiplied by an assumed number of units to obtain an overall project cost. It includes labor for planning for each unit's installation, technician time during installation, individual instrumentation and control setup, unit start-up, and commissioning tests. It does not include the cost of the DG unit. 


\section{Testing}

The testing cost was estimated on a monthly basis. It includes assumed technician and engineering time to run the tests 40 hours a week during normal business hours, time for data reduction, an assumed number of regular project meetings each month, and time for data summary and progress reports. Based on an assumed 1-year testing period, this estimate was multiplied by 12 to obtain an overall project testing estimate.

These cost estimates do not include fuel costs or costs for any overall DG system controls. The estimates include a $20 \%$ contingency because of the many unknowns concerning actual equipment and testing requirements at this time.

\subsubsection{Coordination With Host Utility}

- Personnel Availability

TES personnel are anticipated to have time available for DUIT as PG\&E ramps down its activities at TES because of industry restructuring.

- Facility Availability

The facilities are not being used fully at present because of a reduction in activities as PG\&E spins off resources and activities as a result of industry restructuring. PG\&E recently made a decision not to sell TES or seek outside contracts. Therefore, the availability of the facilities is considered very good.

- Coordination With Operating Personnel

Key personnel in Distribution Operations have expressed interest in being involved in the DUIT effort. These engineers are currently responsible for working with DG that interconnects with PG\&E.

\subsubsection{University of California at Irvine - Irvine, California}

The University of California at Irvine's Advanced Power and Energy Program has facilities for testing DR on its campus at the Distributed Technologies Testing Facility, the adjacent University Research Park, and associated power park sites. The University of California at Irvine (UCI) not only has a world-class test facility for fossil units (especially small gas turbines), but it also exhibits an excellent understanding of the importance of the broader questions of grid interactions and compatibility.

In 1995, the National Fuel Cell Research Center was established at UCI with the mission of researching all aspects of fuel cell development, demonstration, and technology transfer. The University Gas Turbine and Microturbine Generator Laboratory researches "the full spectrum of gas turbine technologies ... from aircraft propulsion to stationary electric power generation." A major focus of its testing program is RAMD: reliability, availability, maintainability, and durability. Testing and analytical methods pertaining to these parameters are based on industry definitions and standards. 
The laboratory has the capability of testing multiple small DG $(<220 \mathrm{~kW})$ in fully instrumented mode with load changes, switching, etc. Larger units up to perhaps $25 \mathrm{MW}$ can be tested in a more limited way at the central campus plant, located about a mile from the lab.

UCI possibly has almost every current technology represented on site, plus access to potential power park sites on land adjacent to the campus that is now under development by UCI itself. The microturbines on site do not seem to be instrumented as fully as rigorous testing of their grid interactions might require. The PV on site is very small, and the grid interconnectivity and inter-technology interaction aspects of its facility are not installed as of this writing.

UCI has strong expertise in testing fossil-fueled generation. It would also be a prime location for power park testing. (The Pleasanton Power Park in Pleasanton, California, is under construction at this time but could be a prime candidate for power park testing in the future.)

A major consideration for UCI as a DUIT site is host utility coordination. At present, UCI has no significant relationship with a host utility; it is primarily a university engineering laboratory. Another factor might be the too-strong grid connection, which, without some additional modifications or equipment, could limit the DG-to-grid interactions testing required by DUIT.

UCI has endeavored to raise public awareness of its capabilities and has made a strong case nationally and within California that it should have major funding to become a national testing resource. So far it has succeeded. Director Scott Samuelsen is a skilled leader and has created a very attractive test facility and staff, including many students. 


\section{Table 4. Summary of Capabilities - University of California at Irvine}

\begin{tabular}{|c|c|}
\hline Parameter & Capabilities \\
\hline Number of test cells or bays & $\begin{array}{l}\text { Five current, six under development, three at } \\
\text { central plant; can test up to four microturbines } \\
\text { plus } 10 \text { other DG units }\end{array}$ \\
\hline Natural gas? & Yes \\
\hline Natural gas pressure (psia) & 5 psi, 40 psi, 150 psi, and 500 psi service \\
\hline Natural gas flow rate (Btu/hr) & $\begin{array}{l}320 \text { MM Btu/hr @ } 500 \text { psi; dedicated online GC } \\
\text { provides actual gas Btu content in real time }\end{array}$ \\
\hline $\begin{array}{l}\text { Other fuels? Diesel, hydrogen, gasoline, LPG, } \\
\text { other }\end{array}$ & $\begin{array}{l}\text { DF-2, Jet-A, LPG, hydrogen, CO, butane, } \\
\text { ethane, N2, etc. }\end{array}$ \\
\hline $\begin{array}{l}\text { Any permanent DG units on site, type, } \\
\text { megawatts }\end{array}$ & $\begin{array}{l}\text { Two PV systems, three fuel cells, including a } \\
25-\mathrm{kW} \text { solid oxide fuel cell (Siemens- } \\
\text { Westinghouse), three microturbines on long- } \\
\text { term loan for testing }\end{array}$ \\
\hline Load banks? Resistive? Reactive? Rotating? & $\begin{array}{l}\text { Resistive } \\
\text { Reactive proposed }\end{array}$ \\
\hline Live loads? & Yes \\
\hline Grid connectivity? Island, connected, either & Either \\
\hline Max single megawatts & $0.22 ; 0.40$ planned \\
\hline Max total megawatts & $\begin{array}{l}1.5 \text { in lab; can do limited testing of up to } 25 \\
\text { MW at central plant }\end{array}$ \\
\hline Multiple DG interacting & Yes \\
\hline Site limitation? Noise & No \\
\hline Site limitation? Footprint & $70 \mathrm{ft}$ by $30 \mathrm{ft}$ \\
\hline Site limitation? Height & "High-bay" design, $\sim 32 \mathrm{ft}$ \\
\hline Site limitation? Width & $30 \mathrm{ft}$ \\
\hline Site limitation? Weight & No \\
\hline Site limitation? Technology type & No \\
\hline Site limitation? Emissions & No \\
\hline Site limitation? Other & \\
\hline Usual purpose of testing & $\begin{array}{l}\text { Reliability/power quality, beta, spec check, } \\
\text { research }\end{array}$ \\
\hline Strengths of facility & $\begin{array}{l}\text { University-based: unbiased, nonprofit, high } \\
\text { visibility to stakeholders, reputation }\end{array}$ \\
\hline Weaknesses of facility & Lack of host utility involvement \\
\hline Describe major test equipment & $\begin{array}{l}\text { Power quality monitoring, exhaust emissions } \\
\text { monitoring, sound emissions monitoring, air } \\
\text { toxics monitoring }\end{array}$ \\
\hline Number of test staff & mormig \\
\hline $\begin{array}{l}\text { Total person-years of relevant DG test } \\
\text { experience }\end{array}$ & $50+$ \\
\hline
\end{tabular}




\subsubsection{Dolan Test Center - Groveport, Ohio}

A very qualified candidate to do grid and load interaction testing is the Dolan Test Center (DTC), sponsored and operated by American Electric Power (AEP) in Groveport, Ohio.

DTC is an AEP entity that works through two AEP subsidiaries to provide a variety of testing services to the company, including new device qualification, protection packages, telecommunications systems, and controls. It is also doing a variety of demonstration projects at AEP, including flywheel, solid-state transfer switch, and premium power park projects.

DTC also does work for outside entities. The Electric Power Research Institute (EPRI) currently does most of its "in depth" testing of DER technologies at DTC; this in-depth testing involves putting the DER in a laboratory environment and testing the electrical and mechanical performance of the device. The California Independent System Operator has also commissioned DTC to perform meter qualification work for grid operations in California.

DTC has been used as a development lab by outside product developers, and it has considerable experience in testing DR. It has tested wind turbines and PV systems and has a strong ongoing AEP-funded wind turbine field monitoring project. It has access to "a fleet of people" to augment in-house expertise, if needed.

So far it has built a test bed with comprehensive instrumentation and support facilities.

- Fully instrumented for testing any DR up to $500 \mathrm{~kW}$

- Voltage sags and swells, capacitor switching, transient overvoltage, voltage and current imbalances

- Utility equipment including reclosers, breakers, and switches

- Fixed resistor and inductor banks, $100 \mathrm{~kW}$ and $100 \mathrm{kVAR}$, respectively; can bring in additional banks if needed

- Fixed capacitor banks that can be switched in steps to test DR response and power factor range

- Can pick up part of the building load under some test conditions

The DTC can test up to $2 \mathrm{MW}$ of total installed DG, but at that level, it sacrifices some flexibility of controlling in-house loads and operations on the utility side. It has a natural gas line for fuel supply; for DG greater than $400 \mathrm{~kW}$, it can bring in gas tanks via truck. DTC has an environmental chamber for variable temperature testing of smaller DR.

DTC's primary laboratory focus has been on "electromechanical compatibility," i.e., connecting DR to the grid to see how the grid affects the DR and how the DR affect the grid (or nearby DR and other devices such as regulators, tap changers, etc.). Another major focus is on inverter-to-grid interconnections and performance, in both grid-connected and standalone (islanded) situations. 
Table 5. Summary of Capabilities - Dolan Test Center

\section{Parameter}

Number of test cells or bays

Natural gas?

Natural gas pressure (psia)

Natural gas flow rate (Btu/hr)

Other fuels? Diesel, hydrogen, gasoline, LPG, other

Any permanent DG units on site, type, megawatts

Load banks? Resistive?

Reactive? Rotating?

Live loads?

Grid connectivity? Island, connected, either

Max single megawatts

Max total megawatts

Multiple DG interacting

Site limitation? Noise

Site limitation? Footprint

Site limitation? Height

Site limitation? Width

Site limitation? Weight

Site limitation? Technology type

Site limitation? Emissions

Site limitation? Other

Usual purpose of testing

Strengths of facility

Weaknesses of facility

Describe major test equipment

Number of test staff

Total person-years of relevant DG test experience

\section{Capabilities}

One for DG up to about $500 \mathrm{~kW}$; outdoor space can accommodate two or three additional DG with temporary connections

Yes

Up to $400 \mathrm{~kW}$; mobile tanks for more capacity if needed

Can be brought in as needed

PV, wind system simulators

$100 \mathrm{~kW}$ resistive, $100 \mathrm{kVAR}$ reactive (both fixed); switched capacitor banks (in steps)

Yes, can pick up part of building load

Either

0.5

0.5

Yes

None

None

None

None

None

None

Prohibited by Ohio law from doing emissions testing for Ohio utilities; therefore, has limited ability in this area

$2 \mathrm{MW}$ total installed DG, but loses some switching flexibility

Performance, reliability/availability, operation and maintenance requirements, DG-to-DG and DG-to-grid interactions

Versatility, connectivity, hybrid system simulation

Megawatt size of DG tested (500 kW max) Control room, data acquisition systems, PV and wind turbine simulators, switching center, battery house, CNG compressor and charging stations, electric vehicle charging stations Numerous in-house staff; access to outside experts as needed 
DTC is currently planning to increase its capability to test up to $4 \mathrm{MW}$ by developing a former peaking station site about a mile away. This site has a high-pressure gas supply from a transmission main and can accommodate several large distributed generators. It will not be as fully instrumented as the main lab but is intended for long-term performance monitoring to supplement DTC's lab testing. At the time of writing, it was due to be operational by late 2001 .

DTC would like to expand its capabilities to test more and bigger systems, larger loads, power quality (PQ) devices that are coming on the market at around $2 \mathrm{MW}$, and capacitors for testing of larger DR.

The strong utility flavor and talents of this facility and the strong EPRI funding and presence makes Dolan a prime competitor for all fossil DER testing and even interconnection standards testing. DTC is the prime component of EPRI's non-PQ testing (PEAC does EPRI's PQ testing). DTC personnel have partnered with PEAC (see below) on research and publications in the PQ area.

\subsubsection{Southwest Research Institute - San Antonio, Texas}

Southwest Research Institute is a multidisciplinary research organization with the expertise and facilities to address a wide array of DER testing needs. Although expertise is spread among several large groups, several hundred staff members could be called on to undertake a variety of individual or system tests. Specialties include almost all facets of reciprocating engines and CTs, fuel cells, fuels and fuel systems, controls software, and power electronics.

Southwest Research Institute is well known for fossil component testing. Southwest Research Institute has been supported by DOE's Office of Industrial Technologies and other sponsors, such as leading manufacturers. At present, an advanced diesel generator program is being initialized. 


\section{Table 6. Summary of Capabilities - Southwest Research Institute}

\begin{tabular}{|c|c|}
\hline Parameter & Capabilities \\
\hline Number of test cells or bays & $40(\max 800 \mathrm{~kW})$ \\
\hline Natural gas? & Yes \\
\hline Natural gas pressure (psia) & $\begin{array}{l}150 \text { psi supply; can generate } 3,600 \text { psi via } \\
\text { compressors and storage tanks }\end{array}$ \\
\hline Natural gas flow rate (Btu/hr) & 8-in. pipe \\
\hline $\begin{array}{l}\text { Other fuels? Diesel, hydrogen, } \\
\text { gasoline, LPG, other }\end{array}$ & All \\
\hline $\begin{array}{l}\text { Any permanent DG units on site, type, } \\
\text { megawatts }\end{array}$ & None \\
\hline Load banks? Resistive? & $\sim 1 \mathrm{MW}$ resistive in $250-\mathrm{kW}$ increments \\
\hline Reactive? Rotating? & \\
\hline Live loads? & No \\
\hline $\begin{array}{l}\text { Grid connectivity? Island, } \\
\text { connected, either }\end{array}$ & Either \\
\hline Max single megawatts & 3 \\
\hline Max total megawatts & 3 \\
\hline Multiple DG interacting & Yes \\
\hline Site limitation? Noise & None \\
\hline Site limitation? Footprint & None \\
\hline Site limitation? Height & None \\
\hline Site limitation? Width & None \\
\hline Site limitation? Weight & None \\
\hline Site limitation? Technology type & None \\
\hline Site limitation? Emissions & None \\
\hline Site limitation? Other & None \\
\hline Usual purpose of testing & Emissions, performance, durability \\
\hline Strengths of facility & $\begin{array}{l}\text { Breadth of expertise; fossil fuel technology } \\
\text { testing expertise }\end{array}$ \\
\hline \multicolumn{2}{|l|}{ Weaknesses of facility } \\
\hline Describe major test equipment & $\begin{array}{l}\text { Dynamometers, PC-based controls, load cells, } \\
\text { emission benches, pressure transducers, } \\
\text { temperature monitors, switchgear for grid } \\
\text { connection, cooling towers, load banks }\end{array}$ \\
\hline Number of test staff & $\begin{array}{l}2,600 \text { total; about } 100-150 \text { would have } \\
\text { relevant expertise for } D G \text { testing }\end{array}$ \\
\hline $\begin{array}{l}\text { Total person-years of relevant DG test } \\
\text { experience }\end{array}$ & $\sim 1,200$ \\
\hline
\end{tabular}




\subsubsection{Power Electronics Applications Center - Knoxville, Tennessee}

The Power Electronics Applications Center (PEAC) is a prime example of a laboratory established by EPRI that is now used by EPRI in a related field: distributed resources. PEAC has fine laboratories and talented staff and would be hard to compete with in the power quality area, its prime area of expertise. PEAC could easily expand into any type of electrical testing of any DR.

Table 7. Summary of Capabilities - Power Electronics Applications Center

\begin{tabular}{|c|c|}
\hline Parameter & Capabilities \\
\hline Number of test cells or bays & 12 \\
\hline Natural gas? & Yes \\
\hline \multicolumn{2}{|l|}{ Natural gas pressure (psia) } \\
\hline \multicolumn{2}{|l|}{ Natural gas flow rate (Btu/hr) } \\
\hline $\begin{array}{l}\text { Other fuels? Diesel, hydrogen, } \\
\text { gasoline, LPG, other } \\
\text { Any permanent DG units on site, type, } \\
\text { megawatts }\end{array}$ & Diesel \\
\hline Load banks? Resistive? & $1 \mathrm{MW}$ \\
\hline \multicolumn{2}{|l|}{ Reactive? Rotating? } \\
\hline Live loads? & No \\
\hline $\begin{array}{l}\text { Grid connectivity? Island, } \\
\text { connected, either }\end{array}$ & Either \\
\hline \multicolumn{2}{|l|}{ Max single megawatts } \\
\hline \multicolumn{2}{|l|}{ Max total megawatts } \\
\hline Multiple DG interacting & Yes \\
\hline Site limitation? Noise & None \\
\hline Site limitation? Footprint & None \\
\hline \multicolumn{2}{|l|}{ Site limitation? Height } \\
\hline \multicolumn{2}{|l|}{ Site limitation? Width } \\
\hline Site limitation? Weight & None \\
\hline Site limitation? Technology type & None \\
\hline Site limitation? Emissions & None \\
\hline Site limitation? Other & None \\
\hline Usual purpose of testing & $\begin{array}{l}P Q \text { effects on hardware operation, DG effects } \\
\text { on grid }\end{array}$ \\
\hline Strengths of facility & PQ experience, interconnection standards \\
\hline Weaknesses of facility & New at DG except solar \\
\hline \multicolumn{2}{|l|}{ Describe major test equipment } \\
\hline \multicolumn{2}{|l|}{ Number of test staff } \\
\hline Total person-years of relevant DG test & \\
\hline experience & \\
\hline
\end{tabular}

PEAC would be a good site for interconnection testing, based on the physical facilities there. A potential drawback is that the existing grid connection is too strong to evaluate grid-to-DG interactions. Some modifications and/or upgrades would likely be needed to accommodate the full range of DUIT testing. On the other hand, some limited tests could likely be performed with minimal upgrades. PEAC has limited experience in renewables, although the inverters that are a part of many such technologies have been tested there extensively. 
PEAC has partnered with AEP's DTC (see above) on research and publications in the PQ area. EPRI contracts for virtually all of its PQ-related work at PEAC, so planning is important to schedule PEAC's resources. Also, it may be necessary to coordinate carefully with PEAC to avoid issues of EPRI proprietary information.

\subsubsection{Sandia National Laboratories - Albuquerque, New Mexico, and Livermore, California}

Sandia is a strong competitor in renewables and standards development and, by extension, in interconnection standards testing. It also has extensive expertise in fossil-fueled generation testing, field tests, analysis of renewable DR, and hybrid systems. Sandia's long-time management of DOE's storage program is an excellent synergy with its renewables expertise. Systems-level development and testing has long been a forte of Sandia. Sandia is a prominent member of the Consortium for Electric Reliability Technology Solutions and has strong storage testing ties with the labs at the University of Wisconsin.

Sandia has PV arrays, solar thermal systems, diesels, natural gas generators (a 3-in. natural gas line is available), inverters, and other DG systems, including an on-loan microturbine. Sandia also has diverse energy storage systems on site and various motors and loads of all types to connect to the generators. It has an extensive data acquisition system (DAS) and such exotic items as a lightning simulator, RFI test equipment, power quality analysis hardware, and a three-phase/single-phase arbitrary waveform generator.

Sandia performs wind turbine tests at the US Department of Agriculture Agricultural Research Station near Bushland, Texas. Bushland is a typical Great Plains location with flat terrain and a high wind regime well suited to studying the wind loads imposed on the components of wind turbines. The 34-m Test Bed, featuring long-term performance testing of a 34-m vertical axis wind turbine (also known as a Darrieus machine), ran from the early 1970s until recently. The emphasis now is on a program called the Long-Term Inflow and Structural Test, which features three 8-m Micon 65/13M horizontal axis wind turbines. Phase 1 of the Long-Term Inflow and Structural Test is focused on the instrumentation and DASs required for the huge amount of data to be collected. In Phase 2, the data systems and analysis techniques developed at Bushland for the Micon wind turbines will be deployed on larger, commercial-size wind machines at other US sites.

Sandia's planned DER testing capabilities include permanent microturbines and advanced controls, perhaps as part of its advanced supervisory control and data acquisition (SCADA) and energy security activities. It hopes to create a test platform for novel SCADA protocols and validate control schemes for multiple DR in distribution systems. 


\section{Table 8. Summary of Capabilities - Sandia National Laboratories}

\section{Parameter}

Number of test cells or bays

Natural gas?

Natural gas pressure (psia)

Natural gas flow rate (Btu/hr)

Other fuels? Diesel, hydrogen,

gasoline, LPG, other

Any permanent $D G$ units on

site, type, megawatts

Load banks? Resistive?

Reactive? Rotating?

Live loads?

Grid connectivity? Island, connected, either

Max single megawatts

Max total megawatts

Multiple DG interacting

Site limitation? Noise

Site limitation? Footprint

Site limitation? Height

Site limitation? Width

Site limitation? Weight

Site limitation? Technology type

Site limitation? Emissions

Site limitation? Other

Usual purpose of testing

Strengths of facility

Weaknesses of facility

Describe major test equipment

Number of test staff

Total person-years of relevant DG test

experience

\section{Capabilities}

Yes

3-in. distribution line

Diesel

92.5-kVA/480-V diesel with paralleling control being added; 8-kVA 120/240 natural gas generator; 30-kVA/480-V inverter; 150-kVA/480VAC and 115-kW/700-VDC motor-generators; two 30-kW PV arrays; 64-kW and 11-kW PV simulators; miscellaneous DC power supplies; 10kW dish Stirling at solar tower; lead-acid battery systems: $720 \mathrm{kWh} / 288 \mathrm{cells} / 24-576 \mathrm{~V} ; 52.8$ $\mathrm{kWh} / 24$ cells/6-48 V; $204 \mathrm{kWh} / 240$ cells/2-480 V Resistive - $150 \mathrm{~kW} / 480 \mathrm{~V}$ (programmable), 360 $\mathrm{kW} / 480 \mathrm{~V}$ (manual); $55 \mathrm{~kW} / 480 \mathrm{~V}$ (manual), 10 $\mathrm{kW} / 120 \mathrm{~V}$ (manual) Inductive - $225 \mathrm{kVAR} / 480 \mathrm{~V}$ (programmable), 55 $\mathrm{kVAR} / 480 \mathrm{~V}$

Capacitive - 250 kVAR/480 V (manual), 12 kVAR/240 V (manual)

Nonlinear - $50 \mathrm{kVA} / 277 \mathrm{~V}$

Motor - up to $10 \mathrm{hp}$, three-phase; $3 / 4 \mathrm{hp} \mathrm{single-}$ phase with dynamometer and computer control

Separately derived grid - 50 kVA 120/240 V

$0.5 \mathrm{MVA} / 480 \mathrm{~V}$

0.5 MVA at PSEL West; 10 MVA at Solar Tower

1.5 acres; $75 \%$ occupied

Lightning simulator, RFI test equipment; $\mathrm{PQ}$ equipment, 5.25-kVA three-phase/single-phase arbitrary waveform generator, extensive DAS 


\subsubsection{National Renewable Energy Laboratory - Golden, Colorado}

The National Renewable Energy Laboratory (NREL) operates a number of laboratories and test centers dedicated to renewable energy technologies. In Golden, near Denver, are:

- The Solar Energy Research Facility, which houses labs for research in PV, superconductivity, and materials science

- The Solar Radiation Research Laboratory, a monitoring and research lab that provides resource information to meteorological organizations, developers, and policymakers

- The Outdoor Test Facility, NREL's primary PV testing facility, with indoor labs for environmental and accelerated testing and an outdoor lab for standalone and grid-tied testing of PV systems

- The Thermal Test Facility, which focuses on energy-saving technologies for buildings

- The Alternative Fuels User Facility for methanol, ethanol, and alternative fuels research, including a pilot plant for biofuels research.

In addition, NREL partners with Sandia National Laboratories in Albuquerque, New Mexcio, to operate SunLab, a concentrating solar power facility, with the goal of developing reliable and efficient systems and increasing their market acceptance.

About one hour north of Golden, NREL operates the National Wind Technology Center at Rocky Flats. Located here are a 23,000- $\mathrm{ft}^{2}$ indoor laboratory for testing and development of wind turbine components and systems and an outdoor facility with fully instrumented test pads for testing wind turbines up to $1 \mathrm{MW}$. Five wind turbines, from $10 \mathrm{~kW}$ to $600 \mathrm{~kW}$, are currently installed and being tested. The National Wind Technology Center provides a worldclass wind machine test facility that is capable of evaluating all the components of small and large wind machines. Included in those capabilities are mechanical load testing of blades and a 2-MW low-speed dynamometer for testing generators.

Integrated with the National Wind Technology Center at Rocky Flats is the Hybrid Test Facility/DER Test Facility, which is designed to test a variety of DG technologies (wind, PV, fuel cells, microturbines, and diesel technologies) in different operating configurations, including grid-tied and standalone configurations. The DER Test Facility consists of a grid designed to simulate a small power system. It can include wind turbines, PV, batteries, microturbines, and diesel generators. Two of the National Wind Technology Center's four rows for wind turbine testing are tied into the facility, providing simultaneous support for numerous wind turbines (space exists for approximately one dozen $25-250 \mathrm{~kW}$ machines). A $10-\mathrm{kW}$ PV array, a $30-\mathrm{kW}$ microturbine, and three diesel generators $(<200 \mathrm{~kW}$ each) are also installed. There is also a $200-\mathrm{kW}$ utility grid simulator with capabilities to control voltage, frequency, and harmonic content. Future plans related to DG primarily involve expansion of the test facility to include more types and quantity of DG technologies and storage.

Infrastructure enhancements will likely include a new building, bringing in a natural gas line, expanding the mini-grid, and installing additional loads and monitoring systems. 
Table 9. Summary of Capabilities - National Renewable Energy Laboratory

\section{Parameter}

Number of test cells or bays

Natural gas?

Natural gas pressure (psia)

Natural gas flow rate (Btu/hr)

Other fuels? Diesel, hydrogen, gasoline, LPG, other

Any permanent DG units on site, type, MW

Load banks? Resistive?

Reactive? Rotating?

Live loads?

Grid connectivity? Island,

connected, either

Max single megawatts

Max total megawatts

Multiple DG interacting

Site limitation? Noise

Site limitation? Footprint

Site limitation? Height

Site limitation? Width

Site limitation? Weight

Site limitation? Technology type

Site limitation? Emissions

Site limitation? Other

Usual purpose of testing

Strengths of facility

Weaknesses of facility

Describe major test equipment

Number of test staff

Total person-years of relevant DG test experience

\section{Capabilities}

Four 1/4-mi rows with buried power cables; Row 1 has 120 VDC/480 VAC; rows 2 and 3 have 13,200; Row 4 has 13,200; Row 1 feeds into hybrid test facility; also has development bays in blade mechanical test area

No

Five diesels (two $40 \mathrm{~kW}$, a $50 \mathrm{~kW}$, an $80 \mathrm{~kW}$, and a $125 \mathrm{~kW}$ )

Various wind turbines (10-750 kW), multiple diesel generators, 10-kW PV, 30-kW

microturbine, three battery banks (110 VDC-1, $100 \mathrm{AH}, 228 \mathrm{VDC}-750 \mathrm{AH}, 48 \mathrm{VDC}-350 \mathrm{AH})$

$100 \mathrm{~kW}$ resistive/inductive, $165 \mathrm{~kW}$ resistive/

404 kVAR inductive/404 kVAR capacitive

Some

Either

25

Yes

No

No

No

No

No

Distributed energy system evaluation, interconnection evaluation, wind system evaluation/development, hybrid system evaluation/development, structural, aerodynamics, electrical, atmospheric, noise Large range of DG ratings possible, lots of real estate, test facilities

Mostly outdoor 2.5-MVA dynamometer, Hybrid Test Facility, multiple turbines

$\sim 65$ 


\subsubsection{University of Wisconsin-Madison - Madison, Wisconsin}

The University of Wisconsin-Madison currently has limited capabilities to test DG but could be expanded into this area of research. It has plans to build outdoor test pads to overcome the space limitations of its indoor lab. Its primary interest is understanding microgrids, a term with many potential meanings. In this case, it means "a single DER entity presenting itself to the grid." Currently, the maximum DG capability is about $300 \mathrm{~kW}$, and it is limited to $480-\mathrm{V}$ circuits. But it has extensive experience in load simulation, adjustable speed drives, highvoltage DC systems, Flexible AC Transmission Systems (FACTS, an EPRI program), and power electronics. Its unique strength is an understanding of the types of loads DER would interact with in industrial environments.

The University of Wisconsin-Madison would like to establish a "microgrid testing station" at $480 \mathrm{~V}$ or less with fuel cells, microturbines, and storage technologies. The microgrid would be tested in grid-connected and grid-isolated modes but would total less than $1,000 \mathrm{~kW}$. The strength of the test facility would be its emphasis on multiple types of loads interacting simultaneously with multiple types of generators, all presenting themselves to the grid as a single entity: aggregatable and controllable. A potential drawback is the preference for unidirectional flow (i.e., no "backflow" or export to the grid). The University of Wisconsin is a major part of the Consortium for Electric Reliability Technology Solutions, it is cooperating with Sandia on storage issues, and it has worked with EPRI and others. 
Table 10. Summary of Capabilities - University of Wisconsin-Madison

\begin{tabular}{ll}
\hline \multicolumn{1}{c}{ Parameter } & \multicolumn{1}{c}{ Capabilities } \\
\cline { 2 - 2 } Number of test cells or bays & \\
Natural gas? & No testing stations, none suitable for DER \\
Natural gas pressure (psia) & Low-pressure supply \\
Natural gas flow rate (Btu/hr) & \\
Other fuels? Diesel, hydrogen, & No \\
gasoline, LPG, other & \\
Any permanent DG units on site, type, & $240-V$ DC feed (simulates a fuel cell) \\
megawatts & \\
Load banks? Resistive? & Yes, primarily a load capability test site, \\
Reactive? Rotating? & resistive, reactive, inductive, live, etc.; can do \\
& single-phase and unbalanced loads \\
Live loads? & Yes \\
Grid connectivity? Island, & Either \\
connected, either & \\
Max single megawatts & 0.15 MW \\
Max total megawatts & $0.3 \mathrm{MW}$ \\
Multiple DG interacting & No DG \\
Site limitation? Noise & Yes, classrooms and offices in floors above \\
Site limitation? Footprint & None \\
Site limitation? Height & $8 \mathrm{ft.}$ (door limits) \\
Site limitation? Width & $8 \mathrm{ft.}$ (door limits) \\
Site limitation? Weight & None \\
Site limitation? Technology type & None \\
Site limitation? Emissions & No \\
Site limitation? Other & $480 \mathrm{~V}$ \\
Usual purpose of testing & Load simulation, adjustable speed drives, \\
Strengths of facility & HVDC, FACTS, power electronics \\
Weaknesses of facility & See above \\
Describe major test equipment & No DG \\
Number of test staff & Loads \\
Total person-years of relevant DG test & Seven professional, two technical \\
experience & $\sim 25$ \\
& \\
& \\
&
\end{tabular}




\subsubsection{Pacific Northwest National Laboratory - Hanford, Washington}

Pacific Northwest National Laboratory has strong experience in understanding and modeling transmission and distribution systems, DG, power electronics, sensors, controls, and diagnostics. However, its current DG testing facilities are not substantial. It is primarily limited to preparing to test a small (5-kW) solid-oxide fuel cell (SOFC) to be delivered by the National Energy Technology Laboratory. Pacific Northwest National Laboratory would like to help establish a Hanford test site for innovative energy technologies. This is envisioned to include distributed generators of varied types, controls and diagnostics, and perhaps a utility staff training capability.

\section{Table 11. Summary of Capabilities - Pacific Northwest National Laboratory}

\begin{tabular}{|c|c|}
\hline Parameter & Capabilities \\
\hline \multicolumn{2}{|l|}{ Number of test cells or bays } \\
\hline Natural gas? & Yes \\
\hline \multicolumn{2}{|l|}{ Natural gas pressure (psia) } \\
\hline \multicolumn{2}{|l|}{ Natural gas flow rate (Btu/hr) } \\
\hline \multicolumn{2}{|l|}{$\begin{array}{l}\text { Other fuels? Diesel, hydrogen, gasoline, LPG, } \\
\text { other }\end{array}$} \\
\hline $\begin{array}{l}\text { Any permanent DG units on site, type, } \\
\text { megawatts }\end{array}$ & Very small SOFC planned in 2001 \\
\hline \multicolumn{2}{|l|}{ Load banks? Resistive? Reactive? Rotating? } \\
\hline Grid connectivity? Island, connected, either & No \\
\hline Max single megawatts & 0.005 \\
\hline Max total megawatts & 0.025 \\
\hline Multiple DG interacting & No \\
\hline \multicolumn{2}{|l|}{ Site limitation? Noise } \\
\hline \multicolumn{2}{|l|}{ Site limitation? Footprint } \\
\hline \multicolumn{2}{|l|}{ Site limitation? Height } \\
\hline \multicolumn{2}{|l|}{ Site limitation? Width } \\
\hline \multicolumn{2}{|l|}{ Site limitation? Weight } \\
\hline \multirow{2}{*}{\multicolumn{2}{|c|}{$\begin{array}{l}\text { Site limitation? Technology type } \\
\text { Site limitation? Emissions }\end{array}$}} \\
\hline & \\
\hline Usual purpose of testing & SOFC performance \\
\hline Strengths of facility & $\begin{array}{l}\text { National Energy Technology Laboratory } \\
\text { funding, Pacific Northwest National } \\
\text { Laboratory experience with T\&D }\end{array}$ \\
\hline Weaknesses of facility & SOFC only \\
\hline Describe major test equipment & SOFC only \\
\hline Number of test staff & \\
\hline Total person-years of relevant DG test & \\
\hline experience & \\
\hline
\end{tabular}




\subsubsection{Solar Test and Research Center - Phoenix, Arizona}

Arizona Public Service (APS) created the Solar Test and Research (STAR) Center in 1987 to do small-scale testing of new products (primarily renewable technologies). Since then, it has evolved broader testing capabilities, which include storage and fossil generation to complement its renewable technologies. Currently under test are PV $(400 \mathrm{~kW})$, solar thermal dishes, inverters, trackers, two sets of batteries, a microturbine, and a coupled load bank.

APS considers the STAR Center a staging area for technologies that are almost ready for use by the utility or its customers. It has several experienced on-site staff members continuously taking and analyzing data. To date, the facility has not been used as a test center for hire by technology developers or to provide DG data to the public in general.

Table 12. Summary of Capabilities - Solar Test and Research Center

\begin{tabular}{|c|c|}
\hline Parameter & Capabilities \\
\hline Number of test cells or bays & Multiple \\
\hline Natural gas? & Yes \\
\hline \multicolumn{2}{|l|}{ Natural gas pressure (psia) } \\
\hline \multicolumn{2}{|l|}{ Natural gas flow rate (Btu/hr) } \\
\hline \multicolumn{2}{|l|}{$\begin{array}{l}\text { Other fuels? Diesel, hydrogen, } \\
\text { gasoline, LPG, other }\end{array}$} \\
\hline $\begin{array}{l}\text { Any permanent DG units on site, type, } \\
\text { megawatts }\end{array}$ & $\begin{array}{l}\text { 100-kW PV, solar thermal dishes, storage } \\
\text { units, inverters, grid-isolated systems }\end{array}$ \\
\hline \multicolumn{2}{|l|}{ Load banks? Resistive? } \\
\hline Reactive? Rotating? & \\
\hline Live loads? & Yes \\
\hline $\begin{array}{l}\text { Grid connectivity? Island, } \\
\text { connected, either }\end{array}$ & Either \\
\hline \multicolumn{2}{|l|}{ Max single megawatts } \\
\hline Max total megawatts & 1 \\
\hline Multiple DG interacting & Yes, but not instrumented to test this facet \\
\hline \multicolumn{2}{|l|}{ Site limitation? Noise } \\
\hline \multicolumn{2}{|l|}{ Site limitation? Footprint } \\
\hline \multicolumn{2}{|l|}{ Site limitation? Height } \\
\hline \multicolumn{2}{|l|}{ Site limitation? Width } \\
\hline \multicolumn{2}{|l|}{ Site limitation? Weight } \\
\hline \multicolumn{2}{|l|}{ Site limitation? Technology type } \\
\hline \multirow{2}{*}{\multicolumn{2}{|c|}{$\begin{array}{l}\text { Site limitation? Emissions } \\
\text { Site limitation? Other }\end{array}$}} \\
\hline & \\
\hline Usual purpose of testing & $\begin{array}{l}\text { Side-by-side testing of small renewables to } \\
\text { evaluate applicability in APS system }\end{array}$ \\
\hline Strengths of facility & $\begin{array}{l}\text { Long-standing system (since 1988), APS } \\
\text { support }\end{array}$ \\
\hline Weaknesses of facility & Outdoor location \\
\hline Describe major test equipment & $\begin{array}{l}\text { PV, solar dishes, battery banks, inverters, test } \\
\text { building }\end{array}$ \\
\hline Number of test staff & Two-four full-time \\
\hline $\begin{array}{l}\text { Total person-years of relevant DG test } \\
\text { experience }\end{array}$ & $50+$ \\
\hline
\end{tabular}




\subsubsection{Oak Ridge National Laboratory - Oak Ridge, Tennessee}

Oak Ridge National Laboratory (ORNL), located near Knoxville, Tennessee, is a large DOE laboratory that performs research in diverse areas of science and engineering. ORNL is the lead agency for many federal energy research programs and collaborates on many levels with other national labs. Electric power-related activities are under way through the Fossil Energy Program, the Power Electronics and Electric Machinery Research Center, the Buildings Technology Center, and the Materials Division. Technical areas in the electric power field are advanced gas turbines, microturbines, engines, fuel cells, geothermal power, hydropower, hydrogen, superconductivity, interconnections, industry restructuring, and modeling and simulation.

The Buildings Technology Center is currently studying energy-efficiency improvement possibilities through thermal management (CHP) of a microturbine system. The Materials Division is researching higher-temperature turbine materials and fuel cell materials.

Table 13. Summary of Capabilities - Oak Ridge National Laboratory

\begin{tabular}{|c|c|}
\hline Parameter & Capabilities \\
\hline Number of test cells or bays & One \\
\hline Natural gas? & Yes \\
\hline \multicolumn{2}{|l|}{ Natural gas pressure (psia) } \\
\hline \multicolumn{2}{|l|}{ Natural gas flow rate (Btu/hr) } \\
\hline \multicolumn{2}{|l|}{$\begin{array}{l}\text { Other fuels? Diesel, hydrogen, } \\
\text { gasoline, LPG, other }\end{array}$} \\
\hline \multicolumn{2}{|l|}{$\begin{array}{l}\text { Any permanent DG units on site, type, } \\
\text { megawatts }\end{array}$} \\
\hline Load banks? Resistive? & No \\
\hline \multicolumn{2}{|l|}{ Reactive? Rotating? } \\
\hline Live loads? & Yes \\
\hline \multicolumn{2}{|l|}{ connected, either } \\
\hline Max single megawatts & $75 \mathrm{~kW}$ \\
\hline Max total megawatts & $75 \mathrm{~kW}$ \\
\hline \multicolumn{2}{|l|}{ Multiple DG interacting } \\
\hline Site limitation? Noise & None \\
\hline Site limitation? Footprint & None \\
\hline \multicolumn{2}{|l|}{ Site limitation? Height } \\
\hline \multicolumn{2}{|l|}{ Site limitation? Width } \\
\hline \multicolumn{2}{|l|}{ Site limitation? Weight } \\
\hline Site limitation? Technology type & None \\
\hline Site limitation? Emissions & None \\
\hline \multicolumn{2}{|l|}{ Site limitation? Other } \\
\hline Usual purpose of testing & CHP, efficiency improvements \\
\hline Strengths of facility & Materials testing, buildings program \\
\hline \multicolumn{2}{|l|}{ Weaknesses of facility } \\
\hline \multicolumn{2}{|l|}{ Describe major test equipment } \\
\hline \multicolumn{2}{|l|}{ Number of test staff } \\
\hline Total person-years of relevant DG test & \\
\hline experience & \\
\hline
\end{tabular}


ORNL participates, along with the National Energy Technology Laboratory, in DOE's Advanced Turbine Systems program, with primary responsibility for high-temperature materials research through the Metals and Ceramics Division. ORNL also participates in the Environmental Technology Verification program with Sandia National Laboratories and the Environmental Protection Agency. Fuel cell systems have been evaluated in this program.

\subsubsection{Other Sites Investigated}

The following were included in the original list of possibilities warranting investigation as potential DUIT sites because of their past work or known expertise in a DER-related field. After the initial round of site screenings, these organizations were deemed secondary possibilities for test sites and, as such, were not investigated to the same degree as the others. In some cases, notably the Greenhouse Gas Technology Center and Underwriters Laboratories (UL), the organization's testing facilities are numerous and dispersed, making assessment difficult.

\subsubsection{Nevada Test Site - Jackass Flats, Nevada}

The US DOE has plans to develop the Jackass Flats site in Nevada for a testing center. Because these plans are tentative and in the formative stage, it is not possible to evaluate this site for DUIT at this time. As the Nevada Test Site is developed by DOE, it may become clearer how the site may rate for DUIT.

\subsubsection{Greenhouse Gas Technology Verification Center-Research Triangle Park, North Carolina}

The Greenhouse Gas Technology Verification Center was established as part of the US Environmental Protection Agency's broader Environmental Technology Verification Program to "verify the performance of innovative technical solutions to problems that threaten human health or the environment" (these include, to date, two microturbines). The center operates under the auspices of the Environmental Protection Agency's Office of Research and Development, whose focus is on the technical, economic, and emissionsrelated performance characteristics of technologies. The center is operated in a public-private partnership with the Southern Research Institute, headquartered in Birmingham, Alabama.

These programs were initiated to address the lack of independent and credible technology performance data, considered to be a major impediment to the acceptance and use of innovative environmental technologies (including DG). The program provides technology performance data to private and public technology decision-makers. A variety of stakeholders need such data to make informed technology marketing, purchasing, and policy decisions.

The center performs field testing only and specializes in most facets of fossil-fueled DG operational characteristics and in testing protocol development in partnership with stakeholders. "Stakeholder groups" consisting of government agencies, vendors/OEMs, technology users, and international technical and policy experts determine the technologies verified and parameters tested. The results include credible performance testing undertaken by an independent third party on commercial technologies and useful data and testing protocols that are available to the public. 


\subsubsection{Underwriters Laboratories}

UL has 44 testing and certification centers and 190 inspection centers worldwide. UL focuses on safety issues, but there are some aspects of DG that are not safety-related. One key example is fuel efficiency. If the unit operates safely and within design temperature and safety parameters, the fuel efficiency has no effect on safety. However, generator output rating does have a safety-related component. The amount of power available affects the switchgear, operating temperatures, and continuous output ratings. Utility interconnection issues are viewed as safety issues because they affect utility personnel safety and public safety.

Field testing has a different connotation for UL than for other testing facilities. At PVUSA, for example, field testing refers to testing of systems under actual, day-to-day, ambient conditions. For UL, it refers to the process by which a specific piece of equipment can be listed in the field after installation. A UL representative visits the site where the equipment is installed and conducts a series of tests on the equipment. If the equipment passes these tests, that one unit receives a "field listing." For UL, it usually does not include running the unit through every possible field condition. Long-term field tests at laboratories such as NREL's DER Test Facility often do include these more comprehensive tests.

UL testing and evaluation services related to DG are based on several testing documents. UL Standard 1741 is currently titled "Standard for Static Inverters and Charge Controllers for Use in Photovoltaic Power Systems." In November of 2000, this title was changed to "Standard for Inverters, Converters, and Controllers for Use in Independent Power Systems," signifying a broadening of the scope of this test standard. Essentially, all inverters, relays, and controllers used in DG systems, regardless of prime mover size or technology, could be tested under this standard. Many of the tests included in UL 1741 are technologyindependent and simply require observing the equipment's response to a variety of inputs. New requirements will be added as equipment with different operational capabilities is tested using this document.

Another key document is UL Standard 2200, "Stationary Engine Generator Assemblies." This test standard covers the safety aspects of internal combustion and small turbo generators. This document includes tests for the motive force (e.g., Backfire-Deflector Test) and containment of fuels (e.g., LP-Gas Container Load Tests). It also covers the electrical safety and power quality portions of the system. It will likely reference UL 1741 for the utility interconnection portion of the engine generator. In concert with UL 2200, UL has specific tests for equipment addressing hazardous location issues. Those DG that require fuel handling are reviewed to ensure that proper hazardous location procedures and equipment are included in a packaged design.

UL is heavily involved with the regulatory bodies that deal with public safety, including local authorities having jurisdiction. The test results of many of UL's products are of interest to many authorities having jurisdiction, and that information must be provided for the authorities to understand how a piece of equipment is tested. 


\subsubsection{Colorado State University - Fort Collins, Colorado}

Colorado State University has for several years run an engine-testing laboratory that has been supported by the Gas Research Institute at times. The primary mission of the engine test center is to determine the efficiency and emissions of natural gas-fueled reciprocating engines. Dr. Brian Wilson is the research director of the laboratory. The laboratory is big enough to test several large reciprocating engines. According to facility staff, there may be some plans to request funding to expand the laboratory into electrical DG testing.

\subsubsection{DTE Energy Technologies - Novi, Michigan}

DTE Energy Technologies recently opened a new testing and research center in Novi, Michigan, and is moving its scientific and engineering personnel into the new facility. No additional information is available at this time.

\subsubsection{Salt River Project - Phoenix, Arizona}

Salt River Project operates the Foothills Training Facility primarily for the purpose of training maintenance personnel. It has a "mock" (i.e., de-energized) 12-kV overhead distribution loop; a 69/12-kV energized distribution substation comprising a 20-MVA transformer, switchgear, and circuit breakers; and a de-energized underground distribution system with a variety of pad-mounted switches and transformers. Adjoining buildings house classroom and office space and the Protective Relay Laboratory. There are no facilities or support for generation and storage equipment at the present time.

\subsection{Analysis}

The criteria used to evaluate the potential test sites included existing space, equipment, fuel supply, and access to utility grid; number and expertise of in-house staff available for testing; involvement, cooperation, and support of a host utility; and potential and costs of upgrades needed for the DUIT.

\subsubsection{Existing Space}

The analysis of space attributes of sites considered both gross real estate and effective space for installing and testing distributed generation and storage devices. Some sites have test bays already built, which are of a certain size; enlarging them or building additional ones will entail costs. Indoor sites require ventilation for the emissions produced, and outdoor sites may require air permits from local authorities.

\subsubsection{Existing Equipment}

Equipment relevant to the DUIT includes distributed generation and storage devices, fuel storage and supply, DASs, distribution feeder circuits or simulators, load banks (resistive, inductive, and capacitive), switches, and relays and breakers. Any DG technology that is permanently installed and available for testing is of prime importance because of its obvious potential for avoiding purchase or rental costs.

\subsubsection{Electrical and Interconnection Capabilities}

Electricity supply by means of a connection to the local utility grid allows the site to simulate a feeder connected to a stiff utility T\&D network. The strength of this connection dictates the ultimate number and size of DG that can be installed and simultaneously operated at the site. 
The ability to backfeed excess power generation to the grid will mean cost savings from generation sold to the utility (if allowed) and avoidance of the cost of load banks. In addition, it is desirable to test DG in grid-connected mode (both radial and network configurations) as well as in islanded mode

\subsubsection{On-Site Staff and Host Utility Collaboration}

Ideally, the on-site personnel are knowledgeable about utility engineering and practices and have experience testing distributed technologies. They should also have access to additional technical personnel should the testing requirements dictate it. A key factor is the host or local utility. Ideally, DUIT testing would require interest and involvement on the part of the utility, especially those T\&D personnel most knowledgeable about the local distribution system and potential DG effects. Those sites where this is not the case are at a disadvantage, albeit one that may not be difficult to overcome.

\subsubsection{Costs of Facility Upgrades}

Arguably the biggest consideration for hosting a DUIT regime will be the anticipated cost. The best sites are those that require the fewest modifications, upgrades, or additions and the least capital outlay (and probably time) to prepare.

In the preliminary stage, a heuristic approach was used to make an assessment of the sites. This entailed a thorough review of the parameters for each candidate site and a comparison with the full range of potential test requirements as outlined in the draft Test Plan to arrive at a subjective evaluation of the sites.

No single site is likely to meet all testing requirements for DUIT. Depending on the final requirements developed by the Test Plan, it may be desirable to use a combination of test sites to cover all the testing possibilities and simultaneously minimize the testing budget.

\subsection{Conclusions and Recommendations}

At the present time, the PG\&E Modular Generation Test Facility appears to be a leading candidate as a DUIT site. This facility was expressly designed for DR testing, the array of equipment and expertise of personnel on site are extensive and of high caliber, and the host utility/owner, PG\&E, is very supportive of the DUIT project. Upgrades to accommodate the

DUIT appear straightforward, and the costs appear reasonable. The MGTF can accommodate radial, network, and island test configurations. MGTF personnel have considerable experience testing and researching distribution systems and equipment.

The Dolan Test Center is also a superior facility and has an extensive array of test equipment and an expert staff schooled in testing of DR. AEP would be an excellent host utility if it were persuaded to support the project efforts at DTC. Upgrade costs should also be reasonable to accommodate the DUIT.

The University of California at Irvine has very strong expertise in fossil fuel technology testing and would be an excellent facility for performing type testing of DG technologies. UCI has impressive strengths in other technology areas (notably fuel cells), the capability of 
modeling both radial and network configurations, and a strong support staff. Host utility sponsorship is an unknown at present and would need to be developed.

It is probable that no single facility can accommodate all of the tests envisioned in the DUIT plan — at least not without major upgrades — and some sites may be more suited to certain tests than others. Having multiple sites available increases the range and scope of testing that can be done and will help minimize total project costs while maximizing results. 


\section{Technology Report}

\subsection{Introduction: Selection and Evaluation of Technologies for the DUIT}

The DUIT project calls for the methodical testing of technologies and their interface with the electric grid. The purchase of DR hardware is beyond the budget and scope of the project; rather, commercial or near-commercial DR and related equipment will be rented, leased, or borrowed. This approach is taken to:

- Minimize system engineering and procurement costs

- Minimize lead times

- Provide results consistent with commercially available DR technologies.

In addition, ownership of equipment is not necessary to meet DUIT goals and objectives.

The project is meant to measure and analyze the interactions among DR technologies rather than to prove the operation of any single DR technology by itself. Thus, rental, lease, or loan of off-the-shelf DR is preferable from both test design and budgetary standpoints.

The DUIT will include DR based on inverters, induction machines, and synchronous machines. The team will make the final selection of which DR technologies to include based on the rank-ordered criteria below. Note that while most DR packages include both the prime mover (internal combustion engine, microturbine, etc.) and the generator (inverter, synchronous, or induction machine), inverters are often sold as a separate component that can be used with a variety of storage devices and prime movers, such as wind turbines, PV, and fuel cells. Some of the criteria below relate to inverter-based systems, and some do not. Those that do will be factored into the selection of the inverters.

Rank-ordered selection criteria include:

- Diversity of prime mover technologies (at least two, preferably more)

- Diversity of electrical generation technologies (examples of inverter, induction, and synchronous generators required, with various designs and controls desired)

- Pre-existing distributed generation and storage technologies on site

- Clean technologies with minimal emissions, permitting problems

- Unit electrical rating size (10 $\mathrm{kW}$ to $2 \mathrm{MW}$ would be ideal)

- Total electrical rating size (1 MW to $3 \mathrm{MW}$ would be ideal)

- Host utility objectives such as compatibility with site physical limitations

- Budgetary considerations such as lease costs, installation costs, and fuel supply hardware 
- Use of proven, off-the-shelf (i.e., reliable, tested, trouble-free) distributed generation and storage technologies to separate integration factors from new technology issues during operation and testing

- Technologies whose development was supported by one of the project participants

- Relocatable devices (e.g., batteries, small gensets, flywheels) to allow some units to be in place for relatively short tests of perhaps a month or more.

Some of these criteria may conflict with one another, making the technology and site selection efforts critically important to the success of the project.

When evaluating technologies for use in DUIT, the following factors may be considered. These are discussed more specifically in later sections.

\subsubsection{Physical Characteristics}

- Size (dimensions)

- Weight

- Ventilation requirements for cooling

- Fuel requirements

- Type: natural gas, propane, liquid fuel

- Flow rate, pressure, supply/availability

- Enclosure

○ Indoor

- Outdoor: NEMA 3R or equivalent

\subsubsection{Mechanical Characteristics}

- Mounting/foundation requirements

○ Skid, legs, mobile

- Foundation strength, dimensions

- Water requirements: coolant make-up water

- Access space requirements

- For servicing

- To meet codes

- Exhaust requirements: stack length, diameter, location, etc.

\subsubsection{Electrical Characteristics}

- Equipment ratings: kilovolt-amperes/kilowatts, voltage, amperage, phases, power factor, three- or four-wire, etc.

- Included interconnection equipment and schemes

- Protection, control and communication functions

- Integrated, separate, or combination

○ Per type of use: load penetration, power export, etc. 
- Meets existing electrical industry standards (NEMA, IEEE, ANSI, UL, etc.): components, subsystem specifications: design, ratings

- Requirements for external equipment

- Need for and location of transformers, additional breakers, disconnects, metering, etc.

○ Need for and location of additional relays, sensors, etc.

\subsubsection{Environmental and Permitting}

- Operating temperature rating

- Exhaust emissions

- Control of effluents (fluids): coolant drainage, oil leaks

- Waste disposal: used oil, used coolant, filters, disposables, etc.

- Noise

- Visual impact

\subsection{Electric Conversion and Grid Interface}

\subsubsection{Issues}

In the past few years, there has been a revolution in electric power generation. The deregulation of the power industry has created an environment in which traditional generation is being reexamined and new forms of generation are being created.

By tradition, rotating electromechanical equipment is used to generate commercial (utility quality) electric power. Mechanical prime movers range from CTs and steam turbines in large power plants to smaller CTs and internal combustion engines in industrial settings. The conversion from mechanical power to electrical power is performed primarily with synchronous generators, with some use of induction generators in smaller units.

Being added to this generation base are new technologies: fuel cells, microturbines, redesigned internal combustion engines, and renewables. Many of these technologies do not use the traditional form of energy conversion. Many rely on power electronics for energy conversion and microprocessors for control and communication. Some do not even have moving parts (fuel cells and PV, for example).

What follows is a brief discourse on electrical energy conversion and grid interconnection. Descriptions of the various forms of electrical energy conversion are provided with a corresponding explanation of how grid interconnection is performed.

\subsubsection{Rotating Equipment}

Historically, most electrical power has been generated with rotating machines. That is, a source of rotating mechanical power (the "prime mover"), such as an engine or a turbine, drives an electrical generator. The generator is normally either synchronous or induction (asynchronous). The generator will have a stator that consists of a set of stationary AC windings and a rotor with windings, either AC or DC. The stator is stationary (i.e., it does not 
rotate). The rotor is rotated by the prime mover. The physical means of power conversion is through the interaction of the magnetic fields of the stator and rotor circuits.

\subsubsection{Synchronous Generators}

Synchronous generators for grid interconnection have three AC windings (three phases) on the stator physically laid out to produce a nearly pure sine wave voltage waveform with $120^{\circ}$ (electrical) shift between phases. Each of these windings is connected to a corresponding grid phase (through protection equipment) to supply power to the power system. To produce the necessary magnetic field on the rotor, a DC current (excitation) is passed through the rotor winding. Power is transmitted from rotor to stator across the magnetic field and is proportional to the phase angle difference in the two fields: the larger the angle (up to a maximum of $90^{\circ}$ ), the greater the power. The throttle of the prime mover is adjusted to produce the desired power output by varying the shaft torque angle. Adjusting the excitation of the machine controls the reactive power output of the generator.

Synchronous generators may be single-phase or three-phase machines, but most utility applications call for three-phase designs. The simplest three-phase generator has two magnetic poles per phase (north and south) and must rotate at exactly 3,600 rpm to produce $60-\mathrm{Hz}$ electrical output. Single-cycle gas turbines, such as aeroderivative types, will typically run at 3,600 rpm. A "four pole" generator will have two sets of three-phase poles and will rotate at $1,800 \mathrm{rpm}$ to produce $60-\mathrm{Hz}$ output when mated to slower prime movers such as steam turbines. Adding more poles to a generator allows even slower machines, such as diesel engines and hydro turbines, to supply $60-\mathrm{Hz}$ power to the grid. Alternatively, gear drives can match prime mover speed to generator configuration to achieve $60-\mathrm{Hz}$ output.

Synchronous generators are used in situations in which power production from the prime mover is relatively constant because of the need to maintain the phase angle difference between the rotor and stator electrical windings. Most utility generators in the larger sizes are synchronous machines. A primary consideration is stability: the ability of the machine to tolerate electromechanical disturbances that occur when changes to the electric system (because of faults, load changes, etc.) cause the machine's equilibrium to be upset. If the machine cannot settle into a new equilibrium state, it will go out of synchronism with the grid and will be tripped off line by the protection equipment.

\subsubsection{Induction Generators}

Induction generators also have a stator and rotor. The stator is similar, if not identical, to that of a synchronous generator. The key difference is the rotor. Typically, the rotor is made of a cast cage without any real windings, though the rotor can have wound windings. A cast rotor results in a short circuit on the rotor, with no electrical connection to the stator. The induction machine (motor or generator) operates through the principle of induction. When voltage is applied to the stator windings, currents are induced in the rotor "windings." With no mechanical input on the rotor shaft, the induction machine will operate as a motor. By turning the shaft faster than synchronous speed, the induction machine will generate power. As the difference in speed (slip) increases (between the grid synchronous speed and the rotor's speed), more power is produced, up to the machine's rated power and slip (which is typically $5 \%$ to $7 \%$ ). Induction generators are ideal for applications in which the input power 
is non-constant, such as when mated to wind turbines and small hydro turbines, but they can also be used with engines and CTs.

Excitation must be supplied from an external source such as the utility or a power supply; this is economical but also means the machine cannot operate on its own. The machine voltage is set by the utility supply; therefore, the induction generator cannot generate reactive power and supplies only real power to the grid proportional to its slip. Capacitors are used to provide excitation in standalone systems, but the voltage is inherently unstable and must be controlled by varying the capacitance according to demands on the generator.

Induction generators may be single-phase as well as three-phase machines; their simplicity of construction and generally lower cost make induction machines the obvious choice for lowerpower and single-phase applications. Induction generators generally have slightly lower efficiency than synchronous generators. When induction generators overspeed because of system faults, they will draw reactive power from the system, depressing voltages and contributing to voltage instability. Induction machines are not capable of supplying sustained fault current to a short circuit.

\subsubsection{Three-Phase Versus Single-Phase}

Three-phase generators put out balanced three-phase power by design. By definition, singlephase generators will cause an imbalance in power among the three phases of an electrical system (unless identical units are installed across all phases). In this way, the implications of single-phase generators on a utility distribution system are identical to single-phase loads. The system will no longer be balanced, and the $120^{\circ}$ phase spacing, equal voltages, and currents will no longer necessarily apply. The system may be able to tolerate small amounts of phase imbalance but not large amounts. Thus, like loads, single-phase generation must be balanced on the feeder. In extreme cases, phase imbalances can cause three-phase generators (and rotating loads) to heat up and operate at lower efficiencies. Other single-phase devices are not likely to be affected. The harmonics and ground currents that may be generated may confound protective devices and negatively affect sensitive loads. Conversely, nonlinear single-phase loads may cause deleterious effects on three-phase generators. Also, fault currents will be less predictable. A fault on a phase with a single-phase generator will have higher fault current than one without a generator, but it may be difficult to calculate how much higher.

\subsubsection{New Prime Mover Technologies}

A microturbine is a small CT coupled to a rotating synchronous-type electric generator. (For classification purposes, the generator is of the synchronous type because the rotor has a constant magnetic field provided by permanent magnets.) Because the rotor is usually mounted on the same high-speed shaft, the output voltage waveform has a very high frequency and cannot be connected directly to the grid. The output has to be fed through a rectifier/inverter to synthesize a sinusoidal voltage waveform suitable for connection to the grid and matching the grid frequency and voltage. The actual electrical output circuit (usually 208 or 480 VAC, three-phase) is configured to whatever is needed to match the local electrical circuit. (The output voltage waveform of a rotating machine is generated as a sinusoidal waveform and, except with the high-frequency case noted above, needs no electronic conditioning.) 
Other new generation technologies, specifically fuel cells and PV, produce DC power. Obviously, DC circuits cannot be connected directly to AC circuits. Inverters are used to convert the DC power to AC for grid interconnection.

Inverters are a key component of many new energy conversion technologies. Inverters are made up of hardware (power electronic switches, circuit boards, wiring, etc.) and software. Software is used to control the operation of the switching, calculate and display electrical quantities (voltage, current, frequency, phase angles, etc.), communicate with external devices (either dial-up or Internet-based), and provide protective and operational functions. Inverter technology is discussed in detail in Section 3.3.

\subsubsection{Grid Interconnection}

Grid interconnection is the act of physically connecting an electrical generator to and operating it in parallel with the utility grid. Grid interconnection can be physically performed at many locations: in an industrial or commercial facility at an existing switchboard, in a residence at the service panel, or directly to the distribution system at a substation. When a generator is interconnected with the grid, interconnection equipment is needed to ensure safe, reliable operation of both the generator and the grid. In this manner, interconnection equipment serves multiple functions, including protection of the grid from a malfunctioning DR, protection of the DR from grid disturbances, the monitoring and metering of energy and power, control of power flows (both real and reactive), and communications.

Interconnection requirements are prescribed by local authorities, which may include a local utility, a public utility commission, or a municipal board of directors. These authorities may develop their own requirements, or, preferably, adopt an existing standard. IEEE has completed a recommended practice for the interconnection of PV systems ${ }^{1}$ and is working on a standard for all DR technologies. ${ }^{2}$

For rotating equipment, protective and control functions traditionally have been performed by separate, multiple, discrete devices hardwired into switchgear. Usually, separate devices perform a specific function such as over/undervoltage protection, synchronizing, and breaker trip/closing control. In the past few years, many of these functions have been combined into multifunction microprocessor packages, reducing the overall cost of providing these functions and making protection design easier. An example of what is available on the market is the Encorp line of equipment (Generator Power Control, Utility Power Control, and Automatic Paralleling Switch), which incorporates protection, control, and communications into one box, and the multifunction protection relays from Beckwith, SEL, and Basler.

Electronic energy conversion has taken advantage of microprocessor-based design to incorporate not only control of the energy conversion process but also the control, protection, and communication for utility interconnection. Not only does the microprocessor control the timing, gating, etc., of the power electronic devices, but it also will adjust power factor; synchronize; sense, monitor, and display voltages, current, and power; react to fault conditions; and more. Now, instead of a discrete relay for over/underfrequency protection,

\footnotetext{
${ }^{1}$ IEEE 929-2000 Recommended Practice for Utility Interface of Photovoltaic Systems.

${ }^{2}$ IEEE P1547 Draft Standard for Interconnecting Distributed Resources With Electric Power Systems.
} 
there is a software routine to perform the same function. Manufacturers have taken this route to reduce costs and to attempt "plug and play" capability for their equipment.

\section{A Basic Interconnection Scheme}

A basic DR interconnection scheme is shown in Figure 9.

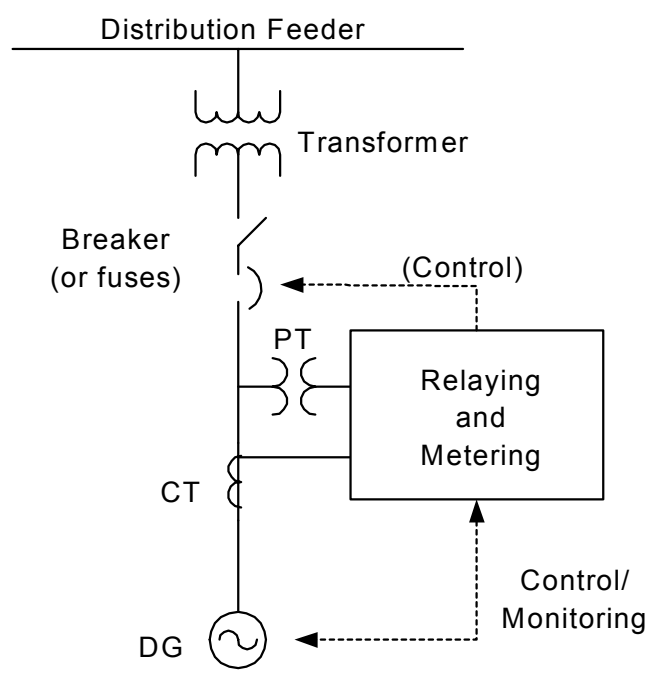

Figure 9. Basic DR interconnection with grid

Starting at the utility distribution feeder, the first component is the transformer. This transformer can be an existing customer transformer (shared or dedicated) or a new transformer dedicated to the DG. The transformer is primarily needed to provide the appropriate voltage level for the customer, generally three-phase $480 \mathrm{VAC}$ or less for commercial and industrial customers and single-phase $240 \mathrm{VAC}$ for residential customers. Distribution line voltages are too high (many thousands of volts) for direct use by most customers, though some industrial customers do connect at multi-kilovolt levels. The transformer also adds isolation of grounds and adds impedance against fault and harmonic currents.

The next component is the disconnect switch. This switch is a lockable, visible-open switch that is normally operated manually. "Visible open" means that when the switch is opened, the switch's blades physically separate with a visible air gap. This disconnect allows utility linemen to verify that the DR customer is isolated from the grid when line work must be performed. Because the utility may have to work on a downed line at any time, day or night, it must have access to this switch at all times.

The next device is the main interrupting device. This device can take the form of a circuit breaker ("breaker"), a set of fuses, a fused disconnect switch, or even a contactor. Regardless of which is used, the purpose is to interrupt the flow of current, from either direction, during fault conditions. Breakers are preferred because they can be reset, "tripped," or used for synchronizing if properly configured. Fuses are one-time devices; once blown, they must be replaced. Contactors are sometimes used in conjunction with protection relaying. 
Last are the sensing devices, potential transformers (PTs) and current transformers (CTs), and their associated relays and meters. Instrument transformers, CTs and PTs, are used to reduce the high line voltages and currents down to a level usable by relays and meters. (Relays and meters normally use voltages at the 120-VAC level and currents at $5 \mathrm{~A}$ and less.) It is standard utility practice to use a separate set of CTs/PTs for relaying and for metering, especially for revenue metering. (Utilities will not allow a DR customer to tap into utility revenue-metering circuits.)

\subsection{Inverters and Inverter-Based Technologies}

\subsubsection{Overview}

This section covers the selection and evaluation of inverters and inverter-based generation systems for DUIT. Two classes of inverter products are considered. The first is the simple inverter, an electronic self-standing piece of equipment capable of converting DC power into grid-compatible AC power and of working with a range of DC input sources such as batteries, PV, and fuel cells. Some inverters, while capable of working with a variety of input sources, are really optimized for a particular generation source. PV inverters, for example, dynamically optimize the operating point of the PV array, a feature that would be incompatible with batteries or fuel cells. These inverters, however, can often be modified in such a way that they can be used with other sources.

The second class of inverter is integrated into generation technology. An example is inverterbased microturbines. Inverters are built into these generation technologies for a variety of reasons, ranging from a unique set of technical requirements on the part of the generation source to the protection of intellectual property and proprietary information.

In both of these cases, the inverter is the electrical interface to the utility and determines the electrical performance and compliance of the generation source to interconnection standards. However, it also determines the performance, ancillary benefits, and economics of the DR. Many of the new DR technologies being brought on line require an inverter for appropriate operation, and it is expected that the use of these devices will grow substantially as DR penetrate the grid.

\subsubsection{Inverter Technology}

The state of the art in inverter design has come a long way over the past 10 years, principally because of the evolution of three fundamental technology areas:

- Microprocessors/digital signal processors

- Control and communications algorithms

- Power semiconductor devices.

The proliferation of microprocessor and digital signal processor devices in the 1990s because of personal computers, the Internet, and a range of "smart" electronic devices has made them ubiquitous in electronic products. In power electronic inverters, these devices have gained wide acceptance and now populate most of the inverter designs discussed in this report. These devices allow for substantially more sophisticated algorithms for power flow and control. 
In the 1990s, a substantial investment in the development of sophisticated power flow and control and communication algorithms not only improved the performance of inverters but also made possible ancillary benefits such as power factor control and voltage regulation. These algorithms, together with the microprocessors that implement them, have led to inverter systems that add substantial economic benefit to the end-user.

Finally, a continual evolution in the area of power semiconductor devices has permitted higher switching frequencies, lower losses, and higher power levels than were possible 10 years ago. Power semiconductor evolution has gone from the silicon-controlled rectifier to the gate turn-off thyristor to the bipolar transistor to the present "device of choice" for DR: the insulated gate bipolar transistor. These devices have not only allowed for higher switching frequencies - and therefore cleaner waveforms at lower prices - but they also have been extended to substantially higher power levels. The first commercial insulated gate bipolar transistors in the early 1990 s were limited to $1,000-\mathrm{V}$ and $50-$ or $100-\mathrm{A}$ ratings. Today, they are available with voltage ratings of $4.5 \mathrm{kV}$ and current ratings up to $2,400 \mathrm{~A}$. This all comes with a fundamental reduction of losses in the devices.

Over the years, inverter manufacturers have incorporated typical protective relaying functions. These features - such as over/underfrequency, over/undervoltage, and antiislanding — can be implemented in a very economical way using the on-board microprocessor. The inverters in this report have some or all of these capabilities, and most are designed to the current applicable standards for protective relaying. Because most manufacturers are following the same type and interconnect standards, the inverters are quite similar. However, there remain unique features, performance characteristics, and selfimposed or commercial requirements and packaging designs that distinguish models.

\subsubsection{Inverter and Inverter-Based DR Evaluation}

When evaluating inverters and inverter-based DR for use in the DUIT, the following criteria will be used.

\subsubsection{Physical Characteristics}

\subsection{Size}

The physical size of inverters and inverter-based systems will be compared to make sure all prospective equipment will fit in the allowed test area. These dimensions will drive the physical design and layout of the DUIT facility.

\subsection{Weight}

Inverters often include large inductors and magnetics that need to be structurally supported. In smaller kilovolt-ampere ratings (below $20 \mathrm{kVA}$ ), the inverters are expected to be wallmount units; in larger kilovolt-ampere ratings, the inverters will be floor-mount units. The test facility must be capable of supporting both types of inverter enclosure. 


\subsection{Venting}

A number of inverter manufacturers have specific requirements for venting and air flow over their electronic systems. Should an inverter with such requirements be selected, this will be provided for during the installation of equipment.

\subsection{Fuel Requirements}

Although inverters themselves do not require fuel, inverter-based systems such as microturbines do. Where fuel is required, it will be so noted. Also noted will be whether a unit's specification is within the fuel delivery capabilities of the DUIT site.

\subsection{Indoor/Outdoor Ratings}

Inverter enclosures are rated based on a US standard known as the National Electrical Manufacturers Association (NEMA) enclosure standard and on an international set of standards by the International Electrotechnical Commission (IEC). Both of these standards have ratings that cover indoor and outdoor applications. Care will be taken in the selection of inverters to make sure that the proper rating is followed in siting the equipment.

\subsection{Enclosure Temperature and Control}

Any special environmental requirements beyond those presented above will be singled out to make sure the requirement can be met by the DUIT facility. The ambient temperature ratings of the inverter equipment will be identified and followed at the facility.

\subsubsection{Mechanical Characteristics}

\subsection{Mounting}

Inverters will be either wall-mounted or floor-mounted depending on their kilovolt-ampere rating. Any special mounting requirements will be identified and followed. Inverter-based systems such as microturbines are likely to have more stringent mounting requirements, and these will be identified and followed if the respective DR technology is selected.

\subsection{Manual Shut-Off}

For safety purposes, many inverters have a collocated local emergency stop or disconnect switch. The existence and suitability of this device will be evaluated in the selection criteria.

\subsubsection{Environmental and Permitting}

\subsection{Emissions}

Inverters by themselves have no associated emissions; however, some of the inverter-based DR systems do. Where this evaluation criteria is appropriate, it will be so noted and reviewed relative to local permitting requirements and standards compliance.

\subsection{Water}

Large inverter systems may require water cooling to manage the temperature of electronic components. These tend to be large systems in the range of hundreds to thousands of kilovolt-amperes. Water flow rate and volume are requirements for these systems, and the 
outflow temperature can be raised to levels $30-40^{\circ}$ above inlet temperature. The types of cooling systems and their requirements will be identified.

\subsection{Special Permitting}

Where special permitting needs arise with the installation or operation of the inverter-based DR systems, it will be highlighted, and the effect of the permitting requirement on the DUIT project will be evaluated.

\subsubsection{Other Considerations}

\subsection{Cost, Rent, Lease, or Buy}

It is the intention to rent or lease as much of the DR and inverter equipment as possible to minimize capital expenditures. This approach can be taken without sacrificing any goals or objectives of the project. Many inverter manufacturers have already been contacted about their willingness to supply equipment. Rent, lease, or buy will be identified for each of the inverter manufacturers and for each of the models considered. The cost-effectiveness of equipment will factor into the selection process with the criterion that no selection should compromise the goals and objectives of the DUIT.

\subsection{Availability}

Because the DUIT will use mature, commercially available technologies, the equipment should be available with a relatively short lead time. There may be some exceptions to this, and these will be closely watched. However, the majority of the desired inverters should be available with lead times of 8 or fewer weeks.

\subsection{Operation and Maintenance Requirements}

The DUIT will run for 18 months. This duration of test will require multiple scheduled maintenance cycles on some of the proposed DR technologies. The inverters, as solid-state devices, typically do not have a significant maintenance requirement for this duration. However, some of the inverter-based DR technologies do. The need for scheduled and preventative maintenance will be identified and used in the selection process of the technologies as well as in the design of operation and maintenance personnel and procedures.

\subsection{Standards Certification}

The DUIT is to use mature, commercial products. It is expected that most of the inverters and inverter-based systems will be type-certified to the appropriate standards. For inverters, this amounts to UL 1741 type certification and compliance with IEEE 929, IEEE 519, and IEEE 1547. IEEE 929 and 519 are existing recommended practices, and IEEE 1547 is under development. European equipment used in the test must conform to these same standards.

\subsection{Market Acceptance}

The intention is to select inverters and DR equipment that will have the largest possible extension of results beyond the test. This amounts to selecting equipment with historically large market acceptance. Because many of the technologies do not have a long track record, consideration will also be given to potential market acceptance and share in a future distributed utility market. 


\subsubsection{Data on Available Inverters and Inverter-Based DR}

Table 14 provides a comparison of the above considerations for potential inverter and inverter-based DR products. Note that the products listed are manufacturers' standard products. It is likely that rented, leased, or donated equipment will be standard product. Many of these companies have the capability to build engineered equipment in low volumes for the DUIT; however, this equipment will likely have to be purchased and will add considerably to the test's capital equipment costs.

Many of the inverters shown in Table 14 are "general purpose" and designed to function with a number of DR technologies. In some cases, the inverter is designed principally for one type of technology but is applicable to other technologies with minor modification. PV is the most obvious example of this. Many of the inverters include a peak power tracking function intended to optimize the operating point of the PV array.

Inverter-based DR systems are technologies in which the inverter is integrated into the generation equipment. Here, the examples are microturbines, fuel cells, and some of the large-scale battery technologies. In these cases, the inverter is either supplied by one of the listed inverter suppliers or built by the generation equipment manufacturer. Whether an inverter or a generation equipment supplier provides the inverter, the same type and interconnect standards are followed. 
Table 14. Inverter Technology

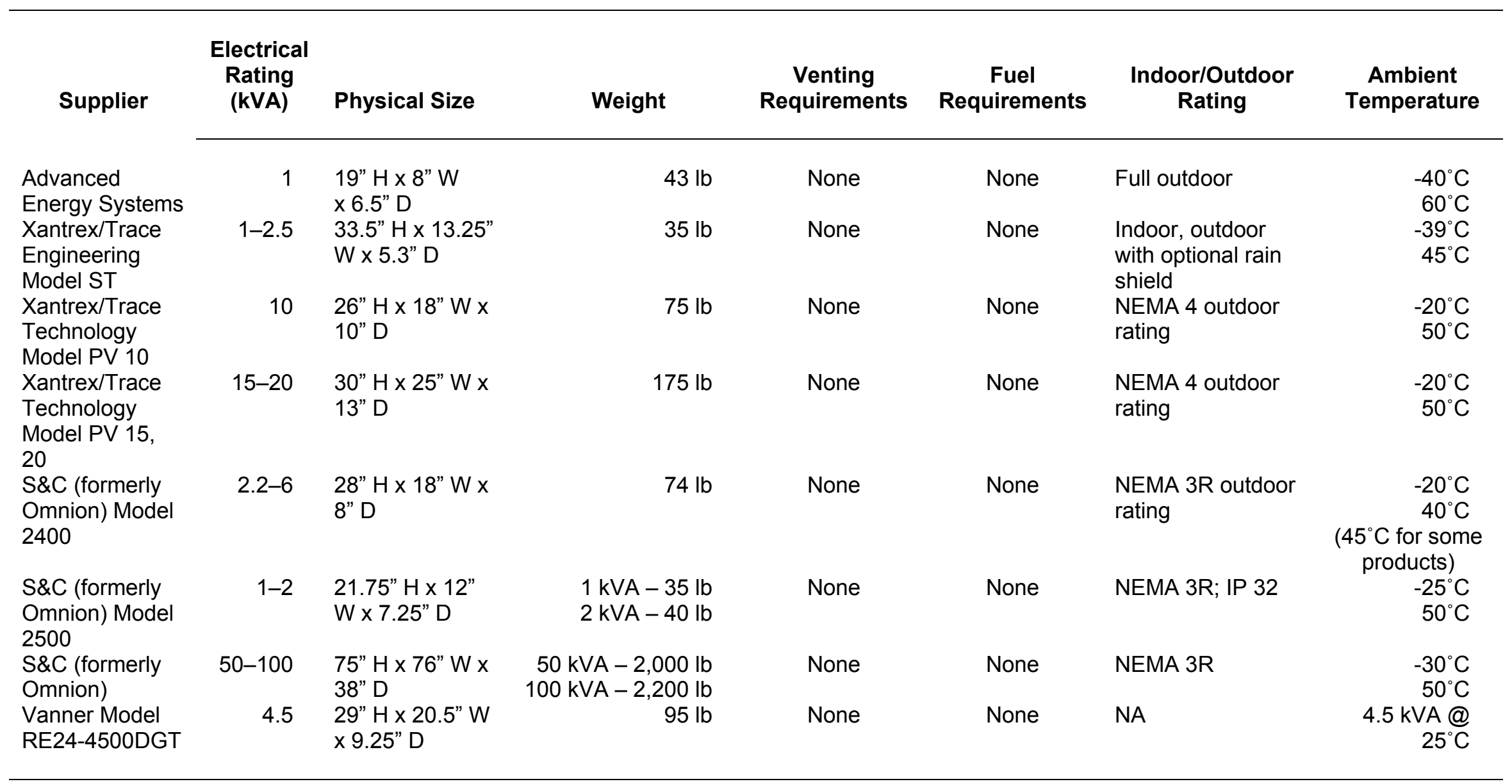




\subsubsection{Photovoltaics}

A PV cell is a semiconductor device that converts light—typically sunlight—striking the cell's surface into DC electricity at the cell's output conductors. Most semiconductor materials are photosensitive and thus can be used for PV. However, each material responds differently to different wavelengths of light, so some materials are more suitable than others. Fortunately, silicon, which is the best-understood semiconductor material — as well as the most abundantresponds well to the visible light spectrum, where most of the energy from sunlight exists. Thus, the same technologies used to make computer chips can be used to make PV cells. There are also commercial products available based on cadmium telluride and copper indium diselenide, and other materials are being developed.

Wafer fabrication techniques, such as those used to make computer integrated circuits, are the most common, and thin-film deposition processes are becoming more widespread. Wafer-based solar cells are single- or poly-crystalline and more efficient but more expensive to manufacture than thin-film cells. PV modules are made by soldering conductors between a number of waferbased cells (connected in series to generate the desired voltage and in parallel to generate the desired current) and laminating them between a transparent cover sheet (usually glass) and a weather-resistant back sheet (usually a polymer). Commercial crystalline modules have efficiencies (sunlight to DC electricity) in the range of $8 \%-14 \%$ percent or so.

Thin-film deposition-based products are poly- or non-crystalline and thus less efficient but less expensive to manufacture. The term thin-film is used generically to describe cells built up of multiple thin layers deposited one on top of another. The deposition is usually done directly on the cover sheet or back sheet with laser or mechanical etching used to delineate the cells (the number of cells determines voltage; the size of cell determines current). Again, a weatherresistant back sheet protects the cells from the elements. Commercial thin-film modules have efficiencies ranging $4 \%-8 \%$.

A different approach to reducing system costs is to use inexpensive plastic Fresnel lenses to concentrate sunlight onto small, high-efficiency PV cells. Concentration ratios of commercially available products range from about 20:1 to 250:1, with research systems reaching ratios of thousands to one. Most PV devices increase in efficiency with increasing sun intensity (irradiance) to a point. Special cells must be used for these concentration ratios, but because a smaller portion of the module cost is in the cell, more expensive - and more efficient — cell technologies can be tolerated. Concentrator modules must track the path of the sun; higher concentration devices must track more accurately. And, it turns out, tracking the sun is beneficial to non-concentrating, or flat-plate, PV modules as well, and there are several options for tracking flat-plate systems.

More detailed explanations of cell physics, fabrication techniques, technologies, and systems issues can be found on the following Web sites:

- http://www.nrel.gov/ncpv/

- http://www.sandia.gov/pv/main2.html

- http://www.eren.doe.gov/RE/solar_photovoltaics.html

- http://www.acre.murdoch.edu.au/ago/pv/pv.html. 
A PV array is a collection of PV modules electrically connected to provide the desired current and voltage. The output of a PV array depends on the level of sunlight striking the array, its operating temperature - which, together with cell chemistry, defines the current-voltage characteristic curve (IV curve) of the cells - and where on that IV curve the cells are operating. An inverter is used to convert the array's DC output into utility-compatible AC and, often, to control the operating point of the array. Maximum array output is achieved by operating the array at the knee of its IV curve, also known as the maximum power point. An inverter with a maximum power point tracker attempts to maintain the array at its peak output. Some systems incorporate battery storage to address the difference between the energy available from the PV array and the needs of customer loads. In those cases, the array is tied to the batteries through a charge controller that determines the array operating point based on the battery state of charge.

Unlike rotating machines, batteries, and some other devices, a PV array's output current is limited by the IV characteristic. Even when shorted, the output current of a PV cell is at most $30 \%$ or $40 \%$ higher than when at its optimal or peak power operating point.

The inverter in a PV system provides all of the utility interconnection functions and features. Unlike other prime movers, PV modules are not designed around a specific inverter. Similarly, inverters are not designed to work with only one module. Thus, many combinations of modules (see Table 15) and inverters (Table 14) can be used. Fortunately, operational results of an inverter coupled to an array should be the same when that inverter is used with a different array. 
Table 15. Photovoltaic Module Data

\begin{tabular}{|c|c|c|c|}
\hline Supplier & Technology & $\begin{array}{c}\text { Module } \\
\text { Rating (W) }\end{array}$ & Dimensions \\
\hline Amonix & $\begin{array}{l}\text { Back contact, single-crystal silicon }(\mathrm{Cz}) \text {, } \\
\text { concentrator }\end{array}$ & 5,000 & $\begin{array}{l}45^{\prime \prime} \times 11^{\prime \prime} \times \\
2.5 "\end{array}$ \\
\hline ASE Americas & Poly-crystal ribbon silicon (EFG) & $50-300$ & $\begin{array}{l}17.8^{\prime \prime} \times 38 " \\
50.5^{\prime \prime} \times 74.5^{\prime \prime}\end{array}$ \\
\hline AstroPower & Single-crystal silicon (Cz) & $50-120$ & $\begin{array}{l}26 " \times 33.8^{\prime \prime} \\
26^{\prime \prime} \times 58.1^{\prime \prime}\end{array}$ \\
\hline AstroPower & Poly-crystal silicon film & & \\
\hline BP Solar & Single-crystal silicon (Cz) & $50-75$ & $\begin{array}{l}20.9^{\prime \prime} \times 32.5^{\prime \prime} \\
20.7^{\prime \prime} \times 46.8^{\prime \prime}\end{array}$ \\
\hline BP Solar & Buried-contact single-crystal silicon $(\mathrm{Cz})$ & 80-133 & $\begin{array}{l}21.2 " \times 54 " \\
31.7^{\prime \prime} \times 53.1 "\end{array}$ \\
\hline BP Solar & Poly-crystal silicon (cast) & $4.5-120$ & $\begin{array}{l}19.8 " \times 19.8 " \\
39 " \times 43.6 "\end{array}$ \\
\hline BP Solar & Amorphous silicon thin-film & $10-56$ & $\begin{array}{l}15^{\prime \prime} \times 24.3^{\prime \prime} \\
26.3^{\prime \prime} \times 48.4 "\end{array}$ \\
\hline BP Solar & Cadmium Telluride thin-film & & \\
\hline Ebara Solar & Single-crystal ribbon silicon (dendritic web) & $1-9$ & $\begin{array}{l}2 " \times 6.9^{\prime \prime} \\
6.9^{\prime \prime} \times 15.5^{\prime \prime}\end{array}$ \\
\hline $\begin{array}{l}\text { Energy } \\
\text { Photovoltaics Inc. }\end{array}$ & Amorphous silicon & $30-40$ & \\
\hline $\begin{array}{l}\text { Entech Inc. } \\
\text { Evergreen Solar }\end{array}$ & $\begin{array}{l}\text { Single-crystal silicon (Cz), concentrator } \\
\text { Poly-crystal ribbon silicon (string ribbon) }\end{array}$ & $\begin{array}{l}430 \\
47-102\end{array}$ & $\begin{array}{l}144 " \text { x } 33.4 " \\
25.7 " \text { x } 32 " \\
25.7 " \text { x } 62.4 "\end{array}$ \\
\hline $\begin{array}{l}\text { First Solar } \\
\text { Kyocera Solar }\end{array}$ & $\begin{array}{l}\text { Cadmium Telluride thin-film } \\
\text { Poly-crystal silicon (cast) }\end{array}$ & $\begin{array}{l}50 \\
60-120\end{array}$ & $23.6 "$ x 47.3" \\
\hline $\begin{array}{l}\text { Matrix Solar } \\
\text { Technologies }\end{array}$ & Poly-crystal silicon (cast) & $11-105$ & $\begin{array}{l}10.3^{\prime \prime} \times 22.9^{\prime \prime} \\
26.5^{\prime \prime} \times 52.6^{\prime \prime}\end{array}$ \\
\hline PowerLight Corp. & $\begin{array}{l}\text { Various OEM modules on insulated } \\
\text { commercial roofing tile }\end{array}$ & $43-150$ & $\begin{array}{l}28 " \text { x } 50 " \\
43^{\prime \prime} \times 49 "\end{array}$ \\
\hline $\begin{array}{l}\text { Siemens } \\
\text { Solar/Shell }\end{array}$ & Single-crystal silicon & $6-150$ & $\begin{array}{l}6.9 " \times 13^{\prime \prime} \\
32 " \text { x } 63.8 "\end{array}$ \\
\hline $\begin{array}{l}\text { Siemens } \\
\text { Solar/Shell }\end{array}$ & Copper-indium diselenide thin film & $5-40$ & $\begin{array}{l}8.1 " \times 13^{\prime \prime} \\
13^{\prime \prime} \times 50.9^{\prime \prime}\end{array}$ \\
\hline Spire Corp & Single-crystal silicon & & \\
\hline SunPower Corp & $\begin{array}{l}\text { Back contact, single-crystal silicon, } \\
\text { concentrator }\end{array}$ & & \\
\hline $\begin{array}{l}\text { United Solar } \\
\text { Systems Corp. }\end{array}$ & $\begin{array}{l}\text { Amorphous silicon thin film (Shingles, peel- } \\
\text { and-stick) }\end{array}$ & $17-128$ & $\begin{array}{l}12 " \times 86.4 " \\
15.5^{\prime \prime} \times 216 "\end{array}$ \\
\hline
\end{tabular}




\subsubsection{Fuel Cell Technology}

Fuel cells and batteries are sources of electrochemical energy conversion. In a simplistic way, a fuel cell can be thought of as a battery that is continually recharged as it is discharged. The constant recharging is accomplished through the use of hydrogen and oxygen. Fuel cells have been widely discussed as possible substitutes for the internal combustion engine in vehicles and in stationary applications for power generation. Fuel cells provide a DC output power that can be used to power light bulbs, motors, and other traditional electrical loads.

Fuel cells are classified by their electrolyte chemistry. One of the simplest chemistry fuel cells is the proton exchange membrane fuel cell (PEMFC), which will be used to illustrate the operation of a fuel cell.

A fuel cell has an anode (negative) connection that conducts electrons that are freed from pressurized hydrogen molecules. The anode typically has etched channels that uniformly distribute the pressurized hydrogen gas over the surface of a catalyst. The cathode is the positive connection of the fuel cell. It carries electrons back from the external circuit to the catalyst, where it combines with hydrogen ions and oxygen to form water, the byproduct of the fuel cell. The electrolyte is the proton exchange membrane, which is a specially treated material that allows for the conduction of positively charged ions. It does not allow electrons to pass through it. Finally, a catalyst material facilitates the reaction of oxygen and hydrogen. The catalyst is usually made of a platinum powder coated on a carbon paper or cloth. The catalyst is porous to maximize the surface area exposed to the hydrogen and oxygen. The platinum-coated side of the catalyst faces the electrolyte.

Figure 10 shows a simplistic proton exchange membrane fuel cell. The reaction described takes place in one cell and results in approximately $0.7 \mathrm{~V}$ cell potential. To bring the operational voltage up to usable levels, many cells are put into an electrical series configuration.

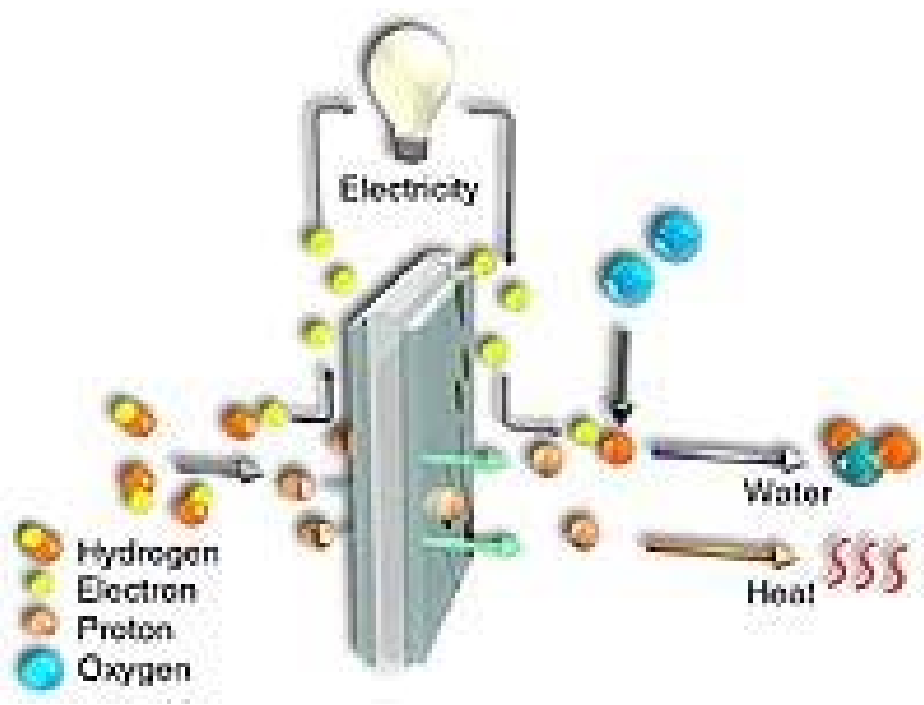

Figure 10. Fuel cell operation 
Other electrolyte materials are shown in Table16.

Table 16. Fuel Cell Characteristics

\begin{tabular}{|c|c|c|c|}
\hline Electrolyte Material & $\begin{array}{l}\text { Operating Temperature } \\
\text { (Warm-Up Time) }\end{array}$ & $\begin{array}{c}\text { Anticipated } \\
\text { Applications }\end{array}$ & Comments \\
\hline $\begin{array}{l}\text { Proton exchange } \\
\text { membrane }\end{array}$ & $80^{\circ} \mathrm{C}$ (relatively short) & $\begin{array}{l}\text { Stationary and } \\
\text { vehicle }\end{array}$ & $\begin{array}{l}\text { Minimum contamination and } \\
\text { material problems }\end{array}$ \\
\hline Alkaline & $\begin{array}{l}\text { Approximately } 100^{\circ} \mathrm{C} \\
\text { (relatively short) }\end{array}$ & $\begin{array}{l}\text { Space } \\
\text { program }\end{array}$ & $\begin{array}{l}\text { Susceptible to contamination, } \\
\text { very expensive }\end{array}$ \\
\hline $\begin{array}{l}\text { Phosphoric Acid } \\
\text { (PAFC) }\end{array}$ & $\begin{array}{l}\text { Approximately } 100^{\circ} \mathrm{C} \\
\text { (longer than PEMFC) }\end{array}$ & Stationary & $\begin{array}{l}\text { Higher temperature and longer } \\
\text { warm-up time make unsuitable } \\
\text { for vehicles }\end{array}$ \\
\hline Solid Oxide & $1,000^{\circ} \mathrm{C}$ (long) & Stationary & $\begin{array}{l}\text { High temperature creates } \\
\text { material problems, steam } \\
\text { generation could increase } \\
\text { efficiency by cogeneration }\end{array}$ \\
\hline $\begin{array}{l}\text { Molten Carbonate } \\
\text { (MCFC) }\end{array}$ & $600^{\circ} \mathrm{C}$ (long) & Stationary & Same as SOFC \\
\hline
\end{tabular}

A number of engineering problems must be overcome before fuel cells can be widely adopted for transportation or stationary power purposes. As shown in the table above, even the lowesttemperature fuel cells operate at $80^{\circ} \mathrm{C}$. This forces the use of expensive materials and can create life-cycle problems because of temperature cycling. This problem is exacerbated by the highertemperature electrolyte designs. Contamination also remains a problem. The use of impure hydrogen causes the deterioration of electrolyte and catalyst materials, which may require the replacement of the entire fuel cell after limited operation. Finally, perhaps the largest problem limiting widespread adoption of fuel cells is the need for safe storage and distribution of hydrogen. This highly volatile element has a relatively low energy-volume ratio. To deal with the hydrogen problem, it is expected that more common fuels (such as natural gas, methanol, and propane) will be stored and distributed, and hydrogen will be reformed from these. This approach has led to a large engineering effort to develop cost-effective, reliable reformer technology. The reformer at present is larger and more expensive than the fuel cell that it drives and therefore is a significant cost addition. Additionally, the reformer has a time response that can affect the response of the fuel cell system.

The role of the inverter in fuel cells is quite obvious because the power generated by the fuel cell is DC. The inverter takes this power and inverts it to grid-compatible $50 / 60-\mathrm{Hz}$ power. In addition to this DC-to-AC function, many of the fuel cell inverters are expected to find the peak power operation point on the fuel cell voltage-current curve. As with other prime movers, the fuel cell inverter provides the utility interconnection capabilities and protective functions as described previously. The DUIT is concerned with the grid-connected aspect of the fuel cells and, thus, the inverter itself. Most fuel cell companies are currently relying on outside suppliers for the inverter section of their systems. In these cases, information about efficiency, protective relaying, and other aspects of utility interconnection falls to the inverter manufacturer. 


\subsubsection{Data on Commercial Fuel Cells}

Table 17 identifies fuel cells that could potentially be used in the DUIT process. Because of the early stage of development of the fuel cell industry, few if any companies currently have "standard" fuel cell offerings. The rate of development of new fuel cell technologies is quite high, and it requires constant attention to keep abreast of the latest offerings.

The DUIT team recognizes the importance of incorporating fuel cell technology into its testing. There have been numerous discussions with fuel cell manufacturers, and it is believed that a fuel cell system will be obtainable for testing purposes. However, the exact configuration is not yet known. In addition to the fuel cell, it may be necessary to obtain a fuel reformer, recommended by the fuel cell company, or to obtain and store hydrogen. In either case, this fuel requirement could have a significant permit requirement associated with it. 
Table 17. Fuel Cell System Data

\begin{tabular}{|c|c|c|c|c|c|}
\hline Supplier & Type & Electrical Rating & Physical Size & Weight & Fuel Requirements \\
\hline Ballard Power Systems & PEM & $250 \mathrm{~kW}$ & $148 \mathrm{ft}^{2}$ & $27,600 \mathrm{lb}$ & Natural gas \\
\hline DCH (Enable Technologies) & PEM & $3 \mathrm{~kW}$ & & & Natural gas, hydrogen \\
\hline DAIS Analytic & PEM & $10 \mathrm{~kW}$ & & & Natural gas \\
\hline H Power Corp. & PEM & $30-1,000 \mathrm{~W}$ & & & Natural gas \\
\hline IdaTech (Northwest Power) & PEM & $5 \mathrm{~kW}$ & $4^{\prime} \times 14^{\prime} \times 4^{\prime}$ & $1,700 \mathrm{lb}$ & Natural gas, propane, diesel fuel, others \\
\hline $\begin{array}{l}\text { IFC/ONSI } \\
\text { (PC25) }\end{array}$ & PAFC & 200 kW & $10^{\prime} \times 10^{\prime}$ x 18' & $40,000 \mathrm{lb}$ & Natural gas, anaerobic digester gas \\
\hline Energy Partners (NuPower) & PEM & 10 kW DC & & & Hydrogen \\
\hline Plug Power & PEM & $5 \mathrm{~kW}$ & & & Gasoline, natural gas \\
\hline Proton Energy Systems & PEM & 100 kW & & $>10,000 \mathrm{lb}$ & Hydrogen \\
\hline FCE (DFC) & & $300 \mathrm{~kW}, 1.5 \mathrm{MW}$, and $3 \mathrm{MW}$ & & & Natural gas \\
\hline M-C Power & MCFC & $250 \mathrm{~kW}$ & & & Natural gas \\
\hline ERC (Santa Clara) & MCFC & $2.5 \mathrm{MW}$ & $3,200 \mathrm{ft}^{2}$ & & Natural gas, methanol, ethanol, biogas \\
\hline ERC (DFC Model 9000) & MCFC & 300 kW & & & Natural gas, methanol, ethanol, biogas \\
\hline GE (Home Gen) & PEM & & & & Natural gas, liquefied petroleum gas \\
\hline
\end{tabular}




\subsubsection{Energy Storage Technologies}

Energy storage technologies are an important component of the DR mix. They can supply power on very short notice - some almost instantaneously. Some can supply power for relatively long periods. They are modular and relatively easy to site. In addition to supplying power, energy storage technologies can draw power from the grid. This feature can be used for various types of power and load control.

The most common type of utility energy storage is battery storage. The charge and discharge characteristics of batteries are well understood in utility practice. Other types of energy storage include flywheels, supercapacitors, and SMES. These are all commercially available, and all have been incorporated into uninterruptible power supply products in sizes ranging from several kilowatts to multiple megawatts.

Energy storage in connection with DR has many of the same issues as other inverter-based technologies. These were discussed in a previous section. Batteries are a DC voltage source. Inverter systems have been designed to connect battery systems directly into the grid. Batteries are typically discharged over a period of hours and are generally recharged at the same rate.

Supercapacitors and ultracapacitors are also DC voltage sources. They are usually designed to be discharged relatively quickly and can be used for power quality functions.

Flywheels come in many varieties. Some products can be discharged quickly; others discharge slowly. Several products include them in traditional uninterruptible power supply systems. Flywheel power systems have been installed for DC telephone system emergency backup of up to 2 hours. Although some flywheels produce variable frequency AC, most modern systems use highly sophisticated inverter configurations to produce either DC power or utility-grade AC.

SMES systems have been designed both for dedicated power quality applications and for gridconnected distribution system support. Discharge and recharge is generally rapid, so SMES can be used for line-stabilization applications.

The evaluation of energy storage technologies for DUIT is similar to that for other DG systems, with the addition of recharging requirements. Table 18 presents characteristics of commercially available energy storage technologies suitable for DR use. 
Table 18. Energy Storage System Data

\begin{tabular}{|c|c|c|c|c|c|c|c|c|c|}
\hline Supplier & Type & $\begin{array}{c}\text { Electrical } \\
\text { Rating }\end{array}$ & $\begin{array}{c}\text { Stored } \\
\text { Energy } \\
(\mathbf{k J})\end{array}$ & $\begin{array}{l}\text { Physical } \\
\text { Sizel } \\
\text { Footprint }\end{array}$ & Weight & $\begin{array}{l}\text { Recharging } \\
\text { Require- } \\
\text { ments }\end{array}$ & $\begin{array}{c}\text { Fuel } \\
\text { Requirements }\end{array}$ & $\begin{array}{l}\text { Indoorl } \\
\text { Outdoor } \\
\text { Rating }\end{array}$ & $\begin{array}{c}\text { Ambient } \\
\text { Temperature }\end{array}$ \\
\hline \multicolumn{10}{|l|}{ Batteries } \\
\hline AC battery & Lead acid & $250 \mathrm{~kW}$ & 2,500 & $56 " \times 39 "$ & $\begin{array}{l}3,600 \\
\mathrm{lb}\end{array}$ & $\begin{array}{l}\text { Slow } \\
\text { recharge }\end{array}$ & None & Full outdoor & \\
\hline Liebert & Lead acid & 1,000 kW & 600,000 & & & & None & Full outdoor & \\
\hline Exide & Lead acid & $1,000 \mathrm{~kW}$ & 600,000 & & & & None & Full outdoor & \\
\hline $\begin{array}{l}\text { Powercell } \\
\text { (PowerBlock) }\end{array}$ & Zinc bromide & 100 kW & 360,000 & $\begin{array}{l}\text { 4.3" Hx } \\
\text { 3.7" W } \mathrm{x} \\
\text { 11.2" D }\end{array}$ & $\begin{array}{l}6,000 \\
\mathrm{lb}\end{array}$ & $4 \mathrm{hrs}$ & None & $\begin{array}{l}\text { NEMA 3/3R } \\
\text { equivalent }\end{array}$ & $0-35^{\circ} \mathrm{C}$ \\
\hline ElectroSource & Lead acid & $4.5 \mathrm{~kW}$ & 135 & $153 \mathrm{in}^{2}$ & $27.5 \mathrm{~kg}$ & & None & & \\
\hline \multicolumn{10}{|l|}{ SMES } \\
\hline $\begin{array}{l}\text { American } \\
\text { Superconductor } \\
\text { (D-SMES) }\end{array}$ & $\begin{array}{l}\text { High-efficiency } \\
\text { Series } 5\end{array}$ & $3 \mathrm{MW}$ & $3 \mathrm{MJ}$ & $48^{\prime}$ or $53^{\prime}$ & $\begin{array}{l}55,000 \\
\mathrm{lb}\end{array}$ & $\begin{array}{l}\text { Rapid } \\
\text { recharge }\end{array}$ & None & $\begin{array}{l}\text { Up to } 28 \\
\text { MVAR } \\
16 \text { MVAR cc }\end{array}$ & \\
\hline \multicolumn{10}{|l|}{ Flywheels } \\
\hline Beacon Power & $\begin{array}{l}\text { High-speed } \\
\text { composite }\end{array}$ & $1 \mathrm{~kW} \mathrm{DC}$ & 7,200 & $2^{\prime} \times 2^{\prime} \times 2^{\prime}$ & $260 \mathrm{lb}$ & Slow & None & Full outdoor & \\
\hline $\begin{array}{l}\text { Active Power } \\
\text { (Clean Energy) }\end{array}$ & Low-speed & 480 kW & 1,200 & $\begin{array}{l}\text { 40.5" W x } \\
39.8 " \mathrm{D} x \\
\text { 82.2" H }\end{array}$ & $\begin{array}{l}4,500 \\
\mathrm{lb}\end{array}$ & $60 \min$ & None & & $-20-40^{\circ} \mathrm{C}$ \\
\hline $\begin{array}{l}\text { International } \\
\text { Computer Power }\end{array}$ & $\begin{array}{l}\text { Low-speed } \\
\text { uninterruptible } \\
\text { power supply }\end{array}$ & 1,000 kW & 15,000 & $16 \mathrm{ft}^{2}$ & & Motor-driven & None & & \\
\hline Piller & $\begin{array}{l}\text { Low-speed } \\
\text { uninterruptible } \\
\text { power supply }\end{array}$ & 1,670 kVA & 16,500 & $\begin{array}{l}166 " \text { L x } \\
52 " \mathrm{~W} x \\
90 " \mathrm{H}\end{array}$ & $\begin{array}{l}25,137 \\
\mathrm{lb}\end{array}$ & & None & & \\
\hline \multicolumn{10}{|l|}{ Supercapacitors } \\
\hline Maxwell & Double layer & $30 \mathrm{~kW}$ & 300 & $3^{\prime}$ x 3' & & Rapid & None & & \\
\hline Power Cell & Three layers & $300 \mathrm{~kW}$ & 10.5 & $12.9 "$ x 4.3" & $17.6 \mathrm{lb}$ & & None & & \\
\hline PEAC (ESMA) & Double layer & $3 \mathrm{~kW}$ & 36 & $\begin{array}{l}330 \times 87 \\
\times 196 \mathrm{~mm}\end{array}$ & 10.8 & Slow & None & & \\
\hline
\end{tabular}




\subsection{Engine Technologies}

\subsubsection{Reciprocating Engines}

The reciprocating internal combustion engine is a widespread and well-known prime mover. North American production tops 35 million units a year for automobiles, trucks, construction equipment, lawn care, marine propulsion, and power generation. These units range from small portable gensets to large stationary power plants. Natural gas is the preferred fuel for power generation; however, internal combustion engines can combust propane or liquid fuels. Diesel cycle, compression ignition engines can operate on diesel fuel or heavy oil, or they can be set up in a dual-fuel configuration that burns primarily natural gas with small amounts of diesel pilot fuel. Internal combustion engines offer low first cost, easy start-up, proven reliability when properly maintained, and good load-following characteristics. Emissions of internal combustion engines have been reduced significantly in the past several years by exhaust catalysts and through better design and control of the combustion process. Internal combustion engines are well suited for standby, peaking, and intermediate applications and for packaged CHP in commercial and light industrial applications of less than $10 \mathrm{MW}$.

\section{Engine Specifications}

Engine systems can provide higher electrical efficiencies than combustion turbines (CTs) in small sizes. Because a significant portion of the waste heat from engine systems is rejected in the jacket water at a temperature generally too low to produce high-quality steam, the ability of engine systems to produce steam is limited.

All turbine and engine manufacturers quote heat rates in terms of the lower heating value of the fuel. In contrast, the energy content of fuels is typically measured on a higher heating value basis. The difference between higher and lower heating values is the energy content of the water vapor in the combustion exhaust. Because heat engines never capture this heat of vaporization, design engineers prefer to quote efficiencies in lower heating value. For natural gas, the average heat content is $1,030 \mathrm{Btu} / \mathrm{ft}^{3}$ on a higher heating value basis and $930 \mathrm{Btu} / \mathrm{ft}^{3}$ on a lower heating value basis, about a $10 \%$ difference.

\subsubsection{Microturbines}

Microturbines are very small CTs with outputs of $30 \mathrm{~kW}$ to $200 \mathrm{~kW}$. Microturbine technology has evolved from automotive and truck turbochargers, auxiliary power units for airplanes and tanks, and small jet engines used for pilotless military aircraft. Recent development has focused on microturbines as prime movers for hybrid electric vehicles and stationary power sources for the DR market. In most configurations, the turbine shaft spins at up to $100,000 \mathrm{rpm}$ and drives a high-speed generator. The high-frequency output is first rectified and then converted to standard AC. Advances in inverters, the power-electronics technology that supports PV and fuel cells, are also making microturbine systems economically feasible. The systems are capable of producing power at around $25 \%-30 \%$ efficiency by employing a recuperator that transfers heat energy from the exhaust stream back into the incoming air stream. The systems are air-cooled, and some even use air bearings, eliminating both water and oil systems. Low-emission combustion systems that provide emissions performance comparable to larger CTs are being demonstrated. Microturbines are appropriately sized for commercial buildings or light industrial markets for CHP or poweronly applications. 


\section{Microturbine Specifications}

Microturbine developers quote an electrical efficiency at the high-frequency generator terminals of $30 \%-33 \%$ on a lower heating value basis. The power electronics component then introduces about $5 \%$ in additional losses in the conversion step from high-frequency to $60-\mathrm{Hz}$ power. Additional parasitic loads of up to $10 \%$ of capacity are often required for a fuel compressor to compress natural gas from typical delivery pressures of 2 psig or less to $75 \mathrm{psig}$. These adjustments bring the electrical efficiency to less than $26 \%$ for some configurations.

Future developments in the technology are expected to improve efficiencies and bring costs down significantly. Performance targets for the 2020 advanced systems are based on DOE goals in the recently released microturbine program solicitation.

\subsubsection{Combustion Turbines}

CTs are an established technology that range in size from several hundred kilowatts to hundreds of megawatts. CTs are used to power aircraft, large marine vessels, gas compressors, and utility and industrial power generators. CTs produce high-quality heat that can be used to generate steam for additional power generation (combined cycle) or on-site steam use. CTs can burn natural gas or a variety of petroleum fuels, or they can have a dual-fuel configuration. CT emissions can be controlled to very low levels using dry combustion techniques, water or steam injection, or an exhaust treatment such as selective catalytic reduction. Maintenance costs per unit of power output are among the lowest of CHP technology options. Low maintenance and high-quality waste heat make CTs an excellent choice for industrial or commercial cogeneration applications larger than $5 \mathrm{MW}$.

\subsubsection{Evaluating Rotating $D R$}

When evaluating rotating DR for use in DUIT, the following factors may be considered. Equipment certification also could be a factor to consider. For many of the newer, more innovative products on the market, certification is not practical because of the evolving nature of the product. Also, certification standards are still evolving. Applying incomplete standards to these products may be premature.

\subsubsection{Physical Characteristics}

The required space for a particular rotating DR will depend on the physical dimensions of the equipment and any space needed for access and ventilation. Weight has an effect on foundation requirements. Because most rotating DR are designed for outdoor use, indoor facilities would not be needed. All of these will determine the physical dimensions and layout of the DUIT facility.

Fuel requirements will have a major bearing on the DUIT facility. Natural gas is the fuel of choice, especially for base-loaded or peak-shaving units. Standby/emergency units normally run on diesel. Some units can run on propane. Fuel supply and availability, gas pressures, and flow rates available on site could be determining factors.

\subsubsection{Mechanical Characteristics}

How the unit is mounted (skid, legs, or mobile) will have a major effect on any foundation requirements. Local code authorities will specify what is allowed. 
Other considerations include:

- Some units could require make-up water for the cooling system.

- Access space will be required for servicing the unit and to meet any code (safety) requirements.

- Local code and air quality authorities may have specific requirements on exhaust gas emissions. These may affect the design of the exhaust stack.

\subsubsection{Electrical Characteristics}

DR equipment ratings should relate to typical customer needs and to what is available at the DUIT site. Standard ratings of 120/208 or 277/480 VAC, three-phase, three or four wires for commercial and industrial customers prevail. Standard residential ratings are 120/240 VAC single-phase. Capacity ratings will vary depending on application and customer load. Utilities generally require a specific power factor (or range) at the point of common coupling (PCC). The distributed generator's power factor capabilities should correspond. How the DR is grounded may be an issue, depending on the customer's transformer connection.

The major issue for utilities is how the utility system is protected from faults or misoperation of the DR while it is operating in parallel with the grid. The type and manner of utility protection should be described (with explanatory diagrams and drawings) as it relates to the intended application. At the minimum, the protection should include over and underfrequency $(81 \mathrm{O} / \mathrm{U})$, over and undervoltage (27/59), and an option for reverse (32R) or over/under $(32 \mathrm{O} / \mathrm{U})$ power. The range of trip set points and delay times should be stated, and a description of how the unit can be tested in the field to verify the protection scheme (and set points) should be provided. Any test results from accepted third-party testing labs also should be provided.

A written description of how the units will be operated and the sequence of events in case of a grid disturbance may be required. Even if this is not required by the utility, it should be performed as a means of verifying the utility protection scheme. (The generator protection scheme should also be similarly analyzed.) The utility will be particularly concerned with protecting against islanding part of the distribution system and exceeding utility equipment ratings (overcurrent and overvoltage.) Coordination with utility devices (fuses, reclosers, and breakers) should also be investigated.

Product literature that documents design and rating specs by component or subsystem vendors according to established national standards (e.g., transfer switches meet UL1008, generators meet NEMA specs, etc.) should be provided. Included in this information should be specific data (machine constants or locked rotor data) to help determine the short-circuit current contribution from the rotating generator. (This information should be readily available from the vendor.) 
Depending on a particular customer's site (and the design of existing electrical service), external electrical equipment may be needed and should be indicated in the installation description. This additional equipment could include:

- An interconnecting transformer

- Breakers or switches to tie into the existing switchboard

- A code-required safety disconnect switch

- Instrument transformers and relays at the PCC

- Metering per utility rate requirements.

\subsubsection{Environmental and Permitting}

Generation equipment may have to operate within a specific temperature range to achieve the designed output rating, for safe operation, or for warranty purposes. Climate and site ventilation can be determining factors.

Air pollution control districts will have emission standards. Generally, these relate to carbon monoxide, nitrogen oxide, and other general pollutants. Control of specific toxins may also be required based on an assessment of health risk.

In addition, the site design should include the control of fluid effluents such as coolant drainage and oil leaks. Used oil, used coolant, filters, and rags should be disposed of in an approved manner. This may also fall under the jurisdiction of the local pollution control district.

A critical factor in siting DG, especially in urban and suburban areas, is noise. Local codes will state acceptable noise levels at specific distances. Similar to the noise issue is the visual impact an installation will have on the surrounding neighborhood. Local code authorities may require fencing, color schemes, or other actions for aesthetic reasons.

Engine technology characteristics are listed in Table 19. 
Table 19. Rotating and Microturbine Technology Data

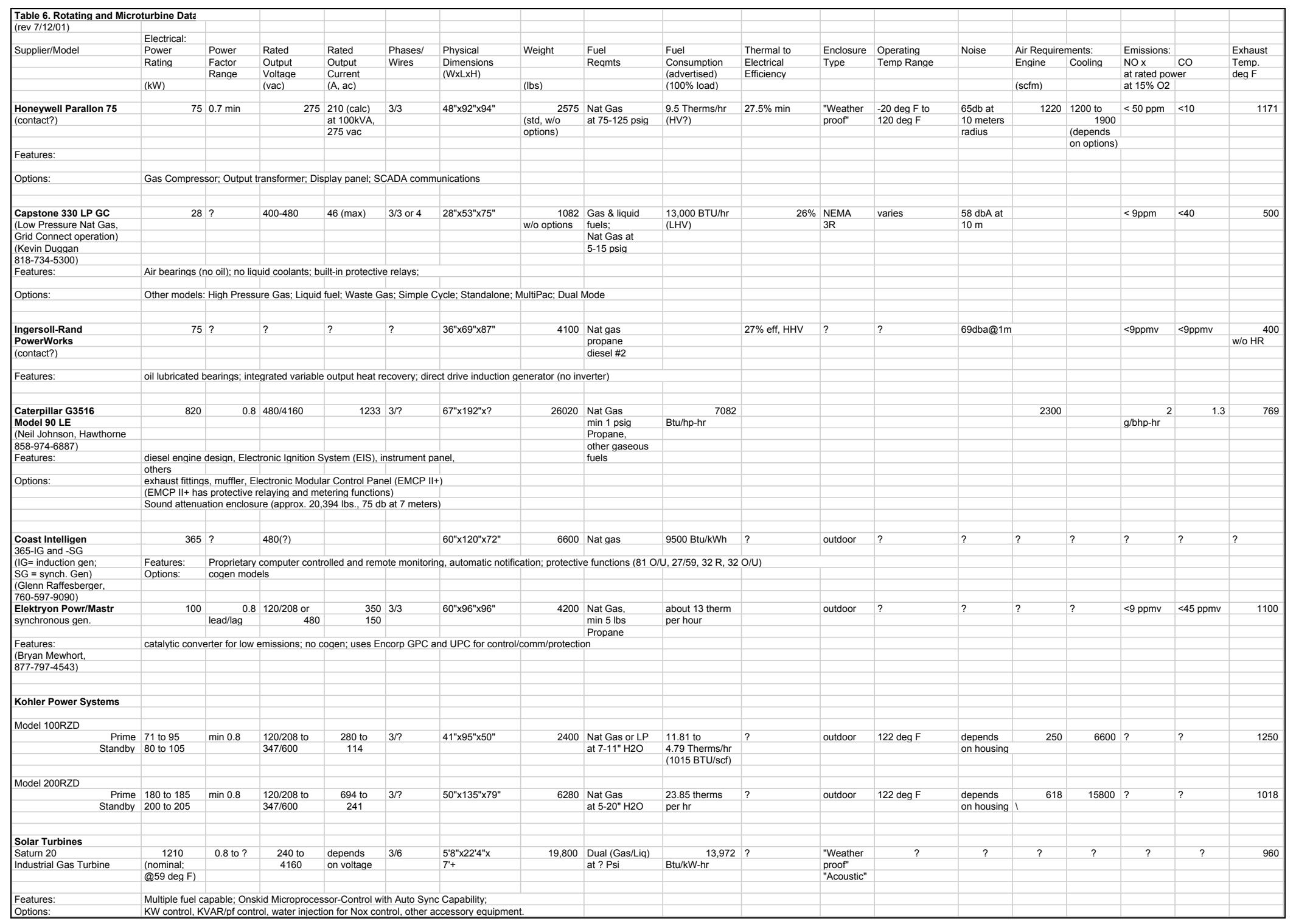




\section{$4 \quad$ Test Protocols}

\subsection{Introduction}

The existing distribution system was engineered to distribute electric power from a single source, the distribution substation, to various customer loads in the most cost-effective manner. It was designed to provide power between zero load and the maximum projected load to all customers on a distribution circuit at voltages and frequencies within the allowable ranges. As with any engineered system, it is based on certain design parameters, local conditions, and local utility assumptions. Thus, there are a variety of viable solutions to the problem of power distribution and implementation in the field.

This section provides test protocols for evaluating various aspects of DR in an area electric power system (EPS, commonly referred to as an electrical distribution system). Protocols are meant to provide a basic understanding of what information should result, how the tests are to be performed, and what facilities (e.g., DR, DASs, etc.) and other requirements are necessary to perform the tests.

Although the results may be used for this purpose, the tests are not necessarily meant to determine if a particular unit passes or fails. More often, they will help establish what reasonable pass/fail criteria should be or if certain configurations are likely to reduce or increase distribution system reliability or safety. The results may be used to determine the conditions or limits under which additional requirements may be necessary. They may also help establish or enhance type tests to verify proper operation and coordination of DR with one another and the Area EPS.

Each protocol includes a list of relevant standards. In particular, the following documents are referenced:

- IEEE P1547

IEEE P1547, "Draft Standard for Interconnecting Distributed Resources with Electric Power Systems," Draft 7

- California Rule 21

"Generating Facility Interconnections." The PG\&E version, available at http://www.energy.ca.gov/distgen/interconnection.html is cited, though the SDG\&E and SCE versions contain similar language

- UL 1741

"Inverters, Converters, and Controllers for Use in Independent Power Systems," Revised Jan. 17, 2001, Underwriters Laboratories

- IEEE 929

IEEE 929-2000, "Recommended Practice for Utility Interface of Photovoltaic Systems." 
Each of the test protocols has an extensive list of possible combinations and permutations, including, but not limited to:

- Level of penetration on the Area EPS circuit

- Connection configuration (single- versus three-phase, transformer configuration, grounding configuration, etc.)

- Combinations of DR types (inverter, synchronous, induction) and sizes

- Interconnection facilities between DR and utility (feeder length, transformer configurations, etc.).

What are presumed to be the most important of these variations are listed in the protocol, but the importance of other variations may become apparent as the tests are performed.

\subsection{Unintentional Islanding Tests}

Tests in this section are intended to address issues and concerns related to unintentional islanding. Although specific anti-islanding tests are prescribed in IEEE P1547, IEEE 929, and UL 1741, these tests are principally DR device-related. Concerns remain that possible shortcomings exist in current anti-islanding approaches when an aggregation of DR devices is applied to a local Area EPS. The tests in this section will deal directly with these concerns.

Islanding detection schemes can be devised to exploit test conditions, and tests can be devised to favor one detection method over another. Any islanding detection scheme can be foiled with a test specifically designed to do so. The proper approach is to define a test procedure that reflects extreme yet realistic conditions that might occur during an island.

The tests in this section are intended to evaluate the limits of detection for various detection methods and how those limits may affect the proper operation of the Area EPS.

Many of the issues related to the integration of DR into the Area EPS are related to islanding. Some of the tests described outside of this section are islanding tests or related to islanding tests, and some tests that might have been described in other sections are provided here.

\subsubsection{Basic Anti-lslanding Test}

This is one of a series of tests dealing with the validity of anti-islanding techniques when multiple DR are in the island.

The test described here is the basic anti-islanding test procedure defined in IEEE 929 and UL 1741. Subsequent procedures in this section will use this procedure with modifications or additions to evaluate various aspects of the procedure or different DR/Area EPS scenarios. 


\subsubsection{Governing IEEE 1547, CA Rule 21, and Other Document Sections}

IEEE 1547: $\$ 4.2 .1,4.4 .1,5.1 .8$, Annex A.5

CA Rule 21: §D.1.i, D.3.d.1), J.3.d

UL 1741: $\quad \S 46.3$

IEEE 929: Annex A

\subsubsection{Test Objectives}

Determine the time it takes the DR to detect the loss of Area EPS from a stable, balanced island and cease energizing the grid ("trip"). The load within the island is designed to be highly resonant with the DR unit to simulate an extreme condition.

\subsubsection{Key Testing Parameters}

The key test parameter is the time required for the DR on the island to trip. This definition is related to current output from the DR because there may be a significant delay between the reduction of current below a threshold and the mechanical opening of a disconnecting device.

\subsubsection{Expected Results}

This test will quantify the time required for the DR to trip once an islanding condition exists.

\subsubsection{Test Procedure:}

This test was developed from the procedure described in IEEE 929 Annex A. That document was defined for inverter-based PV systems, so modifications were incorporated to accommodate other types of DR.

Unless otherwise specified, measurement error for all parameters, except frequency, in the following test procedures will be less than $1 \%$. Measurement error for frequency will be less than or equal to $0.05 \mathrm{~Hz}$.

For this procedure, a utility source implies a source capable of maintaining an island within the recommended voltage and frequency windows. An engine-generator with voltage and frequency control and with no anti-islanding protection is considered a simulated utility source for the purpose of this test. ${ }^{1}$ However, because of the uncertainty associated with the need to sink both real and reactive power from the DR, this test may be performed most conveniently with an actual utility connection rather than a simulated utility connection. This test should be conducted with voltage and frequency near the middle of their operating ranges. Voltage should be at least 3\% inside the most restrictive voltage trip limits. Frequency should be at least $0.25 \mathrm{~Hz}$ inside the most restrictive frequency trip limits. (Note that frequency and voltage variation are not required for this test.)

This test procedure is based on having the quality factor, $\mathrm{Q}$, of the islanded circuit (including load and generator) equal to 2.5 .

\footnotetext{
${ }^{1}$ The output capacity of an engine-generator utility simulator should be at least three times larger than the combined output of the interconnected DR.
} 


$$
Q=(1 / P) \sqrt{P_{q L} \quad \text { x } \quad P_{q C}}
$$

Where:

$Q$ is quality factor

$R$ is effective load resistance

$L$ is effective load inductance

$C$ is effective load capacitance (including shunt capacitors)

$P$ is real power

$P_{q L}$ is inductive load

$P_{q C}$ is capacitive load.

Note also that, in the resonant case:

$$
P_{q L}=P_{q C}=P_{q}
$$

Therefore, in the resonant case:

$$
Q=P_{q} / P
$$

These formulas apply to DR with unity power factor output.

This test procedure is designed to be universally applicable to both unity power factor DR and non-unity power factor DR. With unity power factor DR, the second step below, where $\mathrm{P}_{\mathrm{q}-\mathrm{DR}}$ is measured, will result in a value of $\mathrm{P}_{\mathrm{q}-\mathrm{DR}}$ that is zero, simplifying the remainder of the procedure. For DR for which $\mathrm{P}_{\mathrm{q}-\mathrm{DR}}$ is not zero, the test is complicated by the presence of reactive power.

Harmonic currents by the utility to the capacitor and the DR further complicate the situation by making it appear that current is flowing when the $60-\mathrm{Hz}$ component of current has been zeroed. Thus, it is important when adjusting inductive and capacitive reactance to use instruments that can read only the $60-\mathrm{Hz}$ components of current and power.

The sequence of steps below is suggested for several reasons. The inductance is measured first because that measurement is low in harmonics. The capacitance is added second so that the voltage is stable when the resistance is added. The resistive parallel load is then added and adjusted. Note that this resistance will be in addition to the resistance that will be part of the inductive load.

This test procedure assumes that a non-unity power factor DR will be sourcing, not sinking, reactive power. The procedure refers to a circuit that is configured as shown in Figure 11. Details of this circuit may be changed to suit the specific hardware available to the tester. For example, it may be convenient to replace switch S1 with individual switches on each leg of the RLC load. For each DR-load power combination, the following procedure is suggested to 
achieve the proper generation-to-load complex power balance. In the following description, the utility disconnect switch may be either S3 or S4. Normally, the utility disconnect switch on the secondary side of the distribution transformer, S3, is used for this purpose. This switch removes the distribution transformer from the island circuit (a more difficult requirement). In some cases, it may be desirable or necessary to include the transformer. In those cases, the primary side disconnect, S4, may be used.

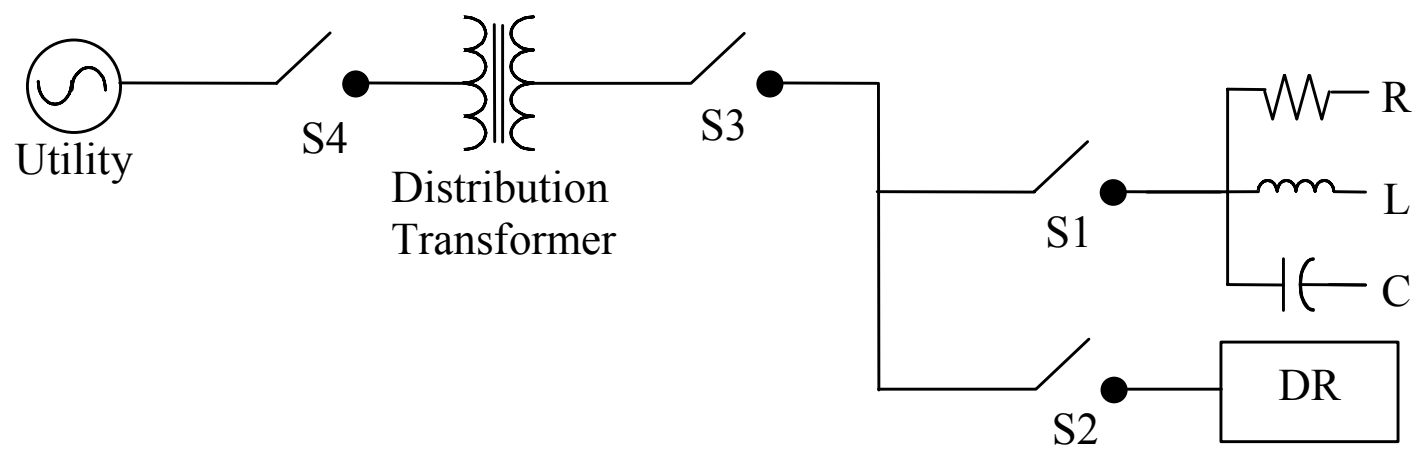

Figure 11. Anti-islanding test circuit

Sequence of steps:

1. Determine the DR test output power, $\mathrm{P}_{\mathrm{DR}}$, that will be used.

2. Operate the DR at $\mathrm{P}_{\mathrm{DR}}$ and measure $\mathrm{DR}$ reactive power output, $\mathrm{P}_{\mathrm{q}-\mathrm{DR}}$. The utility disconnect switch should be closed. With no local load connected (that is, S1 is open so that the RLC load is not connected at this time) and the DR connected to the utility (S2 is closed), turn the DR on and operate it at the output determined in Step 1. Measure real and reactive power flow at the measurement point. The real power should equal $\mathrm{P}_{\mathrm{DR}}$. The reactive power measured in this step is designated $\mathrm{P}_{\mathrm{q}-\mathrm{DR}}$.

3. Turn off the DR and open S2.

4. Adjust the RLC circuit to have $\mathrm{Q}=2.5$ as follows:

A. Determine the inductive reactance required in the resonant RLC circuit using the relation $\mathrm{P}_{\mathrm{qL}}=2.5 \mathrm{P}_{\mathrm{DR}}$.

B. Connect an inductor as the first element of the RLC circuit and adjust the inductance to $\mathrm{P}_{\mathrm{qL}}$.

C. Connect a capacitor in parallel with the inductor. Adjust the capacitive reactance so that $\mathrm{P}_{\mathrm{qC}}+\mathrm{P}_{\mathrm{qL}}=-\mathrm{P}_{\mathrm{q}-\mathrm{DR}}$.

D. Connect a resistor that makes the power consumed by the RLC circuit equal to $\mathrm{P}_{\mathrm{DR}}$.

5. Connect the RLC load configured in Step 4D to the DR by closing S1. Close S2 and turn the DR on, making certain that the power output is as determined in Step 1. 
(Note: The purpose of the procedure up to this point is to zero out the $60-\mathrm{Hz}$ components of real and reactive power or to zero out the $60-\mathrm{Hz}$ component of current flow at the utility disconnect switch. System resonances will typically generate harmonic currents in the test circuit. These harmonic currents will typically make it impossible to zero out a measurement of continuous power or RMS current flow at the disconnect switch. Because of test equipment measurement error and some effect from harmonic currents, it is necessary to make small adjustments in the test circuit to achieve worst-case islanding behavior. The next step is performed to make these small adjustments.)

6. Open the utility disconnect switch to initiate the test.

7. After each successful test, adjust one parameter by approximately $1 \%$ per test within a total range of $\pm 5 \%$ of the operating point determined in Step $4 \mathrm{D}$. The parameter that is adjusted may be load inductance, L, or load capacitance, C. After each adjustment, perform an island test and record the time to trip.

8. For three-phase DR, the test should be run with the utility disconnect occurring in all combinations of one, two, and three phases.

9. For three-phase DR, the test should be done initially with the load determined as described above individually for each phase. The test can then be repeated with an imbalance in real power of 5\%-10\% in various arrangements (i.e., reduce Phase A and B by $5 \%$, increase $\mathrm{C}$ by $10 \%)$.

This test should be performed with the following ratios of real load-to-DR output, where both values are given as a percent of DR full output rating:

$\begin{array}{cc}\text { Real Load } & \text { DR Output } \\ 25 \% & 25 \% \\ 50 \% & 50 \% \\ 100 \% & 100 \% \\ 125 \% & 100 \%\end{array}$

The actual tripping time for each test will be recorded. 


\title{
4.2.1.6 Data Acquisition Requirements
}

Table 20. Basic Anti-Islanding Test Data Acquisition Requirements

\begin{tabular}{|c|c|c|c|c|c|}
\hline Parameter & Units & $\begin{array}{l}\text { Range } \\
\text { (Nom.) }\end{array}$ & Accuracy & $\begin{array}{l}\text { Sampling } \\
\text { Rate }\end{array}$ & $\begin{array}{l}\text { Recording } \\
\text { Rate }\end{array}$ \\
\hline $\begin{array}{l}\text { Island contactor status (i.e., } \\
\text { aux. contact closure) }\end{array}$ & $\begin{array}{l}\mathrm{DC} \\
\text { volts }\end{array}$ & $0-10$ & $5 \%$ & $600 \mathrm{~Hz}$ & $600 \mathrm{~Hz}$ \\
\hline $\begin{array}{l}\text { Island contactor utility-side } \\
\text { voltage }\end{array}$ & $\begin{array}{l}\mathrm{AC} \\
\text { volts }\end{array}$ & 0-480 & $1 \%$ & $600 \mathrm{~Hz}$ & $600 \mathrm{~Hz}$ \\
\hline $\begin{array}{l}\text { Island contactor island-side } \\
\text { voltage }\end{array}$ & $\begin{array}{c}\mathrm{AC} \\
\text { volts }\end{array}$ & 0-480 & $1 \%$ & $600 \mathrm{~Hz}$ & $600 \mathrm{~Hz}$ \\
\hline DR output current (1/DR) & $\begin{array}{c}\text { AC } \\
\text { amps }\end{array}$ & $\begin{array}{l}0-\text { full } \\
\text { scale }\end{array}$ & $1 \%$ & $600 \mathrm{~Hz}$ & $600 \mathrm{~Hz}$ \\
\hline $\begin{array}{l}\text { DR output voltage, DR side of } \\
\text { DR contactor, if accessible }\end{array}$ & $\begin{array}{c}\mathrm{AC} \\
\text { volts }\end{array}$ & 0-480 & $1 \%$ & $600 \mathrm{~Hz}$ & $600 \mathrm{~Hz}$ \\
\hline
\end{tabular}

\subsubsection{Control Requirements}

The basic test is supposed to evaluate autonomous operation of different DR sources with no control interconnection among them. There are no special control system requirements; however, variations of this basic procedure may include some control strategies or equipment.

\subsubsection{Facility Requirements}

The test facility will need adjustable resistive, inductive, and capacitive loads with sufficient capacity and resolution to meet the impedance and step size requirements of a particular test.

\subsubsection{DR Requirements}

This basic test may be performed on a single DR or on multiple units. Subsequent test procedures will have their own specific requirements.

\subsubsection{Other Requirements}

There are no other requirements.

\subsubsection{Modeling Requirements}

There are no modeling requirements.

\subsubsection{Anti-Islanding With Multiple DR Types}

\author{
4.2.2.1 Governing IEEE 1547, CA Rule 21, and Other Document Sections \\ IEEE 1547: $\quad \S 4.2 .1,4.4 .1,5.1 .8$, Annex A.5 \\ CA Rule 21: $§ D .1 . i$, D.3.d.1, J.3.d \\ UL 1741: $\quad \$ 46.3$ \\ IEEE 929: Annex A
}




\subsubsection{Test Objectives}

Perform the basic anti-islanding test individually on three to five DR. At least two of the DR should be inverter-based, at least one should be a synchronous machine, and at least one should be an induction machine. The largest DR unit should not be more than twice the size (rated output) of the smallest. All DR should have some form of anti-islanding detection (or reverse-power or underpower detection, in which case the related RLC load will have to be on the DR side of the underpower measurement point).

\subsubsection{Key Testing Parameters}

The key test parameter is the time required for the DR on the island to trip (cease energizing the line). This definition is related to current output from the DR because there may be a significant delay between the reduction of current below a threshold level and the mechanical opening of a disconnecting device.

\subsubsection{Expected Results}

This test will determine the time required for the DR to trip once an islanding condition exists.

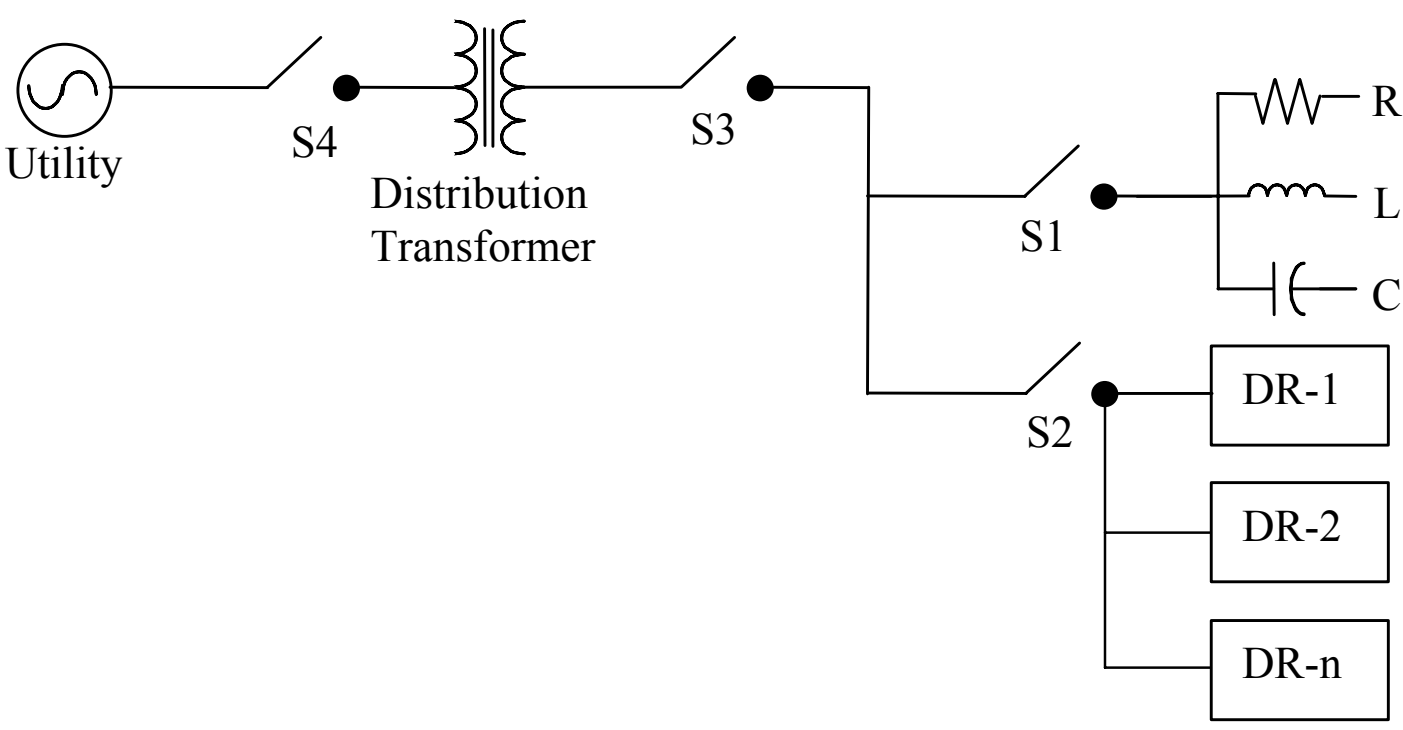

Figure 12. Anti-islanding test circuit with multiple DR

\subsubsection{Test Procedure}

The procedure is the same as for the basic anti-islanding test but with multiple DR. 


\subsubsection{Data Acquisition Requirements}

Table 21. Anti-Islanding With Multiple DR Types Data Acquisition Requirements

\begin{tabular}{|c|c|c|c|c|c|}
\hline Parameter & Units & $\begin{array}{l}\text { Range } \\
\text { (Nom.) }\end{array}$ & Accuracy & $\begin{array}{l}\text { Sampling } \\
\text { Rate }\end{array}$ & $\begin{array}{l}\text { Recording } \\
\text { Rate }\end{array}$ \\
\hline $\begin{array}{l}\text { Island contactor status (i.e., } \\
\text { aux. contact closure) }\end{array}$ & $\begin{array}{l}\mathrm{DC} \\
\text { volts }\end{array}$ & $0-10$ & $5 \%$ & $600 \mathrm{~Hz}$ & $600 \mathrm{~Hz}$ \\
\hline $\begin{array}{l}\text { Island contactor utility-side } \\
\text { voltage }\end{array}$ & $\begin{array}{l}\mathrm{AC} \\
\text { volts }\end{array}$ & 0-480 & $1 \%$ & $600 \mathrm{~Hz}$ & $600 \mathrm{~Hz}$ \\
\hline $\begin{array}{l}\text { Island contactor island-side } \\
\text { voltage }\end{array}$ & $\begin{array}{c}\mathrm{AC} \\
\text { volts }\end{array}$ & 0-480 & $1 \%$ & $600 \mathrm{~Hz}$ & $600 \mathrm{~Hz}$ \\
\hline DR output current (1/DR) & $\begin{array}{c}\text { AC } \\
\text { amps }\end{array}$ & $\begin{array}{l}0-\text { full } \\
\text { scale }\end{array}$ & $1 \%$ & $600 \mathrm{~Hz}$ & $600 \mathrm{~Hz}$ \\
\hline $\begin{array}{l}\text { DR output voltage, DR side of } \\
\text { DR contactor, if accessible }\end{array}$ & $\begin{array}{c}\mathrm{AC} \\
\text { volts }\end{array}$ & 0-480 & $1 \%$ & $600 \mathrm{~Hz}$ & $600 \mathrm{~Hz}$ \\
\hline
\end{tabular}

\subsubsection{Control Requirements}

The test is supposed to evaluate autonomous operation of the different DR sources with no control interconnection among them. There are no special control system requirements; however, variations of this basic procedure may include some control strategies or equipment.

\subsubsection{Facility Requirements}

The test facility will need adjustable resistive, inductive, and capacitive loads with sufficient capacity and resolution to meet the impedance and step size requirements of a particular test.

\subsubsection{DR Requirements}

This test may be performed on a single DR or on multiple units. Subsequent test procedures will have their own specific requirements.

\subsubsection{Other Requirements}

There are no other requirements.

\subsubsection{Modeling Requirements}

There are no modeling requirements.

\subsubsection{Anti-Islanding With Dynamic Load-to-Generation Ratio}

This is one of a series of tests dealing with the validity of anti-islanding techniques when multiple DR are in the island. 


\subsubsection{Governing IEEE 1547, CA Rule 21, and Other Document Sections}

IEEE 1547: $\$ 4.2 .1$ Voltage Disturbances

\$4.4.1 Unintentional Islanding

$\$ 5.1 .8$ Unintentional Islanding

Annex A.5 Interconnection Test to Verify Non-Islanding

CA Rule 21: $\quad \S D .1 . c$ No Unintentional Islanding

$\S D .3 . d .1$ Unintended Islanding for Generating Facilities That Fail the Export Screen

$\S$ J.3.d Anti-Islanding Tests (UL 1741)

UL 1741: \$46.3 Anti-Islanding Tests

\subsubsection{Test Objectives}

It is understood that, with a single DR operating in the steady state, a load-to-generation ratio (L:G) significantly less than or greater than 1 will lead to the disconnection of the resource during the creation of an island because of an imbalance in real power transfer. As the L:G approaches unity, the trip time increases. However, as shown in Figure 13, many islanding tests exhibit a maximum trip time at a point at which the load exceeds the generation by a small amount. It has been suggested that in an islanded Area EPS segment with numerous DG and an initial excess of generation, some DR will trip off and move the segment L:G into a condition more favorable to continued islanding.

Figure 13. Results of islanding tests showing trip times of $L: G$

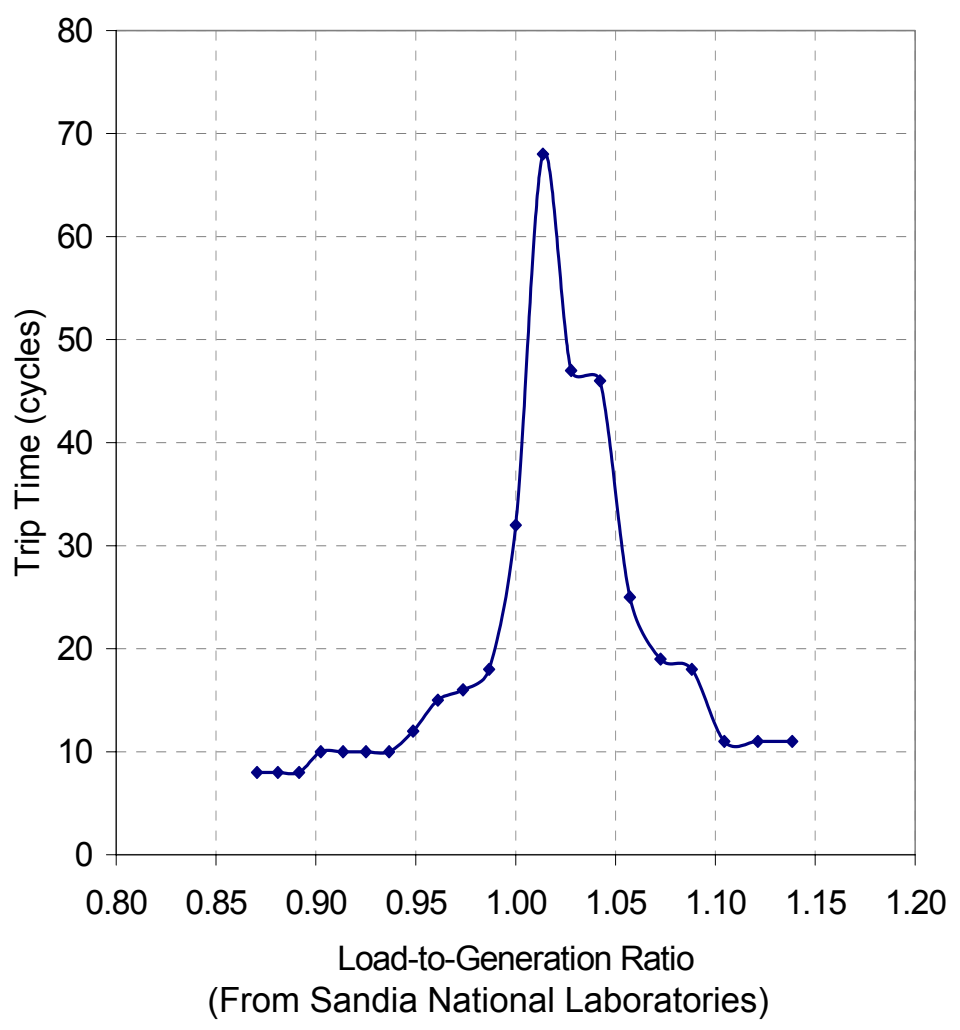


The objective of this test is to determine how the performance of anti-islanding schemes is affected by multiple DR operating in aggregate with an initial L:G less than 1 . The principal question is whether disconnect times are changed (extended) as a small number of DR drop off line and dynamically shift the L:G closer and closer to 1 .

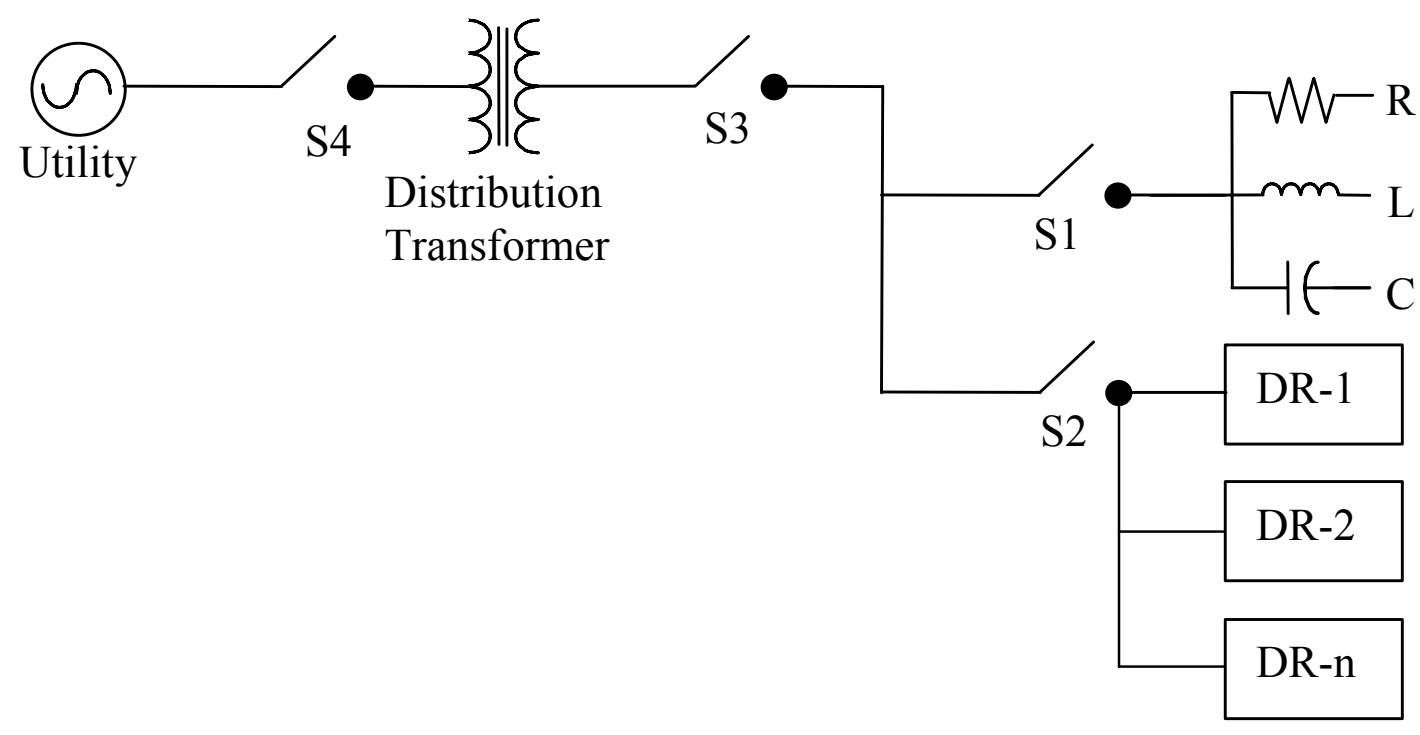

Figure 14. Test configuration for dynamic L:G

\subsubsection{Key Testing Parameters}

The key test parameter is the time required for the last DR in the island to trip. The goal is to determine if the trip time is significantly extended by the changing $\mathrm{L}: \mathrm{G}$ as small numbers of DR come off line.

\subsubsection{Expected Results}

Diverse DR equipment with validated anti-islanding techniques should work in aggregate and still meet the trip times required by the various standards.

\subsubsection{Test Procedure}

1. Setup is shown in Figure 14.

2. Select DR and load for an initial L:G of 0.9.

3. Monitor the required DAS parameters.

4. Disconnect utility source to form an island with the test facility.

5. Determine and record the time required for each DR to trip by comparing the time stamps for the sample that shows the island contactor has opened with the sample (for each DR) that shows the DR has tripped.

6. Repeat three additional trials with initial $\mathrm{L}: \mathrm{G}$ of $0.95,0.85$, and 0.80 .

7. Repeat test with three groups of DR and necessary loads separated by an impedance equivalent to 5-10 miles of distribution line (i.e., Group 1 at $0 \mathrm{mi}$, Group 2 at 10 $\mathrm{mi}$, Group 3 at $20 \mathrm{mi}$ ). 


\subsubsection{Data Acquisition Requirements}

Note that the primary measurement issue is timing between the island formation (signified by the islanding contactor status) and the trip signal (signified by the DR output current); therefore, high sampling rate and high sampling rate precision are important.

Table 22. Anti-Islanding With Dynamic L:G Data Acquisition Requirements

\begin{tabular}{|c|c|c|c|c|c|}
\hline Parameter & Units & (Nom.) & Accuracy & Rate & Rate \\
\hline $\begin{array}{l}\text { Island contactor status (i.e., } \\
\text { aux. contact closure) }\end{array}$ & $\begin{array}{l}\mathrm{DC} \\
\text { volts }\end{array}$ & $0-10$ & $5 \%$ & $600 \mathrm{~Hz}$ & $600 \mathrm{~Hz}$ \\
\hline $\begin{array}{l}\text { Island contactor utility-side } \\
\text { voltage }\end{array}$ & $\begin{array}{c}\mathrm{AC} \\
\text { volts }\end{array}$ & $0-480$ & $1 \%$ & $600 \mathrm{~Hz}$ & $600 \mathrm{~Hz}$ \\
\hline $\begin{array}{l}\text { Island contactor island-side } \\
\text { voltage }\end{array}$ & $\begin{array}{c}\mathrm{AC} \\
\text { volts }\end{array}$ & $0-480$ & $1 \%$ & $600 \mathrm{~Hz}$ & $600 \mathrm{~Hz}$ \\
\hline DR output current (1/DR) & $\begin{array}{c}\text { AC } \\
\text { amps }\end{array}$ & $\begin{array}{l}0-\text { full } \\
\text { scale }\end{array}$ & $1 \%$ & $600 \mathrm{~Hz}$ & $600 \mathrm{~Hz}$ \\
\hline $\begin{array}{l}\text { DR output voltage, DR side of } \\
\text { DR contactor, if accessible }\end{array}$ & $\begin{array}{c}\mathrm{AC} \\
\text { volts }\end{array}$ & $0-480$ & $1 \%$ & $600 \mathrm{~Hz}$ & $600 \mathrm{~Hz}$ \\
\hline
\end{tabular}

\subsubsection{Control Requirements}

The test is intended to cover autonomous operation of the DR with no control interconnection among them. There are no special control system requirements for this test.

\subsubsection{Facility Requirements}

The facility needs to be of sufficient size to connect a large number of DR to the utility and in the formation of the island. A relatively large islanded load may be required (exact size is dependent on available DR).

\subsubsection{DR Requirements}

This test will require a large number of DR that have passed the anti-islanding test in UL 1741 . Because the goal is to step from an L:G of less than 1 to an L:G of 1 by dropping units off line, it is important to ensure the step size (a single unit dropping off) is small enough to provide an indication of rate of change. For example, 50 same-size units will each provide a $2 \%$ step.

Table 23. Anti-Islanding With Dynamic L:G DR Requirements

\begin{tabular}{lccl}
\hline \multicolumn{1}{c}{ Type } & Quantity & Size & \multicolumn{1}{c}{ Other } \\
\cline { 2 - 4 } $\begin{array}{l}\text { Inverter, any prime } \\
\text { mover }\end{array}$ & 20 & $1-10 \mathrm{~kW}$ & $\begin{array}{l}\text { Must have advanced anti-islanding } \\
\text { function }\end{array}$ \\
$\begin{array}{l}\text { Synchronous } \\
\text { Induction }\end{array}$ & $\geq 1$ & $5-50 \mathrm{~kW}$ & $\begin{array}{l}\text { Must have advanced anti-islanding } \\
\text { function }\end{array}$ \\
& $5-50 \mathrm{~kW}$ & $\begin{array}{l}\text { Must have advanced anti-islanding } \\
\text { function }\end{array}$ \\
\hline
\end{tabular}


Where possible, this test should be repeated with a variety of DR using a common islanding detection technique and differing islanding detection techniques. Tests should be done with combinations of single- and three-phase DR.

Alternatively, a couple of large DR with a smaller number of small DR can be used to test the anti-islanding capabilities of the large DR.

\subsubsection{Other Requirements}

Other requirements include variable load for the island with inductor and capacitor banks or rotating motor load to accommodate IEEE 1547 and UL 1741 type testing.

\subsubsection{Modeling Requirements}

Dynamic models of the various anti-islanding schemes will be developed. This test would provide a validation case for these models and for the potential interaction of the schemes.

\subsubsection{DR Anti-Islanding Test Using Rotating Loads}

A common concern about the anti-islanding test in UL 1741, IEEE 929, and IEEE 1547 is the lack of testing with rotating loads. These anti-islanding test procedures involve a passive, tuned RLC circuit that is intended to support the process of islanding. However, there is concern that rotating induction machine loads can also aid in the process of forming and maintaining an island and that these types of loads are predominant in practice. The purpose of this test is to perform the islanding tests prescribed in the standards but with a rotating induction machine and various inertial loads.

\subsubsection{Governing IEEE 1547, CA Rule 21, and Other Document Sections \\ IEEE 1547: $\quad \$ 4.2 .1$ Voltage Disturbances \\ $\S 4.4 .1$ Unintentional Islanding \\ $\S 5.1 .8$ Unintentional Islanding \\ Annex A.5 Interconnection Test to Verify Non-Islanding \\ CA Rule 21: $\quad \S D .1 . c$ No Unintentional Islanding \\ $\S D .3 . d .1$ Unintended Islanding for Generating Facilities That Fail the Export Screen \\ $\S$ J.3.d Anti-Islanding Test (UL 1741) \\ UL 1741: $\quad \S 46.3$ Anti-Islanding Tests}

\subsubsection{Test Objectives}

The inertia and generating capability of induction and synchronous motor loads presents antiislanding schemes with potential problems. It has been argued that these types of loads are more likely to cause islanding conditions than the passive RLC type-testing load identified in IEEE 929 and 1547. Furthermore, these types of loads are more representative of typical distribution system loads. For these reasons, and to demonstrate the performance of antiislanding schemes, a series of anti-islanding tests that use rotating loads will be performed. The tests will be performed with varying real power levels and varying mechanical inertias connected to the rotating machine. The tests will be performed with both induction and synchronous machine loads, individually and collectively. 


\subsubsection{Key Testing Parameters}

The key parameters to be varied in this test are real and reactive power and mechanical inertial load.

\subsubsection{Expected Results}

It is expected that measured trip times for DR with active anti-islanding will appreciably increase with the combination RLC-rotating load.

\subsubsection{Test Procedure}

The setup is shown in Figure 15.

1. With select DR units, run the basic anti-islanding test on individual DR using an induction machine load and varying inertia.

2. Connect a single DR with rotating load and set up conditions of real and reactive power as outlined in the basic anti-islanding test.

3. Disconnect the utility, forming an island containing the DR, RLC load, and rotating machine.

4. Monitor the various voltages, currents, and status signals to determine the time required for the DR to trip.

5. Repeat tests from Step 2 using a synchronous machine load.

6. Perform anti-islanding tests in aggregate (multiple DR with induction and synchronous rotating machine).

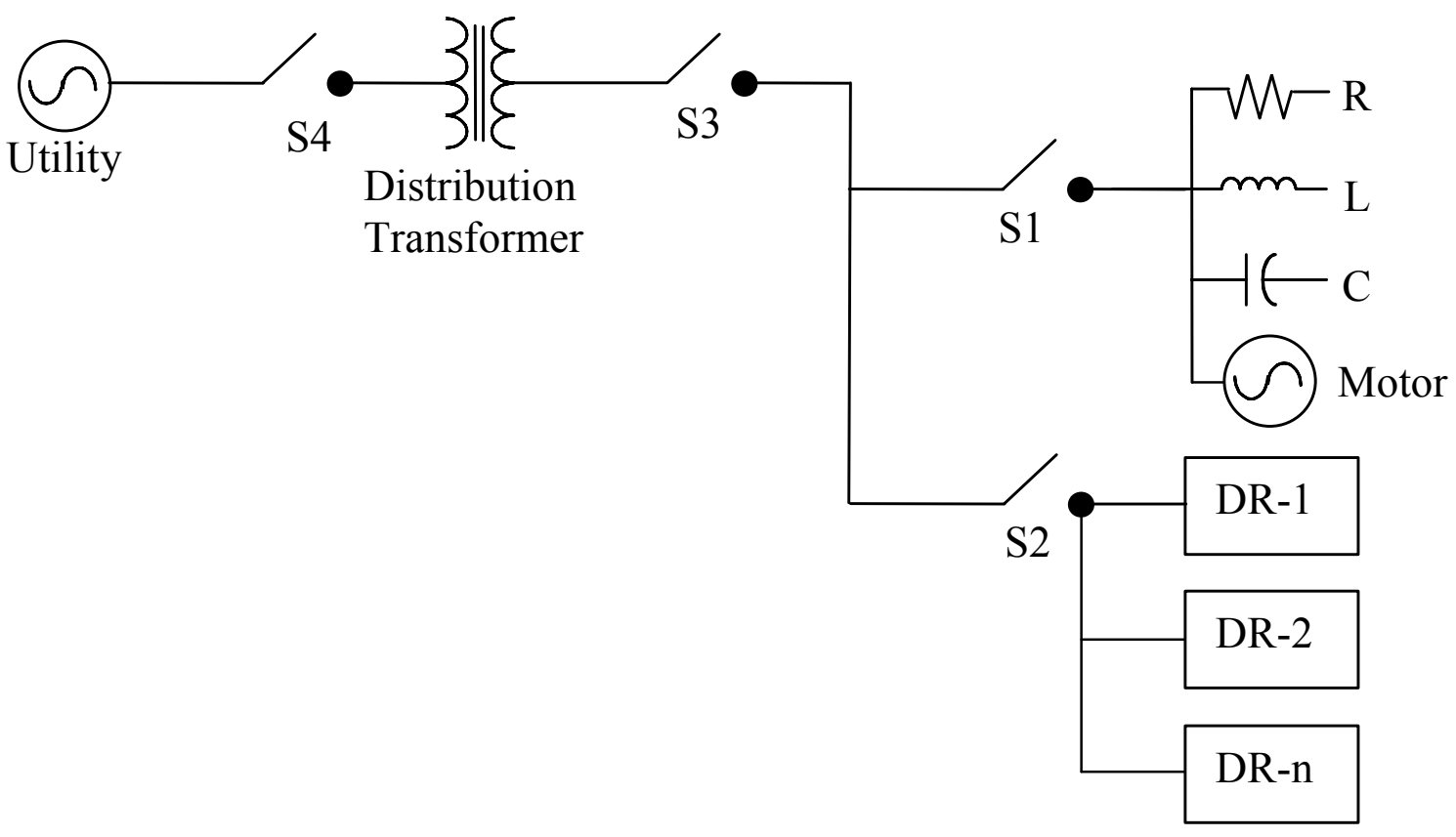

Figure 15. Test configuration with rotating loads 


\subsubsection{Data Acquisition Requirements}

Table 24. DR Anti-lslanding Test Using Rotating Loads Data Acquisition Requirements

\begin{tabular}{|c|c|c|c|c|c|}
\hline Parameter & Units & $\begin{array}{l}\text { Range } \\
\text { (Nom.) }\end{array}$ & Accuracy & $\begin{array}{l}\text { Sampling } \\
\text { Rate }\end{array}$ & $\begin{array}{c}\text { Recording } \\
\text { Rate }\end{array}$ \\
\hline $\begin{array}{l}\text { Island contactor status (i.e., } \\
\text { aux. contact closure) }\end{array}$ & $\begin{array}{l}\mathrm{DC} \\
\text { volts }\end{array}$ & $0-10$ & $5 \%$ & $600 \mathrm{~Hz}$ & $600 \mathrm{~Hz}$ \\
\hline $\begin{array}{l}\text { Island contactor utility-side } \\
\text { voltage }\end{array}$ & $\begin{array}{l}\mathrm{AC} \\
\text { volts }\end{array}$ & $0-480$ & $1 \%$ & $600 \mathrm{~Hz}$ & $600 \mathrm{~Hz}$ \\
\hline $\begin{array}{l}\text { Island contactor island-side } \\
\text { voltage }\end{array}$ & $\begin{array}{l}\mathrm{AC} \\
\text { volts }\end{array}$ & $0-480$ & $1 \%$ & $600 \mathrm{~Hz}$ & $600 \mathrm{~Hz}$ \\
\hline DR output current (1/DR) & $\begin{array}{c}\text { AC } \\
\text { amps }\end{array}$ & $\begin{array}{l}0-\text { full } \\
\text { scale }\end{array}$ & $1 \%$ & $600 \mathrm{~Hz}$ & $600 \mathrm{~Hz}$ \\
\hline $\begin{array}{l}\text { DR output voltage, DR side of } \\
\text { DR contactor, if accessible }\end{array}$ & $\begin{array}{c}\mathrm{AC} \\
\text { volts }\end{array}$ & $0-480$ & $1 \%$ & $600 \mathrm{~Hz}$ & $600 \mathrm{~Hz}$ \\
\hline
\end{tabular}

\subsubsection{Control Requirements}

The test is to rely on the autonomous anti-islanding schemes embedded in DR devices. There are no special control system requirements for this test.

\subsubsection{Facility Requirements}

This test has no unique facility requirements other than the kilovolt-ampere rating and ampacity need to be consistent with the ratings of the DR. The ability to form an island and provide variable load and volt-amperes reactive is also a requirement for this test.

\subsubsection{DR Requirements}

Where possible, this test should be repeated with a variety of DR using a common islanding detection technique and with differing islanding detection techniques. Tests should be done with combinations of single- and three-phase DR.

Table 25. DR Anti-lslanding Test Using Rotating Loads DR Requirements

\begin{tabular}{lccl}
\hline \multicolumn{1}{c}{ Type } & Quantity & Size & \multicolumn{1}{c}{ Other } \\
\cline { 2 - 4 } & & & \\
Inverter, any prime mover & $\geq 3$ & $2-50 \mathrm{~kW}$ & $\begin{array}{l}\text { Should have advanced anti-islanding } \\
\text { function }\end{array}$ \\
Synchronous generator & $\geq 1$ & $50-100 \mathrm{~kW}$ & Advanced anti-islanding is desirable \\
Induction generator & $\geq 1$ & $50-100 \mathrm{~kW}$ & Advanced anti-islanding is desirable \\
\hline
\end{tabular}

\subsubsection{Other Requirements}

This testing will require a variety of single- and three-phase motors and variable inertias that can be tied to the motor load. 


\subsubsection{Modeling Requirements}

Dynamic models of the various anti-islanding schemes will be developed. This test would provide a validation case for these models, but modeling is not required.

\subsubsection{DR Count Test}

This is one of a series of tests dealing with the validity of anti-islanding techniques when multiple DR are in the island.

Active anti-islanding schemes are tested for efficacy by the UL 1741/IEEE 929 islanding test. That test, shown in the basic anti-islanding test, evaluates a single DR in a highly resonant, passive RLC circuit. The procedure detailed here expands on the type test by evaluating the incremental addition of DR units into the island circuit and determining the effect of additional units on detection time.

\subsubsection{Governing IEEE 1547, CA Rule 21, and Other Document Sections}

IEEE 1547: \$4.4.1, 5.1.8, Annex A.5

CA Rule 21: $\quad$ \$D.1.c, D.1.i, D.3.d.1, J.3.d

UL 1741: $\quad \S 46.3$

\subsubsection{Test Objectives}

The objective of this test is to determine the effect of incremental additions of DR to the antiislanding test circuit.

\subsubsection{Key Testing Parameters}

The key testing parameters are the same as for the basic anti-islanding test.

\subsubsection{Expected Results}

Verify whether the incremental addition of DR affects trip times.

\subsubsection{Test Procedure}

Use the test setup shown in Figure16.

1. Perform the basic anti-islanding test on each of three or more samples of a given DR to determine the individual unit trip time.

2. Perform the basic anti-islanding test with the two units exhibiting the longest trip times.

3. Repeat the basic anti-islanding test, each time adding another DR trip time until all available units have been tested in aggregate. 


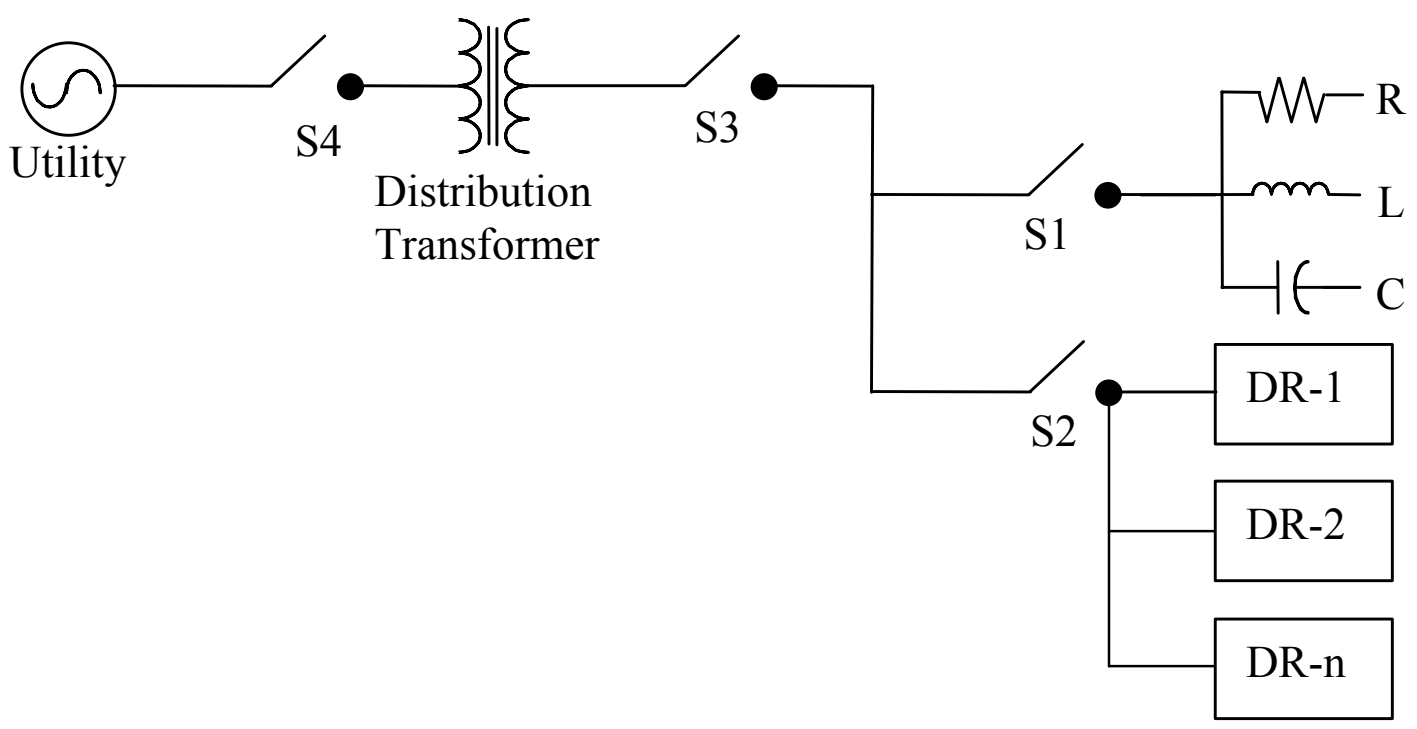

Figure 16. Test configuration for DR count test

\subsubsection{Data Acquisition Requirements}

Data acquisition requirements are the same as those for the basic anti-islanding test but with individual measurements for each DR as appropriate.

\subsubsection{Control Requirements}

Three are no special requirements.

\subsubsection{Facility Requirements}

There are no special requirements.

\subsubsection{DR Requirements}

The test should be performed with DR units that have an active anti-islanding scheme only; different methods are acceptable, but all should be active.

When possible, this test should be repeated with a variety of DR using a common islanding detection technique and with DR using different islanding detection techniques. Tests should be done with combinations of single- and three-phase DR.

Table 26. DR Count Test DR Requirements

\begin{tabular}{lccc}
\hline \multicolumn{1}{c}{ Type } & Quantity & Size & Other \\
\cline { 2 - 4 } & & & \\
Inverter, any prime mover & $\geq 3$ & Any & Must use active anti-islanding \\
Synchronous generator & $\geq 3$ & Any & Must use active anti-islanding \\
Induction generator & $\geq 3$ & Any & Must use active anti-islanding \\
\end{tabular}

4.2.5.10 Other Requirements

No other requirements apply. 


\subsubsection{Modeling Requirements}

No modeling requirements apply.

\subsubsection{High Penetration DR Harmonic Content and Nuisance Tripping Because of Active Anti-Islanding Schemes}

This is one of a series of tests dealing with the validity and performance of anti-islanding techniques when multiple DR are in an Area EPS.

Active anti-islanding schemes rely on methods of perturbing the current waveform in one manner or another. Causing a shift in frequency or phase angle is one approach to determining if an island has been formed. Perturbing the current magnitude or injecting a test signal to determine Area EPS line impedance is another. It has been suggested that, when implemented in larger numbers, some of these methods may adversely affect power quality or may be incompatible with one another, causing missed detections or false detections (nuisance trips).

\subsubsection{Governing IEEE 1547, CA Rule 21, and Other Document Sections}

IEEE 1547: $\quad$ \$4.2.1 Voltage Disturbances

$\$ 4.4 .1$ Unintentional Islanding

$\S 4.4 .3$ Harmonics

$\S 5.1 .8$ Unintentional Islanding

Annex A.5 Interconnection Test to Verify Non-Islanding

CA Rule 21: $\quad \S D .1 . c$ No Unintentional Islanding

$\S D .3 . d .1$ Unintended Islanding for Generating Facilities That Fail the

Export Screen

$\S$ J.3.a Type Tests and Requirements Appropriate for Utility Interactive

Inverter Systems

$\S$ J.3.d Anti-Islanding Test (UL 1741)

UL 1741:

$\S 45.4$ Harmonic Distortion

$\S 46.3$ Anti-Islanding Test

\subsubsection{Test Objectives}

The purpose of this test is to determine if multiple DR operating at a high level of penetration (15\% of peak load or higher) and using an active anti-islanding approach will cause unacceptable harmonic injection because of current perturbation(s). The test will also determine whether an aggregate number of units operating in parallel can cause single or multiple units to inadvertently trip off line by nuisance anti-islanding or other faults.

\subsubsection{Key Testing Parameters}

Key testing parameters include total harmonic distortion (THD) and the inadvertent trip of DR as functions of penetration level and number of DR. 


\subsubsection{Expected Results}

In the event that active islanding schemes inject negligible current perturbations into the utility, then the effect on the current harmonic distortion should be minimal. If all active antiislanding schemes under test are robust toward one another, then there should be no inadvertent anti-islanding faults.

\subsubsection{Test Procedure}

Test setup is shown in Figure 17.

1. The test should be performed with DR units that have an active anti-islanding scheme only; different methods are acceptable, but all should be active.

2. With the DR units operating at $10 \%, 20 \%, 30 \%, 40 \%$, and $50 \%$ of substation continuous rating, measure and record the current and voltage waveform. This data will be post-processed for frequency domain information and THD and TDD determination.

3. At the different levels of penetration, observe and record any inadvertent trip of the DR units specifically because of anti-islanding. Should there be any other type of inadvertent fault, this also should be recorded.

4. With the recorded current data, perform frequency domain analysis on the current and determine individual current harmonics and total THD. Compare with applicable standards for compliance.

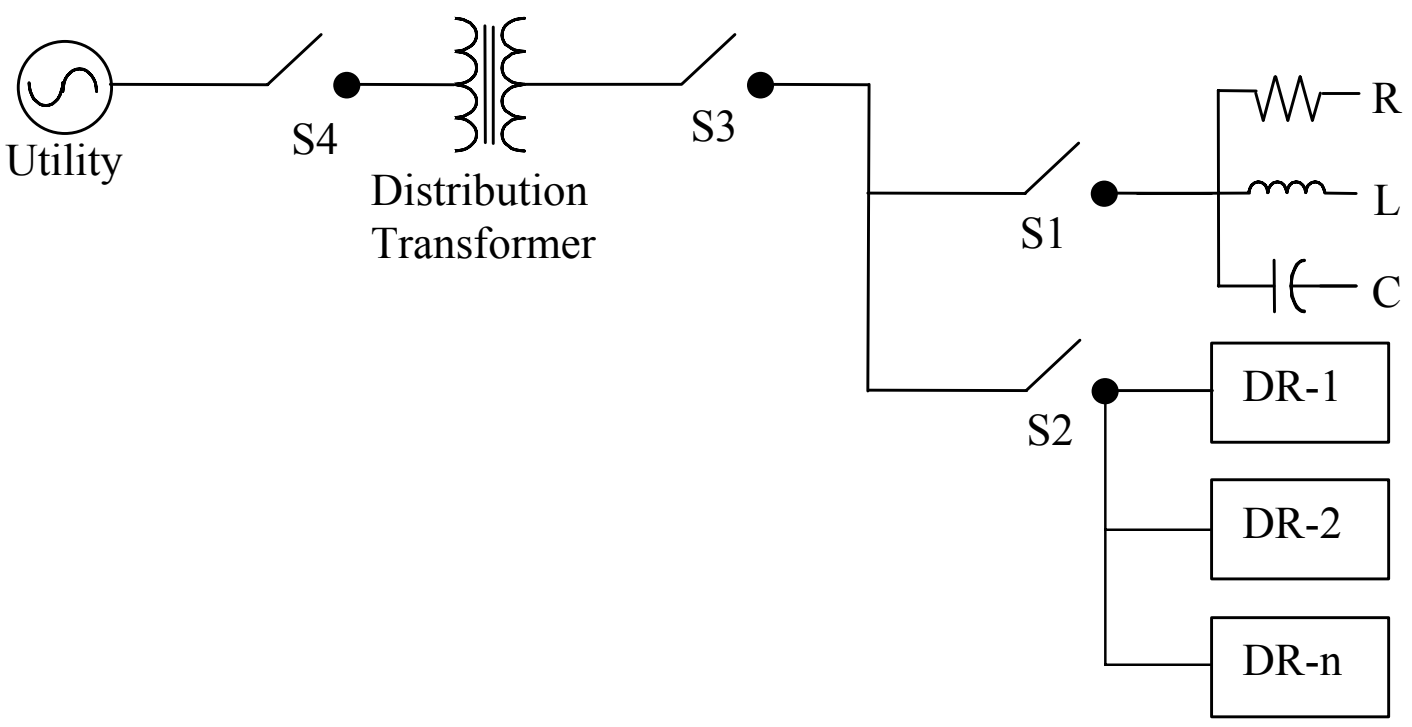

Figure 17. Test configuration for current distortion measurements 


\subsubsection{Data Acquisition Requirements}

Table 27. High Penetration DR Harmonic Content and Nuisance Tripping Because of Active Anti-Islanding Schemes Data Acquisition Requirements

\begin{tabular}{lccccc}
\hline \multicolumn{1}{c}{ Parameter } & Units & $\begin{array}{c}\text { Range } \\
\text { (Nom) }\end{array}$ & Accuracy & $\begin{array}{c}\text { Sampling } \\
\text { Rate }\end{array}$ & $\begin{array}{c}\text { Recording } \\
\text { Rate }\end{array}$ \\
\cline { 2 - 6 } & & & & & \\
PCC voltage measurement & AC volts & 480 & $\pm 1 \%$ & $600 \mathrm{~Hz}$ & $600 \mathrm{~Hz}$ \\
PCC current measurement & AC amps & TBD & $\pm 1 \%$ & $600 \mathrm{~Hz}$ & $600 \mathrm{~Hz}$ \\
$\begin{array}{l}\text { Multiple fault conditions from } \\
\text { DR }\end{array}$ & DC volts & $0-10$ & $<100 \mathrm{~ms}$ & $600 \mathrm{~Hz}$ & $600 \mathrm{~Hz}$ \\
& & & & & \\
\hline
\end{tabular}

\subsubsection{Control Requirements}

This, again, is a test of autonomous DR control and anti-islanding control systems. No "system" level control is required.

\subsubsection{Facility Requirements}

The facility must have the ability to house and operate a relatively large amount of DR. For example, if the local substation is rated at $5 \mathrm{MVA}$, then DR of up to $2.5 \mathrm{MVA}$ ( $50 \%$ of rating) will be required to run this test.

\subsubsection{DR Requirements}

When possible, this test should be repeated with a variety of DR using a common islanding detection technique and with DR using differing islanding detection techniques. Tests should be done with combinations of single- and three-phase DR.

Table 28. High Penetration DR Harmonic Content and Nuisance Tripping Because of Active Anti-Islanding Schemes DR Requirements

\begin{tabular}{|c|c|c|c|}
\hline Type & Quantity & Size & Other \\
\hline Inverter, any prime mover & Multiple $^{(1)}$ & & $\begin{array}{l}\text { Aggregate capacity of up to } 50 \% \text { of } \\
\text { substation continuous rating. Should } \\
\text { have advanced anti-islanding } \\
\text { function. }\end{array}$ \\
\hline $\begin{array}{l}\text { Synchronous generator } \\
\text { Induction generator }\end{array}$ & & & \\
\hline
\end{tabular}

(1) There should be a minimum of 10 units totaling 2.5 MVA on a 5-MVA substation.

\subsubsection{Other Requirements}

There are no other requirements

\subsubsection{Modeling Requirements}

Dynamic models of the various anti-islanding schemes will be developed. This test would allow for a validation case for these models, but modeling is not required. 


\title{
4.2.7 Anti-Islanding Testing Using Nonlinear Loads
}

\author{
4.2.7.1 Governing IEEE 1547, CA Rule 21, and Other Document Sections \\ IEEE 1547: \$4.2.1 Voltage Disturbances \\ $\S 4.4 .1$ Unintentional Islanding \\ \$5.1.8 Unintentional Islanding \\ Annex A.5 Interconnection Test to Verify Non-Islanding \\ CA Rule 21: $\quad \S D .1 . c$ No Unintentional Islanding \\ $\S D .3 . d .1$ Unintended Islanding for Generating Facilities That Fail the \\ Export Screen \\ $\S$ J.3.d Anti-Islanding Test (UL 1741) \\ UL 1741: \$46.3 Anti-Islanding Tests
}

\subsubsection{Test Objectives}

The objective of this test is to determine the effectiveness of commercial DR anti-islanding schemes in the presence of nonlinear loads on an island. Type testing prescribed by various standards uses linear inductive and capacitive components to control VARs and a resistor to form the real power component of the load. Because these are linear elements, they draw 60$\mathrm{Hz}$ fundamental component currents only when connected to an ideal utility. Likewise, a current source DR, such as an inverter-based system, supplies only $60 \mathrm{~Hz}$ fundamental component current. In this proposed test, the real component of power in the island will be determined by a diode rectifier and resistive DC load, which will create substantial current distortion containing 5th, 7th, 11th, 13th, $6 \mathrm{n} \pm 1$ (for all $\mathrm{n}=1,2,3, \ldots$ etc.) harmonics in the three-phase case and 3rd, 5 th, 7 th, $2 \mathrm{n} \pm 1$ (for all $\mathrm{n}=1,2,3, \ldots$ etc.) in the single-phase case. The effect of these current harmonics on trip time will be recorded and compared with requirements from the various standards.

\subsubsection{Key Testing Parameters}

Key testing parameters are tuned circuit volt-amperes reactive and real load (rectifier and DC load).

\subsubsection{Expected Results}

Ideal results would show that commercial DR anti-islanding schemes are sufficiently robust to deal with harmonic currents in the island. The trip times of the various DR (individually and collectively) remain within the acceptable times as stated in the standards, regardless of the harmonic current content of the islanded load.

\subsubsection{Test Procedure}

The procedure for this test is the procedure defined in the basic anti-islanding test with one modification: the linear resistor is replaced with a diode bridge and DC resistive load, as shown in Figure 18. The test is to be completed on single-phase and three-phase systems. 


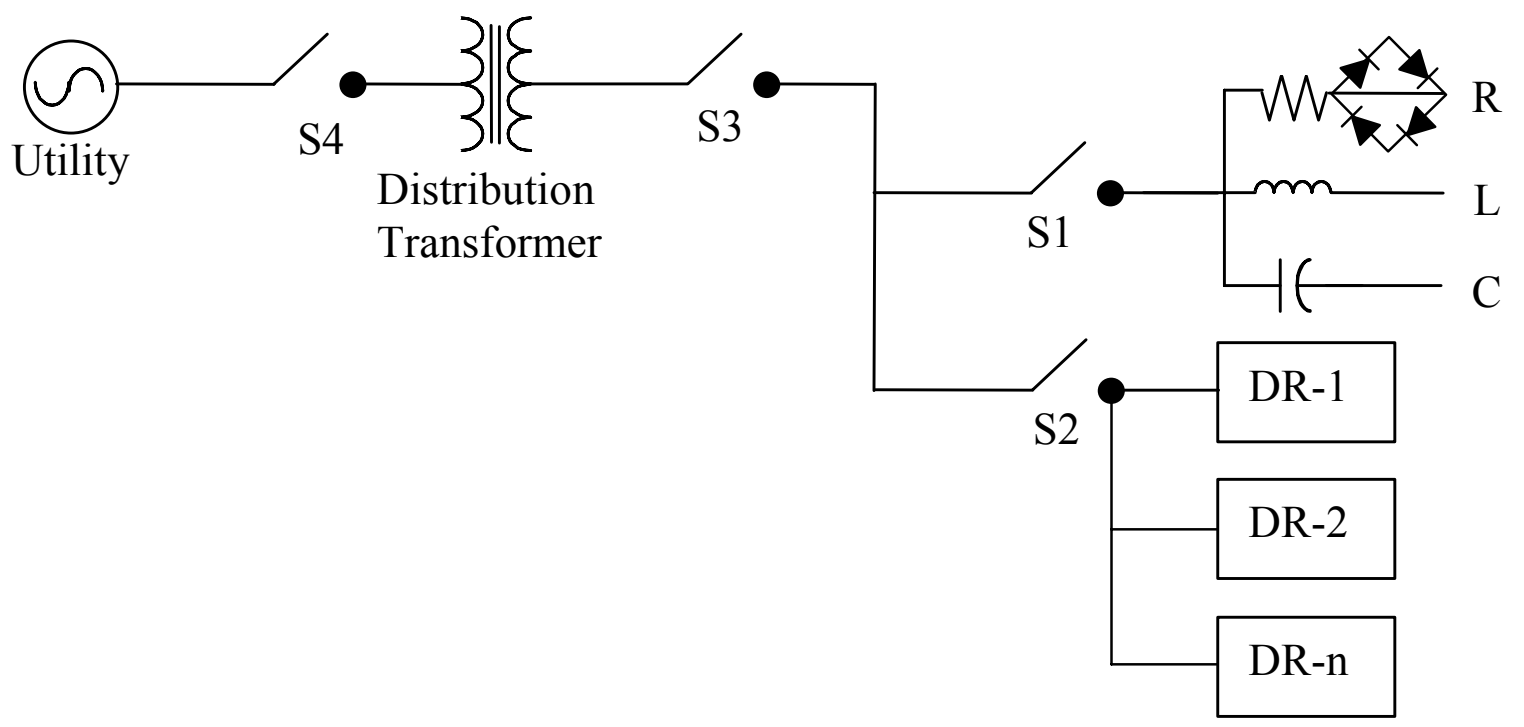

Figure 18. Test configuration of nonlinear anti-islanding tests

\subsubsection{Data Acquisition Requirements}

Table 29. Anti-Islanding Testing Using Nonlinear Loads Data Acquisition Requirements

\begin{tabular}{|c|c|c|c|c|c|}
\hline Parameter & Units & $\begin{array}{l}\text { Range } \\
\text { (Nom.) }\end{array}$ & Accuracy & $\begin{array}{c}\text { Sampling } \\
\text { Rate }\end{array}$ & $\begin{array}{c}\text { Recording } \\
\text { Rate }\end{array}$ \\
\hline $\begin{array}{l}\text { Island contactor status (i.e., } \\
\text { aux. contact closure) }\end{array}$ & $\begin{array}{l}\mathrm{DC} \\
\text { volts }\end{array}$ & $0-10$ & $5 \%$ & $600 \mathrm{~Hz}$ & $600 \mathrm{~Hz}$ \\
\hline $\begin{array}{l}\text { Island contactor utility-side } \\
\text { voltage }\end{array}$ & $\begin{array}{c}\mathrm{AC} \\
\text { volts }\end{array}$ & $0-480$ & $1 \%$ & $600 \mathrm{~Hz}$ & $600 \mathrm{~Hz}$ \\
\hline $\begin{array}{l}\text { Island contactor island-side } \\
\text { voltage }\end{array}$ & $\begin{array}{c}\mathrm{AC} \\
\text { volts }\end{array}$ & $0-480$ & $1 \%$ & $600 \mathrm{~Hz}$ & $600 \mathrm{~Hz}$ \\
\hline DR output current (1 per DR) & $\begin{array}{l}\text { AC } \\
\text { amps }\end{array}$ & $\begin{array}{l}0 \text {-full } \\
\text { scale }\end{array}$ & $1 \%$ & $600 \mathrm{~Hz}$ & $600 \mathrm{~Hz}$ \\
\hline $\begin{array}{l}\text { DR output voltage, DR side of } \\
\text { DR contactor, if accessible }\end{array}$ & $\begin{array}{l}\mathrm{AC} \\
\text { volts }\end{array}$ & $0-480$ & $1 \%$ & $600 \mathrm{~Hz}$ & $600 \mathrm{~Hz}$ \\
\hline
\end{tabular}

\subsubsection{Control Requirements}

Because of autonomous operation of the DR, no centralized control is required.

\subsubsection{Facility Requirements}

The facility must be capable of housing and operating the DR selected for the test. The test will be performed at low voltage ( $480 \mathrm{~V}$ or less). 


\subsubsection{DR Requirements}

Where possible, this test should be repeated with a variety of DR using a common islanding detection technique and with DR using different islanding detection techniques. Tests should be done with combinations of single- and three-phase DR.

Table 30. Anti-Islanding Testing Using Nonlinear Loads DR Requirements

\begin{tabular}{lccl}
\hline \multicolumn{1}{c}{ Type } & Quantity & Size & \multicolumn{1}{c}{ Other } \\
\cline { 2 - 4 } Inverter, any prime mover & $5-10$ & $2-50 \mathrm{~kW}$ & $\begin{array}{l}\text { Should have advanced anti-islanding } \\
\text { function }\end{array}$ \\
Synchronous generator & $\geq 1$ & $100 \mathrm{~kW}$ & Anti-islanding function \\
Induction generator & $\geq 1$ & $100 \mathrm{~kW}$ & Anti-islanding function \\
\hline
\end{tabular}

\subsubsection{Other Requirements}

There are no other requirements.

\subsubsection{Modeling Requirements}

Dynamic models of the various anti-islanding schemes will be developed. This test would allow for a validation case for these models, but modeling is not required.

\subsubsection{Anti-Islanding With Reduced Undervoltage and Underfrequency Trip Settings}

There are several circumstances in which loss of generation may exacerbate an existing problem. The undervoltage setting limits the ability of the DR to ride through voltage sags caused by, for example, a fault on an adjacent feeder. One reason for the current setting is that it is a precaution against islanding: the narrower the operating window, the less likely that islanding will occur. Although there may be other reasons for these settings (e.g., to enhance fault detection) determining the effect of these settings on the DR's ability to detect an island may help determine new or alternative set points.

Under this test, the undervoltage and underfrequency settings will be adjusted down in 5-V and $0.1-\mathrm{Hz}$ increments, and the effect on the cease-to-energize time will be evaluated.

\subsubsection{Governing IEEE 1547, CA Rule 21, and Other Document Sections}

IEEE 1547: $\$ 4.2 .1,4.4 .1,5.1 .8$, Annex A.5

CA Rule 21: $\quad \S D .1 . i$, D.3.d.1, J.3.d

UL 1741: $\quad \$ 46.3$

IEEE 929: $\quad$ Annex A

\subsubsection{Test Objectives}

The objective of this test is to characterize device performance by performing the antiislanding test with sequentially reduced settings for undervoltage and underfrequency settings. 


\subsubsection{Key Testing Parameters}

The key test parameter is the time required for the DR on the island to trip. This definition is related to current output from the DR because there may be a significant delay between the reduction of current below a threshold level and the mechanical opening of a disconnecting device.

\subsubsection{Expected Results}

This test will quantify the time required for the DR to trip once an islanding condition exists.

\subsubsection{Test Procedure}

The test procedure is the same as for the basic anti-islanding test, with single and multiple DR and additional variables of sequentially reduced undervoltage and underfrequency settings in steps of $5 \mathrm{~V}$ and $0.1 \mathrm{~Hz}$, respectively.

\subsubsection{Data Acquisition Requirements}

Table 31. Anti-Islanding With Reduced Undervoltage and Underfrequency Trip Settings Data Acquisition Requirements

\begin{tabular}{|c|c|c|c|c|c|}
\hline Parameter & Units & $\begin{array}{l}\text { Range } \\
\text { (Nom.) }\end{array}$ & Accuracy & $\begin{array}{l}\text { Sampling } \\
\text { Rate }\end{array}$ & $\begin{array}{l}\text { Recording } \\
\text { Rate }\end{array}$ \\
\hline $\begin{array}{l}\text { Island contactor status (i.e., } \\
\text { aux. contact closure) }\end{array}$ & $\begin{array}{l}\mathrm{DC} \\
\text { volts }\end{array}$ & $0-10$ & $5 \%$ & $600 \mathrm{~Hz}$ & $600 \mathrm{~Hz}$ \\
\hline $\begin{array}{l}\text { Island contactor utility-side } \\
\text { voltage }\end{array}$ & $\begin{array}{c}\mathrm{AC} \\
\text { volts }\end{array}$ & $0-480$ & $1 \%$ & $600 \mathrm{~Hz}$ & $600 \mathrm{~Hz}$ \\
\hline $\begin{array}{l}\text { Island contactor island-side } \\
\text { voltage }\end{array}$ & $\begin{array}{c}\mathrm{AC} \\
\text { volts }\end{array}$ & $0-480$ & $1 \%$ & $600 \mathrm{~Hz}$ & $600 \mathrm{~Hz}$ \\
\hline DR output current (1/DR) & $\begin{array}{c}\text { AC } \\
\text { amps }\end{array}$ & $\begin{array}{l}0-\text { full } \\
\text { scale }\end{array}$ & $1 \%$ & $600 \mathrm{~Hz}$ & $600 \mathrm{~Hz}$ \\
\hline $\begin{array}{l}\text { DR output voltage, DR side of } \\
\text { DR contactor, if accessible }\end{array}$ & $\begin{array}{c}\mathrm{AC} \\
\text { volts }\end{array}$ & $0-480$ & $1 \%$ & $600 \mathrm{~Hz}$ & $600 \mathrm{~Hz}$ \\
\hline
\end{tabular}

\subsubsection{Control Requirements}

The basic test is supposed to evaluate autonomous operation of the different DR sources with no control interconnection between them. There are no special control system requirements; however, variations of this basic procedure may include some control strategies or equipment.

\subsubsection{Facility Requirements}

The test facility will need adjustable resistive, inductive, and capacitive loads with sufficient capacity and resolution to meet the impedance and step-size requirements of a particular test.

\subsubsection{DR Requirements}

This basic test may be performed on a single DR or on multiple units. Subsequent test procedures will have their own specific requirements. 


\subsubsection{Other Requirements}

There are no other requirements.

\subsubsection{Modeling Requirements}

There are no modeling requirements.

\subsection{Voltage Regulator Tests}

Tests in this section are intended to investigate the inherent voltage regulation capabilities of substation transformers, long distribution feeder lines, and automatic voltage regulating equipment used in conjunction with DR equipment. According to IEEE P1547, DR equipment cannot cause the prevailing voltage level of the Area EPS to frequently go outside of the limits of ANSI C84.1, Range A. These tests will look at all the elements affecting voltage regulation and the interaction of these elements. The tests will evaluate voltage regulators designed for unidirectional operation, which are believed to be in widespread use and represent legacy systems, and bi-directional power flow regulators, which are less widely used but are expected to become more popular with the promulgation of DR.

\subsubsection{Feeder and Automatic Voltage Regulating Device Characterization}

This test deals with the characterization of components affecting voltage regulation in a typical radial distribution system. The first test will also examine the simple addition of DR at the end of the feeder and its effect on the voltage regulation along the feeder.

\subsubsection{Governing IEEE 1547, CA Rule 21, and Other Document Sections \\ IEEE 1547: \$4.1.1 Voltage Regulation \\ $\S 4.2 .1$ Voltage Disturbances}

CA Rule 21: $\S$ D.2.a.1, D.2.a.2, D.2.a.3 Normal Voltage Operating Range

UL 1741: $\$ 42$ Maximum-Voltage Measurements

$\$ 46.2$ Utility Voltage and Frequency Variation Test

$\S 55$ Overvoltage Test

\subsubsection{Test Objectives}

The objective of this test is to characterize the fundamental voltage regulation elements in a long radial feeder system. The criteria by which the test results will be measured are contained in the ANSI C84.1 standard as identified in IEEE 1547. Voltage will be measured at different points along the feeder to determine compliance with this standard under varying load conditions. This voltage will then characterize the performance of the feeder. Two additional tests will then be performed to characterize the voltage regulator and the voltage regulator with DR added at a single point at the end of the feeder.

\subsubsection{Key Testing Parameters}

Key testing parameters in the characterization test are the amount of load on the feeder and voltage measurements at predetermined points along the feeder. 


\subsubsection{Expected Results}

The expected result is that the voltage at all points will drop with increasing load but still should remain within the range identified by ANSI C84.1. Furthermore, it is expected that the addition of DR at the end of the feeder will cause the voltage regulator to operate over a smaller range than in the case of the long feeder without voltage regulation. The DR may eliminate the need for voltage regulation equipment altogether.

\subsubsection{Test Procedure}

1. Using a long distribution feeder (30 mi), load the feeder up to the full rating of the substation in increments of $25 \%$ at unity power factor. Obtain the voltage at the substation and at 10-, 20-, and 30-mi points along the feeder. There should be no voltage regulation equipment active during this first test. See Figure 19(a).

2. Repeat the test in Step 1 but with the addition of DR at the end of the feeder. The DR generation should be adjusted so that it is equal to the load. See Figure 19(b).

3. Insert a voltage regulator at the 20-mi point. Repeat the test described in Step 1. Record the data as described in Step 1, with two measurements made at the voltage regulator. See Figure 19(c).

4. With the voltage regulator inserted at the 20-mi point, repeat the test described in Step 2. Again, the DR should be adjusted to equal the load. See Figure 19(d).

5. Repeat the tests described in steps 1 through 4 with power factors of 0.9 and 0.8 .

\subsubsection{Data Acquisition Requirements}

Table 32. Feeder and Automatic Voltage Regulating Device Characterization Data Acquisition Requirements

\begin{tabular}{lccccc}
\hline \multicolumn{1}{c}{ Parameter } & Units & $\begin{array}{c}\text { Range } \\
\text { (Nom) }\end{array}$ & Accuracy & $\begin{array}{c}\text { Sampling } \\
\text { Rate }\end{array}$ & $\begin{array}{c}\text { Recording } \\
\text { Rate }\end{array}$ \\
\cline { 2 - 5 } & & & & & \\
Voltage (12 required) & Kilovolts & $0-21$ & $\pm 0.5 \%$ & $600 \mathrm{~Hz}$ & $600 \mathrm{~Hz}$ \\
$\begin{array}{l}\text { Current (9 required) } \\
\text { Grid-interconnected }\end{array}$ & Amperes & $0-300$ & $\pm 0.5 \%$ & $600 \mathrm{~Hz}$ & $600 \mathrm{~Hz}$ \\
$\begin{array}{l}\text { synchronous generator } \\
\text { MG set (watts, volt- }\end{array}$ & & & & & \\
$\begin{array}{l}\text { amperes reactive, volts, } \\
\text { amps) }\end{array}$ & & & & & \\
& & & & & \\
\hline
\end{tabular}




\section{Substation}

Transformer

$3 \|\} \overbrace{\text { Vsub }}^{3}$

\section{Substation}

Transformer

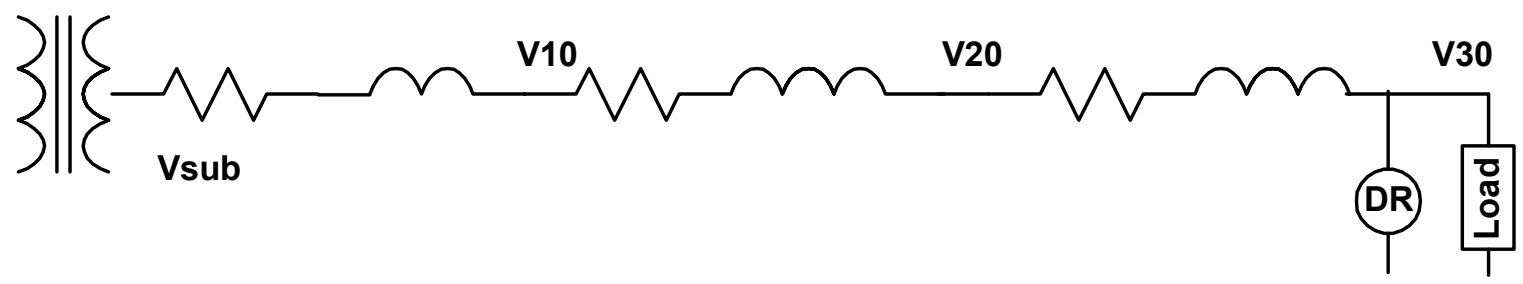

\section{Substation}

\section{Transformer}

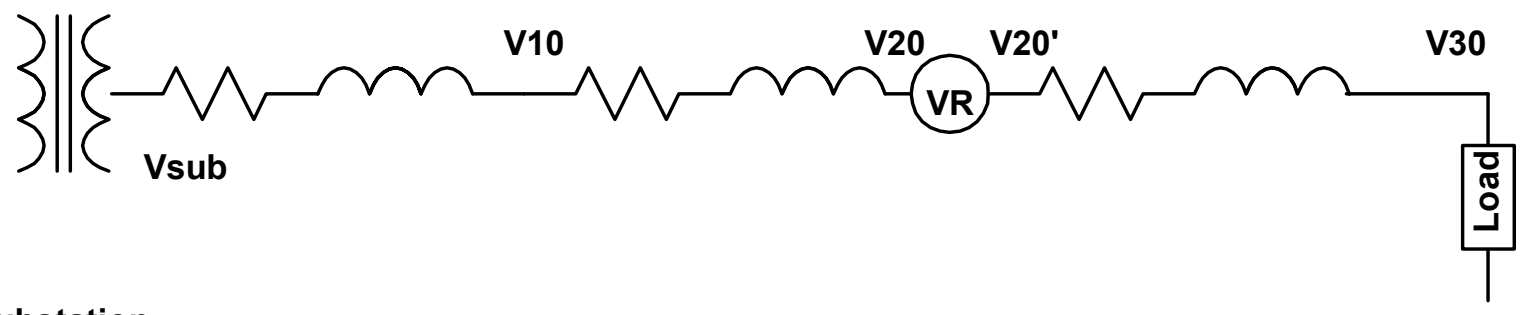

\section{Substation}

Transformer

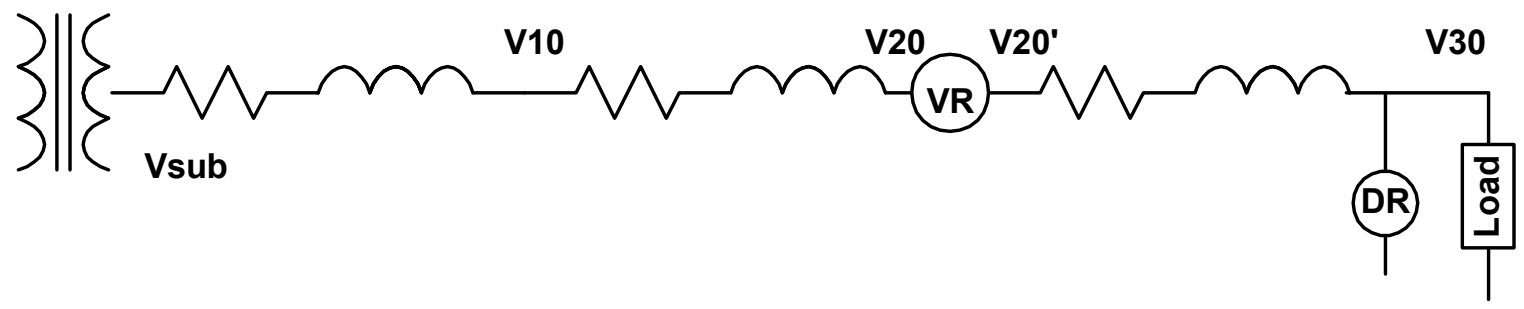

Figure 19. Test configuration

\subsubsection{Control Requirements}

This test has no special control requirements.

\subsubsection{Facility Requirements}

The facility will require a long feeder system operating at distribution voltage and capable of being loaded to substation megavolt-ampere rating. The abilities to measure voltage at different points along the feeder and to install voltage-regulating equipment at the 20 -mi point are also requirements. 


\subsubsection{DR Requirements}

Table 33. Feeder and Automatic Voltage Regulating Device Characterization DR Requirements

\begin{tabular}{cccc}
\hline Type & Quantity & Size & Other \\
\cline { 3 - 4 } Grid-connected synchronous generator & 1 & $1 \mathrm{MW}$ & IEEE 1547-compliant \\
& & & \\
\hline
\end{tabular}

\subsubsection{Other Requirements}

There are no other requirements.

\subsubsection{Modeling Requirements}

This problem lends itself to modeling using standard voltage prediction load flow software. This test could be used to verify voltage regulation modeling programs. The modeling can be done in the frequency or time domain.

\subsubsection{Performance of Voltage-Regulating Device With Reverse Power Flow} It is expected that a significant amount of DR will be added to utility distribution systems over the next 10 to 15 years. One concern is reverse power flow through protection and voltage-regulating equipment that was not originally designed for this type of operation. In this test, DR that export to the grid and load are added at points in the distribution system to create reverse power flow through the voltage-regulating element. The criterion for success is the ability of the voltage regulator to keep all points along the feeder within ANSI C84.1 voltage tolerances. In addition, the test will determine if there is more or less active operation of the voltage regulator, which could indicate reduced or extended product life. Finally, circumstances and conditions that lead to regulator misoperation will be determined.

\subsubsection{Governing IEEE 1547, CA Rule 21, and Other Document Sections}

IEEE 1547: $\$ 4.1 .1$ Voltage Regulation

$$
\S 4.2 .1 \text { Voltage Disturbances }
$$

CA Rule 21: §D.2.a.1, D.2.a.2, D.2.a.3 Normal Voltage Operating Range

UL 1741: $\quad \$ 42$ Maximum-Voltage Measurements

$\S 46.2$ Utility Voltage and Frequency Variation Test

$\S 55$ Overvoltage Test

\subsubsection{Test Objectives}

The purpose of this test is to determine if legacy distribution systems with unidirectional voltage regulators will maintain voltage regulation within ANSI C84.1 when dealing with reverse power flow. The distribution system will be intentionally set up to cause varying levels of reverse power through the voltage-regulation device. Voltage measurements will be made along the feeder to determine compliance with ANSI C84.1 and help define the conditions that cause noncompliance for a specific regulator. 


\subsubsection{Key Testing Parameters}

The key testing parameters are reverse power flow through the unidirectional voltageregulating element and voltage levels along the distribution feeder.

\subsubsection{Expected Results}

It is expected that some (but not all) voltage regulators will drive the load-side voltage in the "wrong" direction (i.e., counter to normal regulation because of the unidirectional design of the device). It is important to understand how far in the wrong direction the voltage-regulating element will travel and whether the necessary standards are maintained.

\subsubsection{Test Procedure}

1) With the distribution system, DR, load, and unidirectional power voltage regulator wired as shown in Figure 20, run the load at 25\%,50\%, 75\%, and 100\% of rated load. Allow the substation to provide this load, and record voltages at the substation and the 10- and 20-mi points.

2) Repeat Step 1, but this time with the DR brought up to the load level so that the substation is not supplying any load. Again, record the voltages at the substation and the 10- and 20-mi points.

3) Repeat steps 1 and 2 with bi-directional power flow regulators.

\section{Substation}

Transformer

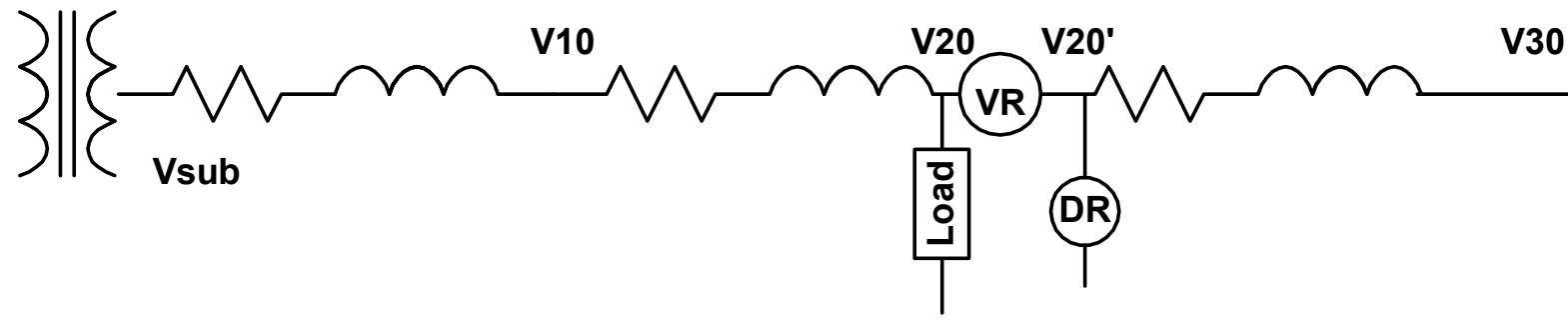

Figure 20. Reverse power flow voltage-regulating test 


\subsubsection{Data Acquisition Requirements}

Table 34. Performance of Voltage-Regulating Device With Reverse Power Flow Data Acquisition Requirements

\begin{tabular}{lccccc}
\hline \multicolumn{1}{c}{ Parameter } & Units & $\begin{array}{c}\text { Range } \\
\text { (Nom.) }\end{array}$ & Accuracy & $\begin{array}{c}\text { Sampling } \\
\text { Rate }\end{array}$ & $\begin{array}{c}\text { Recording } \\
\text { Rate }\end{array}$ \\
\cline { 2 - 6 } & & & & & \\
Voltage (12 required) & Kilovolts & $0-21$ & $+/-0.5 \%$ & $600 \mathrm{~Hz}$ & $600 \mathrm{~Hz}$ \\
$\begin{array}{l}\text { Current (9 required) } \\
\begin{array}{l}\text { Grid-interconnected } \\
\text { synchronous generator MG }\end{array}\end{array}$ & Amps & $0-300$ & $+/-0.5 \%$ & $600 \mathrm{~Hz}$ & $600 \mathrm{~Hz}$ \\
$\begin{array}{l}\text { set (watts, volt-amperes } \\
\text { reactive, volts, amps) }\end{array}$ & & & & & \\
& & & & & \\
\hline
\end{tabular}

\subsubsection{Control Requirements}

This test requires the use of an IEEE P1547-compliant control on the DR. No additional controls are required.

\subsubsection{Facility Requirements}

The test requires a facility with a long feeder system operating at distribution voltage and capable of being loaded to substation megavolt-ampere rating. The abilities to measure voltage at different points along the feeder and to install voltage-regulating equipment at the 20-mi point are also requirements.

\subsubsection{DR Requirements}

Table 35. Performance of Voltage-Regulating Device With Reverse Power Flow DR Requirements

\begin{tabular}{cccc}
\hline Type & Quantity & Size & Other \\
\cline { 2 - 4 } Grid-connected synchronous generator & 1 & $1 \mathrm{MW}$ & IEEE 1547-compliant \\
\hline
\end{tabular}

\subsubsection{Other Requirements}

There are no other requirements.

\subsubsection{Modeling Requirements}

No modeling is required for this test. However, it would be useful to use the test to develop a model of the voltage regulator and its operation under reverse power flow. 


\subsubsection{Multiple DR Stability Test With Voltage-Regulating DR Devices}

One concern about the installation of multiple DR on a distribution feeder is whether voltageregulated DR will create voltage stability problems by interacting with one another and result in a deterioration of the feeder voltage. The tests will answer questions about DR interaction and the effects of distribution feeder impedance on interaction. It may be that dispersed DR will cause little, if any, problem when connected near the substation, but they could cause a significant problem when they are located far from the substation because of the introduction of feeder impedance.

\subsection{Reclosing Tests}

Tests in this section are intended to address issues related to reclosing devices and procedures and the effects that DR may have on them. Of particular concern for reclosing is the speed of the DR in detecting loss of utility and disconnecting from the grid compared with the speed of the reclose activity. Another concern is the effect a recloser will have on the operating DR and loads if, under extreme conditions, the DR do not disconnect.

\subsubsection{Islanding Detection Timing}

DR coordination with reclosing activities is, in part, related to the speed with which the antiislanding function is able to detect the island and cease energizing the Area EPS. The antiislanding test in UL 1741 determines if the detection method is able to detect the island and cease energizing within $2 \mathrm{~s}$. It is not intended to provide the end-user with detection speed. This test could be done as an independent procedure or as part of other islanding-related test procedures.

\subsubsection{Governing IEEE 1547, CA Rule 21, and Other Document Sections IEEE 1547: \$4.4 Islanding $\$ 5.1 .8$ Unintentional Islanding \\ CA Rule 21: $\quad \$ 4.1 .3$ \\ $\S$ B3.4 Anti-Islanding Test \\ UL 1741: $\quad \S 46.3$ Anti-Islanding Test}

\subsubsection{Test Objectives}

The objective of this test is to determine the time the DR needs to detect an island condition and cease energizing the Area EPS to provide a basis for coordinating with Area EPS reclosing cycles.

\subsubsection{Key Testing Parameters}

The key testing parameters are:

- Islanded Area EPS circuit "Q" factor

- Types of other DR on the circuit

- Type, quantity, and characteristics of loads, especially nonlinear, high-inertia, etc.

- DR current into Area EPS

- Time from opening of islanding switch to DR ceasing to energize Area EPS. 


\subsubsection{Expected Results}

The results will be DR islanding detection times.

\subsubsection{Test Procedure}

Perform the basic anti-islanding test procedure. Record the trip time for five or more repetitions of the prescribed test. The maximum trip time recorded is the time used for coordination with recloser devices.

\subsubsection{Data Acquisition Requirements}

Table 36. Islanding Detection Timing Data Acquisition Requirements

\begin{tabular}{lccccc}
\hline \multirow{1}{*}{ Parameter } & Units & $\begin{array}{c}\text { Range } \\
\text { (Nom.) }\end{array}$ & Accuracy & $\begin{array}{c}\text { Sampling } \\
\text { Rate }\end{array}$ & $\begin{array}{c}\text { Recording } \\
\text { Rate }\end{array}$ \\
\cline { 2 - 6 } & & & & & \\
DR voltage (three-phase) & Volts & $0-480$ & \pm 1 & $6 \mathrm{kHz}$ & $6 \mathrm{kHz}$ \\
$\begin{array}{l}\text { Utility voltage (three-phase) } \\
\text { "Island" disconnect switch } \\
\text { status }\end{array}$ & Volts & $0-480$ & \pm 1 & $6 \mathrm{kHz}$ & $6 \mathrm{kHz}$ \\
Time & -- & Open/Closed & -- & $6 \mathrm{kHz}$ & $6 \mathrm{kHz}$ \\
& Seconds & $0-10$ & $0.1 \mathrm{~ms}$ & $6 \mathrm{kHz}$ & $6 \mathrm{kHz}$ \\
\hline
\end{tabular}

\subsubsection{Control Requirements}

No hierarchical control is required because of autonomous operation of each DR.

\subsubsection{Facility Requirements}

See UL 1741 or other prescribed test procedure.

\subsubsection{DR Requirements}

Typically, there are no special requirements, but this will depend on the specific test performed.

Table 37. Islanding Detection Timing DR Requirements

\begin{tabular}{lcccl}
\hline \multicolumn{1}{c}{ Type } & Quantity & Size & \multicolumn{1}{c}{ Comments } \\
\cline { 2 - 4 } $\begin{array}{l}\text { Inverter-based DR } \\
\text { Diesel genset with generator control } \\
\text { including anti-islanding function }\end{array}$ & 2 & $50 \mathrm{~kW}-$ & $\begin{array}{l}\text { Must have anti-islanding } \\
\text { detection algorithm }\end{array}$ \\
& & $100 \mathrm{~kW}$ & $\begin{array}{l}\text { Must have synchronous } \\
\text { generator anti-islanding } \\
\text { protection }\end{array}$ \\
\hline
\end{tabular}

4.4.1.10 Other Requirements

There are no other requirements. 


\subsubsection{Modeling Requirements}

It is possible that modeling may be used to define specific islanding conditions that might be relevant during a reclosing operation.

\subsubsection{Reclose Under Load}

This test evaluates the effect of a reclose operation that occurs before the DR is able to detect the loss of utility and trip off. This would be an abnormal situation that would occur under extreme conditions in which the load and generation were well matched and stable such that the voltage and frequency did not rapidly collapse. Results from this testing may provide better guidance on the need for recloser coordination and reclose blocking.

\subsubsection{Governing IEEE 1547, CA Rule 21, and Other Document Sections \\ IEEE 1547: $\$ 4.4$ Islanding $\$ 5.1 .8$ Unintentional Islanding \\ CA Rule 21: $\$ 4.1 .3$ \\ UL 1741: $\quad \$ 46.3$ Anti-Islanding Test}

\subsubsection{Test Objectives}

The test objective is to evaluate the effect of reclose operations on an island segment in which DR continue to operate. NEMA MG- 1 tests motors to ensure they are not damaged by a momentary outage that leads to a synchronization error of $27^{\circ}$ when the utility returns.

\subsubsection{Key Testing Parameters}

The key testing parameters are:

- Islanded Area EPS circuit "Q" factor

- Types of other DR on the circuit

- Type, quantity, and characteristics of loads, especially nonlinear, high-inertia, etc.

- DR current into Area EPS

- Synchronization error between the Area EPS and the DR island (phase, voltage, frequency).

\subsubsection{Expected Results}

- Show the effect of reclose action with DR remaining online.

- Determine if the DR or loads are damaged.

- Quantify the synchronization error as a function of reclose timing.

\subsubsection{Test Procedure}

1. Set up the island segment with at least three DR devices.

2. Perform the basic anti-islanding test procedure with $\mathrm{Q}=2.5$. It will be useful to include rotating equipment as part of the load.

3. Record the trip time for five or more repetitions of that test. 
4. Note the minimum trip time.

5. Perform the islanding test, but close the utility disconnect at $90 \%$ of the minimum trip time recorded in Step 4. Repeat this test until five runs have been recorded with all DR remaining online.

6. Repeat steps 2 through 5 with $\mathrm{Q}=5$.

If the anti-islanding function can be temporarily defeated (e.g., if it is provided by a central control system), disable the anti-islanding function and perform the islanding tests with reclose times of 20 cycles, 60 cycles, and 120 cycles.

\subsubsection{Data Acquisition Requirements}

Standard islanding measurements should be used. Also, any mechanical or electrical damage to loads or DR should be noted.

\subsubsection{Control Requirements}

This test involves standard islanding control requirements.

\subsubsection{Facility Requirements}

This test involves standard islanding facility requirements.

\subsubsection{DR Requirements}

DR should be selected so that various types of synchronous, induction, and inverter-based machines are tested in various combinations. When possible, this test should be repeated with a variety of DR using a common islanding detection technique and, alternatively, with DR using different islanding detection techniques. Tests should be done with combinations of single- and three-phase DR.

\subsubsection{Other Requirements}

This test should be performed with a variety of reclosers, including single- and three-phase and electronic and hydraulic.

\subsubsection{Modeling Requirements}

There are no modeling requirements.

\subsection{Sectionalizing Devices Tests}

The tests in this section are designed to investigate issues related to sectionalizer operation and coordination with other devices, specifically reclosers, when DR exist on the feeder. Ideally, the sectionalizer should count a set number of reclosing operations before opening and locking out for sustained faults, but it should not operate (lock out) before the recloser has operated its specified number of times. Test results should provide insight into how the presence of DG on the feeder affects the ability of the sectionalizer to operate properly and coordinate with other protection, specifically reclosers and fuses. The primary interest will likely be in DR with high fault current capability, though distinguishing between low and high fault contribution devices could be informative. 


\subsubsection{Sectionalizer-Recloser Coordination Test}

\subsubsection{Governing IEEE 1547, CA Rule 21, and Other Document Sections}

IEEE 1547: $\$ 4.2 .1$. Voltage Disturbances

$\S 4.4 .1$. Unintentional Islanding

\$5.1.8 Unintentional Islanding

$\S 5.3 .4$. Feeder Reclosing Considerations

UL 1741: $\quad$ \$46.3: Anti-Islanding Test

IEEE 929: Appendix A

CA Rule 21: $\S D .2$. Prevention of Interference (specifies limitations on effects to system from DR [e.g., voltage, harmonics, flicker, etc.])

\subsubsection{Test Objectives}

The test objective is to determine the proper sectionalizer operation and coordination with the recloser under both normal and fault conditions on a feeder with DR. Specifically:

1. For temporary (non-permanent) faults that would normally be cleared by recloser operation, determine scenarios in which the presence of DR may cause the sectionalizer to operate (lock out) prematurely (i.e., before the recloser operates the specified number of times to clear the fault).

2. For sustained (permanent) faults on the line section protected by the sectionalizer, determine scenarios in which the presence of DR may cause the sectionalizer to operate too late (i.e., after the recloser locks out).

3. Identify the differences between the non-export and export situations for DR on the feeder in regard to effects on sectionalizer operation.

4. Determine the scenarios in which overvoltages that will affect the correct operation or physical integrity of the protective equipment may occur.

\subsubsection{Key Testing Parameters}

The key testing parameters are:

- Fault location and type (single-phase, phase-phase, three-phase, bolted, highimpedance)

- DR power level: megawatts, percent loading, export versus non-export condition

- Stiffness ratio of system

- Type of DR: synchronous, induction, inverter-based

- Number of DR on the feeder

- Impedance(s) between key points and devices on the feeder.

\subsubsection{Expected Results}

The expected results are:

- The effect(s) of DR on recloser/sectionalizer operation and coordination

- Insight into the differences between DR non-export and export situations. 


\subsubsection{Test Procedure}

1. Set up DR, recloser, and sectionalizer as shown in Figure 21.

2. Verify settings and correct coordination and operation of sectionalizer and recloser for faults in baseline case (i.e., no DR on feeder). (Note: It is presumed that the protection settings are developed for the particular scenario and configuration according to utility practices.)

3. Connect DR and bring up to desired loading.

4. Simulate a fault between the recloser and sectionalizer.

5. Record the timing of recloser and sectionalizer operations.

6. Record voltages at various points on the feeder circuit.

7. Vary the test by DR power level (megawatts, percent loading, export/non-export).

8. Vary the test by number of DR (single, multiple).

9. Vary the test by type of fault (single-phase, phase-phase, three-phase, bolted, temporary/sustained, high-impedance).

10. Vary the test by fault location (e.g., Fault \#1, Fault \#2 in Figure 21).

11. Vary the test by stiffness ratio of the system.

12. Vary the test by type of DR (synchronous, induction, inverter-based).

Repeat the test procedure for other configurations as needed.

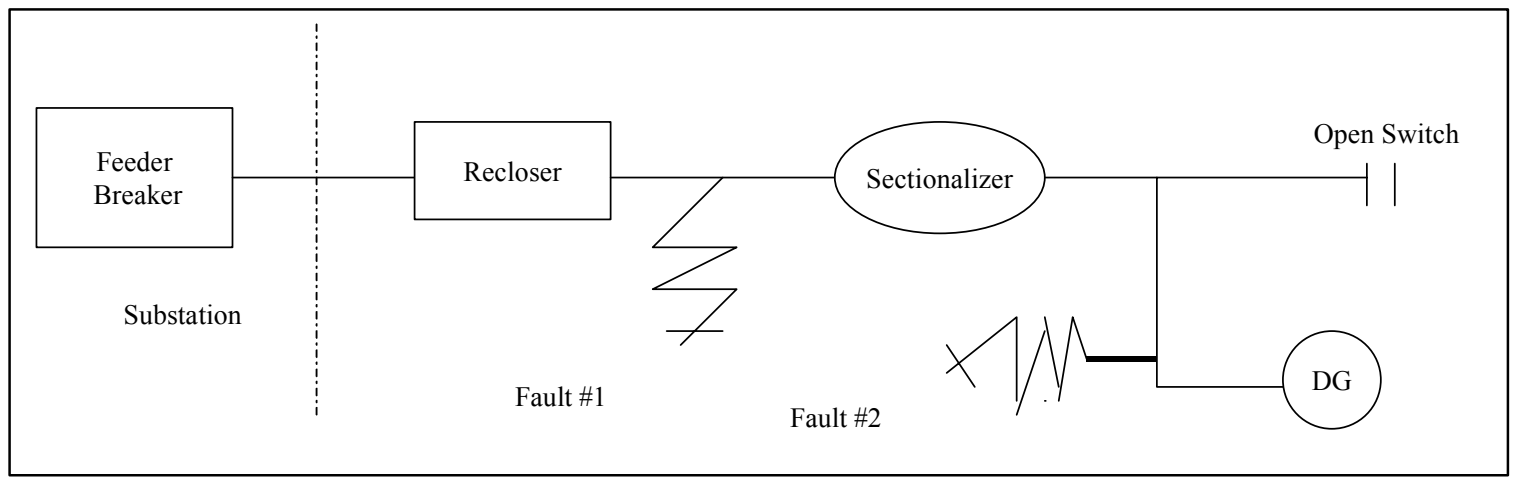

Figure 21. Schematic for basic sectionalizer test 


\subsubsection{Data Acquisition Requirements}

Table 38. Sectionalizer-Recloser Coordination Test Data Acquisition Requirements

\begin{tabular}{lllrcc}
\hline Parameter & Units & $\begin{array}{l}\text { Range } \\
\text { (Nom) }\end{array}$ & Accuracy & $\begin{array}{l}\text { Sampling } \\
\text { Rate }\end{array}$ & $\begin{array}{l}\text { Recording } \\
\text { Rate }\end{array}$ \\
\cline { 2 - 6 } & & & & & \\
DR voltage (three-phase) & Volts & $0-600$ & $\pm 1 \mathrm{~V}$ & $6 \mathrm{kHz}$ & $6 \mathrm{kHz}$ \\
$\begin{array}{l}\text { DR current (three-phase) } \\
\text { Utility voltage (three- }\end{array}$ & Amps & $0-100$ & $\pm 1 \mathrm{~A}$ & $6 \mathrm{kHz}$ & $6 \mathrm{kHz}$ \\
phase) & Volts & $0-15 \mathrm{kV}$ & $\pm 0.1 \mathrm{kV}$ & $6 \mathrm{kHz}$ & $6 \mathrm{kHz}$ \\
Sectionalizer status & Open/closed & $0-5 \mathrm{~s}$ & $\pm 0.01 \mathrm{~s}$ & $6 \mathrm{kHz}$ & $6 \mathrm{kHz}$ \\
Recloser status & Open/closed & $0-5 \mathrm{~s}$ & $\pm 0.01 \mathrm{~s}$ & $6 \mathrm{kHz}$ & $6 \mathrm{kHz}$ \\
Sectionalizer current & Amps & $0-100$ & $\pm 1 \mathrm{~A}$ & $6 \mathrm{kHz}$ & $6 \mathrm{kHz}$ \\
Recloser current & Amps & $0-100$ & $\pm 1 \mathrm{~A}$ & $6 \mathrm{kHz}$ & $6 \mathrm{kHz}$ \\
Sectionalizer voltage & Volts & $0-15 \mathrm{kV}$ & $\pm 0.1 \mathrm{kV}$ & $6 \mathrm{kHz}$ & $6 \mathrm{kHz}$ \\
Recloser voltage & Volts & $0-15 \mathrm{kV}$ & $\pm 0.1 \mathrm{kV}$ & $6 \mathrm{kHz}$ & $6 \mathrm{kHz}$ \\
Fault voltage & Volts & $0-600$ & $\pm 1 \mathrm{~V}$ & $6 \mathrm{kHz}$ & $6 \mathrm{kHz}$ \\
Fault current & Amps & $0-500$ & $\pm 1 \mathrm{~A}$ & $6 \mathrm{kHz}$ & $6 \mathrm{kHz}$ \\
& & & & & \\
\hline
\end{tabular}

4.5.1.7 Control Requirements

There are no control requirements.

\subsubsection{Facility Requirements}

Table 39. Sectionalizer-Recloser Coordination Test Facility Requirements

\begin{tabular}{lcll}
\hline \multicolumn{1}{c}{ Type } & Quantity & \multicolumn{1}{c}{ Size } & \multicolumn{1}{c}{ Comments } \\
\cline { 2 - 4 } & $1+$ & $10 \mathrm{ft} \times 20$ & Per number of DR in test \\
DR test bays & $1+$ & Variable & Per rating of DR in test \\
Load bank & 1 & $2-32 \mathrm{mi}$ & \\
$\begin{array}{l}\text { Feeder system (or } \\
\text { simulator) }\end{array}$ & 1 & $500 \mathrm{~A}$ & To initiate faults \\
$\begin{array}{l}\text { Ground switch } \\
\text { Impedance (load bank) }\end{array}$ & 1 & Variable & To simulate fault impedance \\
$\begin{array}{l}\text { Recloser } \\
\text { Sectionalizer }\end{array}$ & 1 & $12 \mathrm{kV}$ & \\
& 2 & $12 \mathrm{kV}$ & $\begin{array}{l}\text { Test both hydraulic and electronic } \\
\text { versions }\end{array}$ \\
\hline
\end{tabular}




\subsubsection{DR Requirements}

Tests should be done with combinations of single- and three-phase DR.

Table 40. Sectionalizer-Recloser Coordination Test DR Requirements

\begin{tabular}{lll}
\hline \multicolumn{1}{c}{ Type } & Quantity & \multicolumn{1}{c}{ Size } \\
\cline { 2 - 3 } & & \\
Inverter, any prime mover & 1 & $2-200 \mathrm{~kW}$ \\
Synchronous generator & 1 & $10-1,000 \mathrm{~kW}$ \\
Induction generator & 1 & $10-1,000 \mathrm{~kW}$ \\
\hline
\end{tabular}

\subsubsection{Other Requirements}

The test should be performed with sectionalizers with and without inrush restraint.

\subsubsection{Modeling Requirements}

No modeling input is required.

\subsubsection{Sectionalizer, Recloser, and Fuse Coordination Test}

\subsubsection{Governing IEEE 1547, CA Rule 21, and Other Document Sections}

IEEE P1547: \$4.2.1. Voltage Disturbances

$\$ 4.4 .1$. Unintentional Islanding

\$5.1.8 Unintentional Islanding

UL 1741: $\quad \S 46.3$

\$5.3.4. Feeder Reclosing Considerations

IEEE 929: Appendix A

CA Rule 21: $\S D$. Generating Facility Design and Operating Requirements

$\S D .2$. Prevention of Interference (specifies limitations on effects to system from DR [e.g., voltage, harmonics, flicker, etc.])

\subsubsection{Test Objectives}

The test objectives are to determine the proper sectionalizer operation and coordination with (downstream) fuse and (upstream) recloser when a fault occurs on a feeder with DR. In general, fuses are used as inexpensive alternatives to sectionalizers when the feeder is long and the load below the fuse is relatively low. The fuse should blow for sustained faults on its load side. The sectionalizer and recloser should operate as in Test 1 for faults on the source side of the fuse. Specifically:

1. Determine scenarios in which the presence of DR interferes with proper coordination between the fuse, the sectionalizer, and the recloser. The fuse should only blow for sustained faults on the line section it protects. For all other faults, sectionalizer and recloser operation should be as in Test 1 .

2. Identify the differences between the DR non-export and export cases. 


\subsubsection{Key Testing Parameters}

Key testing parameters are:

- Fault location and type (single-phase, phase-phase, three-phase, bolted, highimpedance)

- DR power level (megawatts, percent loading, export versus non-export condition)

- Stiffness ratio of system

- Type of DR (synchronous, induction, inverter-based)

- Number of DG on the feeder

- Impedance(s) between key points and devices on the feeder.

\subsubsection{Expected Results}

The expected results are:

- The effect(s) of DR and the fuse on recloser/sectionalizer operation and coordination.

- Insight into the differences between the DR non-export and export situations.

\subsubsection{Test Procedure}

1. Set up DR, recloser, sectionalizer, and fuse as shown in Figure 22.

2. Verify settings and correct operation(s) of recloser, sectionalizer, and fuse for baseline case (i.e., no DR on feeder). (Note: It is presumed that the protection settings are developed for the particular scenario and configuration according to utility practices.)

3. Connect DR and bring up to desired load level.

4. Simulate a fault between the recloser and sectionalizer.

5. Record timings of recloser, fuse, and sectionalizer operations.

6. Record voltages at various points on the feeder circuit.

7. Vary the test by DR power level (megawatts, percent loading, export/non-export).

8. Vary the test by number of DR (single, multiple).

9. Vary the test by type of fault (single-phase, phase-phase, three-phase, bolted, temporary/sustained, high-impedance).

10. Vary the test by fault location (e.g., Fault \#1, Fault \#2, Fault \#3, and other locations as needed).

11. Vary the test by stiffness ratio of system.

12. Vary the test by type of DR (synchronous, induction, inverter-based). 


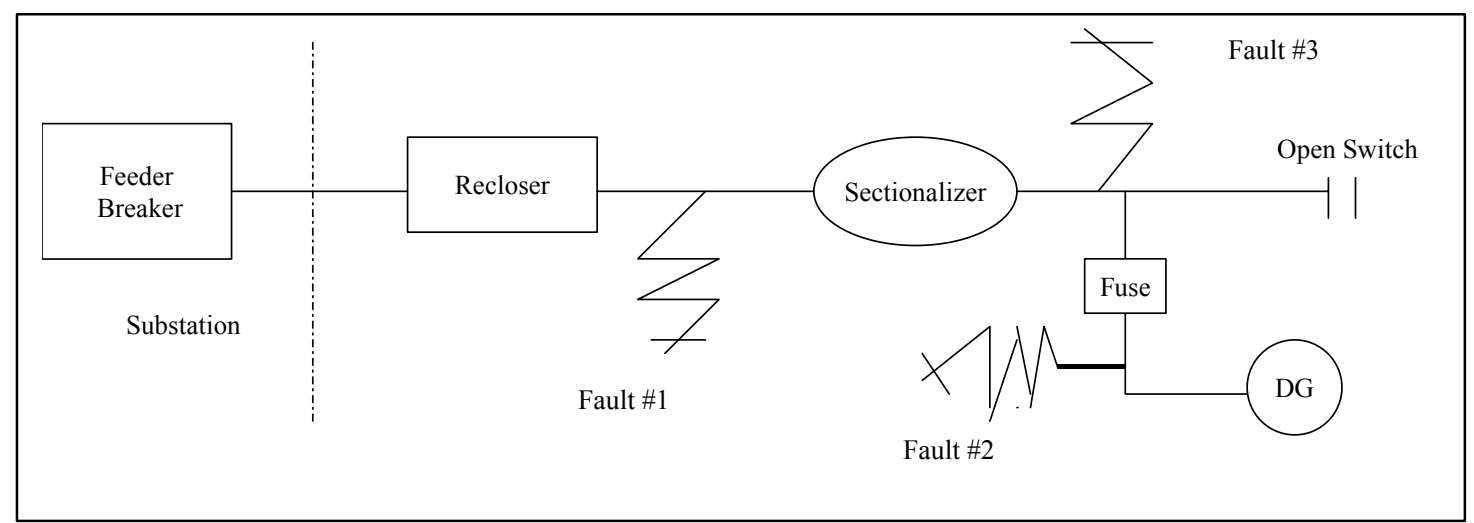

Figure 22. Schematic for basic sectionalizer test with DR fuse protection

\subsubsection{Data Acquisition Requirements}

Table 41. Sectionalizer, Recloser, and Fuse Coordination Test Data Acquisition Requirements

\begin{tabular}{lccccc}
\hline \multicolumn{1}{c}{ Parameter } & Units & $\begin{array}{c}\text { Range } \\
\text { (Nom.) }\end{array}$ & Accuracy & $\begin{array}{c}\text { Sampling } \\
\text { Rate }\end{array}$ & $\begin{array}{c}\text { Recording } \\
\text { Rate }\end{array}$ \\
\cline { 2 - 6 } & Volts & $0-600$ & $\pm 1 \mathrm{~V}$ & $6 \mathrm{kHz}$ & $6 \mathrm{kHz}$ \\
$\begin{array}{l}\text { DR voltage (three- } \\
\text { phase) }\end{array}$ & Amps & $0-100$ & $\pm 1 \mathrm{~A}$ & $6 \mathrm{kHz}$ & $6 \mathrm{kHz}$ \\
$\begin{array}{l}\text { DR current (three- } \\
\text { phase) }\end{array}$ & & & & \\
Utility voltage (three- & Volts & $0-15 \mathrm{kV}$ & $\pm 0.1 \mathrm{kV}$ & $6 \mathrm{kHz}$ & $6 \mathrm{kHz}$ \\
phase) & & & & & \\
Sectionalizer status & Open/closed & $0-5 \mathrm{~s}$ & $\pm 0.01 \mathrm{~s}$ & $6 \mathrm{kHz}$ & $6 \mathrm{kHz}$ \\
Recloser status & Open/closed & $0-5 \mathrm{~s}$ & $\pm 0.01 \mathrm{~s}$ & $6 \mathrm{kHz}$ & $6 \mathrm{kHz}$ \\
Fuse status & Open/closed & $0-5 \mathrm{~s}$ & $\pm 0.01 \mathrm{~s}$ & $6 \mathrm{kHz}$ & $6 \mathrm{kHz}$ \\
Sectionalizer current & Amps & $0-100$ & $\pm 1 \mathrm{~A}$ & $6 \mathrm{kHz}$ & $6 \mathrm{kHz}$ \\
Recloser current & Amps & $0-100$ & $\pm 1 \mathrm{~A}$ & $6 \mathrm{kHz}$ & $6 \mathrm{kHz}$ \\
$\begin{array}{l}\text { Fuse current } \\
\text { Sectionalizer voltage }\end{array}$ & Amps & $0-100$ & $\pm 1 \mathrm{~A}$ & $6 \mathrm{kHz}$ & $6 \mathrm{kHz}$ \\
Recloser voltage & Volts & $0-15 \mathrm{kV}$ & $\pm 0.1 \mathrm{kV}$ & $6 \mathrm{kHz}$ & $6 \mathrm{kHz}$ \\
$\begin{array}{l}\text { Fuse voltage } \\
\text { Fault voltage }\end{array}$ & Volts & $0-15 \mathrm{kV}$ & $\pm 0.1 \mathrm{kV}$ & $6 \mathrm{kHz}$ & $6 \mathrm{kHz}$ \\
Fault current & Volts & $0-15 \mathrm{kV}$ & $\pm 0.1 \mathrm{kV}$ & $6 \mathrm{kHz}$ & $6 \mathrm{kHz}$ \\
& Volts & $0-600$ & $\pm 1 \mathrm{~V}$ & $6 \mathrm{kHz}$ & $6 \mathrm{kHz}$ \\
& Amps & $0-500$ & $\pm 1 \mathrm{~A}$ & $6 \mathrm{kHz}$ & $6 \mathrm{kHz}$ \\
\hline
\end{tabular}

\subsubsection{Control Requirements}

There are no control requirements. 


\subsubsection{Facility Requirements}

Table 42. Sectionalizer, Recloser, and Fuse Coordination Test Facility Requirements

\begin{tabular}{lcll}
\hline \multicolumn{1}{c}{ Type } & Quantity & \multicolumn{1}{c}{ Size } & \multicolumn{1}{c}{ Other } \\
\cline { 2 - 4 } & $1+$ & $10 \mathrm{ft} \times 20 \mathrm{ft}$ & $\begin{array}{l}\text { Per number of DR in test } \\
\text { DR test bays }\end{array}$ \\
$\begin{array}{l}\text { Load bank } \\
\text { Feeder system (or }\end{array}$ & $1+$ & Variable & $\begin{array}{l}\text { Per rating of DR in test } \\
\text { simulator) } \\
\text { Ground switch }\end{array}$ \\
$\begin{array}{l}\text { Impedance (load bank) } \\
\text { Recloser }\end{array}$ & 1 & $2-32 \mathrm{mi}$ & \\
Sectionalizer & 1 & $\begin{array}{l}500 \mathrm{~A} \\
\text { Variable }\end{array}$ & $\begin{array}{l}\text { To initiate faults } \\
\text { To simulate fault impedance }\end{array}$ \\
Fuse & 1 & $12 \mathrm{kV}$ & $\begin{array}{l}\text { Test both hydraulic and electronic } \\
\text { versions } \\
\text { Amp rating to coordinate with }\end{array}$ \\
\hline
\end{tabular}

\subsubsection{DR Requirements}

Tests should be done with combinations of single- and three-phase DR.

Table 43. Sectionalizer, Recloser, and Fuse Coordination Test DR Requirements

\begin{tabular}{lcl}
\hline \multicolumn{1}{c}{ Type } & Quantity & \multicolumn{1}{c}{ Size } \\
\cline { 2 - 3 } & & \\
Inverter, any prime mover & 1 & $2-200 \mathrm{~kW}$ \\
Synchronous generator & 1 & $10-1,000 \mathrm{~kW}$ \\
Induction generator & 1 & $10-1,000 \mathrm{~kW}$ \\
\hline
\end{tabular}

\subsubsection{Other Requirements}

Fuel supply is needed for the DR.

\subsubsection{Modeling Requirements}

There are no modeling requirements.

\subsection{Synchronization Tests}

Tests in this section are intended to address issues related to synchronization of DR and loads with the Area EPS. 
Three scenarios are of potential concern:

- Synchronization on initial startup

- Synchronization during a momentary island condition, before the islanding detection scheme performs its function

- For a DR capable of standalone operation, resynchronization upon Area EPS return to service after an outage.

Initial startup and transition from standalone operation are primarily type-testing issues and therefore not considered in tests described here.

\subsubsection{Transition From Momentary Island}

All islanding detection schemes take some time to cease energizing. If a momentary balanced island condition occurs (e.g., as the result of a high impedance fault and a reclosing operation) and if the reclosing operation takes place within the DR's island detection time, there is a slight possibility that the DR within the islanded segment will continue to operate through the momentary outage. Depending on the length of the outage, the balance of the load and generation, and other factors, there could be a shift in the voltage and phase angle between the islanded segment and the rest of the Area EPS. This test examines the effect of a step change in utility voltage waveform (i.e., a momentary outage).

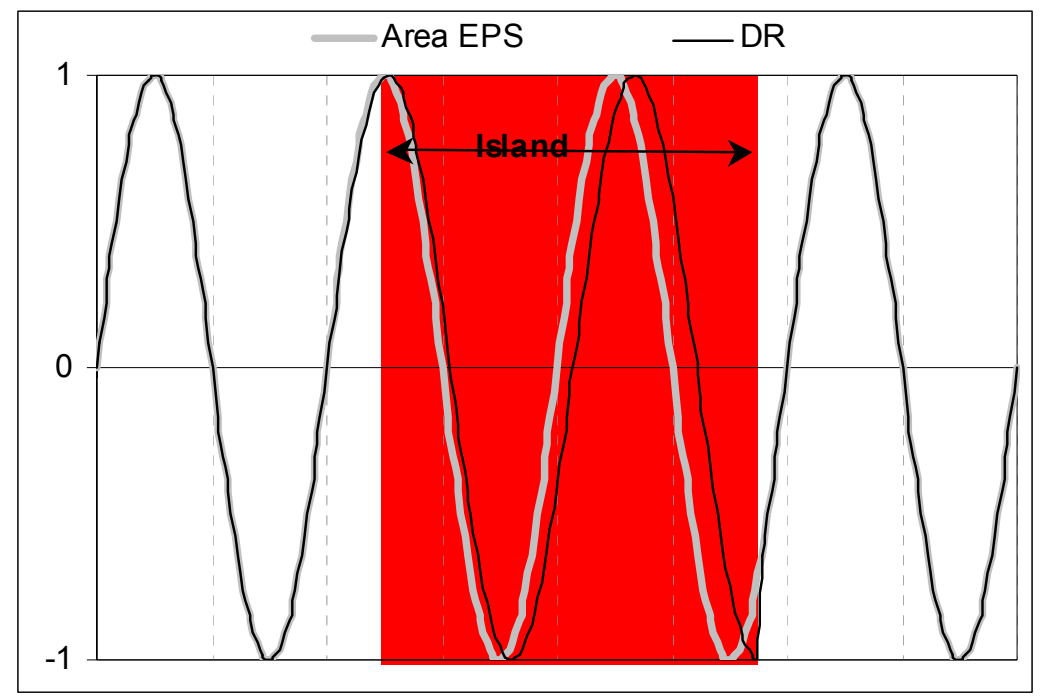

Figure 23. Resynchronization after a momentary island

Figure 24 represents a possible scenario. When the momentary island occurs, the DR and Area EPS waveforms are no longer synchronized, and the DR begins to drift. The drift rate is unrealistically high in this diagram and is only for display purposes. In this case, the DR is $25^{\circ}$ out of phase with the Area EPS when the switch is closed. 


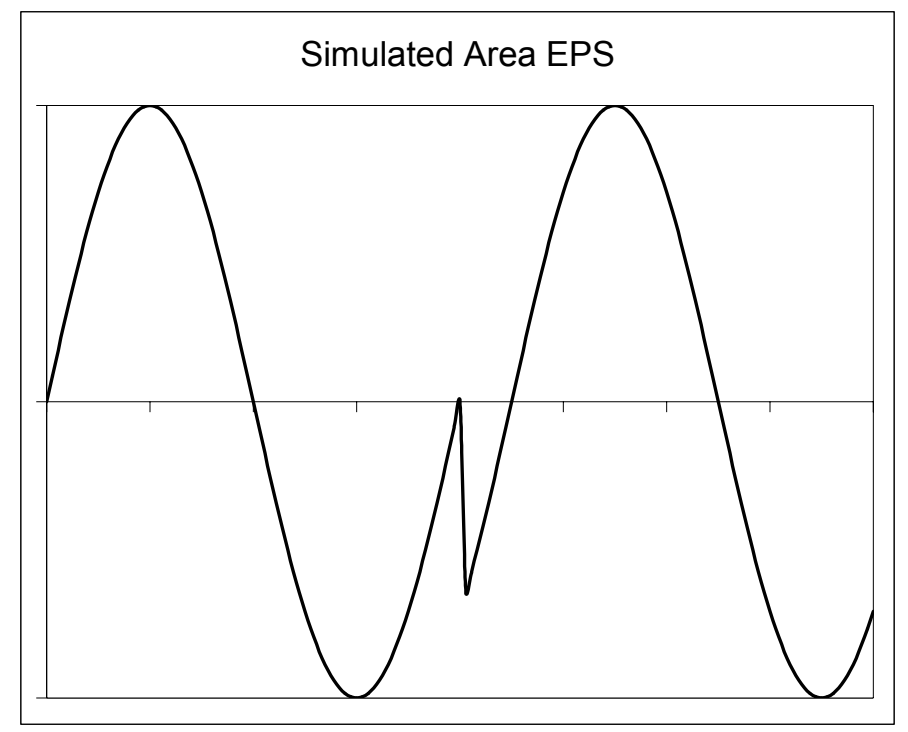

Figure 24. Momentary island test waveform

\subsubsection{Test Objectives}

The test objective is to determine if DR with the capability of standalone operation will properly synchronize upon return to service after an Area EPS outage.

\subsubsection{Expected Results}

Verify that DR can tolerate a step change in voltage.

\subsubsection{Test Procedure}

1. Set up the DR as specified by the manufacturer.

2. Connect the DR to a simulated Area EPS generator that is capable of the step change shown in Figure 24 ( $45^{\circ}$ phase shift).

3. Operate the DR at $50 \%$ of its rated output using available loads and load banks.

4. With the DR operating in a stable, steady-state condition, instruct the simulator to affect the step change.

5. Measure the response of the DR and loads to the step change. 


\subsubsection{Data Acquisition Requirements}

Table 44. Transition From Momentary Island Data Acquisition Requirements

\begin{tabular}{lccccc}
\hline \multicolumn{1}{c}{ Parameter } & Units & Range (Nom) & Accuracy & Sampling Rate & Recording Rate \\
\cline { 2 - 5 } & & & & & \\
DR voltage (three-phase) & Volts & $0-480$ & $\pm 1 \mathrm{~V}$ & $6 \mathrm{kHz}$ & $6 \mathrm{kHz}$ \\
DR current (three-phase) & Amps & $0-?$ & $\pm 1 \%$ & $6 \mathrm{kHz}$ & $6 \mathrm{kHz}$ \\
Utility voltage (three-phase) & Volts & $0-480$ & $\pm 1 \mathrm{~V}$ & $6 \mathrm{kHz}$ & $6 \mathrm{kHz}$ \\
\hline
\end{tabular}

\subsubsection{Control Requirements}

There are no control requirements.

\subsubsection{Facility Requirements}

The facility must have an Area EPS simulator capable of providing the required waveform.

\subsubsection{DR Requirements}

- Approval from the manufacturer to perform the test is needed.

- The test may be done on any DR, with manufacturer approval.

- Tests should be done with combinations of single- and three-phase DR.

\subsubsection{Other Requirements}

There are no other requirements.

\subsubsection{Modeling Requirements}

There are no modeling requirements.

\subsection{Fuse Coordination Tests}

The purpose of these tests is to investigate the effects of fuse coordination on a distribution feeder with DR. In particular, they will show under what scenarios DR will cause improper fuse operation (i.e., a fuse not blowing when it should or blowing when it should not).

\subsubsection{Fuse Desensitization Test}

\subsubsection{Test Objectives}

The test objective is to determine the effects of DR on the distribution system on fuse protection coordination.

Specifically:

1. Determine the scenarios in which the presence of DR on the feeder may cause the fuse to operate at the wrong time.

2. Determine the scenarios in which the presence of DR on the feeder may cause the fuse to fail operate at the correct time. 
3. Determine the effect of number of DR, their locations, and overall DR penetration level (as a percentage of feeder load) on fuse coordination.

\subsubsection{Key Testing Parameters}

Key testing parameters are:

- DR size (megawatts) and type (synchronous, induction, inverter-based)

- Number and location of DR on the feeder

- DR penetration level (as a percent of load on feeder)

- Fault location and type (single-phase, phase-phase, three-phase, bolted, highimpedance)

- Stiffness ratio of system.

\subsubsection{Expected Results}

The expected result is insight into the effects of DR on fuse operation and coordination with other protective devices.

\subsubsection{Test Procedure}

See Figure 25 for a general schematic of the fuse coordination test.

1. Connect DR to the simulated utility.

2. Connect loads equal to $\mathrm{DR}$ rated power.

3. Bring DR and loads up, operating in parallel with the simulated utility.

4. Simulate a fault (single-phase, phase-phase, three-phase, bolted, high-impedance) on the EPS by throwing a switch from the feeder to ground, through a load bank if necessary, to simulate fault impedance.

5. Measure the fuse current and time to operation. Measure current and time to operation of other protective devices on the system as needed.

6. Vary the test by location of fault in the distribution system.

7. Vary the test by location of DR in the distribution system.

8. Vary the test by penetration level (DR as a percentage of feeder load).

9. Vary the test by type of DR (synchronous generator, induction generator, inverterbased).

10. Vary the test by stiffness ratio of system.

11. Vary the test by system configuration (radial or network). 


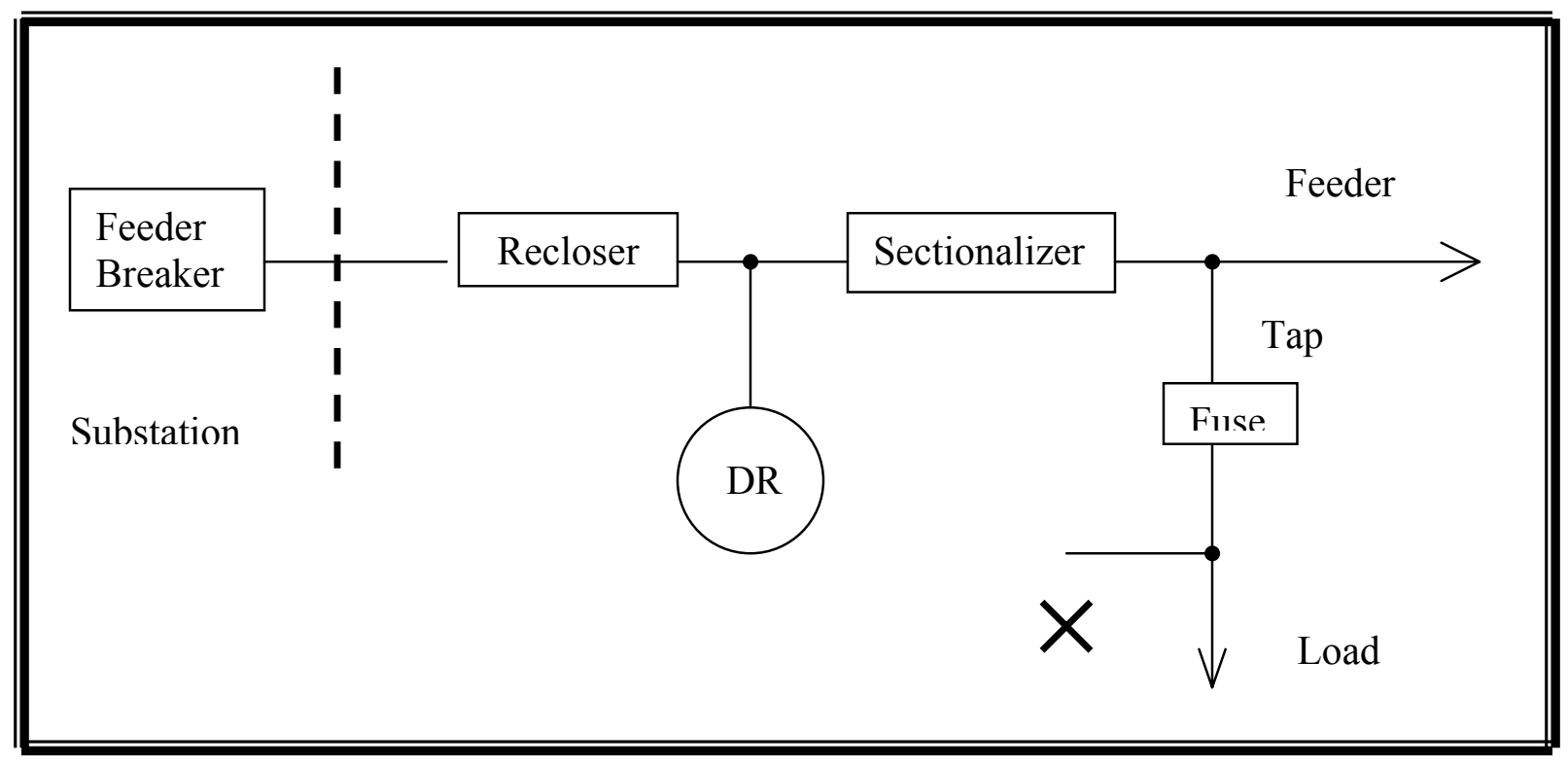

Figure 25. Schematic for fuse coordination tests

\subsubsection{Data Acquisition Requirements}

Table 45. Fuse Desensitization Test Data Acquisition Requirements

\begin{tabular}{lccccc}
\hline \multicolumn{1}{c}{ Parameter } & Units & $\begin{array}{c}\text { Range } \\
\text { (Nom) }\end{array}$ & \begin{tabular}{c} 
Accuracy \\
\cline { 2 - 5 }
\end{tabular} & $\begin{array}{c}\text { Sampling } \\
\text { Rate }\end{array}$ & $\begin{array}{c}\text { Recording } \\
\text { Rate }\end{array}$ \\
$\begin{array}{l}\text { DR voltage (three- } \\
\text { phase) }\end{array}$ & Volts & $0-600$ & $\pm 1 \mathrm{~V}$ & $6 \mathrm{kHz}$ & $6 \mathrm{kHz}$ \\
$\begin{array}{l}\text { DR current (three- } \\
\text { phase) }\end{array}$ & Amps & $0-100$ & $\pm 1 \mathrm{~A}$ & $6 \mathrm{kHz}$ & $6 \mathrm{kHz}$ \\
$\begin{array}{l}\text { Utility voltage (three- } \\
\text { phase) }\end{array}$ & Volts & $0-15 \mathrm{kV}$ & $\pm 0.1 \mathrm{kV}$ & $6 \mathrm{kHz}$ & $6 \mathrm{kHz}$ \\
$\begin{array}{l}\text { Utility current } \\
\text { Fuse status }\end{array}$ & Amps & $0-1,000$ & $\pm 10 \mathrm{~A}$ & $6 \mathrm{kHz}$ & $6 \mathrm{kHz}$ \\
$\begin{array}{l}\text { Fuse voltage } \\
\text { Fuse current }\end{array}$ & Open/closed & $0-5 \mathrm{~s}$ & $\pm 0.01 \mathrm{~s}$ & $6 \mathrm{kHz}$ & $6 \mathrm{kHz}$ \\
Fault voltage & Volts & $0-15 \mathrm{kV}$ & $\pm 0.1 \mathrm{kV}$ & $6 \mathrm{kHz}$ & $6 \mathrm{kHz}$ \\
$\begin{array}{l}\text { Fault current } \\
\text { Amps }\end{array}$ & $0-100$ & $\pm 1 \mathrm{~A}$ & $6 \mathrm{kHz}$ & $6 \mathrm{kHz}$ \\
& Volts & $0-15 \mathrm{kV}$ & $\pm 0.1 \mathrm{kV}$ & $6 \mathrm{kHz}$ & $6 \mathrm{kHz}$ \\
& Amps & $0-1,000$ & $\pm 10 \mathrm{~A}$ & $6 \mathrm{kHz}$ & $6 \mathrm{kHz}$ \\
\hline
\end{tabular}




\subsubsection{Facility Requirements}

Table 46. Fuse Desensitization Test Facility Requirements

\begin{tabular}{|c|c|c|c|}
\hline Type & Quantity & Size & Other \\
\hline DR test bay & $1+$ & $\begin{array}{l}10 \mathrm{ft} \times 20 \\
\mathrm{ft}\end{array}$ & \\
\hline Load banks & $1+$ & Variable & Per rating of $D R$ in test \\
\hline $\begin{array}{l}\text { Feeder system (or } \\
\text { simulator) }\end{array}$ & 1 & $2-32 \mathrm{mi}$ & \\
\hline Ground switch & 3 & $500 \mathrm{~A}$ & $\begin{array}{l}\text { To initiate faults, single-phase or three- } \\
\text { phase }\end{array}$ \\
\hline $\begin{array}{l}\text { Fault impedances (load } \\
\text { banks) }\end{array}$ & 3 & Variable & $\begin{array}{l}\text { To simulate fault impedances, single-phase } \\
\text { or three-phase }\end{array}$ \\
\hline Recloser & 1 & $12 \mathrm{kV}$ & \\
\hline Sectionalizer & $1+$ & $12 \mathrm{kV}$ & \\
\hline
\end{tabular}

\subsubsection{DR Requirements}

Tests should be done with combinations of single- and three-phase DR.

Table 47. Fuse Desensitization Test DR Requirements

\begin{tabular}{lll}
\hline \multicolumn{1}{c}{ Type } & Quantity & \multicolumn{1}{c}{ Size } \\
\cline { 2 - 3 } & & \\
Inverter, any prime mover & $1+$ & $2-200 \mathrm{~kW}$ \\
Synchronous generator & $1+$ & $10-1,000 \mathrm{~kW}$ \\
Induction generator & $1+$ & $10-1,000 \mathrm{~kW}$ \\
\hline
\end{tabular}

\subsubsection{Other Requirements}

There are no other requirements.

\subsubsection{Modeling Requirements}

No modeling is required.

\subsection{Capacitor Switching and Operation}

One concern about the use of DR on distribution feeders is the switching and operation of distributed and lumped capacitors on the feeder system. One simple example is that the switching of capacitors may inadvertently cause false tripping of the dispersed DR devices. Another example is that there may be enough capacitance added externally to a customer's facility to achieve high $\mathrm{Q}$ factors, which could cause certain anti-islanding schemes to become ineffective at island detection. This section deals with tests that address these concerns and others related to capacitor switching, operation, and potential resonances. 


\subsection{Short Circuit Tests}

The purpose of these tests is to verify or determine the short circuit current contribution of DR under various faults, fault locations, feeder configurations, and penetration levels. The information obtained will be used to evaluate whether manufacturer data and system modeling are adequate to describe the performance of DR under distribution system fault conditions.

\subsubsection{DR Short Circuit Characteristics Test}

\subsubsection{Governing IEEE 1547, CA Rule 21, and Other Document Sections \\ IEEE 1547: \$4.0. Interconnection Technical Specifications and Requirements \\ $\S 4.1$. General Requirements}

\$4.1.2. Integration With Area Electric Power System Grounding (provides that ground fault current contribution from the DR shall not exceed the fault current contribution of the DR to a three-phase fault)

$\S 4.2$. Response to Area EPS Abnormal Conditions

\$4.2.3: Disconnection for Faults (provides that for a stiffness ratio $\leq 10$, the DR shall be equipped with current-based protection and ground fault protection that will detect Area EPS faults)

CA Rule 21: $\quad \S D$. Generating Facility Design and Operating Requirements

$\S D .3$. Control, Protection, and Safety Equipment Requirements

$\S D .3 . b$. Technology Specific Requirements (\$1-3) (specifies protective devices required for $\mathrm{DR}$ as a function of short circuit contribution ratio)

IEEE 115-1995: Test Procedures for Synchronous Machines

IEEE 112-1996: Test Procedures for Polyphase Induction Motors and Generators

IEC 909: $\quad$ Short Circuit Calculation for Three-Phase AC Systems

\subsubsection{Test Objectives}

The objective of this test is to determine the fault current contribution, under varying conditions and system configurations, of individual DR interconnected to the distribution system. The information acquired by this test will be used to evaluate the regulatory "rules of thumb" applied to DR penetration in the distribution system (e.g., the 15\% screening criterion for simplified interconnection).

\subsubsection{Key Testing Parameters}

The key testing parameters of this test are:

- Connection mode (radial and network)

- DR size (megawatts) and type (synchronous, induction, inverter-based)

- DR penetration level (as a percent of load on feeder)

- Fault location and type (single-phase, phase-phase, three-phase, bolted, highimpedance)

- Stiffness ratio of the system.

\subsubsection{Expected Results}

The expected result is the short circuit current contribution of DR as a function of system configuration, stiffness ratio, and DR type. 


\subsubsection{Test Procedure}

Follow industry standards to the extent possible.

1. Connect DR to the simulated utility.

2. Connect loads equal to DR rated power.

3. Bring DR and loads up, operating in parallel with the simulated utility.

4. Simulate a fault (single-phase, phase-phase, three-phase, bolted, high-impedance) on the EPS by throwing a switch from the DR's terminals to ground for a time period greater than or equal to the maximum fault clearing time required for the DR.

5. Measure the magnitude of the output phase currents and ground fault current of the DR during the fault period.

6. Measure time elapsed to disconnection from utility.

7. Measure the terminal voltage of the DR before, during, and after the fault period.

8. Vary the "location" of the fault in the distribution system by imposing varying amounts of impedance between the fault and the DR (simulating "distance" to the fault).

9. Vary the test by type of transformer connection of the DR to the Area EPS.

10. Vary the test by type of DR (synchronous generator, induction generator, inverterbased).

11. Vary the test by the stiffness ratio of the system.

12. Vary the test by system configuration (radial or network).

\subsubsection{Data Acquisition Requirements}

Table 48. DR Short Circuit Characteristics Test Data Acquisition Requirements

\begin{tabular}{lccccc}
\hline \multicolumn{1}{c}{ Parameter } & Units & Range (Nom) & Accuracy & Sampling Rate & Recording Rate \\
\cline { 2 - 6 } & & & & & \\
DR voltage (three-phase) & Volts & $0-600$ & $\pm 1 \mathrm{~V}$ & $6 \mathrm{kHz}$ & $6 \mathrm{kHz}$ \\
DR current (three-phase) & Amps & $0-100$ & $\pm 1 \mathrm{~A}$ & $6 \mathrm{kHz}$ & $6 \mathrm{kHz}$ \\
Utility voltage (three-phase) & Volts & $0-600$ & $\pm 1 \mathrm{~V}$ & $6 \mathrm{kHz}$ & $6 \mathrm{kHz}$ \\
Fault voltage & Volts & $0-600$ & $\pm 1 \mathrm{~V}$ & $6 \mathrm{kHz}$ & $6 \mathrm{kHz}$ \\
Fault current & Amps & $0-500$ & $\pm 1 \mathrm{~A}$ & $6 \mathrm{kHz}$ & $6 \mathrm{kHz}$ \\
& & & & & \\
\hline
\end{tabular}




\subsubsection{Facility Requirements}

Table 49. DR Short Circuit Characteristics Test Facility Requirements

\begin{tabular}{lclll}
\hline \multicolumn{1}{c}{ Type } & Quantity & Size & \multicolumn{1}{c}{ Other } \\
\cline { 2 - 5 } & & & \\
DR test bay & 1 & $10 \mathrm{ft} \times 20 \mathrm{ft}$ & \\
Load banks & $1+$ & Variable & Per rating of DR in test \\
Feeder system (or simulator) & 1 & $2-32 \mathrm{mi}$ & \\
Ground switch & 1 & $500 \mathrm{~A}$ & To initiate faults \\
Fault impedance (load bank) & 1 & Variable & To simulate fault impedance \\
& & & \\
\hline
\end{tabular}

\subsubsection{DR Requirements}

Tests should be done with combinations of single- and three-phase DR.

Table 50. DR Short Circuit Characteristics DR Requirements

\begin{tabular}{lcl}
\hline \multicolumn{1}{c}{ Type } & Quantity & \multicolumn{1}{c}{ Size } \\
\cline { 2 - 3 } & & \\
Inverter, any prime mover & 1 & $2-200 \mathrm{~kW}$ \\
Synchronous generator & 1 & $10-1,000 \mathrm{~kW}$ \\
Induction generator & 1 & $10-1,000 \mathrm{~kW}$ \\
& &
\end{tabular}

\subsubsection{Other Requirements}

There are no other requirements.

\subsubsection{Modeling Requirements}

Modeling required for this test includes:

- Short circuit current contribution of the utility system

- Short circuit current contribution of DR

- Impedance of DR step-up transformer.

\subsubsection{Multiple DR Short Circuit Test}

\subsubsection{Governing IEEE 1547, CA Rule 21, and Other Document Sections}

IEEE 1547: $\quad$ 4.0. Interconnection Technical Specifications and Requirements \$4.1. General Requirements

§4.1.2. Integration With Area Electric Power System Grounding (provides that ground fault current contribution from the DR shall not exceed the fault current contribution of the DR to a three-phase fault) §4.2. Response to Area EPS Abnormal Conditions 
\$4.2.3: Disconnection for Faults (provides that for a stiffness ratio $\leq 10$, the DR shall be equipped with current-based protection and ground fault protection that will detect Area EPS faults)

CA Rule 21: $\quad \S D$. Generating Facility Design and Operating Requirements

$\S D$. 3. Control, Protection, and Safety Equipment Requirements

$\S D .3 . b$. Technology Specific Requirements (\$1-3) (specifies protective devices required for DR as a function of short circuit contribution ratio)

IEEE 115-1995: Test Procedures for Synchronous Machines

IEEE 112-1996: Test Procedures for Polyphase Induction Motors and Generators

IEC 909: $\quad$ Short Circuit Calculation for Three-Phase AC Systems

\subsubsection{Test Objectives}

The test objective is to determine the fault current contribution, under varying conditions and system configurations, of multiple DR interconnected with the distribution system. The information acquired by this test will be used to evaluate the regulatory "rules of thumb" applied to DR penetration in the distribution system (e.g., the 15\% screening criterion for simplified interconnection).

\subsubsection{Key Testing Parameters}

Key testing parameters are:

- Connection mode (radial and network).

- DR size (megawatts) and type (synchronous, induction, inverter-based).

- Number of DR on the feeder

- DR penetration level (as a percent of load on feeder)

- Fault location and type (single-phase, phase-phase, three-phase, bolted, highimpedance)

- Stiffness ratio of system

- Distance(s) and electrical impedance(s) between DR.

\subsubsection{Expected Results}

The expected result is the short circuit current contribution of DR as a function of system configuration, stiffness ratio, and DR type.

\subsubsection{Test Procedure}

Follow industry standards to the extent possible.

1. Connect multiple DR to the simulated utility.

2. Connect loads equal to DR rated power.

3. Bring DR and loads up, operating in parallel with the simulated utility.

4. Simulate a fault (single-phase, phase-phase, three-phase, bolted, high-impedance) on the EPS by throwing a switch from the DR's terminals to ground for a time period equal to or less than the maximum fault clearing time required for the DR. 
5. Measure the magnitude of the output phase currents and ground fault current of the DR during the fault period.

6. Measure the terminal voltage of the DR before, during, and after the fault period.

7. Vary the "location" of the fault in the distribution system by imposing varying amounts of impedance between the fault and the DR (simulating distance to the fault).

8. Vary the test by types and sizes of DR (synchronous generator, induction generator, inverter-based).

9. Vary the test by the stiffness ratio of the system.

10. Vary the test by system configuration (radial or network).

\subsubsection{Data Acquisition Requirements}

Table 51. Multiple DR Short Circuit Test Data Acquisition Requirements

\begin{tabular}{lccccc}
\hline \multicolumn{1}{c}{ Parameter } & Units & Range (Nom) & Accuracy & Sampling Rate & Recording Rate \\
\cline { 2 - 6 } & & & & & \\
DR voltage (three-phase) & Volts & $0-480$ & $\pm 1 \mathrm{~V}$ & $6 \mathrm{kHz}$ & $6 \mathrm{kHz}$ \\
DR current (three-phase) & Amps & $0-1,000$ & $\pm 1 \mathrm{~A}$ & $6 \mathrm{kHz}$ & $6 \mathrm{kHz}$ \\
Utility voltage (three-phase) & Volts & $0-480$ & $\pm 1 \mathrm{~V}$ & $6 \mathrm{kHz}$ & $6 \mathrm{kHz}$ \\
& & & & & \\
\hline
\end{tabular}

\subsubsection{Facility Requirements}

Table 52. Multiple DR Short Circuit Test Facility Requirements

\begin{tabular}{lc}
\hline \multicolumn{1}{c}{ Type } & Quantity \\
\cline { 2 - 2 } & \\
DR test bay & 1 \\
Load banks & 1 \\
Feeder simulator & 1 \\
Fault switch & 1 \\
\hline
\end{tabular}




\subsubsection{DR Requirements}

Tests should be done with combinations of single- and three-phase DR.

Table 53. Multiple DR Short Circuit Test DR Requirements

\begin{tabular}{lcc}
\hline \multicolumn{1}{c}{ Type } & Quantity & Size \\
\cline { 2 - 3 } & & \\
Inverter, any prime mover & 2 & $2-50 \mathrm{~kW}$ \\
Synchronous generator & 2 & $10-500 \mathrm{~kW}$ \\
Induction generator & 2 & $10-500 \mathrm{~kW}$
\end{tabular}

\subsubsection{Other Requirements}

There are no other requirements.

\subsubsection{Modeling Requirements}

The modeling requirements are:

- Short circuit current contribution of utility system

- Short circuit current contributions of DR

- Impedances of DR step-up transformers.

\subsection{Distribution System Stability Tests}

The tests in this section are designed to investigate issues related to stable operation of DR on a distribution feeder. A working hypothesis is that for DG penetration below $15 \%$ (per screening criteria) and for stiffness ratios greater than 20 , no stability problems should occur.

\subsubsection{DR Stability Characterization Test}

\subsubsection{Governing IEEE 1547, CA Rule 21, and Other Document Sections}

IEEE P1547: \$4.0. Interconnection Technical Specifications and Requirements

$\S 4.2$. Response to Area EPS Abnormal Conditions

$\S 4.2 .1$. Voltage Disturbances

$\S 4.2 .4$. Loss of Synchronism

$\S 4.4$. Islanding

\$4.4.1. Unintentional Islanding

§5.0. Test Specifications and Requirements

$\S 5.1$. Interconnection Test

§5.1.8 Unintentional Islanding Test

IEEE 115-1995: Test Procedures for Synchronous Machines

IEEE 112-1996: Test Procedures for Polyphase Induction Motors and Generators

UL 1741: $\quad \S 46.3$ Anti-Islanding Test

CA Rule 21: $\quad \S D$. Generating Facility Design and Operating Requirements

$\S D .2$. Prevention of Interference (specifies limitations on effects to system from DR [e.g., voltage, harmonics, flicker, etc.]) 


\subsubsection{Test Objectives}

The objective of this test is to determine the stability characteristics of individual DR interconnected with the utility distribution system.

\subsubsection{Key Testing Parameters}

The key testing parameters are:

- Connection mode (grid [radial and network], islanded)

- DR type (synchronous, induction, inverter-based)

- Length of feeder between DR and utility

- Type of loads on feeder, particularly large rotating loads

- DR control types (governor, exciter, etc.) and speed of response

- Power level of DR (percent of rating)

- Penetration level (DR as a percent of feeder load)

- Location, type (single-phase, phase-phase, and three-phase, bolted, high-impedance) and duration of fault

- Stiffness ratio of system.

\subsubsection{Expected Results}

This text should provide information about the:

- Relationship of DR power level to stability margin

- Relationship of DR type to stability margin

- Natural modes of oscillation (if any) of the DR, between the DR and the system, and between DR and feeder loads

- Relationship of fault duration to stability margin of DR

- Relationship of stiffness ratio to stability margin of DR

- Stability margin under islanded conditions versus grid-connected conditions.

\subsubsection{Test Procedure}

Follow industry standards to the extent possible.

1. Connect DR to the simulated utility.

2. Connect loads equal to DR rated power.

3. Bring DR and loads up, operating in parallel with the simulated utility.

4. Simulate a fault (single- or three-phase, as appropriate) on the EPS by throwing a switch from the appropriate circuit points to ground for a time equal to or less than the maximum fault clearing time dictated by the protective equipment.

5. Measure the magnitude and phase angle of the output current of the DR during the fault period.

6. Measure the magnitude and phase angle of the terminal voltage of the DR before, during, and after the fault period. 
7. Plot the voltage(s) and current(s) versus time to ascertain the frequency of oscillation and damping of the DR after the fault.

8. Perform test for both grid-connected (radial and network) and islanded conditions.

9. Vary the test by the time duration of the fault to determine the maximum time the machine remains stable (i.e., does not slip out of synchronism or oscillate indefinitely).

10. Vary the test by the distance of the fault from the DR to gauge the effect of impedance between the fault and DR on fault duration.

11. Vary the test by type of DR (synchronous generator, induction generator, inverterbased).

12. Vary the test by stiffness ratio.

13. Vary the test by types of loads on the feeder, particularly large rotating loads.

14. Vary the test by penetration level (i.e., DR output as percentage of load on feeder).

\subsubsection{Data Acquisition Requirements}

Table 54. DR Stability Characterization Test Data Acquisition Requirements

\begin{tabular}{lccccc}
\hline \multicolumn{1}{c}{ Parameter } & Units & Range (Nom.) & Accuracy & Sampling Rate & Recording Rate \\
\cline { 2 - 6 } & & & & \\
DR voltage (three-phase) & Volts & $0-600$ & $\pm 1 \mathrm{~V}$ & $6 \mathrm{kHz}$ & $6 \mathrm{kHz}$ \\
DR current (three-phase) & Amps & $0-100$ & $\pm 1 \mathrm{~A}$ & $6 \mathrm{kHz}$ & $6 \mathrm{kHz}$ \\
Utility voltage (three-phase) & Volts & $0-15 \mathrm{kV}$ & $\pm 0.1 \mathrm{kV}$ & $6 \mathrm{kHz}$ & $6 \mathrm{kHz}$ \\
Utility current (three-phase) & Amps & $0-500$ & $\pm 1 \mathrm{~A}$ & $6 \mathrm{kHz}$ & $6 \mathrm{kHz}$ \\
\hline
\end{tabular}

\subsubsection{Control Requirements}

The control system must coordinate the imposition of a fault within a specified data recording period. For example, once the system is in steady state, all parameters for $5 \mathrm{~s}$ before the fault, during the fault, and for 1 min afterward should be recorded. 


\subsubsection{Facility Requirements}

Table 55. DR Stability Characterization Test Facility Requirements

\begin{tabular}{lccl}
\hline \multicolumn{1}{c}{ Type } & Quantity & Size & Other \\
\cline { 2 - 4 } & \multicolumn{3}{c}{} \\
DR test bay & 1 & $10 \mathrm{ft} \times 20 \mathrm{ft}$ & \\
Load bank & $1+$ & Variable & Per rating of DR in test \\
Feeder system (or simulator) & 1 & $2-32 \mathrm{mi}$ & \\
Ground switch & 1 & $500 \mathrm{~A}$ & To initiate faults \\
Impedance (load bank) & 1 & Variable & To simulate fault impedance \\
Current transformers & 2 & $5 \mathrm{~A}$ & \\
Potential transformers & 3 & $480 \mathrm{~V}$ & \\
& & & \\
\hline
\end{tabular}

\subsubsection{DR Requirements}

Table 56. DR Stability Characterization Test DR Requirements

\begin{tabular}{lcc}
\hline \multicolumn{1}{c}{ Type } & Quantity & Size \\
\cline { 2 - 3 } & & \\
Inverter, any prime mover & 1 & $2-200 \mathrm{~kW}$ \\
Synchronous generator & 1 & $10-1,000 \mathrm{~kW}$ \\
Induction generator & 1 & $10-1,000 \mathrm{~kW}$ \\
\hline
\end{tabular}

\subsubsection{Other Requirements}

A plotter is needed to produce transient curves from logged data.

\subsubsection{Modeling Input Required}

Modeling input is not required for these tests, but it is desirable to have if available. Results of tests can be correlated with model data to gauge the accuracy of manufacturers' supplied data.

- Machine parameters:

Reactance, transient reactance, subtransient reactance, frequency of oscillation, rotating inertia

- Control system parameters:

Excitation and governor system time constants, gain settings, droop, etc. 


\subsubsection{DR-to-DR Stability Test}

4.10.2.1 Governing IEEE 1547, CA Rule 21, and Other Document Sections

IEEE 1547: \$4.0. Interconnection Technical Specifications and Requirements

\$4.2. Response to Area EPS Abnormal Conditions

$\S 4.2 .1$. Voltage Disturbances

\$4.2.4. Loss of Synchronism

\$4.4. Islanding

\$4.4.1. Unintentional Islanding

§5.0. Test Specifications and Requirements

$\S 5.1$. Interconnection Test

\$5.1.8 Unintentional Islanding Test

IEEE 115-1995: Test Procedures for Synchronous Machines

IEEE 112-1996: Test Procedures for Polyphase Induction Motors and Generators

UL 1741: Inverters, Converters, and Controllers for Use in Independent Power Systems, §46.3: Anti-Islanding Test

CA Rule 21: $\quad \S D$. Generating Facility Design and Operating Requirements

$\S D .2$. Prevention of Interference (specifies limitations on effects to system from DR [e.g., voltage, harmonics, flicker, etc.])

\subsubsection{Test Objectives}

The test objectives are to determine the possible reductions in stability margin and the potential for inter-oscillation among DR and between DR and loads when multiple DR are interconnected with the distribution system.

\subsubsection{Key Testing Parameters}

The key testing parameters are:

- Connection mode (grid [radial and network], islanded)

- DR types (synchronous, induction, inverter-based)

- Length of feeder between DR and utility

- DR control types (governor, exciter, etc.) and speed of response

- Type of loads on feeder, particularly large rotating loads

- Power levels of DR (percent of rating)

- Penetration level (DR as percent of feeder load)

- Location, type (single-phase, phase-phase, and three-phase, bolted, high-impedance), and duration of fault

- Stiffness ratio of system. 


\subsubsection{Expected Results}

This test should provide information about the:

- Relationship of power levels of DR to stability margin

- Relationship of DR type(s) to stability margin

- Modes of oscillation (if any) among the DR, between the DR and the system, and between DR and feeder loads

- Relationship of fault duration to stability margin of system

- Relationship of stiffness ratio to stability margin system

- Stability margin under islanded conditions versus grid-connected conditions.

\subsubsection{Test Procedure}

Follow industry standards to the extent possible.

1. Connect DR to the simulated utility in various combinations:

- Similar DR of same size and loading

- Similar DR, dissimilar sizes

- Similar DR, same sizes, different control settings

- Synchronous DR versus induction DR

- Synchronous DR versus inverter-based DR

- Induction DR versus inverter-based DR

- Other (as experience dictates).

2. Connect loads equal to total output power of DR.

3. Bring DR and loads up, operating in parallel with the simulated utility.

4. Simulate a fault (single- or three-phase, as appropriate) on the EPS by throwing a switch from the DR's terminals to ground for a time period equal to or less than the maximum fault clearing time required for the DR.

5. Measure the magnitude and phase angle of the output current of the DR during the fault period.

6. Measure the magnitude and phase angle of the terminal voltage of the DR before, during, and after the fault period.

7. Plot the voltage(s) and current(s) versus time to ascertain the frequency of oscillation and damping of the DR after the fault.

8. Perform test for both grid-connected (radial and network) and islanded conditions.

9. Vary the test by the time duration of the fault to determine the maximum time the machine remains stable (i.e., does not slip out of synchronism or oscillate indefinitely).

10. Vary the test by the distance of the fault from the DR to gauge the effect of impedance between the fault and DR on fault duration. 
11. Vary the test by stiffness ratio.

12. Vary the test by types of loads on the feeder, particularly large rotating loads.

13. Vary the test by penetration level (i.e., DR output as percentage of load on feeder).

14. Vary the test by types of DR (synchronous generator versus synchronous generator, synchronous generator versus induction generator, synchronous generator versus inverter-based, etc).

\subsubsection{Data Acquisition Requirements}

Table 57. DR-to-DR Stability Test Data Acquisition Requirements

\begin{tabular}{lccccc}
\hline \multicolumn{1}{c}{ Parameter } & Units & Range (Nom) & Accuracy & Sampling Rate & Recording Rate \\
\cline { 2 - 6 } & & & & \\
DR voltage (three-phase) & Volts & $0-600$ & $\pm 1 \mathrm{~V}$ & $6 \mathrm{kHz}$ & $6 \mathrm{kHz}$ \\
DR current (three-phase) & Amps & $0-100$ & $\pm 1 \mathrm{~A}$ & $6 \mathrm{kHz}$ & $6 \mathrm{kHz}$ \\
Utility voltage (three-phase) & Volts & $0-15 \mathrm{kV}$ & $\pm 0.1 \mathrm{kV}$ & $6 \mathrm{kHz}$ & $6 \mathrm{kHz}$ \\
Utility current (three-phase) & Amps & $0-500$ & $\pm 1 \mathrm{~A}$ & $6 \mathrm{kHz}$ & $6 \mathrm{kHz}$ \\
& & & & & \\
\hline
\end{tabular}

\subsubsection{Control Requirements}

The control system must coordinate the imposition of a fault within a specified data recording period. For example, once the system is in steady state, all parameters for $5 \mathrm{~s}$ before fault, during the fault, and for 1 min afterward should be recorded.

\subsubsection{Facility Requirements}

Table 58. DR-to-DR Stability Test Facility Requirements

\begin{tabular}{lclll}
\hline \multicolumn{1}{c}{ Type } & Quantity & Size & \multicolumn{1}{c}{ Other } \\
\cline { 2 - 4 } & & & \\
DR test bay & 3 & $10 \mathrm{ft} \times 20 \mathrm{ft}$ & \\
Load bank & $1+$ & Variable & Per ratings of DR in test \\
Feeder system (or simulator) & 1 & $2-32 \mathrm{mi}$ & \\
Ground switch & 1 & $500 \mathrm{~A}$ & To initiate faults \\
Impedance (load bank) & 1 & Variable & To simulate fault impedance \\
& & & \\
\hline
\end{tabular}




\subsubsection{DR Requirements}

Tests should be done with combinations of single- and three-phase DR.

Table 59. DR-to-DR Stability Test DR Requirements

\begin{tabular}{lcl}
\hline \multicolumn{1}{c}{ Type } & Quantity & \multicolumn{1}{c}{ Size } \\
\cline { 2 - 3 } & & \\
Inverter, any prime mover & $1+$ & $2-200 \mathrm{~kW}$ \\
Synchronous generator & $1+$ & $10-1,000 \mathrm{~kW}$ \\
Induction generator & $1+$ & $10-1,000 \mathrm{~kW}$ \\
& &
\end{tabular}

\subsubsection{Other Requirements}

A plotter is needed to produce transient curves from logged data.

\subsubsection{Modeling Input Required}

Modeling input is not required for these tests, but it is desirable to have if available. Results of tests can be correlated with model data to gauge the accuracy of manufacturers' supplied data.

- Machine parameters:

Reactance, transient reactance, subtransient reactance, frequency of oscillation, rotating inertia

- Control system parameters:

Excitation and governor system time constants, gain settings, droop, etc.

\subsection{Cold Load Pickup Tests}

Although the issue of cold load pickup after an outage is of concern to both the Area EPS operator and the customer, the solutions to the problem are load- and DR control strategyrelated. Type testing would adequately show if a load-DR control system is able to provide the desired relief to the Area EPS and customer. No DUIT-related tests have been defined.

\subsection{Faults on Adjacent Feeders Tests}

Issues identified as related to faults on feeders adjacent to those with DR are addressable through testing individual substation components (type testing), modeling of high penetration scenarios, or both. No DUIT-related tests have been identified specifically for this area.

\subsection{Network Secondary Tests}

Although there are many items related to network secondaries that are important to the implementation of DR, there are ongoing discussions about the requirements and issues. DUIT testing certainly can and should consider these issues, but this area of testing should be developed after further consideration of any consensus or priorities that result in this area. 


\subsection{Substation Backfeed Tests}

Issues identified as related to substation backfeed are addressable through testing of individual substation components (type testing), modeling of high penetration scenarios, or both. No DUIT-related tests have been identified specifically for this area. 


\subsection{Prioritization}

Table 60. Prioritization of Issues

\begin{tabular}{|c|c|c|c|c|c|c|c|c|}
\hline & Position & $\begin{array}{l}\text { Highest } \\
\text { Priority }\end{array}$ & Priority \#2 & Priority \#3 & Priority \#4 & Priority \#5 & Etc. & Unimportant \\
\hline Lynnda Ell & $\begin{array}{l}\text { Utility } \\
\text { engineer }\end{array}$ & $\begin{array}{l}\text { Voltage } \\
\text { regulation }\end{array}$ & Reclosing & $\begin{array}{l}\text { Synchroniza- } \\
\text { tion }\end{array}$ & Short circuit & Stability & & $\begin{array}{l}\text { Too much emphasis on } \\
\text { islanding }\end{array}$ \\
\hline Wall & DR mfg & $\begin{array}{l}\text { Islanding w/ } \\
\text { motor }\end{array}$ & $\begin{array}{l}\text { Islanding w/ } \\
\text { mixed DR }\end{array}$ & $\begin{array}{l}\text { Recloser } \\
\text { coordination }\end{array}$ & Stability & & & \\
\hline SRP & $\begin{array}{l}\text { Utility } \\
\text { engineer }\end{array}$ & Islanding & & & & & & \\
\hline Koepfinger & $\begin{array}{l}\text { Utility } \\
\text { engineer }\end{array}$ & & & & & & & \\
\hline Sun & $\begin{array}{l}\text { Utility } \\
\text { engineer }\end{array}$ & Islanding & & & & & & $\begin{array}{l}\text { Others much less } \\
\text { important }\end{array}$ \\
\hline Redding & $\begin{array}{l}\text { Utility } \\
\text { engineer }\end{array}$ & $\begin{array}{l}\text { Fuse } \\
\text { coordination } \\
\text { (7) and short } \\
\text { circuit (9) }\end{array}$ & $\begin{array}{l}\text { Islanding }(2.2 \text {, } \\
2.3,2.4)\end{array}$ & $\begin{array}{l}\text { Sectionalizer } \\
(5)\end{array}$ & $\begin{array}{l}\text { Voltage } \\
\text { regulation } \\
(3)\end{array}$ & $\begin{array}{l}\text { Faults on } \\
\text { adjacent } \\
\text { feeder (12) } \\
\text { and } \\
\text { substation } \\
\text { backfeed }\end{array}$ & $\begin{array}{l}\text { Network } \\
\text { secondary } \\
\text { moves way } \\
\text { up if DR } \\
\text { allowed }\end{array}$ & $\begin{array}{l}\text { Remaining tests not } \\
\text { much value }\end{array}$ \\
\hline Grebel & $\begin{array}{l}\text { Utility } \\
\text { engineer }\end{array}$ & Islanding & $\begin{array}{l}\text { High } \\
\text { penetration } \\
\text { (fuse/recloser } \\
\text { coordination) }\end{array}$ & $\begin{array}{l}\text { Ferro- } \\
\text { resonance } \\
\text { because of } \\
\text { shunt cap } \\
\text { banks }\end{array}$ & & & & \\
\hline $\begin{array}{l}\text { Hudson } \\
\text { Ball }\end{array}$ & $\begin{array}{l}\text { DR mfg } \\
\text { System } \\
\text { integrator }\end{array}$ & Islanding & & & & & $\begin{array}{l}\text { Others are } \\
\text { important }\end{array}$ & \\
\hline
\end{tabular}




\section{Project Plan}

\subsection{Introduction}

\subsubsection{DUIT Project Rationale}

The DUIT project represents the first full-scale integration test of electric distribution systems with multiple distributed generation and storage technologies. The DUIT project confronts a broad range of issues and concerns related to interconnecting DR to the utility distribution system. The test plan includes detailed exercising and sophisticated monitoring of the interaction of the various DR with one another and with the electric utility grid. Furthermore, DUIT is designed to illuminate certain specific issues-both problems and benefits - with regard to the level of penetration of DR into the electric distribution system. These issues include interconnection technologies and practices; interconnection equipment performance and functional characterization; instrumentation, monitoring, and control technologies; and methods of controlling and dispatching DG remotely in a utility/regional hierarchical scheme and in a local/independent mode.

Multiple distributed generators, storage devices, load banks (resistive, capacitive, and inductive), and other components will be installed at the test site and operated in a variety of configurations, including autonomous control (each DR controls itself independent of other DR) and aggregated control (centralized control operates some or all of the DR for protection, load management, and other reasons). Aggregated control will use state-ofthe-art control, communications, and data-logging systems. The DR will be interconnected to the distribution system with a variety of configurations, representing the least-understood conditions as well as those of greatest concern.

In the process of examining the available sites, the team developed selection criteria for evaluating sites for DUIT. These criteria led to the conclusion that the sites most likely to be considered prime candidates for DUIT will be those that have existing DR technologies, testing and monitoring infrastructure, and the collaboration and support of the host utility. Also, the presence of staff experienced in the DR field, flexible loads, and a re-configurable distribution system are considered important, positive factors. It was initially believed that no single site would be sufficient for accommodating all DUIT testing; however, a site was selected that is sufficient for completing all of the test protocols as documented in the DUIT Test Plan.

\subsubsection{Project Objectives}

The objectives of this project were to bring together a team of diverse stakeholders to create a project plan that includes all the elements necessary to exercise a scientifically rigorous hardware test of DR and their effects on, and interactions with, the electric grid.

To achieve these objectives, the DUIT Test Plan includes the creation of the team, the host site evaluation and selection process, and the assessment of available distributed generation and storage technologies. It also encompasses the development of the "test protocols," detailed descriptions of the specific test procedures, which are contained in 
Chapter 4. Finally, the Test Plan includes a description of the control and data acquisition requirements.

The primary objective of the DUIT project is to advance the state of the art in distributed generation and storage integration practices and strategies to accelerate the market entry of advantageous modular technologies and lead to lower ratepayer cost of service and improved service quality and reliability.

The goals of the DUIT project are to prove the feasibility and quantify the benefits of the integration of diverse distributed generation and storage technologies in a distribution system and to provide a testing ground for observing and measuring the beneficial or detrimental interactions among the distributed technologies on the distribution system. These goals require a project that will entail full-scale multi-megawatt implementation, testing, and demonstration of DG technologies in an actual utility installation.

From the customer's perspective, proof is needed that traditional and emerging technologies can work together seamlessly to provide the desired mixture of benefits (to multiple stakeholders).

Utilities are seeking evidence that any of these technologies can be used as reliable energy resources to improve system operation and lower the cost of electric service for all customers.

Technology development stockholders have a significant interest in DUIT because it provides a vehicle for demonstrating the benefits of their equipment to customers, utilities, and regulators. Confidence by these bodies could remove significant barriers to the wide adoption and implementation of DER technologies. Large-scale adoption also creates the opportunity for new business initiatives, such as the development of privately held, independent DR generation and storage projects.

From a policy standpoint, federal, state, and utility regulators will be more confident as they consider standardization of interconnection procedures.

The increasing potential of DR in emerging utility markets has focused attention on two critical issues: the interconnection of DR with the electric distribution system and the unknown nature of potential interactions among multiple distributed devices.

Interconnection is a critical issue because of the diversity of distributed technologies and the variability of interconnection standards and practices from state to state and utility to utility. Interactions among multiple DR are largely unpredictable because of limited operating experience to date; this uncertainty contributes to the inhibition of market acceptance of DR.

By examining current and emerging technologies and operational concepts to properly integrate diverse DR, this project will provide new insights into grid support issues and will ultimately suggest innovative system protection design concepts. In particular, the DUIT will illuminate the following issues of interest to DOE: 
- Universal distributed and electric power system interconnection technology, including current and advanced/future designs and requirements and tests for interconnection

- Interconnection equipment performance and functional characterization and installation test method design, development, validation, and documentation

- Command, control, communication, monitoring, and remote and on-site intelligent controls for interconnection

- Interconnection equipment/technology tests and procedures

- Design and development requirements for the establishment of an industry-wide third party for interconnection equipment and on-site interconnection approval.

The following sections of this chapter provide a description of the DUIT project. Section 5.2 describes how the members were selected and how the DUIT project team was formed. Section 5.3 is an in-depth analysis of the site selected as the leading candidate: PG\&E's MGTF. Section 5.4 provides the rationale behind the choice of particular technologies selected to be included in DUIT. Section 5.5 is a technical overview of the test plan, organized by specific testing categories as laid out in the DUIT test protocols. Section 5.6 describes the control and DASs that are expected to be necessary for fulfilling the data requirements for DUIT. Section 5.7 is a summary of the DUIT project.

\subsection{Assembling the Team}

\subsubsection{The DUIT Team}

The DUIT project was not the idea of a single person but rather the shared vision of many activists in the DER community over the past decade. Thus, the team that eventually defined and detailed the DUIT project is diverse and national in scope.

The current members of the DUIT team are:

- Pacific Gas and Electric Co. (PG\&E)

- Salt River Project

- Niagara Mohawk

- Exelon (Philadelphia Electric/Commonwealth Edison)

- Sacramento Municipal Utility District

- Edison Electric Institute

- U. S. DOE/National Renewable Energy Laboratory

- California Energy Commission

- Gas Research Institute (former)

- Encorp

- Caterpillar/Solar Turbines

- Capstone Turbines

- Distributed Utility Associates 
- Endecon Engineering

- On-Site Energy

- Public Utility Commission of Texas.

This broad consortium was formed and is led by Distributed Utility Associates.

Because the DUIT would address the national need to study distributed generation and storage and its effects on utility systems, a host utility with substantial resources for testing, PG\&E, was critically important in bringing credibility to the team from the utility point of view. The other utilities (or utility groups) on the team-Salt River Project, Niagara Mohawk, Exelon (Philadelphia Electric/ComEd), Sacramento Municipal Utility District, and the Edison Electric Institute - provided balance and a national perspective. Other utility staff around the United States reviewed drafts or otherwise provided value to the effort.

The field testing (needed to support the development of new concepts, topologies, and technologies for the application and control of distributed power resources) would not be inexpensive and must be national in scope to maximize its value to the DER community. National DR research and development organizations and the most prominent state DR research and development organizations have been deeply involved in defining and optimizing the DUIT. The US DOE, through NREL, has sponsored this design project, and the California Energy Commission and the Gas Research Institute were part of the initial team that proposed it to DOE. The California Energy Commission has been especially attentive to the progress of the DUIT design and hopes to leverage the test designs into a much-needed field test quickly.

The purveyors of DR equipment are interested in the limitations of integration of DR into distribution systems and especially the effects of multiple, diverse DER in highpenetration scenarios. Because the integration tests are not limited to IEEE P1547 draft standards and are, in fact, intended to provide information that could refine or supplement those standards, DR hardware manufacturers such as Encorp, Caterpillar, Solar Turbines, and Capstone have been supportive. Encorp, the leading manufacturer of control systems for distributed generators, was part of the original proposal team.

The project design team is rounded out by consulting organizations - such as Distributed Utility Associates, Endecon Engineering, and On-Site Energy - that provide market intelligence, manufacturer contacts, field installation, and site-related experience.

\subsubsection{Matching DUIT to Diverse Stakeholder Needs}

The DUIT design process has been open to public scrutiny and participation to gather input regarding DR community stakeholder needs for such testing.

NREL has required DUIT plan development presentations at each of its quarterly Distribution and Interconnection R\&D reviews, at which project managers, program managers, and other program participants provide their input. 
The DUIT plan was developed to match the needs of the diverse stakeholders in the implementation of DR. Team members, outside utility protection engineers, and technology development companies have all been used in the construction and review of the DUIT plan.

The effect of having DUIT's technical answers will differ depending on the stakeholder.

- Regulators will be able to make more informed decisions regarding the adoption of IEEE P1547 or other proposed interconnection standards.

- Utilities will be able to see firsthand the protection afforded by those standards and better understand the remaining issues.

- Utilities will better understand and accept deeper DR penetration of the distribution system.

- Utilities and distribution companies will have more confidence in the use of DR for their own purposes.

- ISOs, RTOs, generation companies (GENCOs), transmitting utilities (TRANSCOs), and energy brokers will have more confidence in the operation and benefits of grid-connected DG.

- DG installations will be less likely to have excessive interconnection costs imposed because of fears of potential adverse effects.

- Customers will have more assurance that their DR will be interconnected safely, smoothly, and with minimum cost.

- Customers will be less likely to be adversely affected by their neighbor's DR.

- Manufacturers will be able to better anticipate the types of protection devices required for most beneficial incorporation of DG into utility systems or at customer sites.

- Standards-setting bodies such as IEEE will feel more (or less) comfortable about aspects of the current standards, leading them to refine, reconsider, or expand subsequent versions.

- Some stakeholders will consider the DUIT a good first step but still inadequate to resolve some of their most important issues.

\subsubsection{Sharpening the Test Plan}

The DUIT Plan was developed in the context of all of the landmark work done on DER integration and interconnection in the United States to date. IEEE P1547 working group participants, especially Richard DeBlasio and Murray Davis, helped start the list of testing issues, and Edison Electric Institute and EPRI provided major input to that IEEE effort. Members of the DUIT team have been active in IEEE P1547 development from the beginning. 
Other vital inputs and points of departure have come from California Rule 21 and the recently issued Texas DG interconnection rules and manual. Again, the DUIT team has been involved firsthand with both of these activities.

PG\&E has been especially generous with its support of the DUIT project and has encouraged staff beyond DUIT team members to review and discuss the needs of the utility industry for such testing.

\subsubsection{Looking Forward}

The two factors that will ultimately determine the widespread acceptance of DR are overcoming existing electrical concerns regarding large-scale DER operation on distribution systems and confirming that the identified benefits of such generation can, in fact, be realized in real-world settings. Broadly, the results obtained from DUIT testing will be targeted at answering these questions.

Clearly, the next step must be for a major research and development organization to step forward to take responsibility for constructing and operating all or part of the DUIT facility. Such construction could be phased to meet the most urgent testing needs.

\subsection{Details of the Leading Site Candidate}

\subsubsection{Overview}

The PG\&E Modular Generation Test Facility was expressly designed for DR testing. In particular, advanced DG systems such as natural gas engines and fuel cells were extensively tested here in the late ' 80 s and early '90s. Consequently, the array of equipment and expertise of personnel on site are extensive and of high caliber.

Upgrades to accommodate DUIT testing appear straightforward and the costs reasonable. The MGTF can accommodate radial, network, and island test configurations at distribution voltages. MGTF personnel have considerable experience in testing and research in distribution systems and equipment. A detailed discussion of the necessary upgrades is provided later.

TES has unique capabilities for testing and evaluating DR equipment and their interactions with a utility grid. The site houses several facilities that could be used to perform the types of tests envisioned for the project. This includes the MGTF, which was constructed more than 10 years ago for research and demonstration of new generation technologies. The facility is designed for testing grid-connected and off-grid power generation and storage technologies. Although it has not been used for this purpose for several years, much of the necessary hardware and infrastructure is still in place. The second facility is an outdoor area adjacent to the MGTF called the Smart Substation. This facility contains additional capabilities for DR testing and is electrically connected to the MGTF and the utility grid. The 1-MVA transformer at this facility is fully instrumented for thermal performance monitoring. The third facility is another outdoor area adjacent to the MGTF called the High Current Yard. This facility has a separate utility grid 
connection and historically has been used for full-power testing of transformers, capacitors, switchgear, and other distribution hardware.

In addition, TES works closely with PG\&E's transmission and distribution personnel on technical areas of investigation related to day-to-day utility operation issues. One of these issues is the effect of DR technologies on the PG\&E grid.

An overall site plan for the TES facility is shown in Figure 26. The MGTF, Smart Substation, and High Current Yard are listed in bold and have circles as label symbols.

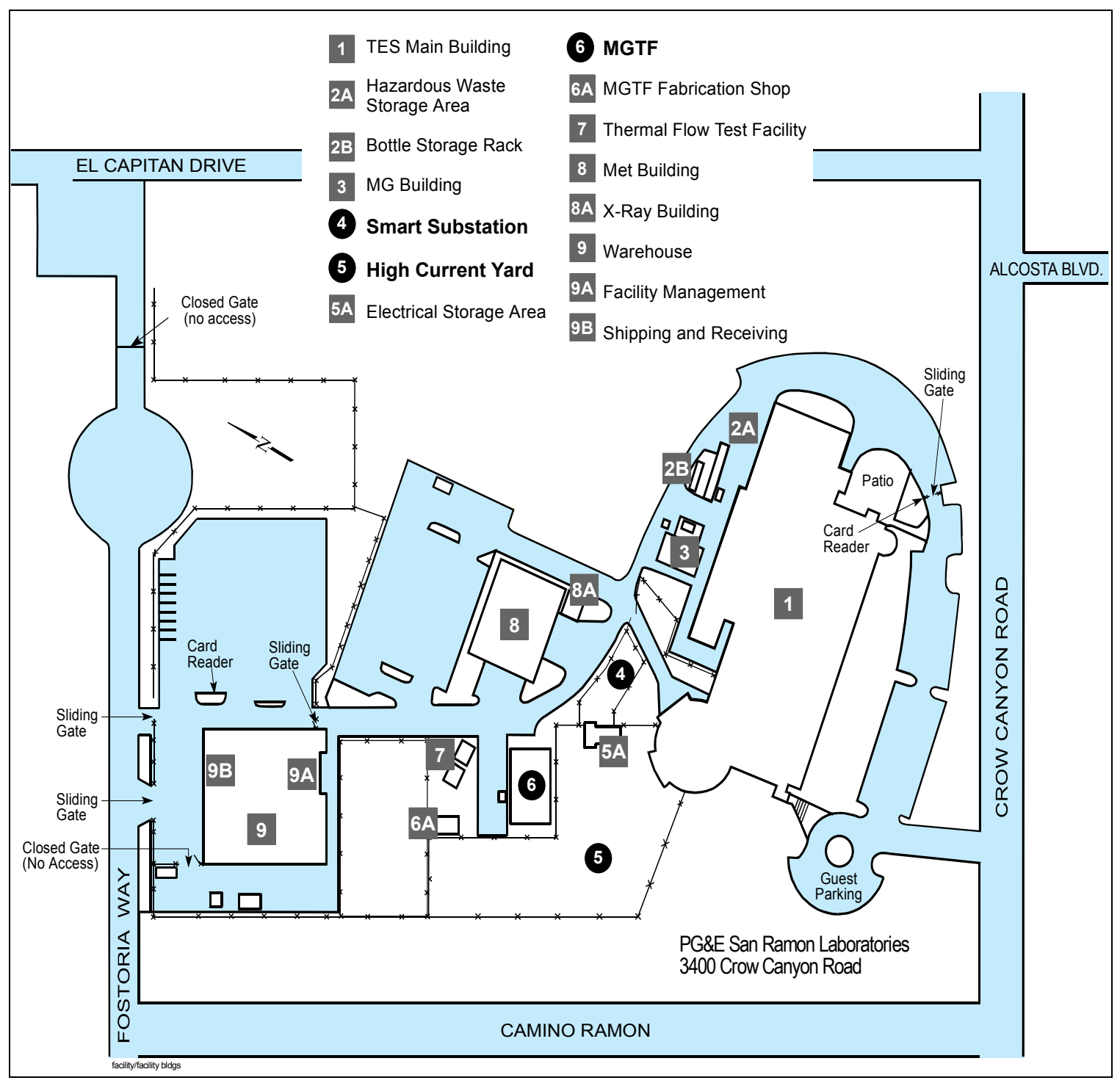

Figure 26. Overall TES site plan 


\subsubsection{Existing Test Facilities (MGTF, Smart Substation, High Current Yard)}

An overall, simple diagram of the three facilities, showing how they are connected to one another and to the utility grid, is given in Figure 27. A single line diagram of the MGTF and Smart Substation is shown in Figure 28, and Figure 29 shows a single line diagram for the High Current Yard. Table 61 gives a summary of the features of these three facilities. Table 62 gives some additional details for the MGTF.

In summary, the MGTF and Smart Substation have the following:

- A 70-ft-by-40-ft building designed for DR testing (the MGTF)

- An additional outdoor area available for DR testing (the Smart Substation)

- Capability of up to a 1.5-MW grid connection

- Three-phase, 480-V wye service

- Multiple bus configurations for islanding capability

- Protection for utility under/overfrequency, under/overvoltage, and ground fault current

- 400-kW variable resistive load controllable in 5-kW increments

- 300-kVAR variable inductive load controllable in 3.75-kVAR increments

- Additional capacitance, resistance, and inductance that can be added as required

- Up to 30-mi simulated distribution line

- 1 -in., 50-psi natural gas supply

- 8-ft-by-13-ft acoustic isolation enclosure for engine tests.

The High Current Yard is a large area adjacent to the MGTF that is connected to a 230$\mathrm{kV}$ transmission line. It has the potential to connect larger generating units to the grid and operate at various distribution voltage levels (i.e., 2.4-34.5 kV). However, the existing $230-\mathrm{kV}$ transformers present a limitation. Overheating problems allow them to be energized for no more than about 8 consecutive hours. It would be expensive to replace these transformers. However, for longer tests, an alternate scheme-bringing $21 \mathrm{kV}$ into the High Current Yard for DR testing and connecting it to the MGTF/Smart Substation facility — was evaluated for this report. This alternative appears to be practical. 


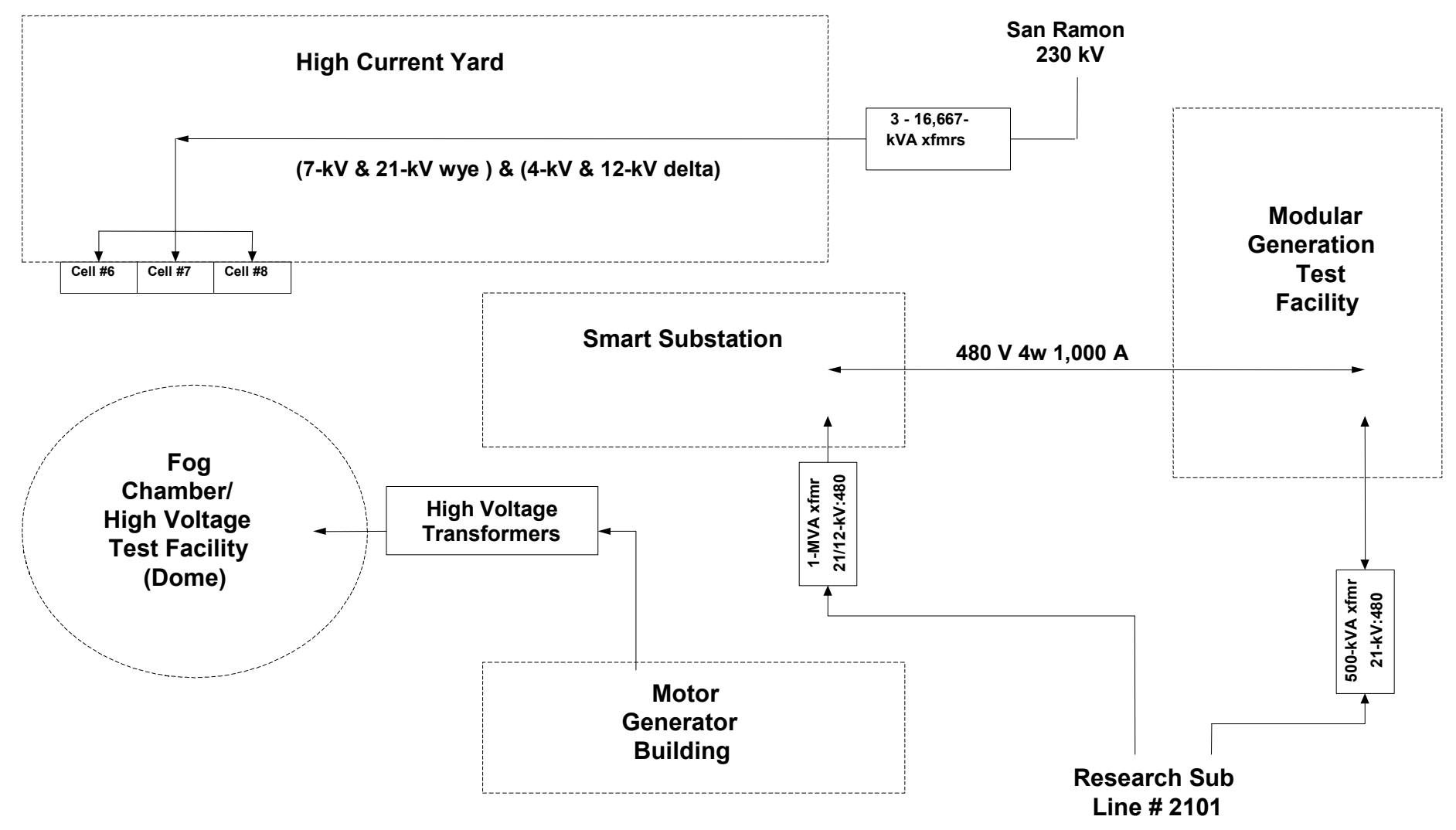

Figure 27. TES electrical test facilities 


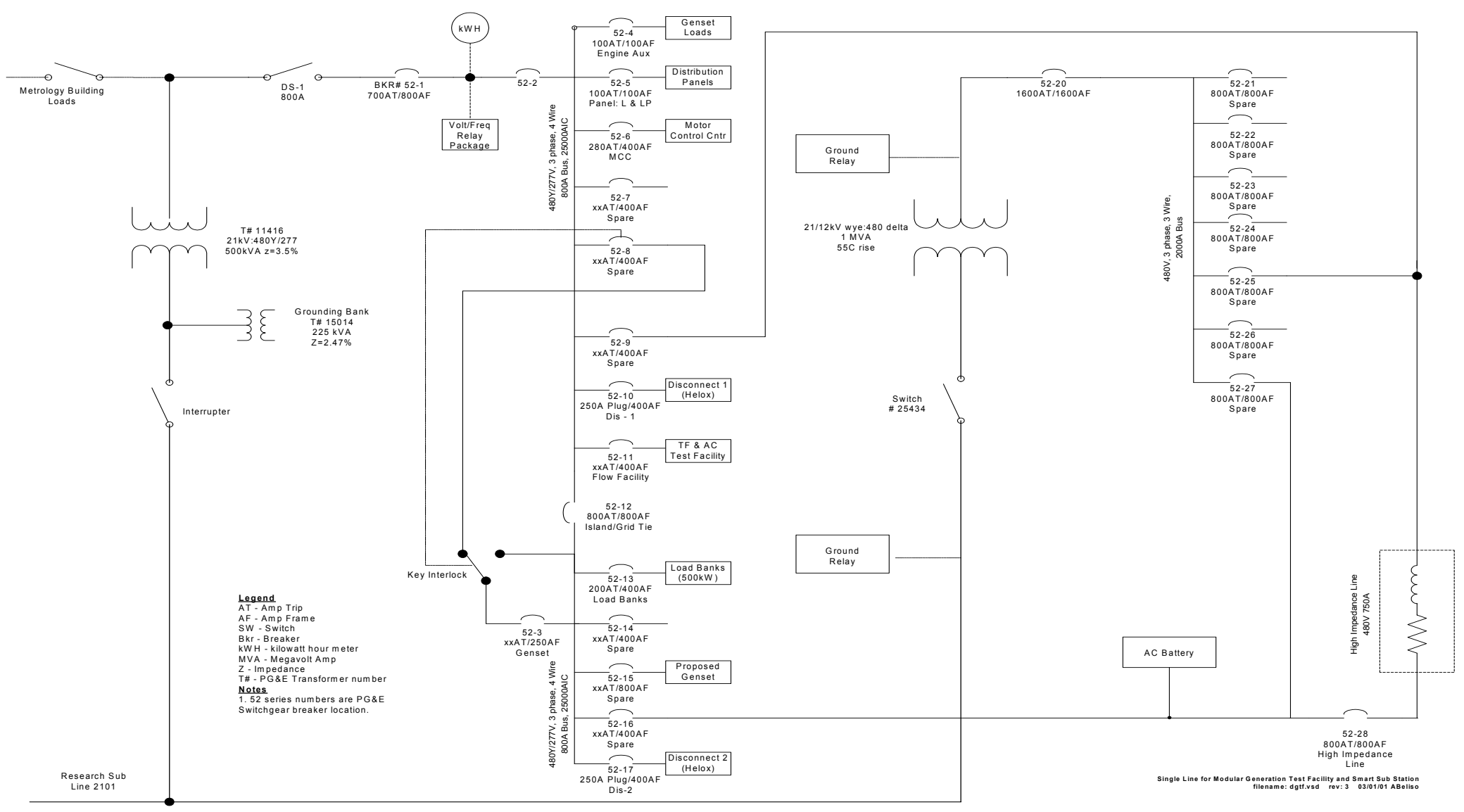

Figure 28. MGTF/Smart Substation single line diagram 


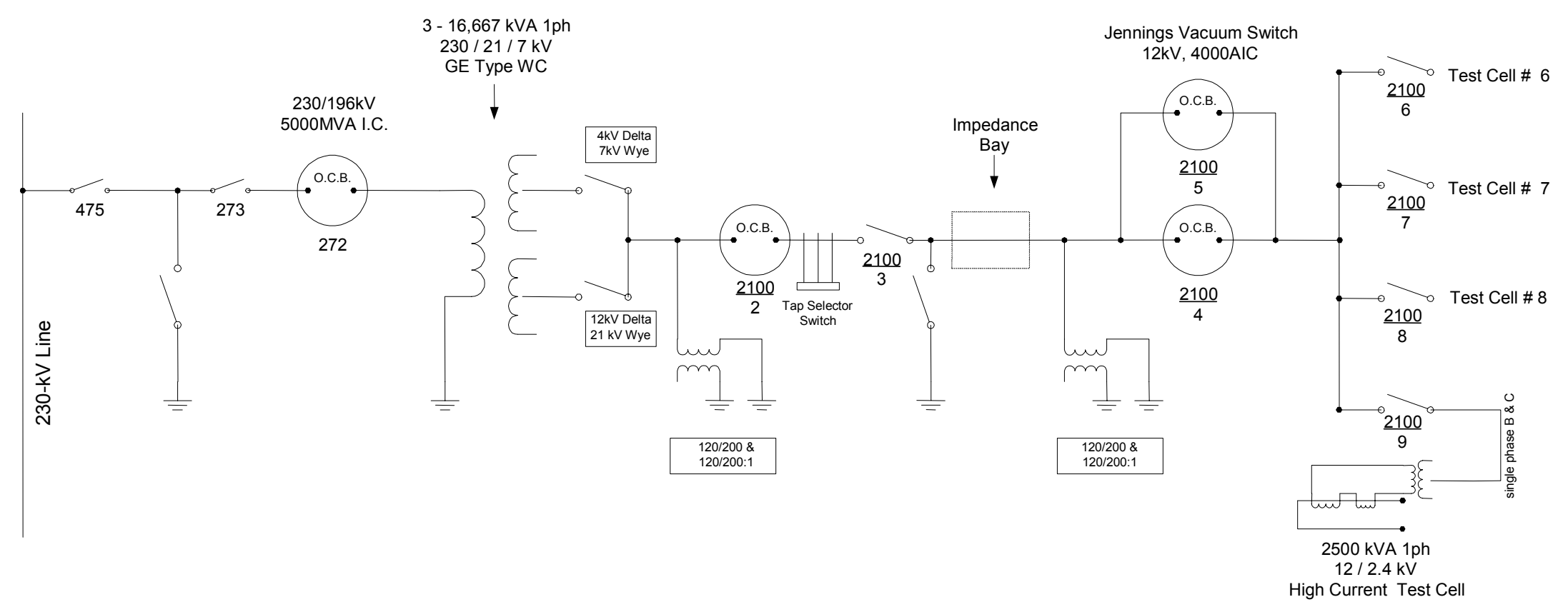

Figure 29. Schematic of PG\&E TES research facility 
Table 61. Smart Substation and High Current Yard Components

\begin{tabular}{|c|c|c|c|c|c|c|c|c|c|c|c|c|c|c|c|}
\hline & $\begin{array}{l}\text { Space } \\
\text { (sq ft) }\end{array}$ & Drawings & WYE & Delta & Controls & Circuits & Switchgear & Protection & $\begin{array}{c}\text { Load } \\
\text { Banks } \\
\end{array}$ & Xfrmrs & $\begin{array}{c}\text { Grid } \\
\text { Connect }\end{array}$ & \begin{tabular}{|c|} 
Equipment \\
Instrumention, \\
DAS
\end{tabular} & Existing & Gas & Permits \\
\hline MGTF & $2800 / 2000$ & Visio & 480 & 480 & synch & $\begin{array}{l}\text { grid and/or } \\
\text { island }\end{array}$ & & relay/fuse & $\begin{array}{c}\text { 500kw } \\
\text { (400res) } \\
\text { (300reac) }\end{array}$ & $\begin{array}{c}15,30,75,1 \\
12.5\end{array}$ & $\begin{array}{c}\text { research } \\
2101\end{array}$ & $\begin{array}{c}\text { various power } \\
\text { meters, } \\
\text { yokogawa,bmi, } \\
\text { wavebook, spec } \\
\text { analyzer, rpm, } \\
\text { ct,pt, infrared } \\
\text { temp, emf, and } \\
\text { others }\end{array}$ & \begin{tabular}{|c|} 
\\
flow facility \\
motor (100 hp, \\
var freq drive), \\
$2-50 \mathrm{kw}$ motors; \\
PV simulator \\
$(192 \mathrm{~kW})$
\end{tabular} & $\begin{array}{l}\text { Natural } \\
\text { gas } \\
\text { @50psi }\end{array}$ & $\begin{array}{l}\text { other fuel } \\
\text { requires } \\
\text { permit, } \\
\text { zinc } \\
\text { bromine } \\
\text { (notify fire } \\
\text { and city) }\end{array}$ \\
\hline $\begin{array}{c}\text { HIGH } \\
\text { CURRENT } \\
\end{array}$ & $\begin{array}{c}\text { Outdoor } \\
\text { na/6000+ }\end{array}$ & Visio & \begin{tabular}{|c} 
7kVA, 21 \\
$\mathrm{kVA}$
\end{tabular} & $\begin{array}{c}\text { 4kVA, } 12 \\
\mathrm{kVA}\end{array}$ & \begin{tabular}{|c|}
$2100 / 2$ \\
auto, \\
manual (air \\
breakers)
\end{tabular} & $\begin{array}{l}\text { grid (see } \\
\text { drawings) }\end{array}$ & $\begin{array}{c}\text { test cells - } \\
6,7,8 \\
2100 \mathrm{amp} \\
\end{array}$ & relay & $\begin{array}{c}\text { various } \\
\text { reactors, } \\
\text { adjustable } \\
\text { resitive } \\
\text { loads }\end{array}$ & $\begin{array}{c}230 \mathrm{kVA}: \\
2.4-34.5 \\
\mathrm{kV}\end{array}$ & $\begin{array}{c}\text { san ramon } \\
\text { sub }\end{array}$ & same as above & capacitors & none & $\begin{array}{c}\text { same as } \\
\text { above }\end{array}$ \\
\hline $\begin{array}{c}\text { SMART } \\
\text { SUB }\end{array}$ & $\begin{array}{l}\text { Outdoor } \\
\text { limited }\end{array}$ & Visio & & 480 & $\begin{array}{c}\text { Impedance } \\
\text { loop }\end{array}$ & grid or island & 2000A Bus & relay & $\begin{array}{c}\text { same as } \\
\text { MGTF }\end{array}$ & $\begin{array}{c}21 \mathrm{kV} \text { to } \\
480\end{array}$ & $\begin{array}{c}\text { research } \\
2101\end{array}$ & same as above & $\begin{array}{c}\text { PQ2000 battery } \\
\text { (2 MW for } 10 \\
\text { sec) }\end{array}$ & n/a & $\begin{array}{c}\text { same as } \\
\text { above }\end{array}$ \\
\hline
\end{tabular}


Table 62. MGTF Inventory

\begin{tabular}{|c|c|c|c|c|}
\hline Item & Description & Power Rating & Voltage & Notes \\
\hline Building & $70 \mathrm{ft}$ by $40 \mathrm{ft}$ & 500 kVA & $4804 w$ & Natural gas \\
\hline Working area & $1,800 \mathrm{ft}^{2}$ & & & Floor space \\
\hline SS switchgear & $9 \mathrm{ckt}$ brkr cell & $1,600 \mathrm{AF}$ & $4804 w$ & $1 @ 1,600$ \\
\hline MGTF switchgear & 10 ckt brkr cell & $800 \mathrm{AF}$ & $4804 w$ & Various \\
\hline PV simulator & DC power supply & $192 \mathrm{~kW}$ & $4803 w$ & \\
\hline Wavedriver & Inverter & $60 \mathrm{~kW}$ & 208 & \\
\hline Load bank & Simplex (resistive) & $400 \mathrm{~kW}$ & $4803 w$ & \\
\hline Load bank & Simplex (reactive) & 300 kVAR & $4803 w$ & \\
\hline Sound enclosure & $8 \mathrm{ft}$ by $13 \mathrm{ft}$ by $8 \mathrm{ft}$ & & & \\
\hline DC supply & Batteries & & $12-396$ VDC & (Can be increased) \\
\hline Impedance loop & (3) $2-1 / 2 \%$ Z steps & 750a continuous & $4803 w$ & Variable \\
\hline Island bus & & $500 \mathrm{kVA}$ & $4803 w$ & Grid or island \\
\hline Helox Connector 1 & Quick test & $250 \mathrm{kVA}$ & $4804 w$ & Grid \\
\hline Helox Connector 2 & Quick test & $250 \mathrm{kVA}$ & $4803 w$ & Island \\
\hline Helox Connector 3 & Quick test & $112.5 \mathrm{kVA}$ & $2084 w$ & Grid \\
\hline Amp Connector 1 & Quick test & $112.5 \mathrm{kVA}$ & 208 or 120 & 208 or $1203 p h$ \\
\hline Trace inverters (12) & 24 VDC & $4 \mathrm{~kW}$ & $1201 \mathrm{ph}$ & SW4024 \\
\hline$M C C-1$ & Motor control center & & $4804 w$ & \\
\hline Power meters & Yokogawa & & $600 / 600$ & $A C / D C$ \\
\hline$P Q$ meter & $P Q$ nodes & & & \\
\hline PQ THD meters & RPM & & $600 / 1,000^{*}$ & $24-000-1650$ \\
\hline Spectrum analyzer & $\mathrm{HP}$ & & & $1.5 \mathrm{GHz}$ \\
\hline JEM - 1 metering & Main utility meter & Transformer rated & $4804 w$ & \\
\hline Fuel Supply 1 & Natural gas & & & 1 in. @ 50 psi \\
\hline Fuel Supply 2 & Natural gas & & & $8,000 \mathrm{ft}^{3} 3,100 \mathrm{psi}$ \\
\hline Fuel Supply 3 & Natural gas & & & 5 cfm @ 3,100 psi \\
\hline
\end{tabular}

\subsubsection{Additional Capabilities}

PG\&E's TES Department provides a full range of testing, analytical, and environmental services at its 13-acre site and at field locations throughout the PG\&E system. TES has more than 140 engineers, scientists, and technicians who work in various areas, including:

- Failure analysis and service life enhancement

- Performance assessment and optimization

- Evaluation and development of measurement methods and test equipment

- Environmental assessment and compliance monitoring

- Meteorological measurement and forecasting

- In-service inspection

- Instrument calibration and repair

- Material and product evaluation

- Welding and machine shop. 
In regard to DR technology evaluation, capabilities exist for additional testing related to:

- Emissions

- Noise

- EMF

- Efficiency

- Vibration.

\subsubsection{Host Utility Commitments}

The host utility will be required to allocate the necessary personnel and facility resources for the duration of the project. This allocation includes time necessary for overall coordination with the project managers and other project members. Because of PG\&E's continued interest in DG technologies and their interaction with the utility grid, it is committed to making every effort to meet all the objectives described in this document that are authorized for the final project.

\subsubsection{PG\&E Facility Modifications Required for DUIT}

The PG\&E site can be easily upgraded and expanded to handle the full range of DUIT testing. Additional features and capabilities include:

- Variable resistive, reactive, and capacitive load banks at six DR sites

- Can accommodate up to 14 DR units, grouped in six sites, with isolation transformers

- Simulated impedance between three sites, 10-30 mi total

- Can increase the current maximum loading of $250 \mathrm{~kW}$ on any individual DR unit

- 480-V radial and network distribution

- At least six DR sites can operate at the same time

- 21-kV radial distribution system

- Other distribution voltage levels available.

Cost Estimates

A cost estimate for the range of options listed above was prepared by breaking the work into three areas:

- Facility Preparation

This was an overall cost based on project planning; modifications and materials needed in the facility; general instrumentation, data acquisition, and control setup and calibration; and teardown at the conclusion of the test.

- DR Unit Installation, Startup, and Commissioning This cost was estimated on a DR-unit basis and then multiplied by an assumed number of units to obtain an overall project cost. It included labor for planning each unit's installation, technician time during installation, individual instrumentation and control setup, unit startup, and commissioning tests. It did not include the cost of the DR unit. 
- $\quad$ Testing

Testing costs were estimated on a monthly basis. This included an assumed amount of technician and engineering time to run the tests 40 hours a week during normal business hours, time for data reduction, an assumed number of regular project meetings per month, and time for data summary and progress reports. Based on an assumed 1-year testing period, this monthly estimate was multiplied by 12 to obtain an overall testing estimate.

This cost estimate did not include fuel costs or costs for any overall DR system controls. The estimates included a $20 \%$ contingency because of the many unknowns concerning actual equipment and testing requirements at this time.

\subsection{Selecting the Technologies}

The DUIT project calls for the methodical testing of technologies and their interface to the electric grid. The purchase of DR hardware is beyond the budget and scope of the project; rather, commercial or near-commercial DR and related equipment will be rented, leased, or borrowed. This approach is taken to:

- Minimize system engineering and procurement costs

- Minimize lead times

- Provide results consistent with commercially available DR technologies.

Several suppliers have already been approached by DUIT team members about the possible loan of equipment for such an integration test. It is likely that DR manufacturers will be eager to include their equipment in a nationally visible, world-class project such as DUIT.

The project is meant to measure and analyze the interactions among DR technologies rather than to prove the operation of any single DR technology by itself. Thus, rental, lease, or loan of offthe-shelf DR is preferable from both test design and budgetary standpoints.

The DUIT will include DR based on inverters, induction machines, and synchronous machines. The team will make the final selection of technologies to include based on the rank-ordered criteria below. Note that although most DR packages include both the prime mover (internal combustion engine, microturbine, etc.) and the generator (inverter, synchronous, or induction machine), inverters are often sold as a separate component. Inverters can be used with a variety of storage devices and prime movers, such as engines, turbines, wind machines, PV systems, and fuel cells. Some of the criteria below relate to inverter-based systems, and some do not. Those that do will be factored into the selection of the inverters.

Rank-ordered selection criteria include:

1. Diversity of prime mover technologies (at least two, preferably more)

2. Diversity of electrical generation technologies (examples of inverter, induction, and synchronous generators required and various designs and controls desired)

3. Pre-existing distributed generation and storage technologies on site 
4. Clean technologies with minimal emissions, permitting problems

5. Unit electrical rating size ( $10 \mathrm{~kW}$ to $2 \mathrm{MW}$ would be ideal)

6. Total electrical rating size (1 MW to $3 \mathrm{MW}$ would be ideal)

7. Host utility objectives such as compatibility with site physical limitations

8. Budgetary considerations such as lease costs, installation costs, and fuel supply hardware

9. Use of proven, off-the-shelf (i.e., reliable, tested, trouble-free) distributed generation and storage technologies to separate integration factors from new technology issues during operation and testing

10. Technologies whose development was supported by one of the project participants

11. Relocatable devices (e.g., batteries, small gensets, flywheels) to allow some units to be in place for only relatively short tests, perhaps a month or more.

Some of these criteria may conflict with one another, making the technology and site selection efforts critically important to the success of the project.

\subsection{Test Plan}

\subsubsection{Overview}

A key aspect of the DUIT project is a thorough test of the feasibility and value of collocation of diverse DR technologies in the electric distribution system and the integration of those technologies into the distribution system. Ideally, several DR technologies will be installed within electrical interaction proximity of one another to allow their aggregate benefits and compounding operational issues to become evident.

The DR units will be instrumented and monitored to measure the potential electric distribution system advantages and challenges of substantial penetration (significantly greater than $10 \%$ of local peak load) of DR at distribution voltage levels. The data will be gathered and analyzed to characterize the actual value or consequence of DR to the utility and the DR owner.

The detailed test plan is in Chapter 4. However, preliminary discussions have led to a general list of test requirements to address utility concerns with DR interconnection issues. These discussions were necessary to develop the test facility requirements. Table 63 provides an outline of DR-related testing categories and issues to consider when developing tests. Not all of these categories and issues will necessarily be addressed as part of the DUIT project, but their requirements were taken into account when assessing the capabilities of the candidate sites, and they will be used to develop detailed test procedures.

Based on this outline, a series of test protocols was developed to describe in a minimum of detail what tests would be performed to address the topics listed under grid impacts. These protocols were distributed to a select group of nearly 50 experts in utility interconnection for comment and prioritization. This survey was neither scientific nor comprehensive; rather, it was directed at 
companies and individuals considered to be up to speed on interconnection issues, likely to provide a critical unbiased review, and representative of a broad spectrum of interests.

Comments were received from 18 individuals, of which 10 provided some sort of prioritization. The group that commented included utility distribution and protection engineers, equipment manufacturers, and consultants, most of whom were active in the ongoing development of IEEE P1547. Anti-islanding appeared as one of the top issues in nearly every response, though one respondent felt that there may be too much emphasis on the topic. Beyond that, there was little in the way of consensus, though issues that were of interest to most respondents were mostly related to high DR penetration levels, including voltage regulation, short circuit (fault current) contribution, and fuse coordination. Networked distribution systems were not considered a priority, though one reviewer noted that, if DR were to be allowed on networks, it would move to a very high priority. 


\section{Table 63. DUIT Testing Requirements}

1. Commissioning tests

2. Performance

2.1 Load following

2.2 Parallel-standalone transition

3. Grid impact

3.1 Power quality

3.1.1 Harmonics

3.1.2 Power factor

3.1.3 Flicker

3.1.3.1 Flicker meter

3.1.3.2 In-rush

3.1.4 DC injection

3.1.5 EMI/EMF

3.2 System protection

3.2.1 Abnormal conditions

3.2.1.1 Voltage trip points

3.2.1.2 Frequency trip points

3.2.1.3 Reverse power/underpower trip points

3.2.1.4 Fault detection

3.2.1.5 Loss of synchronism

3.2.2 Unintentional islanding

3.2.3 Intentional islanding

3.2.4 Synchronization

3.3 Distribution system impact/interaction

3.3.1 Network system

3.3.2 Fuse protection

3.3.3 Recloser coordination

3.3.4 Short circuit current contribution

3.3.5 Capacitor switching and operation

3.3.6 Stability

3.3.6.1 DR type testing

3.3.6.2 Interaction among DG

3.3.6.3 Islanding

3.3.7 Cold load pickup

3.3.8 Sectionalizing devices

3.3.8.1 Automatic circuit reconfiguration

3.3.8.2 Misoperation because of DR voltage

3.3.9 Voltage regulation

3.3.10 Substation backfeed

3.3.10.1 Adjoining feeders

3.3.10.2 Transmission system

3.3.11 Single-phase faults

3.3.12 Faults on adjacent feeders

3.4 DR Interaction

4. Data

4.1 Measurements

4.1.1 Voltages

4.1.2 Currents

4.1.3 Power

4.1.4 Power factor
4.1.5 Harmonics

4.1.6 Impedance

4.1.7 EMI/EMF

4.2 Sampling rates

4.3 Averaging rates

5. Test equipment

$5.1 \quad$ Monitoring

5.2 Control

5.3 Loads

$5.4 \quad$ Faults

6. Issues

6.1 Legacy versus future systems

6.2 Export versus non-export

6.3 Control aggregation

6.4 Scalability

6.5 Long-term versus short-term

6.6 Low versus high penetration

6.7 DR as nuisance versus DR as utility resource

6.8 Start-up versus steady-state operation

6.9 Single-phase versus three-phase

6.10 Three-wire versus four-wire

6.11 DR type

6.11.1 Inverter-based

6.11.2 Synchronous

6.11.3 Induction

6.12 Prime mover

6.12.1 Fuel cell

6.12.2 Photovoltaics

6.12.3 Microturbines

6.12.4 Combustion turbines

6.12.5 Reciprocating engines

6.13 Storage

6.13.1 Batteries

6.13.2 Flywheels

6.13.3 Capacitors

6.13.4 SMES

6.14 Controls

6.14.1 DR unit control

6.14.2 Area control

7. Benefits

7.1 Asset utilization

7.2 Voltage and stability support

7.3 Ancillary services

7.4 Reliability/PQ

7.5 Demand reduction

7.6 Energy efficiency/CHP

7.7 Emissions trading/offsets

7.8 T\&D congestion

7.9 Risk reduction/sharing

7.10 Emergency/backup power 
The lack of strong consensus suggests that additional evaluation - a more thorough survey, feedback from the various modeling efforts, etc. - may be needed to develop an approach to testing that will provide the greatest and most immediate benefits to the industry.

The following is a discussion of some of the major topics surrounding the interconnection of DR to the Area EPS.

\subsubsection{Unintentional Islanding}

\subsubsection{Background}

Unintentional islanding is probably the most contentious - certainly the most discussedinterconnection issue. Area EPS operators have tremendous liability serving customers in their service areas. The payouts that the Area EPS operator makes to cover customer equipment damaged by momentary sags and surges can be staggering. The problem is bad enough when the utility has control over the generation equipment providing the power. The thought of customerowned generation operating a portion of the Area EPS without utility control keeps utility protection engineers awake at night.

Many of the problems utilities encounter result from small generators that are connected inappropriately and illegally to a customer's electric service panel without disconnection from the Area EPS. Intended to power the customer's loads in an outage, these generators are not designed to operate in parallel with other generation or power significant portions of the utility grid. They have caused damage to other customers' equipment (primarily because of undervoltage), are usually damaged catastrophically when the utility returns, and have injured and killed unsuspecting utility line workers.

Testing and theoretical analyses have shown that under reasonably well-balanced load and generation conditions, loss of utility, such as by opening a sectionalizing switch, will not necessarily lead to immediate system instability. Sandia National Laboratories has shown that inverters using only under/overfrequency and under/overvoltage tripping can maintain a stable island with a load-to-generation ratio between $80 \%$ and $120 \%$.

If the DR is not tripping off, then the frequency and voltage must be within specifications. The frequency and voltage windows that the DR is allowed to operate in $(59.3-60.5 \mathrm{~Hz}, 106-132$ VAC) are substantially wider than the utility is normally required to maintain $(59.97-60.02 \mathrm{~Hz}$, 114-126 VAC). The wide windows let the DR ride through disturbances and utility problem situations. Should islanded DR operate loads for an extended period at either extreme of voltage, other customers' equipment could be damaged, and the deep-pocketed Area EPS would most likely be held responsible.

The next question is: how likely are such "ideal" balanced island conditions to occur and remain stable for any significant period of time? Begovic, Ropp, et. al. looked at the probability of an island occurring, relying only on voltage and frequency trip points. This paper notes that all techniques of detecting islanding can be fooled and defines the term non-detect zone (NDZ) to describe the conditions, specific to each detection method, that cause failure to detect. Having an 
NDZ does not mean the method is inadequate. The NDZ may be well outside reasonable operating conditions, or it may require multiple unique (unlikely) situations to occur simultaneously.

In fact, much of the debate surrounding islanding has to do with the probability of the required conditions occurring. It is generally agreed that the probability need not be zero for a method to be effective, but the debate continues over what is an acceptable level of probability and what the probability is of any specific situation or set of conditions occurring.

Various techniques have been developed to detect and prevent the formation of an unintentional island. Most potential islands are unstable and quickly fall outside standard voltage or frequency limits. Simple detection techniques developed in the 1980s, such as frequency shift, were able to reduce the islanding window, or NDZ, significantly. Advanced techniques, now standard on commercially available products, have squeezed the NDZ even further such that it exists only for unrealistic grid conditions.

\subsection{Islanding Detection Methods}

The most effective method for detecting an island condition is for the utility to provide a signal telling the DR it is OK (or, more commonly, it is not OK) to parallel. For 100-kW and larger DR systems, the use of such a signal - typically called a transfer trip - may be an economically justifiable anti-islanding technique. However, depending on the implementation, it is not always flawless, and it is not economical for smaller systems. For this reason and others, there has been substantial activity in developing active and passive ${ }^{1}$ islanding detection methods for small inverters for PV systems. Beginning in the early 1980s, PV inverter manufacturers began developing and implementing anti-islanding techniques. At the time, the most effective techniques were those that attempted to destabilize the grid, most commonly trying to push the frequency up or down. With utility generation sources present, the inverter is unable to affect the line frequency; however, when the utility sources go away, the inverters can shove the island frequency out of tolerance and trip off. This approach, commonly used in the United States and other places, can potentially be defeated by rotating loads or DR on the same line or by a balanced number of DR trying to push in opposite directions. For example, when the utility goes away, a motor load tends to spin down, reducing frequency, while an under-loaded rotating generator will tend to speed up. Either of these could tend to balance out a simple frequency push method. In addition, if the push is uncoordinated, half of the DR could push up and the other half down, again stabilizing the island.

A method currently favored in parts of Europe is based on measuring the impedance of the Area EPS. By injecting a current pulse and measuring the voltage response, the impedance of the Area EPS grid can be measured. Typically, the grid impedance changes when the utility disconnects from the island. Thus, when the impedance drops below a predetermined value or when it changes by more than a certain amount, the unit initiates a disconnect. This technique is very sensitive to

\footnotetext{
${ }^{1}$ The terms active and passive islanding detection have a variety of interpretations. Often, they are used to differentiate between techniques that try to actively effect a change in one or more Area EPS parameters, such as frequency push, and those that passively measure grid parameters such as under/overfrequency. Alternatively, they are used to distinguish between methods that control the inverter output and those that don't. The impedance methods, in which the inverter output is changed as a way of measuring — but not affecting — grid impedance would be considered passive under the first definition and active under the second. Another interpretation might be that passive methods attempt to detect the island condition while active methods attempt to inhibit the formation of an island.
} 
loss of utility but has a few drawbacks. The act of injecting a current pulse is a form of distortion. If this pulse is of high enough magnitude and is performed frequently enough, it will have an adverse effect on harmonics. The solution to this is to keep the current pulse small and relatively infrequent (e.g., once a second). Infrequent measurements slow the detection.

There is also a potential interference problem at high penetration levels leading to nuisance tripping. If two units are close enough and inject the pulse at about the same time, there will be a reduction in the perceived impedance (twice the current should result in a doubling of the voltage change), which could lead to a trip. Nonetheless, there are several small inverters that have effectively implemented this technique, and some empirical data suggest there is little interference between units.

As a result of the1997 Sandia Anti-Islanding Working Group, described below, two detection methods were developed. These methods are similar to techniques developed by Toshiba and, before it, American Power Conversion. Essentially, the Sandia Frequency Shift and Sandia Voltage Shift attempt to push the frequency or voltage first in one direction and then in the other. If the parameter in question appears to be affected, the unit continues to push in the same direction, successively harder each time. Together, these methods tend to be effective at detecting island conditions and do so quickly. These methods may also be subject to self-interference if an aggregate of units is attempting to push in one direction while a nearly equal aggregate of units is pushing in the other. Incorporating a small, random offset in the rate at which each unit attempts to push should reduce this possibility. There is also a concern that large DR on weak Area EPS line segments trying to push the utility frequency or voltage around may actually do so, even with the utility present.

Along with these two detection methods, a more precise procedure for evaluating islanding detection techniques was described based solely on passive resistive/inductive/capacitive elements. Most notably, the pass/fail criterion was defined in terms of circuit resonance, or Q. The test is believed to eliminate the need for rotating loads, which are very difficult to define and implement in a replicable way. Also, the circuit $Q$ is related to power factor-a parameter of significance to Area EPS engineers. The selected Q of 2.5 is equivalent to a circuit with a power factor of about 0.37 , which is poorer than would be reasonably expected on an operating or islanded Area EPS line segment. This test procedure has been adopted and documented in IEEE 929 and UL 1741, and it is being considered for IEEE P1547 and, internationally, by IEC Technical Committee 82 .

The use of a motor load in the test circuit is considered necessary by some. The inertia provided by a motor is a characteristic not found in passive RLC circuits. This inertia may affect methods to destabilize the island. However, the nonlinear current required by the motor is not easy for some inverters to provide. Thus, their presence may enhance the DR's ability to detect an island. 


\subsection{Notable Activities in DR Islanding}

- Rokko Island (Kobe, Japan) - Initiated in 1987 and operated by Kansai Electric Co., this facility consists of 100 residential PV systems ( 2 and $3 \mathrm{~kW}$ each), two 15-kW wind turbines, and up to 10 or so $50-\mathrm{kW}$ fuel cells. The DR units are tied to a configurable 6.6$\mathrm{kV}$ distribution system. Each DR also has local resistive and reactive load controlled by the main DAS. The purpose of this facility is to evaluate the effect of high penetration of customer-owned DR on a distribution system. Numerous tests have been performed, and many technical papers have been presented. Results indicate that there are numerous ways to detect potential islanding conditions and that these have varying degrees of success.

- Sandia Anti-Islanding Working Group - In 1997, a group of US inverter manufacturers and interested parties met at Sandia National Laboratories to discuss methods of islanding detection and to work toward an improved method. This group discussed existing methods, shared what had previously been trade secrets, and supported the further development of a pair of detection methods: the Sandia Frequency Shirt and the Sandia Voltage Shift. This meeting was also the genesis of the anti-islanding test described in IEEE Standard 929 and used in UL 1741.

- International Energy Agency PV Interconnection Workshop in Zurich - An International Energy Agency workshop on islanding was held in 1997 in Zurich, Switzerland. It brought together interconnection experts from utilities, manufacturers, and test and research organizations around the world. Though the meeting was meant to broadly address issues related to the interconnection of PV systems to the utility grid, nearly every presentation and discussion revolved around or ended up dealing with islanding. A generalized conclusion from this workshop was "Islanding is a problem. Islanding is not a problem." The fact that so much of the discussion dealt with islanding underscored the extent of concern. On the other hand, it was also generally agreed that the conditions required for islanding to occur are highly unlikely. Further work needs to be done to address the high level of concern. New results on this very topic were recently presented at a follow-up meeting in January 2002 in the Netherlands.

\subsubsection{Issues}

The following is a list of known issues and concerns related to islanding. DUIT testing will attempt to address some or all of these issues.

- Large numbers of small units tripping independently can act as a stabilizing factor in the formation of an island. Islands are usually more stable when the load-to-generation ratio is equal to or slightly greater than 1 . When this ratio is less than 1 , a few DR units tripping off will move the island into a more stable condition.

- The inertia of rotating electrical machines combined with their tendency to, under loss of load, spin down (rotating loads) or up (rotating generators) can confound some active islanding detection schemes, tending to stabilize the island. 
- Motors, transformers, and other devices can require complex current waveforms that improve the ability of some DR to detect an island condition. This may depend on device design (motor type, transformer design, magnetization current, etc.).

- High penetration of DR with active anti-islanding (i.e., frequency push) may cause power quality problems or force the Area EPS to be unstable or to shift voltage unnecessarily.

- High penetration of DR with active anti-islanding (even some passive) may interact to cause nuisance tripping.

- Some anti-islanding techniques may be incompatible. Interaction of different techniques may cause non-detect or nuisance tripping (one "bad" unit causes all the neighbors to trip or not detect).

- The size of the island (number and magnitude of load and DR) may make detection easier or more difficult. Does the size of the island make an islandable load-to-generation match more or less likely?

- Autonomous voltage support schemes (active VAR compensation) may enhance or impede islanding detection

- Grandfathered voltage-source DR without anti-islanding may interfere with islanding detection techniques.

- Automated meter reading/utility signal may provide a cheap, standard, simple, accurate detection method.

- Will the results from multiple small DR and small loads equate to larger DR and larger loads? Are there voltage-related issues?

- Are there techniques that are more applicable to low penetration? Are there different issues at high penetration than at low penetration?

- Can an autonomous DR be sufficiently anti-islanding? Can DR be operated in a way to create a stable, intentional island?

- What are the similarities and differences between single-phase and three-phase DR and combinations of these?

- Do slow-response DR island more easily?

- What are the key issues of three-wire and four-wire distribution systems?

- Are there network-specific islanding issues?

- What are the issues related to transformer configuration and grounding? 


\subsubsection{Considerations}

- In general, islanding testing will require fairly careful matching of generation with real and reactive load, possibly on a real-time basis.

- Indications from manufacturers of relatively small three-phase inverters $(10 \mathrm{~kW})$ is that defining a load to make the unit island with all anti-islanding schemes turned off is not trivial; finding the NDZ is likely to be extremely difficult.

- Get utility people comfortable. They want to see rotating loads/gen. What will be a realistic worst case? Use a synchronous motor/rotating condenser as part of the load.

- The test should include one or more inverters/devices that use impedance detection techniques.

- Go beyond standards.

\subsection{Classes of Islanding Tests}

1. Motor loads

- Ratio of load to generation to motor load

- Type of motor (synchronous, induction, capacitor start)

- Inertia versus mechanical load

- Other electrical characteristics (equivalent circuit)

2. Islands with and without transformers (or small transformers)

3. Multiple DR interaction

4. Detect time versus Q (recloser coordination)

\subsection{Data Measurement Needs (Channels, Equipment, Sampling Rates, Etc.)}

Data measurement needs include voltage, current, power, and reactive power on all DR and loads under test. Some testing will require only moderate data rates of 0.1 to 10 samples per second. Other testing may require high-speed sampling to evaluate sub-cycle response.

\subsubsection{Related Modeling Needs and Validation}

Validation work could cover models that attempt to predict DR response in island conditions. Such models could also be used to define realistic worst-case test scenarios.

Modeling might prove useful in defining appropriate motor loads. 


\subsubsection{Voltage Regulation}

\subsubsection{Overview}

The use of capacitors at the Area and Local EPS is a method of attempting to regulate voltage. One of the significant values that DR offer is the ability to intentionally improve the Local EPS voltage, and by default Area EPS voltage, without the application of capacitors and their associated problems. In addition, the act of current injection by DR - whether simply reducing on-site load or exported to the Area EPS-will affect voltage unintentionally. That effect may be beneficial or detrimental to the Area EPS depending on the specific circumstances.

DR can have a significant, incidental effect on line voltage within the Local EPS. DR output current interacting with Local and Area EPS impedance causes an increase in the local voltage levels. The amount that the voltage is pumped up depends principally on the penetration level of the DR or aggregated DR relative to the EPS kilovolt-ampere rating. In P1547 terms, the stiffness ratio - the total short circuit current contribution at the PCC (including the Area EPS and the DR) divided by the DR's short circuit current contribution - may provide an indication of the potential incidental effect of the DR on voltage. Utilities are concerned that DR, especially those that export, may push a line segment that would otherwise operate within prescribed voltage limits outside of those limits. Some jurisdictions have rules limiting voltage operation to the lower end of the allowable range to limit power consumption, and significant penetration of DR could conceivably cause the voltage to rise above accepted levels.

Real power generation will necessarily cause an increase in local voltage. An example of DR that inadvertently reduce Local EPS voltage is non-corrected induction generators that operate at a power factor related to load. In spite of real power output, these generators typically reduce the voltage because of the VARs they consume. This has been a historic problem with large wind plants that use induction generators. Power factor limits are often specified in part to address this problem.

Many of the new DR technologies have the ability to actively supply or absorb VARs within a limited range and, thus, may help regulate or at least affect local EPS voltage (VAR compensation). The DR responds to the voltage regulation set point and provides the appropriate level of VARs for a given amount of real power. Under most cases, the DR will end up sourcing VARs just as a parallel capacitor bank would.

DR has two important advantages over the capacitor bank:

- No switching events or associated switching problems

- The ability to finely adjust the VAR levels where capacitors typically provide relatively large step increments. 


\subsubsection{Possible Testing Procedures}

- Demonstrate VAR compensation features and value that the DR provides. This can be accomplished by monitoring the voltage at a selected PCC and regulating this voltage with one or multiple DR systems.

- Evaluate the compatibility of multiple DR systems when they all are attempting to autonomously regulate EPS voltage at their output terminals, in particular looking for instability issues.

- Evaluate the response of utility voltage regulation equipment to exported power (incidental effects) and DR VAR compensation routines.

\subsubsection{Reclosing Coordination}

\subsubsection{Overview}

Many faults that occur on a utility system are transient in nature. A wind-blown tree limb that knocks overhead power lines together may cause a momentary short between the two phases. Even though the tree limb falls away, allowing the lines to separate, an arc can be drawn between the lines because of the voltages involved. This arc, ionized air, becomes a conductive path that maintains the fault. A recloser is a fast-acting device that senses the fault and opens the circuit. With no voltage to sustain the arc, the ionized air quickly dissipates, and the fault is eliminated.

Reclosers are set to open for a fixed period (typically between 20 cycles and $3 \mathrm{~s}$ ) and then to reclose and check if the fault is gone. Some reclosers can be programmed or otherwise set up to perform several such "recloser operations" with successively longer open intervals to allow the arc to extinguish. If the fault still does not clear, then the recloser remains open, leaving that line section offline. A utility line worker will need to be dispatched to clear the fault and restore service.

Because the voltage level necessary to sustain an arc is small, it is critical for the DR to disconnect quickly to allow the recloser to work as intended. Interconnection standards include under/overvoltage and under/overfrequency trip points and clearing times. A primary consideration for the selection of the undervoltage clearing times is recloser coordination.

Table 64 and the associated paragraph delineate the voltage and frequency trip points and clearing times defined in Draft 7 of IEEE P1547. 
Table 64. Interconnection System Response to Abnormal Voltages

Voltage Range ( $\%$ of base voltage)

\begin{tabular}{|c|c|}
\hline$V<50$ & 0.16 \\
\hline $50 \leq \mathrm{V}<88$ & 2 \\
\hline $110<V<120$ & 1 \\
\hline$V \geq 120$ & 0.16 \\
\hline
\end{tabular}

Note: Base voltages are the nominal voltages stated in ANSI C84.1.

${ }^{*} \mathrm{DR} \leq 30 \mathrm{~kW}$, maximum clearing times; $\mathrm{DR}>30 \mathrm{~kW}$, default clearing times ${ }^{2}$

Frequency Disturbances:

All DR units shall follow the interconnected Area EPS frequency within the range $59.3-60.5 \mathrm{~Hz}$ (on a 60 $\mathrm{Hz}$ base). The frequency measurements shall be either at the point of DR connection or the PCC.

A DR unit $<30 \mathrm{~kW}$ shall cease to energize the Area EPS within $0.16 \mathrm{~s}$ if the frequency goes outside this range. A DR unit $>30 \mathrm{~kW}$ shall (1) cease to energize the Area EPS within $0.16 \mathrm{~s}$ if the frequency exceeds $60.5 \mathrm{~Hz}$, (2) be capable of time-delayed disconnection with adjustable underfrequency settings in the range of $59.3-57 \mathrm{~Hz}$, and (3) disconnect within $0.16 \mathrm{~s}$ if the frequency is less than $57 \mathrm{~Hz}^{3}$

Thus, for example, the DR must trip within 10 cycles $(0.16$ seconds $)$ if the utility voltage drops below $50 \%$ of nominal. For reclosers set to trip at 20 cycles or more, a 10 -cycle clearing time should allow enough time for the recloser to detect the fault (e.g., a ground fault on the primary side of the distribution system), the voltage to collapse to $50 \%$ or less, and the DR to detect the fault and trip.

Two possible situations arise that could be of concern to the utility. The first situation is highspeed reclosing. Some reclosers are capable of responding very quickly, with clearing times of 1012 cycles. These reclosers could open before the DR. The second situation is a high-impedance fault that does not cause the voltage to collapse. In this case, the DR is allowed $2 \mathrm{~s}$ to clear if the voltage is in the $50 \%-88 \%$ range and possibly longer ${ }^{4}$ if the voltage remains in the nominal range and anti-islanding methods must be relied on. Even "normal speed" reclosing could be affected. It would be possible for the recloser to operate several times before all of the DR units were able to detect the island condition. The DR could maintain the fault, and if the utility frequency and the island frequency differed by $0.5 \mathrm{~Hz}$ (the DR is allowed to operate between $59.3 \mathrm{~Hz}$ and $60.5 \mathrm{~Hz}$ ), after one second the two systems would be $180^{\circ}$ out of phase, a potentially dangerous scenario.

Reclosing out of phase into inverter-based DR would likely only be detrimental to the inverter itself because inverters usually do not have sufficient fault duty to pose a threat. Rotating generators would have sufficient fault duty to potentially cause problems on the distribution system. As the generator is forced to match the phase and frequency of the utility, the inertia of the prime mover could also cause mechanical damage to the DR. The fault would have to be of high

\footnotetext{
${ }^{2}$ The Area EPS operator can specify different voltage settings or trip times to accommodate Area EPS system requirements.

${ }^{3}$ This frequency in the range $59.3-57 \mathrm{~Hz}$ and time delay can be selected by the Area EPS operator to provide system security.

${ }^{4}$ IEEE 929 and UL 1741 both require the device to detect the island condition within $2 \mathrm{~s}$; IEEE P1547 is considering "up to 10 seconds."
} 
enough impedance to not drag the aggregate DR down but also be low enough to be detected as a fault. Thus, it must look like a fault to the recloser and like a load to the DR.

DUIT testing could be performed to ascertain the probability of this fault scenario and to investigate methods of mitigation. Issues to consider include penetration, fault requirements (what impedances are required and how "stable" it would have to be), and the islanding stability issues. One test might include one or more DR with a variable simulated fault device (a light bulb is a fixed impedance line to neutral fault device). DR islanding detection might need to be disabled, though this makes the test a very contrived situation.

\subsubsection{Possible Test Procedures}

The primary concern of recloser coordination is the speed at which the islanding detection device is able to perform and the speed at which reclosing occurs.

- Basic test description

Recloser coordination testing will be an islanding test to determine run under "rated" conditions.

- Basic test configuration(s) - (numbers/type/size of DR, loads, etc.) Match load to generation. It is primarily a type test issue.

- How will the test address one or more of the interests/concerns?

If anti-islanding operation is timed and presented as a characteristic, that value can be used for relay coordination

- Known/anticipated testing pitfalls/limitations

Test does not represent worst case, but it is arguable that it represents a worse-than-realistic case.

- Data measurement needs

Evaluate the effect on DR and loads of a step change in utility waveform, as when an outof-synch DR island is suddenly snapped back into synchronization.

\subsubsection{Sectionalizing Devices}

\subsubsection{Overview}

A sectionalizer is a device designed to operate in conjunction with a recloser or circuit breaker. Its principal application is to protect line taps on systems with reclosing equipment. The sectionalizer is connected in series with the line on the load side of its associated recloser.

The operation of the sectionalizer is dependent on an integrator that counts overcurrent and subsequent openings of an associated recloser. The counting is accomplished by means of a magnetically compensated oil pump. The sectionalizer can be adjusted to cause the trip piston to trip the release mechanism on the first, second, or third recloser opening. This causes the sectionalizer contacts to drop open, sectionalizing the faulted line section. Then the recloser or breaker will close, restoring the unfaulted balance of the system. The sectionalizer switch is 
designed to operate when the circuit is de-energized, and, therefore, it usually has negligible fault current interrupting ability.

If the fault is temporary and is cleared before the sectionalizer locks out, the sectionalizer will start resetting immediately. When the sectionalizer has locked out, a manual operation is necessary to close the sectionalizer.

IEEE/ANSI specifications for line sectionalizers are given in Standard C37.63-1997. Minimum activating current of the line sectionalizer is specified to be 1.6 times the continuous current rating with a tolerance of $\pm 10 \%$.

The opening time between interruption of fault current by the backup recloser and opening of the sectionalizer contacts is typically approximately 10 cycles, with a reset time of approximately 3 minutes if the sectionalizer has not opened on a temporary fault. The standard rated making current is the same value as the rated momentary current; therefore, the sectionalizer can be closed in on a permanent fault with no danger to the operator because the backup recloser would clear the circuit.

Selectivity among sectionalizers in series and among sectionalizers and circuit breakers or reclosers is obtained by counting the number of dead times (times the circuit becomes deenergized) rather than by evaluation of current magnitudes, as with fuses. The application problem is somewhat simplified, but a rudimentary knowledge of fault currents is still required to make sure the current passing through the solenoid is more than the minimum value for counting pulses and not in excess of short-time thermal rating.

Increased interest is being shown in the application of sectionalizers for underground systems. Because most cable faults are permanent faults, it is desirable that the sectionalizer protecting the underground system open on the first count, thus eliminating any automatic reclosing on a faulted cable that could cause further cable damage. A dry type sectionalizer is available that will permit the backup breaker or recloser to interrupt the fault current within 2 to 5 cycles. The sectionalizer then drops out, isolating the fault from the remainder of the system.

Advantages of the sectionalizer are:

1. Approximate methods for fault current calculation may be used because extreme accuracy is not necessary.

2. Replacement of fuse links is not required after a permanent fault.

3. The sectionalizer relates the fault closing time to the relay setting on the fast-tripping station circuit breaker, thus eliminating arcing, expelling of ionized gases, and the loud report usually associated with the operation of a fuse cutout.

The main disadvantages of the sectionalizer are higher initial cost (about twice that of a sectionalizing fuse installation) and increased maintenance requirements. 


\subsubsection{Distribution System Automation Circuit Reconfiguration}

Utility distribution system automation is often based on a SCADA system. SCADA consists of a master station located at the switching center, where it communicates with remote devices such as line switches and reclosers. SCADA provides the means for the switching center operator to perform two main functions remotely:

1. Locate and isolate a faulted section of a primary feeder and restore service to unfaulted sections within a few minutes

2. Transfer load from one primary to another without an outage.

\subsubsection{Issues}

- Determine how to reconfigure or coordinate the SCADA's switch and recloser so that the load will not equal generation output (a fault within a line section can cause an islanding condition).

- Do DR have any effect on the remote terminal unit's storage energy operator?

- What are the effects on SCADA feeders that have multiple generation units?

- At what level is reclose blocking required? $<400 \mathrm{~kW}$ (50\% of the minimum load) for induction generator?

- At what level is transfer trip required? $>400 \mathrm{~kW}$ for synchronous generator, wind farm generator, induction generator?

\section{Voltage Maintained by DR Leading to Sectionalizer Misoperation}

IEEE Standard C37.63-1997 specifies design and production testing for sectionalizers. For DUIT testing, these tests should be evaluated for the situation in which DR may result in the sectionalizer energizing on the circuit during the period when it is operating. In particular, testing could help determine how counting of recloser operations is affected, what level of DR would cause overstress or non-operation of the sectionalizer, and whether the presence of DR will cause damage to the sectionalizer when it operates.

The primary voltage on the distribution feeders must be held within standard allowable maximum and minimum limits. A voltage problem can occur when DR are suddenly disconnected from the distribution feeder. The abrupt voltage drop may exceed the allowable limits for voltage fluctuation (limit is $5 \mathrm{~V}$ on a $120-\mathrm{V}$ base). DR also have an effect on substation bus voltage. For example, under peak load conditions, DR may reduce bank loading, which reduces regulator or LTC output voltage below the levels required to maintain voltages within limits on the feeders connected on the same bus.

1. How many stages of regulation are allowed for a feeder with DR? (This is to prevent voltage hunting.)

2. How is voltage brought within allowable limits? Can the voltage be corrected with capacitor banks, regulators, boosters, etc.? 
3. What happens if the DR is a single-phase generator? What are the unbalanced voltages?

4. Is a DR penetration of $<15 \%$ of load on the line section an appropriate or useful rule of thumb for preventing voltage problems?

\subsubsection{Fuse Coordination}

\subsubsection{Overview}

Fuses are very common on distribution circuits. Fuses are typically installed on taps of the main line on both overhead and underground systems. Fuses on taps isolate outages so that the number of customers affected by the outage is minimized, expedite location of a fault, and protect overhead and underground conductor from $I^{2} R$ damage. Fuses are single-phase devices and may not all melt on a three-phase circuit. It is possible that a fuse can partially melt without blowing, which will effectively change the fuse rating. Current-limiting fuses have a high impedance when interrupting, which will limit the fault current that can flow to a relatively low value.

Because fuses are single-phase devices, there can be situations in which one or two phases open while the other phase(s) remains closed, which could "single phase" a circuit or part of a circuit. Three-phase generators and load may see unbalanced voltage depending on the transformer configuration.

By design, the time-current curves of fuses are steep, meaning that small changes in current translate into large changes in clearing time. Generation on the fault side of a fuse will provide fault current, which could reduce the amount of utility-supplied current through the fuse and desensitize the protection on fused taps.

DR may affect fuse savings schemes on an adjacent feeder if they do not take into account the additional DR fault contribution

Localized generation could increase the fault current and cause fuses to melt improperly when upstream fuse-saving schemes are installed. Fuses could melt on the fault-side current from a distributed generator for a fault on the utility side of the fuse.

\subsubsection{Possible Test Procedures}

1. Set up different distribution system configurations and note when coordination problems occur.

2. Look at the repetitive fault current issue of constantly pounding the fuse with fault current just under its trip rating. How many times can it be hit before it changes its trip characteristics?

3. Test to determine how to design/modify distribution system fusing to deal with DR. 


\subsubsection{Capacitor Switching and Operation}

Although the interconnect standards remain mostly silent on the issue of capacitor switching, there are potential problems with DR and with coordinated protection when EPS capacitors are switched. Momentary high inrush currents, excitation of potential resonant conditions, and voltage transients are the most prevalent situations that can interfere with otherwise coordinated protection systems on the DR and EPS.

The two principal reasons for the use of capacitors at the Area and Local EPS levels are for power factor correction and voltage regulation. These factors are, of course, related; however, it is common to separate them because the cost of voltage regulation is covered through normal usage (real energy) rates while power factor correction is addressed through special charges. Power factor correction is the process of bringing the power factor of the Area EPS back toward unity. Capacitors are used to supply reactive power because typical Local EPS loads are inductive and consume reactive power. When the Local EPS power factor approaches unity, the Area EPS operates more efficiently as current corresponding only to real power is provided, resulting in lower current magnitude.

Low power factor at the Area or Local EPS level causes low voltage for two reasons. First, low power factor increases the total current, and this increased current interacts with line impedances to reduce Area EPS voltage. Second, the consumption of reactive power at the Local EPS interacts with Area and higher-level EPS reactances to further reduce voltage at the PCC.

Power factor correction has historically been accomplished at both the Area EPS and Local EPS levels. Voltage regulation is more typically accomplished at the area level but is occasionally provided at the local level. DUIT testing that is performed relative to capacitor switching issues will consider both levels. One of the principal values that DR can bring to the EPS is that they can effectively deal with power factor correction and voltage regulation issues and potentially can minimize the sizing of EPS capacitors or eliminate the need for these capacitors altogether.

Possible conditions arise with capacitor switching and its influence on DR that would be of concern to the utility and should therefore be considered by the DUIT. First, the switching of the capacitor typically causes a voltage transient on the Area EPS; this transient is potentially capable of tripping overvoltage protection on the DR and causing the DR to trip off line. Obviously, it is undesirable for the DR to trip off line every time an Area EPS capacitor is switched. Related to this is the voltage withstand capability of the DR device and other associated components. These devices will have to be capable of withstanding multiple short, high-voltage transients caused by capacitor switching. Second, the DR can be exposed to high current inrush conditions because capacitor switching is capable of tripping off the DR because of a momentary high current condition. The DR must be able to withstand these conditions without tripping off line or causing damage to the DR device. 


\subsubsection{Short Circuit Current Contribution}

\subsubsection{Overview}

Electrical devices in distribution systems are separated from ground and one another by insulating materials (e.g., air, paper, oil, ceramics and polymers). Unpredictable breakdowns in these materials because of deterioration or age or by intrusions of outside agents can cause a short circuit between conducting elements. These occurrences are known as faults, and the short circuit currents that result are dangerous for two reasons. First, short circuit currents can be high enough to damage electrical equipment before they are cleared, or they may even be high enough to damage the protective equipment designed to interrupt them (i.e., circuit breakers). In the latter case, the equipment being protected (e.g., a generator) may also be damaged. Second, short circuit currents in distribution systems may, under certain circumstances, be too small for the protective relays to detect. This occurs when the fault path is through a high-impedance element, which limits the short circuit current, and presents a particularly difficult problem for the protection engineer.

In all cases, short circuit currents present hazards to people and electrical apparatus. It is therefore important to be able to predict their magnitudes under a variety of operating conditions so that the distribution system can be adequately protected. Utility engineers may also evaluate the short circuit current contribution of a distributed generator as one of the factors to consider when assessing the potential effects to a particular feeder.

\subsection{Types of Faults}

Faults are classified generally as either balanced or unbalanced. Balanced faults occur when all three phases of a network are equally affected. The symmetry among the voltages and currents in the three phases is maintained. This condition is met by three-phase faults (all three phases shorted together but not to ground) and by three-phase-to-ground faults. A single-phase circuit representation can be used to calculate short circuit currents because of balanced faults. Unbalanced faults generally refers to all other types of faults, such as single-phase-to-ground, phase-to-phase (two-phase), or two-phase-to-ground. Unbalanced faults create an asymmetry in the network, necessitating a complex analysis based on the mathematical method of symmetrical and Clark components.

The short circuit currents from a particular source are known as the short circuit current contribution from that source when it is interconnected to the distribution network. It can be calculated given the Thevenin equivalent circuit for the source (i.e., an ideal voltage $\mathrm{V}_{\text {th }}$ and internal impedance $Z_{\mathrm{th}}$ of the source, and the impedance $Z_{\mathrm{f}}$ between the source and the fault). See Figure 30 and Equation 1.

$$
I f=\frac{V t h}{Z t h+Z f}
$$




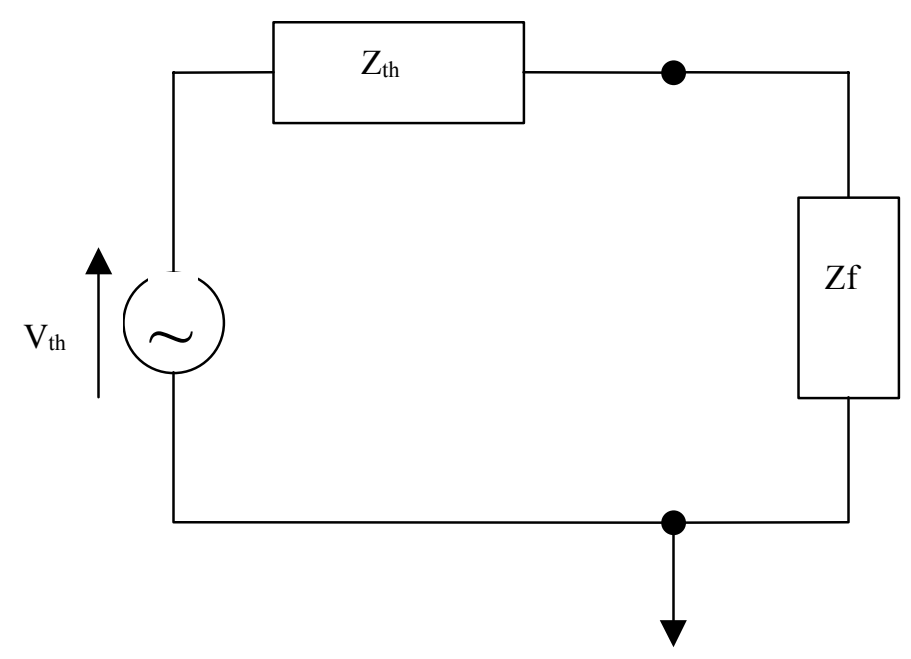

Fault

Figure 30. Thevenin equivalent circuit for a distribution system fault

\subsection{Stiffness Ratio Versus Short Circuit Current Contribution Ratio}

IEEE P1547 defines stiffness ratio as follows:

Stiffness ratio is calculated at the PCC, except when there is a transformer dedicated to one customer, in which case the stiffness ratio is calculated on the high-voltage side of the dedicated transformer.

$$
\text { StiffnessRatio }=\frac{S C_{A r e a E P S}+S C_{D R}}{S C_{D R}}=\frac{S C_{A r e a E P S}}{S C_{D R}}+1
$$

Where:

$\mathrm{SC}_{\text {Area EPS }}=$ the short circuit contribution in kilovolt-amperes of the Area EPS (including all other sources)

$\mathrm{SC}_{\mathrm{DR}}=$ the short circuit contribution in kilovolt-amperes of the $\mathrm{DR}$ in question.

California's Rule 21, adopted in June 2000, defines short circuit contribution ratio (SCCR) as:

The ratio of the Generating Facility's short circuit contribution to the Electrical Corporation's short circuit contribution for a three-phase fault at the high voltage side of the distribution transformer connecting the Generating Facility to the Electrical Corporation's system. 
Using the P1547 variables, this becomes:

$$
S C C R=\frac{S C_{D R}}{S C_{\text {AreaEPS }}}
$$

So the two parameters are related by the equation:

$$
\text { StiffnessRatio }=\frac{1}{S C C R}+1
$$

In $§ 4.2 .3$ Disconnection for Faults, P1547 states:

The DR unit shall cease to energize the Area EPS for faults on the Area EPS circuit to which it is connected.

With a stiffness ratio of 10 or less, the DR unit shall be equipped with current-based protection and current-based or voltage-based ground fault protection suitable for the detection of Area EPS faults.

In §4.2.4 Loss of Synchronism, P1547 further states:

Synchronous generator DRs in applications with a stiffness ratio of 20 or less shall be equipped with loss of synchronism (out-of-step) protective functions to isolate the DR from the Area EPS without any intentional time delay.

California Rule 21 uses SCCR as one of several screens to determine if an application qualifies as a simplified interconnection:

\section{Short Circuit Current Contribution Screen:}

A. At primary side (high side) of the Dedicated Distribution Transformer, for the specified feeder, the sum of the SCCR of all DR on the feeder must be less than or equal to 0.1 .

B. At secondary (low side) of a shared distribution transformer, the short circuit contribution of the proposed DR must be less than or equal to $2.5 \%$ of the interrupting rating of the Customer's Service Equipment.

Significance:

No significant DR impact on:

- Distribution System's short circuit duty

- Distribution System fault detection sensitivity

- Distribution System relay coordination

- Distribution System fuse-saving schemes. 
A stiffness ratio of 10 equals an SCCR of 0.11 ; an SCCR of 0.1 equals a stiffness ratio of 11 . Thus, the two requirements are roughly equivalent.

\subsubsection{Testing}

\subsection{Rotating Machines}

For purposes of testing distributed generators to determine or verify their short circuit current contributions, the maximum value would occur for a fault at the terminals of the device. For this case, $\mathrm{Zf}=0$. For rotating machinery, Equation 1 reduces to:

$$
\text { If }=\frac{V t h}{Z t h}
$$

The short circuit current contribution of a distributed generator could be measured in a straightforward manner by imposing fault impedances across the output terminals while the device is operating under no-load, open-circuit conditions and measuring the resultant phase currents. For three-phase machines both balanced and unbalanced faults can be staged. External fault impedances can be varied from zero to various lengths so that short circuit current contributions can be evaluated for a variety of conditions, if desired. IEC and IEEE standards define the calculation methods and test procedures employed in the determination of short circuit current contributions of rotating machines.

\subsection{Inverter-Based Distributed Generators}

- What is the scalability?

- A combination of generator and reactors limits fault current on neighbors.

- DR SCCC reduces the distribution system sensitivity to faults.

\subsubsection{Distribution System Stability}

\subsubsection{Overview}

Note that this section deals only with stability issues related to the distribution system, not with utility generation- or transmission-level stability issues.

A power system is in equilibrium when the voltage magnitude and angle at each bus are such that power flows from buses with excess generation or to buses with excess demand (load) in a steadystate condition (i.e., voltages, currents, power flows, and frequency are constant). The power flow equation in the simplest case, from Bus A to Bus B, is given by the equation:

$$
\mathrm{P}_{\mathrm{ab}}=\left(\frac{1}{X}\right)\left|\mathrm{V}_{\mathrm{A}}\right|\left|\mathrm{V}_{\mathrm{B}}\right| \sin \left(\delta_{\mathrm{A}}-\delta_{\mathrm{B}}\right)
$$


Where:

$$
\begin{aligned}
& X=\text { impedance between buses } A \text { and } B \\
& \left|V_{A}\right|=\text { magnitude of voltage at Bus } A \\
& \left|V_{B}\right|=\text { magnitude of voltage at Bus B } \\
& \delta_{A}=\text { phase angle of voltage at Bus A } \\
& \delta_{B}=\text { phase angle of voltage at Bus B }
\end{aligned}
$$

Implicit in the concept of equilibrium is that all these values are constant (i.e., not time-varying). When a disturbance or change occurs - such as a fault, switching operation, or load change - the system will transition to a new equilibrium point if there is adequate stability margin. If the new system condition is not a stable one, the system will lose synchronism, and breakup or collapse will occur. System planners ordinarily evaluate the stability of a system by means of simulation studies, in which the dynamic response of the system to a range of contingencies is studied to determine if the specified configuration is a stable one. That is, an operating condition may be stable, but if a foreseeable disturbance is sufficient to make it unstable, it is considered to have inadequate stability margin. According to the above equation, system voltages and impedances should be such that the $\delta_{\mathrm{A}}-\delta_{\mathrm{B}}$ term is below $90^{\circ}$. Alternatively, the impedance between the generator and the load bus should be kept low.

For a generating unit, the mechanical power of the prime mover should equal the electrical output of the generator (neglecting losses). A fault on the system will typically cause a decrease in the electrical output of the generator because of depression of the voltages, and the input to the prime mover will take some time to adjust downward. Until it does, the excess mechanical power will accelerate the machine, causing an increase in the frequency of the power generated, which has the effect of increasing the phase angle of the voltage at the generator bus. Because a rotating machine has angular momentum, if the accelerating power is too great, the phase angle will go past $90^{\circ}$ and the machine will slip out of synchronism and most likely trip off line. Protective relays should be designed to act fast enough to clear the fault before the generator becomes unstable. The longer the clearing time, the more accelerating power goes into the machine.

The characteristics of the generator's excitation system, which are not taken into account in this simple example, will have a major effect on stability. Also, losses in the system can provide damping of oscillations.

\subsubsection{Long Feeders}

The closer a generator is to a stiff system (e.g., a transmission system or primary distribution), the more the generator will be tied, dynamically speaking, to that system. Distribution systems, especially radial systems, are inherently weaker than networked or transmission systems. If a generator is farther out on a feeder, it will tend to oscillate according to faults on the feeder. In other words, voltage variations will be greater, and these will affect the machine.

Also, generators on the transmission system tend to be larger with greater mass and to accelerate more slowly relative to the system compared with the smaller machines typically found on the distribution system. It is relatively straightforward to determine the measures necessary to stabilize a large machine against a very stiff "infinite bus" such as the transmission system. This assumption 
will not hold in general for distributed generators; the strength (or weakness) of the system to which it is connected must be taken into account.

If the generator is prone to oscillations, then nearby customers on the feeder will see variations in voltage such as surges, sags, or flicker. It is possible that responses triggered in customer loads may feed back to the DR, and interactions may result.

Induction generator dynamics are somewhat different from synchronous generator dynamics. Its tendency to increase slip angle under faults results in the generator absorbing reactive power, depressing voltages, and increasing the likelihood of non-recovery from the fault.

If other DR are on the feeder, then the electromechanical oscillations of one generator will cause a response in the others, possibly causing a positive feedback condition that will result in instability. It is also possible that the generator will interact dynamically with rotating loads (pumps, motors, compressors, etc.) or nonlinearly with non-sinusoidal devices such as inverters.

\subsubsection{Possible Testing Procedures}

Testing of distributed generators to determine their key parameters for dynamic stability could include:

- Lab testing to determine a generator's "natural" or mechanical modes of oscillation

- Lab testing to measure DR parameters such as inertia, internal impedance (synchronous, subsynchronous, transient), damping, natural frequency, excitation or governor response, etc., for use in simulation studies

- Testing to determine the effects of "tweaking" the governor or excitation controls

- Testing the dynamic response with increasing amounts of impedance between generator and load (to simulate longer feeders)

- Testing between a rotating machine and an inverter to determine the potential for interactions/oscillations

- $\quad$ Testing between a rotating generator and rotating load (motor, etc.).

\subsubsection{Cold-Load Pickup}

Transient start-up power consumed by electrical equipment can be up to six times as much as steady-state requirements. The utility must size its distribution equipment to handle a large percentage of its load starting simultaneously after an outage. A customer's peak demand is often established by the start-up of certain loads, such as induction motors. Under such start-up conditions, voltage sags can occur, high currents can stress equipment, and high demand charges can be incurred. DR can provide benefits to the distribution system, but many of those benefits are lost if the customer load is allowed to start up before the DR after an outage. In addition, the entire annual benefit of DR peak shaving could be negated if a long DR restart delay is required in utilities with short demand charge intervals, and long restart delays could affect demand charge. 
Some DR, such as induction generators, use power from the utility during start-up to "motor" the generator up to a certain speed, after which the prime mover takes control. During this time, the DR is contributing to the utility's load and potentially to the DR owner's demand charge.

The amount of cold load that the utility must pick up after an outage depends the types of load, the inherent or programmed delay between when the utility returns and when the load restarts, the delay between when the utility returns and when the DR restarts, and, to some extent, on the length of the outage (i.e., how cold the load is). An energy management system could be employed to coordinate the restart of loads with the DR.

DR restart delay is defined in IEEE P1547 Draft 7 \$4.1.5.2 Reconnection After Area EPS Outage. This section states that the DR shall not restart until the utility has operated continuously within the normal operating range (i.e., between $88 \%$ and $110 \%$ of nominal voltage and between 59.3 and $60.5 \mathrm{~Hz}$ ) for a defined delay period. The current draft of P1547 states that the delay shall be fixed at 5 min or adjustable up to $5 \mathrm{~min}$.

This delay is necessary to ensure that, after an outage, the Area EPS has adequate time to stabilize before the DR restarts.

DUIT testing could:

- Investigate DR operation during distribution system operations to determine appropriate restart delay

- Evaluate energy management systems that control both load and DR.

\subsubsection{Faults on Adjacent Feeders}

Issues with DR for faults on adjacent feeders include:

- Overstress of station and feeder equipment

- Variation in source impedance for feeder protection studies

- Coordination problems between feeders

- Desensitization of backup protection for feeder breaker failure

- Impact of generator to adjacent feeder coordination

- Voltage sag caused by fault on adjacent feeder leads to loss of DR (a function of under voltage trip settings.

\subsection{Overstress of Substation and Distribution Feeder Equipment}

Higher fault duties from DG may cause overstress of station and distribution equipment. Periodically, equipment is installed with minimal margin, and even a small fault duty addition can cause overstress. Even when equipment is adequately rated, higher fault duty causes increased fault stress. 


\subsection{Variation in Source Impedance for Feeder Protection Studies}

Based on the amount and variation of cogeneration in service, there could be considerable difference in the source impedance used when checking protection on a feeder. Generation on all adjacent feeders will affect this impedance. Currently, when a feeder is fed from a typical utility system, the source impedance to the feeder is essentially constant. This impedance is primarily the substation distribution bank. The source impedance for feeder protection studies does not vary much for differences in the transmission system.

\subsection{Coordination Problems Between Feeders}

Coordination is never checked between feeders. Feeder relays are nondirectional. A feeder could trip for a fault on an adjacent feeder if there is a big enough source on the feeder.

\subsection{Desensitization of Backup Protection for Feeder Breaker Failure}

Distribution feeders breaker fail backup is typically the high side overcurrent relay on the distribution bank. As more generation is added on the distribution, this relay is less likely to detect a feeder fault and trip.

\subsection{Effect of Generator on Adjacent Feeder Coordination}

Coordination is not checked on a distribution generator for a fault on an adjacent feeder. A fault on an adjacent feeder could trip generation on an adjacent feeder.

\subsection{Induced Voltage Sag Leads to DR Abnormal Condition Outage}

- Function of undervoltage trip settings

- Those settings defined, in part, as islanding mitigation

- Perform islanding test while varying undervoltage trip point and timing

\subsubsection{Secondary Networks}

In a secondary network distribution system, service is provided through multiple network transformers and multiple secondary feeders, in contrast with radial distribution systems, in which there is only one path for load current to flow from the distribution substation to a particular load. The secondaries of network transformers are connected together via a system of network feeders to provide multiple electrical paths for power flow, resulting in a higher degree of reliability than can be achieved with a single radial feeder. To keep power from inappropriately feeding from one network transformer back through another network transformer (feeding a fault on the primary side, for example), devices called network protectors are used to detect such backfeeds and open very quickly (within a few cycles). This action is required to isolate faulted network transformers and primary feeders and maintain proper load flows to the secondary network.

Many urban downtown areas have secondary networks. Facilities in the center of downtown areas are very likely to be on networks, whereas facilities in suburban and rural areas are almost certain to be on a radial distribution system. The geographic size and electrical capacity of a secondary network is a function of the density of the load and a number of other factors. 
- $\quad$ Large critical loads

- Does the presence of DR make a difference to fault detection?

- Nuisance network protector tripping

- $\quad$ Texas $=25 \%$ of load, inverter-based, no study needed.

- Can network protectors take a 2PU voltage (DR-fed island on one side of NP falls $180^{\circ}$ out of phase with utility on other side of NP)?

- Local regenerative loads (elevators) cause nearby network protectors to trip. Will DR do the same?

- Will NP trip/close operations increase because of DR?

What is the typical rating of one network transformer as a percent of total network capacity? Network transformers are 75-150 kVA single phase and 300-1,000 kVA three phase.

If the aggregate DR output within a networked secondary exceeds the aggregate load, the excess power will backfeed the transformers and activate one or more network protectors. If such a situation were allowed, the reliability of the secondary network would be reduced and the stability of the network jeopardized. In such a circumstance, DR could compromise grid reliability.

\subsubsection{Issues to Address in Testing of DR for Network Systems}

Several issues are of interest when looking at the characteristics of the DR facility that may be sited on a network system. These include:

1. Fault current contribution from a DR on a secondary network

2. DR capacity relative to site and network loads

3. Anti-islanding

4. Inrush current (voltage flicker).

\subsection{Fault Current Contribution From a DR on a Secondary Network}

The available fault current from a DR facility is of concern to a utility when it is considering the rating of network protective devices. Should a fault occur on the primary side of the network in the vicinity of a DR facility, the fault duty of the network protector could be exceeded if the available additional fault duty of the DR increased the available fault current beyond the limits of the network protector. This typically requires an engineering study to determine whether the additional fault current of the DR could cause damage to the network protector in the event of a fault.

Possible test procedures include:

1. Testing currents on equivalent secondary network circuits with DR connected to better understand where fault currents travel in a network and why

2. Determining under what conditions a network protector will be operated given a specific DR located in the network and determining how this is different from the variety of other existing circumstances in which network protectors operate. 


\subsection{DR Capacity Relative to Site and Network Loads}

Secondary networks are installed where load is sufficiently dense to justify the added reliability and added cost of such a system. As a result, the DR facility (or aggregate DR) could be sizeable before the utility engineer needs to be concerned. For example, a 1-MW DR on a 50-MW network may be of little concern. Conversely, a 1-MW DR on a 3-MW network would likely be a significant concern.

Texas, for instance, has chosen to assume that all inverter-based DR under $20 \mathrm{~kW}$ is so small that no study is necessary. This means that no studies or further review are necessary for small installations like this because it is assumed that there is little or no effect on a secondary network.

However, there can be large disparities between peak and minimum loads on network systems, and the issues and concerns are typically based on aggregate DR capacity, not individual unit size. The question that DR testing must answer is at what point and for what reasons does a DR facility become a concern to a utility protection engineer. If power is being exported to the secondary network, it may be necessary to determine how much power will be exported and whether any condition exists in which a network protector will be operated because of the addition of the DR. If power is never exported, there may be very little, if any, effect of the operation of the DR on network protector operation.

\subsubsection{Power Export Review}

A DR system designed for non-export (i.e., only offsets customer load without feeding into the grid) simplifies the review process. It can be assumed that the DR will not adversely effect the voltage regulation of the secondary network or cause nuisance tripping of network protectors. Additional islanding detection may not be needed if the unit is incapable of maintaining site load. There are three methods of ensuring that power is not exported:

1. To ensure no export of power without the use of additional devices, the capacity of the DR compared with the facility load must be no greater than the customer's verifiable minimum annual load.

2. To ensure power is never exported, a reverse power protective function must be implemented at the PCC (the meter). The default setting shall be $0.1 \%$ (export) of transformer rating, with a maximum 2-s time delay.

3. To ensure at least a minimum import of power, an underpower protective function must be implemented at the PCC. The default setting shall be 5\% (import) of DR gross nameplate rating, with a maximum 2 -s time delay.

A possible test procedure is to determine the local effect of an exporting DR on the operation of a lightly loaded network protector. 


\section{Conditions in Which Service Needs To Be Converted to Radial}

As the total DR on a secondary network grows relative to total network load, it becomes more likely that the local network load near a network protector could be reduced to the point that the network protector opens and interrupts service on the network. In this case, power flow studies may be needed to determine if it is possible for the network protector to see reverse power (even momentary) from the DR and initiate a trip.

If the power flow study determines that the DR installation could cause unintended operation of the network protector, one way to mitigate this problem is to switch the DR facility service to a radial service. If the proposed DR location is close to a network protector, it might be easy to switch the DR onto a radial feeder, making the change less costly. If the $25 \%$ of network load requirement is not met, the utility should conduct a power flow study and investigate whether it is necessary to convert the DR service from network to radial to mitigate the unintended operation of the network protectors.

\subsubsection{Proposed Tests}

Determine what the sphere of influence of a DR actually is and what implications this holds for applications that require conversion of service from network to radial.

\subsection{Anti-Islanding}

Given the density of load and lack of line sectionalizing equipment (switches, fuses, etc.), what are the implications for anti-islanding and how do they differ from a radial system? It is suggested that this issue be studied to determine what types of scenarios could create an islanded condition and how this is affected by DR size and relative network size.

\subsection{Inrush Current}

Given the generally low impedance found in networked systems, at what level does inrush become an issue on secondary networks? How do networks differ from radial systems in analyzing possible problems?

\subsection{Data Acquisition Requirements}

\subsubsection{General}

To perform the tests described in this report, the DAS for the DUIT project will need to provide the following functions, capabilities, and specifications. The primary measurements will be voltage and current (not RMS), one per phase for each DR, load, and Area EPS interconnection point. ${ }^{5}$ From these measurements, it will be possible to determine real and reactive power, true and displacement power factor, harmonics, etc.

To determine channel count requirements for the MGTF, it is assumed that there are four threephase interconnection points on the feeder and 24 three-phase DR or load measurement points.

Because the current level will vary depending on the test configuration, CTs will be installed as needed.

\footnotetext{
5 Single- and three-phase voltage measurements may be shared if the voltage drop between the actual measurement point and the desired measurement point is less than $1 \%$.
} 
For the purposes of power and power quality measurement, a minimum 3-kHz measurement bandwidth is required. Anti-aliasing and actual sample rate shall be defined as appropriate to limit aliasing error to less than $0.25 \%$ of full scale. This requirement will necessarily increase the minimum storage rate beyond the values quoted below, but the actual rates will depend on the available filter characteristics.

The DAS should be expandable beyond the requirements set forth here.

\subsubsection{Potential Transformers (120 VAC Output)}

The quantities in Table 65 assume four feeder tap points (medium voltage four-wire connections) and allow for up to 14 independent load and DR measurements (low voltage three-wire connections). All three phases are monitored. PT channel count equals 54.

Table 65. Potential Transformers Required for DUIT Data Acquisition System

\begin{tabular}{cccc}
\hline Quantity & Nominal Voltage & Accuracy & Minimum Storage Rate \\
\cline { 2 - 4 } & & & \\
12 & $21 \mathrm{kV}$ & $0.5 \%$ & $0.6 \mathrm{kHz}$ \\
42 & $480 \mathrm{~V}$ & $0.5 \%$ & $6 \mathrm{kHz}$ \\
\hline
\end{tabular}

\subsubsection{Current Transformers (5 A AC Output)}

Because the actual current level will depend on the number and size of DR and load, a variety of CTs must be available. For channel count considerations, assume that three-phase current measurements will be made at each of the four feeder tap locations and two-phase current measurements will be made for each of the 14 load and DR points. CT channel count equals 40 .

The selection of CTs given in Table 66 is strictly for budgetary purposes. Actual CT purchases would depend on the actual DR units under test.

Table 66. Current Transformers Required for DUIT Data Acquisition System

\begin{tabular}{cccccc}
\hline Quantity & $\begin{array}{c}\text { Current } \\
\text { Level }\end{array}$ & $\begin{array}{c}\text { Nominal } \\
\text { Voltage }\end{array}$ & Accuracy & $\begin{array}{c}\text { Minimum PQ Storage } \\
\text { Rate }\end{array}$ & $\begin{array}{c}\text { Minimum Timing } \\
\text { Sample Rate }\end{array}$ \\
\cline { 2 - 6 } 8 & 100 & $21 \mathrm{kV}$ & $0.5 \%$ & - & \\
8 & 25 & $21 \mathrm{kV}$ & $0.5 \%$ & - & $0.6 \mathrm{kHz}$ \\
8 & 1,000 & 480 & $0.5 \%$ & $6 \mathrm{kHz}$ & $0.6 \mathrm{kHz}$ \\
28 & 300 & 480 & $0.5 \%$ & $6 \mathrm{kHz}$ & $0.6 \mathrm{kHz}$ \\
28 & 75 & 480 & $0.5 \%$ & $6 \mathrm{kHz}$ & $0.6 \mathrm{kHz}$ \\
21 & 40 & $240 / 120$ & $0.5 \%$ & $6 \mathrm{kHz}$ & $0.6 \mathrm{kHz}$ \\
& & & & & $0.6 \mathrm{kHz}$ \\
\hline
\end{tabular}




\subsubsection{Status Channels}

In addition, there may be up to 10 status signals (e.g., secondary contacts on the utility isolation switch for islanding testing). These channels will need to be sampled at up to $600 \mathrm{~Hz}$, providing 0.1 -cycle resolution. In addition, some DR may provide similar contact closures to show the status of various aspects such as DR interconnection contactor.

\subsubsection{Other Measurements}

Meteorological data will be monitored. It is also possible that DR or Area EPS component temperatures will need to be monitored. Channel count equals 14 .

Table 67. Other DUIT Data Acquisition System Requirements

\begin{tabular}{ccccc}
\hline Quantity & Parameter & Range & Accuracy & Maximum Storage Interval \\
\cline { 2 - 5 } & & & & \\
1 & Ambient air temperature, ${ }^{\circ} \mathrm{C}$ & -20 to +60 & $\pm 1^{\circ} \mathrm{C}$ & 5 minute \\
1 & Wind speed, $\mathrm{m} / \mathrm{s}$ & 0 to 45 & $\pm 0.5 \mathrm{~m} / \mathrm{s}$ & 5 minute \\
1 & Relative humidity, $\%$ & 0 to 100 & $\pm 1^{\circ} \mathrm{C}$ & 5 minute \\
1 & Irradiance, $\mathrm{W} / \mathrm{m}^{2}$ & 0 to 1500 & $\pm 5 \%$ & 5 minute \\
10 & Type T or J thermocouple & & $\pm 1^{\circ} \mathrm{C}$ & 5 minute \\
\hline
\end{tabular}

\subsubsection{Control Output Channels}

The DAS will need to provide 16 digital and eight analog control signals that will be used to operate contactors, DR, and other equipment. Analog outputs should be 12-bit.

\subsubsection{Signal Conditioning}

Signal conditioning shall be provided to accommodate the specified signal levels, storage rates, and accuracies. Differential measurements are preferred.

\subsubsection{Physical Layout}

In general, the control and measurement points will be physically dispersed over a $300-\mathrm{ft}-\mathrm{by}-300-\mathrm{ft}$ indoor and outdoor area, although most measurement points will likely be located within the 100$\mathrm{ft}-$ by-50-ft MGTF building. Ambient temperature may range from $-5^{\circ} \mathrm{C}$ to $45^{\circ} \mathrm{C}$. Computing facilities may be assumed to be environmentally controlled.

\subsubsection{Data Sampling}

To control burden errors in CTs and limit EMI, digital sampling devices will have to be physically located adjacent to the measurement point (most likely within $6 \mathrm{ft}$ ). It is also critical that the combination of sampling offset and jitter between any two voltage and current channels at a specific power measurement point be sufficiently short that the reading at the second channel does not change significantly between the first and second samples. That is, if square-wave signals are assumed, power and power quality data samples must be acquired within $0.42 \mathrm{~ms}$ of each other. For timing purposes, step changes in the time stamp of each sample must be known within $0.5 \mathrm{~ms}$ to achieve the desired error limit of $1 \mathrm{~ms}$ for calculating the interval between an auxiliary contact opening and current in or out of a DR dropping to zero. 
Digital-to-analog conversion must have a minimum 13-bit resolution and $\pm 0.1 \%$ full-scale accuracy to allow all signals to vary by three octaves without replacing signal conditioning equipment and retaining a $0.1 \%$ resolution.

\subsubsection{Real-Time Data Processing}

Using Visual Basic or a similarly programmable environment for automating data collection and test sequencing, the DAS will need to calculate RMS voltage and current, real and reactive power, and power factor for selected channels and be able to provide programmable control sequencing response within $2 \mathrm{~s}$ based on those signals. The computed quantities must be updated at least 10 times per second.

\subsubsection{Data Storage}

The requirements outlined above suggest that the DAS front-end will need to handle sustained data rates of $1 \mathrm{MB}$ per second for up to several minutes. It is unlikely that all of the high-rate data acquired will actually be needed for analysis, so a report-by-exception technique that omits recording high-rate data when the RMS data, average power data, and wave shapes are constant may be acceptable. The acceptability of such data reduction in the DAS front-end is contingent on the availability of (pre-computed) RMS voltage and current, real and reactive power, and power factor.

\subsubsection{Post-Processing}

Data will be managed by an SQL-based relational database. Data collection software should accommodate this approach.

\subsubsection{Anticipated Solutions}

The most straightforward way to meet all of the requirements (particularly the potential real-time control requirements) is to use standard automated test environment (ATE) techniques to integrate a DAS using separate signal conditioning, sampling, recording, and storage devices. Alternatively, commercial PQ recording systems that integrate many of these functions into a single package, including a considerable amount of tested functionality, are currently available. The drawback to such systems is that their software is not necessarily designed for an ATE, and support is limited for automating repetitious tasks or adapting data collection to meet specific measurement requirements. The identified advantages and disadvantages of these solutions are described below.

In both cases, $21-\mathrm{kV}$ metering-class voltage and current instrument transformers are not specified for wide bandwidth operation, though one manufacturer has informally suggested reasonable results can be obtained up to about the 20th harmonic. Thus, if standard medium voltage metering CTs and PTs are used, they would have to be specially calibrated. Fortunately, the standards laboratory at PG\&E's TES facility (where the MGTF is located) should be able to perform such calibrations. Very wide bandwidth voltage step-down could be achieved with a Ross Engineering voltage divider, but each voltage divider costs more than $\$ 3,000$. Similarly, very wide bandwidth/high-voltage CTs are available from Pearson Electronics. But again, each CT costs more than $\$ 3,000$.

In both the ATE and PQ system solutions, multiple individual chassis supporting data sampling and temporary storage are believed to be necessary. Ethernet should transport data from the voltage and current data collection points to the central data storage and analysis computers. 
Separate data collection for the weather and component temperature measurements can be implemented with a datalogger with appropriate analog input capabilities.

One advantage of the PQ system approach is the integrated analog isolation and filtering circuitry. ATE systems usually assemble the appropriate anti-aliasing, voltage level conversion, and isolation functions using separate components, leading to generally higher cost and larger space requirements.

A typical advantage of ATE systems is channel count density because 16 and 32 input cards are readily available. Also, the ATE systems are typically more flexible as to how the available inputs are used (e.g., to measure combinations of single- and three-phase devices). However, the physical spacing, frequent rearrangement of measurement points, and need for short CT leads will limit the ability to take advantage of this feature.

The time delay from a contactor auxiliary relay state-change (measured at one location) to the reduction of current to below a threshold value (measured at another location) is a key measurement capability for islanding testing. To maintain time base synchrony between the separate chassis, two approaches could be used: hardware synchronization or network synchronization. Hardware synchronization involves transmitting discrete clock signals or trigger signals to every chassis and using these signals to synchronize sampling to within $1 \mathrm{~ms}$ between chassis. This level of synchronization is required to allow time delay measurements to within $2 \mathrm{~ms}$, or approximately one-tenth of a cycle. Network synchronization would eliminate the need for separate wiring and central triggering hardware. However, the algorithms required to achieve 1-ms accuracy depend on clock control capabilities that are typically limited to real-time operating systems, so it may be cheaper to use the hardware option. PQ systems are not typically designed to provide this level of synchronization between units, and it may be difficult to obtain.

Software available with ATE hardware will include drivers for controlling the sampling hardware and generic network communications. From this base, additional software would have to be developed to:

- Manage the sampling and conversion to engineering units

- Compute rms, voltage and current, and average real and reactive power (in real time)

- Compute estimates of harmonic distortion (post processing)

- Transfer post-test data to the central database

- Interactively review the contents of the central database.

PQ measurement system software may include many of these features already, which may positively affect their cost-effectiveness but limit their ability to perform special tests (for example, timing of an islanding test). If not, custom software will have to be developed to fill in the missing functions. In this case, access to functions or data formats by external programs may determine whether such capabilities can be added. Thus, such reductions in capital cost may incur higher risk. In addition, although ATE systems can be set up to record a continual stream of data or report by exception, PQ measurement systems are usually limited to report by exception, which makes postprocessing of the data more difficult. Nevertheless, in all cases, custom software will need to be 
developed to automate test performance, test sequencing, and results extraction as needed to streamline common procedures.

The capabilities of PQ measurement systems to be integrated into larger automated test systems vary widely. Issues include external access to "current" data, accessibility and organization of collected data, data record lengths, and time measurement accuracy. 


\subsection{DUIT Program Summary}

Task

Description

Deliverable

1

\section{Procurement Process}

Develop and implement a procurement process for vendors and suppliers of the distributed resource equipment that will be tested. A framework for evaluating the proposals will be developed with the key stakeholders' input. The framework will be used to undertake a systematic review of proposals/quotes that are submitted. It is expected that many of the distributed resources can be leased or rented. In this task, it will be determined what can be leased or rented and what needs to be purchased. Also, Letters of Intent that contain schedule dates will be obtained. This schedule data will then be used in the Electrical Test Plan Scheduling in Task 3.

Develop a procurement package for a request for proposals for all DR and infrastructure components not already on site. This excludes the control and data acquisition system. This will include specifications, terms and conditions, and delivery schedule for the hardware.

\section{Develop Test Management Control System Specification}

Develop specification for a test control system to be used with DUIT DR technologies and test loads. Although the control system will be designed specifically to facilitate and perform the DUIT test plan, it will largely represent hardware and software that is capable of aggregating and dispatching DR in the "real world." Important validation of the concept of monitoring and control needs will be incorporated into the specification. Other work addressed under this task will:

- Specify how data should be processed

- Specify how much data can/should be used to communicate and control

- Specify which/how much data operators need for aggregation and dispatch

- Determine what control variables are most important

- Emphasize controls and data collection so that the evaluation of benefits related to intentional islanding can be determined.

\section{Develop Technology-Specific Engineering and Electrical Test Plan}

Working from the project test protocols developed in 2001, this task will overlay the prioritized protocols with the scheduling and availability of DR hardware, fuel needs, maintenance, and other operational factors and establish an efficient optimal test plan schedule.
Procurement package

Description of bid evaluation methodology

Copies of letters of intent

Specification document for test management system

Hardware design documents

Optimal test and installation plan and schedule

National prioritized test needs 
Other factors included in the plan development with input from Task 1 are:

- DR capital and installation costs

- DR operating and maintenance costs as well as operating manpower

- Fuel consumption, fuel cost, and fuel availability

- Development of an operations log, annual capacity factor, annual kilowatt-hours produced, plant annual kilowatt-hours consumed.

$4 \quad$ Pre-Installation Engineering and Documentation Task

Under this task, all pre-installation and site preparation engineering will be performed. This includes design and line diagrams for the selected technologies, instrumentation and control, and monitoring equipment. This task also includes a final design review with all stakeholders.

\section{$5 \quad$ Modeling and Analysis}

Modeling of California prioritized DUIT testing is important as it will allow subsequent test conditions to be repeated on the computer rather than having to actually set up and reexecute testing. The ability to extend the DUIT results to these subsequent conditions will minimize actual testing and maximize value of results. Furthermore, the models, as validated during testing, will be available for use in extending test results to other "real world" projects, which will likely have slightly modified configurations. For these reasons, it is important to develop and validate models as testing is being performed. Under this task, those tests that lend themselves to modeling for future applications will be identified, models will be developed, and when testing takes place, the runs will be compared with actual test data. The loop is closed when this data is then used to adjust or tune the models.

Other factors to be addressed under this task include:

- Key and/or unique modeling requirements and modeling packages

- Use of existing models and capabilities

- Determination of testing data necessary to validate model

- Model development and validation experience.

\section{Data Acquisition Infrastructure Hardware Design and Software}

This task will complete the hardware and software design of the DAS infrastructure. The DAS infrastructure is that portion of the DAS hardware and software that remains essentially unchanged from test to test. The hardware design will include engineering layout drawings of the signal cable routing, data collection points, hardware selection, and data storage locations. The DAS functions that will be covered in this task include low-level code that causes $D / A$ and $A / D$ converters to communicate with computers, signal synchronization, and others.

Construction ready design documents and permits

Prioritized list of tests to be modeled

\section{Models}

Preliminary simulation runs

\section{Hardware design}

Infrastructure test results 
The DAS and test control system will be co-located and executed from the same hardware.

\section{$7 \quad$ Test Control System Hardware Design and Software}

The DUIT test requires a unique control system of which a portion is integrated into the DAS computer hardware and software. Many tests require autonomous control of DR, and other tests require aggregated control. This task will develop the software necessary for the control portion of the combined DAS/control system software. Closed-loop control of independent DR within an aggregation so that aggregated operation is smooth and stable will be an objective. Remote dispatching of DR independently or in aggregation will be designed into the control system.

The DAS and test control system will be co-located and executed from the same hardware.

\section{Delivery, Installation, and Testing of DAS/Control System}

In this task, the hardware and software necessary for the complete DAS/control system will be procured, and installed and initial acceptance testing will be performed. The procurements also include all the necessary sensors (i.e., CTs, PTs, isolation and antialiasing filters, $A / D$ converters, etc.).

\section{PG\&E Hardware Procurement and Engineering Task}

This task will allow PG\&E to procure a portion of the hardware needed to perform the DUIT tests. Only that hardware to be used in the early phases of the testing will be procured at this time. The engineering effort necessary for this procurement and the construction of infrastructure equipment drawings are the task identified here.

\section{Install DR Systems, Complete Acceptance Testing of DR}

This task includes renting and leasing DR hardware necessary to execute tests as called for in the prioritization of the test plan. This will include up to $2 \mathrm{MW}$ of DR together with the necessary fuel to operate these systems for 12 months of tests. The DR will comprise the following:

- Two to four microturbines at $30 \mathrm{~kW}$

- Four diesel gensets ranging from $100 \mathrm{~kW}$ to $500 \mathrm{~kW}$

- $25 \mathrm{~kW}$ of advanced PV systems interconnected through multiple grid-connected inverters

- A flywheel energy storage system and inverter system

- An advanced battery storage system with inverter (flowing electrolyte type)

- Lead-acid battery system with inverter system.
Hardware design

Control system test report

Acceptance test procedure

Signed-off acceptance test report

Load banks, capacitor banks, instrumentation delivered to the MGTF

Installation and acceptance of DR at the MGTF facility 
This task represents the labor costs associated with the first round of testing of the DUIT

project. The costs reflect test technician and engineer time from PG\&E as well as a 0.5 fulltime equivalent program oversight engineer. These tests will be executed in an order of

Stakeholders meeting and highest priority to lowest. review of results 


\section{Appendix A. Q\&A}

\section{How will this project advance science or technology, especially with respect to resolving the key issues?}

This project will provide answers to many of the questions that have thus far prevented DER from being used pervasively as a utility solution (despite its attractiveness in "paper studies" that were initiated nearly a decade ago and have proliferated ever since). Customers will be able to refer to an actual "case study" to learn about interactions among various DER technologies, systems integration and interoperability issues, and the capabilities of an automated "microgrid" that can serve some or all of their power needs. Manufacturers will have a "proving grounds" to identify possible weak spots in their designs and needs for "standards." They will also be able to gain insights into how they can optimize their technologies for use in combination with other technologies. Finally, utilities will have the chance to review "real world" experiences in dispatching DER for peak demand reduction plus enhanced system/customer reliability while determining what obstacles may remain for DER integration with other utility information and management systems.

\section{Why would the project not be adequately addressed by competitive or regulated markets?}

Regulated utilities are severely cutting research and development to prepare for competition that will result from deregulation. At the same time, these utilities are not willing to experiment with new technologies by using customers as "test sites." To make matters worse, regulated markets have no economic incentive to look for more cost-effective solutions if it means incurring additional risk (whether real or perceived). Although competitive markets may eventually change this situation, most utilities have not yet figured out whether DER is an opportunity or a threat to their future business. Thus, it is unlikely that this type of DER demonstration project will be undertaken by a regulated utility to serve the public good, and competitive markets would, of course, keep results of this nature proprietary as a means of obtaining a competitive advantage.

The DUIT is a clear example of the need for state- and local-level research for the common good. Because it investigates the interaction among distributed generation and storage technologies, the DUIT project helps customers and utilities alike and is supportive of all distributed generation and storage technologies simultaneously. Thus, the benefits of the project are substantial and broad, and the likelihood of any individual firm undertaking such a test is very small.

\section{What will determine if the project is successful?}

In many ways, this project will set the standards by which distributed generation and storage technologies will be measured regarding their applicability for distribution system integration. No one has attempted deep penetration (greater than $10 \%$ of the local load) of the distribution system with distributed generation and storage. The team does not know precisely what to expect and what problems may be encountered. To date, studies of the effects of distributed generation and storage on the distribution system have not predicted concerns, but without testing in the real world, this cannot be proved to the point where customers and utilities feel comfortable with these units in the system. 
The project will be a considered a success if:

1. Any electrical problems that occur are captured by instrumentation for further analysis and resolution

2. The field experience and its subsequent analysis teaches the DR community how to improve its components, integration techniques, and economics; maximize its benefits; or recognize which electrical interconnection situations should be avoided

3. Distributed generation and storage interconnection standards are confirmed or revised in regards safety, reliability, protection, economic effect on project costs, etc.

4. The electrical and economic results of this test can be extrapolated to similar locations, technologies, and circumstances

5. Utilities and customers feel more confident in the benefits of significant distributed generation and storage installations.

\section{Why should this test be performed now?}

Distributed generation and storage technologies are only now being considered for the broad range of applications they can address. To date, their cost, efficiency, emissions, and reliability have not been able to compete with many central station technologies. Further, their positive attributes of local benefits have been overlooked by utilities used to optimizing very large plant operations and economics.

Recent advances in technology costs and performance, massive planned investments by the modular distributed generation and storage industry, and the delamination of the electric utility industry have changed the rules of the game to make distributed generation and storage a near-term reality. But one of the hurdles that will remain (even if the technologies themselves are ready) is the lack of field experience and successful integration via a robust distributed generation and storage control system. This project is the most timely way to address both of these hurdles.

\section{Who makes up the DUIT team?}

Members of this team have been active in DR concept development, integration technology development, and defining the objectives and design of a test to ensure the seamless integration of distributed generation and storage into utility systems.

The scope of the team goes beyond its members; contacts and influence with other research organizations, technology developers, and utilities will continue to be an important part of this project. This project will be the culmination of nearly a decade of DR research and development by team members.

It is clear that a more complete evaluation of the benefits and limits of operation of DER for all stakeholders (e.g., energy customers, electric transmission and distribution companies, and equipment manufacturers) is needed. The ultimate deliverable of this project is a report documenting all aspects, results, conclusions, and recommendations resulting from this project. Transferring the knowledge base and results of this integration test to the appropriate 
state regulators, electric utilities, and energy customers is critical to addressing the issues described in the project objectives and reducing any institutional or operational barriers that may prevent the DER market from being fully realized. The project team will interact with key industry groups to ensure that the results, conclusions, needs for further technology development, and identified issues are effectively communicated. 


\section{Appendix B. Summary of DER Technologies}

The summaries below provide brief descriptions of leading DER technologies. For context, they include generic cost and performance information. Readers should note that, for any given situation, it is important to consult with vendors or their agents or dealers regarding actual price.

\section{B.1 Internal Combustion/Reciprocating Engine Generators}

An internal combustion/reciprocating (piston-driven) engine generator set (or genset) includes an internal combustion engine as the prime mover coupled with an electric generator. Gensets often include control and power conditioning subsystems. Sound attenuation enclosures may also be needed.

Most engines are one of two types:

1. Compression ignition of fuel: the diesel cycle in which fuel combustion occurs as fuel is compressed, causing heat leading to ignition

2. "Spark ignited" combustion of fuel: the Otto cycle, characterized by spark ignition of fuel (gasoline-fueled automobile engines employ the Otto cycle).

\section{B.1.1 Diesel Engine Generators}

Diesel gensets consist of a diesel-cycle reciprocating engine prime mover coupled with an electric generator. The diesel engine operates at a relatively high compression ratio and at relatively low revolutions per minute (compared with Otto-cycle/spark engines and combustion turbines).

Diesel engine gensets are very common, especially in areas where grid power is not available or is unreliable. They are manufactured in a wide range of sizes up to about $15 \mathrm{MW}$; however, for typical distributed energy applications, multiple small units, rather than one large unit, are installed for added reliability.

These power plants can be cycled frequently and operate as peak load power plants or as load-following plants. In some cases, usually at sites not connected to a power grid, diesel gensets are used for baseload operation (sometimes referred to as "village" power). Diesel gensets are proven, cost-effective, and extremely reliable and should have a service life of 20 to 25 years if properly maintained.

The installed cost of diesel engines varies significantly. Used or refurbished models can cost as little as $\$ 200 / \mathrm{kW}$, and newer, more robust, more efficient machines may cost $\$ 500 / \mathrm{kW}$ or more. Depending on duty cycle and engine design, nonfuel operations and maintenance for diesel gensets operating on diesel fuel can vary widely, typically ranging from $\$ 0.025 / \mathrm{kWh}$ to $\$ 0.04 / \mathrm{kWh}$, with an allowance for overhauls. Frequent cycling increases operations and maintenance costs considerably. Although fuel conversion efficiency for diesels engines can exceed $43 \%$ (fuel input of about 7,900 Btu/kWh), typical heat rates range widely from 8,000 $\mathrm{Btu} / \mathrm{kWh}$ to $10,000 \mathrm{Btu} / \mathrm{kWh}$. 


\section{B.1.2 "Dual Fuel” Diesel Engine Generators}

A dual-fuel engine is a diesel engine modified to use mostly natural gas. Diesel engines cannot operate on natural gas alone because natural gas will not combust under pressure like diesel fuel does, so they must operate in what is called dual-fuel mode. In dual-fuel mode, natural gas is mixed with a small portion of diesel fuel (i.e., $5 \%$ to $10 \%$ diesel fuel) so that the resulting fuel mixture does combust under pressure. This requires derating of and modest modifications to a diesel engine (i.e., for the same displacement, a diesel engine modified to operate on natural gas generates less power than the same-sized engine operating on diesel fuel only).

Although diesel engines are common, dual-fuel versions are not. But because the underlying technology is commercial and well known, in theory, natural gas-fired versions (for power generation) could become much more common in sizes ranging from kilowatts to megawatts. For distributed energy systems, small multiple-unit systems would probably be installedrather than one single, large unit - to improve electric service reliability.

Dual-fuel gensets can be cycled frequently to provide peaking power or "load following," or they can be used for baseload or cogeneration applications. They employ mostly well-proven technology and are very reliable. Service life should be at least 20 to 25 years if properly maintained.

The nonfuel operations and maintenance cost is similar to that for diesel gensets. It typically ranges from $\$ 0.02 / \mathrm{kWh}$ to $\$ 0.04 / \mathrm{kWh}$, including allowance for overhauls. Typical heat rates also have a wide range, from $8,200 \mathrm{Btu} / \mathrm{kWh}$ to $10,000 \mathrm{Btu} / \mathrm{kWh}$.

\section{B.1.3 Spark-Ignited/Otto-Cycle Engine Generators}

Spark-ignited combustion (Otto-cycle) reciprocating engines are very common. They range in power output from a fraction of a horsepower to several megawatts. Perhaps the most familiar use for these engines is for automobiles. For stationary power applications, including DER, the system includes an engine as prime mover coupled with an electric generator. The engine prime mover is usually one of two types: liquid-fueled or natural gas-fueled.

Although spark-ignition engines designed to use gasoline are common, natural gas-fueled versions are not. However, because the underlying technology is commercial and well known, in theory, natural gas-fired versions (for power generation) could become much more common for a variety of applications and load sizes.

Natural gas-fueled reciprocating engine gensets can be cycled frequently to provide peaking power or "load following," or they can be used for baseload or cogeneration applications. They employ mostly well-proven technology and are very reliable. Service life should be at least 20 to 25 years if properly maintained.

The installed cost tends to range between $\$ 400 / \mathrm{kW}$ and $\$ 600 / \mathrm{kW}$. Operations and maintenance cost is similar to, and possibly somewhat lower than, that for diesel gensets. It typically ranges from $\$ 0.02 / \mathrm{kWh}$ to $\$ 0.045 / \mathrm{kWh}$. Typical heat rates also have a wide range, from $8,800 \mathrm{Btu} / \mathrm{kWh}$ to $10,500 \mathrm{Btu} / \mathrm{kWh}$. 


\section{B.2 Combustion Turbines}

Combustion turbines (also called gas turbines) burn gaseous or liquid fuel to produce electricity in a relatively efficient, reliable, cost-effective, and, in some instances, clean manner. Generically, combustion turbines are "expansion turbines" that derive their motive power from the expansion of hot gases through a turbine with multiple blades. The resulting high-speed rotary motion is converted to electricity via a generator. A full generation system consists of the turbine, a compressor, a combustor, power conditioning equipment (usually an electricity generator and transformer), a fuel handling subsystem, and possibly other subsystems such as emissions controls or a sound attenuation enclosure.

Combustion turbine generation systems are commonplace as electricity generators and are available in sizes from hundreds of kilowatts to very large units rated at hundreds of megawatts. Combustion turbine systems have a moderate capital cost, but they often are used to burn relatively high-cost distillate oil or natural gas. Combustion turbine generation systems should have a minimum service life of 25 to 30 years if properly maintained and depending on how they are used and how often they are started up.

Depending on the size, type, and application of a unit, heat rates for commercial equipment can range from $8,000 \mathrm{Btu} / \mathrm{kWh}$ to $14,000 \mathrm{Btu} / \mathrm{kWh}$. Nonfuel operation and maintenance costs are relatively low, typically ranging from $\$ 0.005 / \mathrm{kWh}$ to $\$ 0.05 / \mathrm{kWh}$. Variation is a function of turbine size, age, materials and turbine complexity, the required level of reliability, the availability of components, and maintenance requirements.

Combustion turbines can start and stop quickly and can respond to load changes rapidly, making them ideal for peaking and load-following applications. In many industrial cogeneration applications, they would also make excellent sources of baseload power, especially at sizes in the 5-to-50-MW range.

\section{B.2.1 "Conventional" Combustion Turbine Generators}

Conventional combustion turbine generators vary significantly in price and size and are designed for a wide range of duty cycles. Typical sizes range from $1 \mathrm{MW}$ to $300 \mathrm{MW}$. Smaller turbines used for stationary power generation are often developed for transportation applications, especially for marine vessels and airplanes. (Note that, for those applications, reliability and, in some cases, fuel efficiency are important performance criteria.)

Installed costs range from as low as $\$ 300 / \mathrm{kW}$ for refurbished units and lighter duty machines to $\$ 700 / \mathrm{kW}$ or $\$ 800 / \mathrm{kW}$ for heavier-duty or more efficient versions. Nonfuel operations and maintenance costs range from $\$ 0.0075 / \mathrm{kWh}$ to $\$ 0.04 / \mathrm{kWh}$, depending in large part on the intended duty cycle and maintenance practices.

\section{B.2.2 Microturbine Generators}

Microturbines are small versions of traditional gas turbines and have very similar operational characteristics. They are based on designs developed primarily for transportation-related applications such as turbochargers and power generation in aircraft. In general, electric generators using microturbines as the prime mover are designed to be very reliable with simple designs, some with only one moving part. Typical sizes are $20 \mathrm{~kW}$ to $300 \mathrm{~kW}$. 
Microturbines are "near-commercial," with many demonstration and evaluation units in the field. Several companies, some of which are very large, are committed to making these devices a viable, competitive generation option. One key characteristic of microturbines is that their simple design lends itself to mass production. For the most part, prices are still being established; possibly the key driver will be manufacturing scale. Installed price is currently in the range of about $\$ 1,000 / \mathrm{kW}$ to $\$ 1,500 / \mathrm{kW}$.

Definitive data on reliability, durability, and nonfuel operation and maintenance costs are just being developed. However, because of simplicity and, in some cases, well-proven designs, nonfuel operations and maintenance costs should be similar to those of conventional combustion turbines.

Fuel efficiency tends to be somewhat or even significantly lower than that of larger combustion turbines and internal combustion reciprocating engines, ranging from 10,000 $\mathrm{Btu} / \mathrm{kWh}$ to $15,000 \mathrm{Btu} / \mathrm{kWh}$. Note, however, that if microturbines are used in situations involving the use of steam or hot water, they can generate electricity and thermal energy (CHP) in a cost-effective manner.

\section{B.2.3 Advanced Turbine System Generators}

The Advanced Turbine System is being developed as a 4.2-MW, efficient, clean, low-cost power generation prime mover by Solar Turbines in conjunction with the US DOE. It employs the latest combustion turbine design philosophy and state-of-the-art materials. Fuel requirements are about $8,800 \mathrm{Btu} / \mathrm{kWh}$ to $9,000 \mathrm{Btu} / \mathrm{kWh}$. Installed cost is expected to be about $\$ 400 / \mathrm{kW}$, with nonfuel operations and maintenance expected to be less than $\$ 0.005 / \mathrm{kWh}$ generated.

\section{B.3 Fuel Cells}

Fuel cells are energy conversion devices that convert hydrogen or high-quality (hydrogen-rich) fuels such as methane or natural gas into electric current without combustion and with minimal environmental effects. Because of they way fuel cells convert fuel to electricity (i.e., without combustion), conversion is relatively efficient, and fuel cells' emissions of key air pollutants are much lower than combustion technologies', especially nitrogen oxides. Fuel cells are very modular (from a few watts to one megawatt).

Fuel cells are often categorized by the type of electrolyte used. The most common electrolyte for fuel cells used for stationary power is phosphoric acid. Other types are solid oxide and molten carbonate. Another promising type of fuel cell uses a proton exchange membrane, hence the name PEM fuel cell.

A fuel cell system consists of a fuel processor, a chemical conversion section (the fuel cell "stack"), and a power conditioning unit to convert the direct current electricity from the fuel cell's stack into alternating current power for the grid, for loads, or for supporting systems such as gas purification systems. 
Unless hydrogen is used as the fuel, prior to entering the fuel cell stack, the raw fuel (e.g., natural gas) must be dissociated to produce hydrogen, and a supply of oxygen from air must be available. Within the fuel cell stack, the hydrogen and oxygen react to produce a voltage across the electrodes with water as a byproduct, essentially the inverse of the process that occurs in a water electrolyzer.

Hundreds of fuel cells are in service worldwide, and the number of units in service is growing rapidly. Advocates are awaiting expected manufacturing advances that will reduce fuel cell equipment cost and improve efficiency such that they produce very low-cost energy. Typical plant sizes (which can be aggregated into any plant output rating needed) are expected to range widely from a few kilowatts to $200 \mathrm{~kW}$.

Currently available fuel cells based on phosphoric acid electrolytes have heat rates of 9,500 $\mathrm{Btu} / \mathrm{kWh}$ to $10,000 \mathrm{Btu} / \mathrm{kWh}$ and cost about $\$ 3,000 / \mathrm{kW}$ installed. Nonfuel operations and maintenance for installed devices is about $\$ 0.025 / \mathrm{kWh}$ to $\$ 0.03 / \mathrm{kWh}$.

Advanced fuel cell systems are expected to have efficiencies ranging from $40 \%$ to perhaps as high as $55 \%(6,300 \mathrm{Btu} / \mathrm{kWh}$ to $8,500 \mathrm{Btu} / \mathrm{kWh})$ over the next 5 years and ultimately to cost less than $\$ 1,000 / \mathrm{kW}$ installed.

\section{B.4 Energy Storage Systems}

Energy storage systems used for DER applications can store energy electrochemically or as mechanical energy and discharge electricity for use when needed. Battery energy storage systems consist of the battery and a power conditioning unit subsystem to convert grid power from alternating current power to direct current power during battery charging and to convert battery power from DC to AC power during battery discharge. Most batteries can change their rate of discharge/storage in milliseconds.

There are two key elements to energy storage plant cost (unlike generators, which have just one): (1) output rated in watts (or volt-amps) indicating the rate at which the system can discharge (i.e., provide energy to a load) and (2) the energy storage capacity, the amount of energy that can be stored (rated in kilowatt-hours).

Storage is used for a variety of applications, such as:

- To increase reliability_for longer duration power outages

- To reduce effects from an electric supply's poor power quality-for shorter duration electric service disruptions

- To take advantage of "buy low-sell high" (energy cost reduction) opportunities or peak shaving (electric demand reduction) opportunities

- To reduce peak demand on local electricity infrastructure.

Electrochemical batteries are by far the most common type of battery. Primarily, these are the lead-acid type, though other types are emerging as competitive options. They are proven, 
reliable, and highly modular. A robust international industry exists to support the use of electrochemical batteries. Off-the-shelf and, in the future, "advanced" battery systems will be viable for distributed energy systems.

Plant costs range from about $\$ 200 / \mathrm{kW}$ to $\$ 300 / \mathrm{kW}$ of maximum power output/discharge and from about $\$ 200 / \mathrm{kWh}$ to $\$ 400 / \mathrm{kWh}$ installed cost for energy storage "reservoir" capacity. Operation and maintenance includes replacement of battery cells, periodic watering of the cells, and periodic maintenance of the power conditioning unit. Nonfuel operation and maintenance ranges from $\$ 0.0075 \phi / \mathrm{kWh}$ to $\$ 0.015 / \mathrm{kWh}$. "Round trip" energy efficiency (AC to $\mathrm{DC}$ to $\mathrm{AC}$ or charge-discharge) usually ranges from $65 \%$ to $75 \%$.

There may be limited hazardous emissions from battery charging, and some batteries contain hazardous material(s).

SMES, flywheels, and "supercapacitors" are emerging alternatives to electrochemical batteries and tend to be more efficient. SMES units may be superior for larger-scale applications. SMES units are used commercially in the US to stabilize voltage on transmission lines. Flywheels and supercapacitors are more modular and tend to be relatively light.

In addition to being a discrete system type, often energy storage is a key subsystem within systems employing other types of DER. Depending on the type of system, energy storage does one or more of the following: provide power for loads during engine start-up, provide electric energy needed to start the engine itself, or store electric energy from a DER system (or even the utility grid) for later use.

\section{Uninterruptible Power Systems}

Uninterruptible power systems are connected to specific equipment, buildings, or entire facilities with critical loads to provide protection from power fluctuations lasting from just a few milliseconds to a few minutes. Specifically, they provide filtered/high-quality power on a continuous basis or energy for use during power outages lasting several minutes. Often, they have sufficient energy to power loads long enough to allow orderly shutdowns (e.g., of information or process equipment).

Uninterruptible power systems can be either standby or in-line. Standby devices monitor the line (power source) and provide energy as needed when problems are detected. In-line systems are connected between the power source and the load and thus can provide very complete, continuous filtering of grid power, although "throughput" losses can be as high as $40 \%$.

\section{B.5 Photovoltaics}

Photovoltaics are semiconductor devices that convert sunlight directly to DC electricity; power conditioners (inverters) are used to convert the DC to standard AC power.

Photovoltaic cells are thin layers of semiconductor (usually crystalline silicon). The cells are integrated in series and parallel into a module that is easily mountable on a structure.

Modules can be attached to fixed surfaces, accepting output variations because of the sun's position, or they can track the sun for maximum output. 
PV systems using crystalline silicon are readily available. However, PV lifecycle and equipment costs are not competitive with more conventional generation technologies for large-scale generation applications. Conversely, PV is cost-effective in a growing number of circumstances for applications requiring low power and/or small amounts of energy. Therefore, remote installations and niche applications (e.g., power for communications systems, roadside emergency cellular phones, and off-grid homes) are the most common applications for PV.

Photovoltaic energy production can vary dramatically from one day to the next, due mostly to weather, and from one region to the next, due mostly to differences in latitude and climate. Frequently, battery storage or diesel genset systems are integrated with photovoltaics to carry loads through times when sunlight does not provide enough energy.

PV systems can cost between $\$ 5,000 / \mathrm{kW}$ and $\$ 10,000 / \mathrm{kW}$ installed, with variation driven mostly by system maximum output and cost for subsystems such as inverters, integrated engine-generators, or battery energy storage.

\section{B.6 Wind}

A wind generation system (also called a wind turbine) converts the kinetic energy in wind into mechanical work and then to electric energy. Key subsystems include airfoil shaped blades; a rotor (to which blades are attached) that converts wind energy to rotational shaft energy; a drive train, usually including a gearbox; a tower that supports the rotor and drive train; a generator that converts mechanical energy to electricity; and power conditioning that converts the electricity generated into a form (voltage and current frequency) used by the grid. Systems also include other equipment such as electrical wires, ground support equipment, interconnection gear, and controls.

During generation, wind passes over both surfaces of the airfoil shaped blade. Air passes over the longer (upper) side of the airfoil more rapidly than it moves past the underside, creating a lower-pressure area above the airfoil. The pressure differential between top and bottom surfaces results in a force called aerodynamic lift (the same phenomenon that causes aircraft wings to "lift" an airplane).

Wind turbine electric power output varies with wind speed. The "rated wind speed" is the wind speed at which the "rated power" is achieved and generally corresponds to the point at which the conversion efficiency is near its maximum. In many systems, during times when wind speed exceeds the rated wind speed, turbine speed is maintained at a constant maximum level, allowing more stable system control. Note that at lower wind speeds the power output drops off sharply, as turbine output is a function of the cube of the wind speed (i.e., power available in the wind increases eight times for every doubling of wind speed).

Individual wind generation systems range in electrical output from a few watts to more than $1 \mathrm{MW}$ and can be used for applications from small/residential electricity production to utility-scale power generation. In both cases, power from the turbine must be converted to the form used by the grid before being transferred to the grid (i.e., the process called power conditioning). 
For large-scale applications, turbines are often constructed in "wind farms" whose total output can range from tens to hundreds of megawatts.

\section{B.7 Controls}

Control subsystems perform a variety of tasks within a DER system, including:

- Engine start-up and shutdown

- Fuel management

- Energy storage charge/discharge control

- Communications among DER subsystems and with external systems

- Monitoring and recording key performance and operational parameters

- System diagnostics.

\section{B.8 Power Conditioning}

Unless a DER system provides power in the form needed by the grid or by loads, some type of power conditioning is required. For example, fuel cell, PV, and battery systems produce direct current electricity. Power conditioning inverters are used to convert DC electricity to the AC electricity used by most types of electricity-using equipment.

Reciprocating engines and combustion turbines create rotational mechanical power that must be converted to electricity. To do that, the engine is attached to a generator. Generators create electricity via electromagnetism using coils of wire and magnets (electricity is created by the motion of the wire coils or magnets relative to each other).

Generators used with combustion turbine- and reciprocating engine-based DER systems usually produce electricity at frequencies and voltages that may have to be modified before being used by loads or by the grid. Step-up or step-down transformers are used to increase/decrease voltage respectively.

\section{B.9 Data Caveats}

Cost and performance information presented herein is based on data from various sources. In many cases, manufacturers supplied their best current data, or they developed estimations based on projected costs or fuel efficiency. Installed costs for actual DG projects are usually quite site-specific. 


\section{Appendix C. Transmission and Distribution Cost/Benefits}

\section{C.1 Deferral of Capital Expenditures}

As load on a distribution system grows, eventually a point is reached when the load outgrows the capacity of one or more components of the power system, such as a transformer or distribution line (feeder). The traditional utility response to this situation is to install additional capital equipment to relieve the overloading. Not investing in capacity upgrades increases the risk that system components will fail under stress, degrading reliability and increasing operations and maintenance costs.

A load duration curve is an analysis tool used to depict the amount of time (in percent) during a year that the load on a system is above a given fraction of its maximum (peak) value. Typical load duration curves for distribution systems are shown in Figure C-1. Because load duration curves are normalized to the peak during the year, the curve begins at $100 \%$ and declines steadily to the right, eventually showing the minimum load point on the right edge. At any point in between, a load duration curve shows the need to serve load relative to the peak demand. For example, for a typical transmission and distribution system with a mix of residential, commercial, and industrial load (the solid curve in Figure C-1), the total load will exceed $70 \%$ of its peak for only about $10 \%$ of the year, or about 900 hours.

The load will exceed $80 \%$ of peak for only about $3 \%$ of the year, about 260 hours. Although extreme peaks are very infrequent events, the transmission and distribution system is designed specifically to serve peak loads, and, thus, growth in peak loading determines when action is needed to prevent system overloads during peaks.

The dashed curve in Figure C-1 depicts the load duration characteristics of a feeder that is primarily residential and commercial with a minimal industrial component, a characteristic that is increasingly common for many feeder systems in suburban areas. The load profile of this feeder is characterized by a higher component of air conditioning load during summer peaks. For this curve, the $70 \%$ load level corresponds to about $2 \%$ of the year (175 hours), and the $80 \%$ load level corresponds to less than $1 \%$ of the year (about 80 hours).

Understanding the duration of loads on a feeder indicates how much DG could be used to reduce peak demands on the distribution wires and how many hours of operation on peak would be needed. 


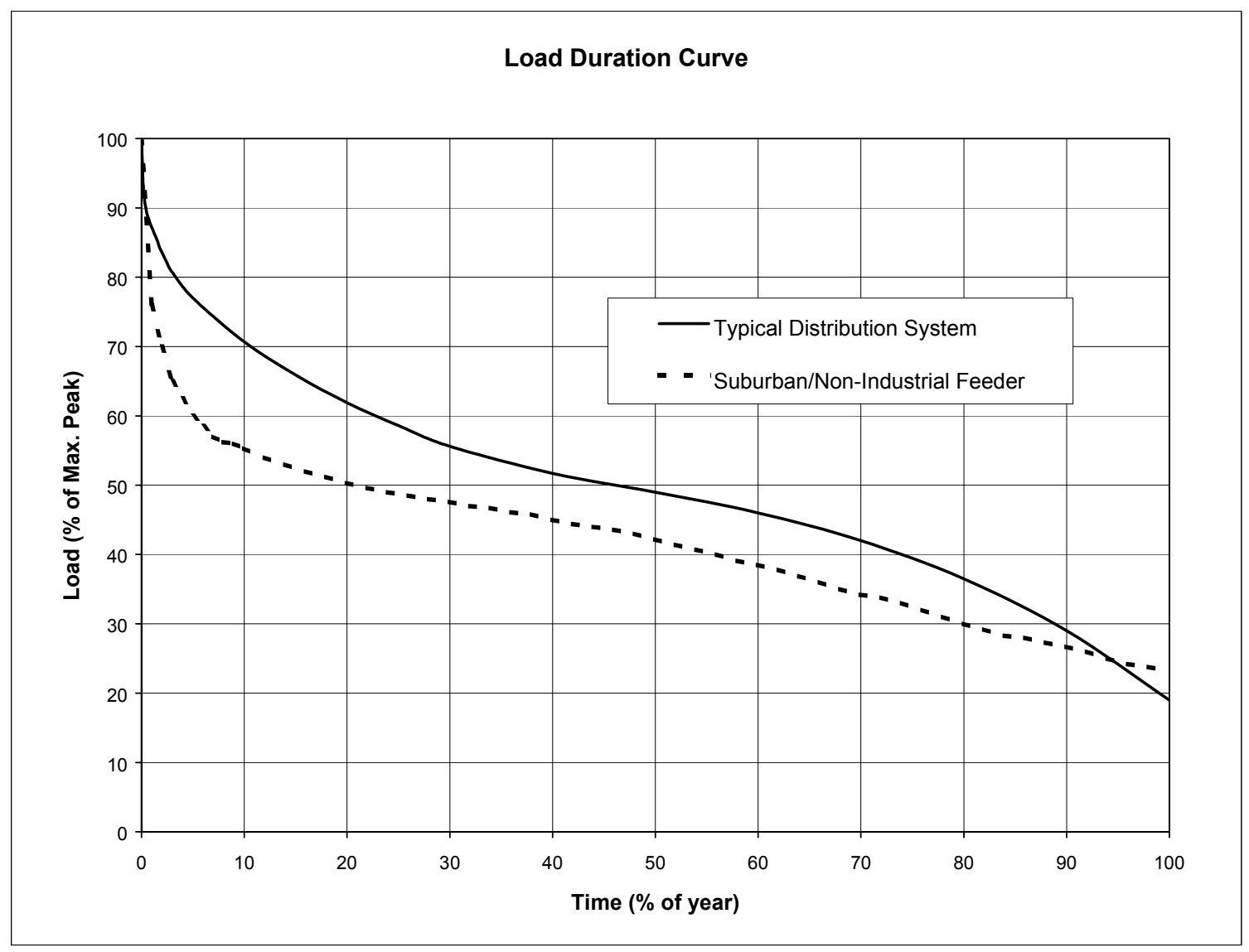

Figure C-1: Load duration curves

These curves clearly illustrate the potential for DER as a peaking resource to defer or avoid transmission and distribution capital investments. As the load grows past the capacity of the distribution system to handle the peaks, small amounts of DER operating a few hours a year could "clip" the top of the curve by meeting applicants' energy needs at the point of use rather than relying on grid-delivered power. For either of the curves in Figure C-1, and assuming that the peak feeder load is $10 \mathrm{MW}$, it would appear that $1 \mathrm{MW}$ of DG operating less than 100 hours per year would provide relief for feeder line loads during times when the feeder is under its most severe situations.

Capacity costs are quantified in terms of dollars per kilowatt per year $(\$ / \mathrm{kW}-\mathrm{yr})$. Budgets for capacity upgrades can be translated into capacity costs by dividing the budget dollars by the capacity in kilowatts that those upgrades provide:

Capacity cost, $\$ / \mathrm{kW}-\mathrm{yr}=\frac{\text { Budget } \$}{(\mathrm{~kW}) *(\text { years })}$ 
The benefit is calculated by evaluating the present worth of the kilowatts deferred. A present worth calculation assumes a certain number of megawatts installed each year, with costs discounted according to the estimated interest rate and referred back to the present year.

Benefit, $\$ /$ year $=$ present worth $\left\{(\mathrm{kW} \text { of DER })^{*}(\right.$ capacity cost, $\$ / \mathrm{kW}-\mathrm{yr}) *(\#$ of years $\left.)\right\}$

\section{Example Calculation}

Consider the case in which transmission capacity planned for the next 10 years is 1,000 MW at a budget of $\$ 200$ million. Assume the capacity would be installed in equal increments of $100 \mathrm{MW}$ each year.

Installing $100 \mathrm{MW}$ of DER this year can defer $100 \mathrm{MW}$ of capacity for one year:

$$
\begin{aligned}
& \text { Capacity cost, } \$ / \mathrm{kW}-\mathrm{yr}=(\$ 200,000,000) /((1,000,000 \mathrm{~kW}) *(10 \text { years })) \\
& =\$ 20 / \mathrm{kW}-\mathrm{yr} \\
& \text { Benefit }(\$)=(100,000 \mathrm{~kW}) *(\$ 20 / \mathrm{kW}-\mathrm{yr}) *(1 \text { year })
\end{aligned}
$$

\section{C.2 Utilization of Existing Transmission and Distribution Assets}

If DER are used to serve peak load growth, the load duration curve will "flatten" out. The existing distribution system will become loaded to a higher percentage of its maximum capability more of the time and become more fully utilized. In general, the closer to the load DG can be located, the greater the asset utilization benefits possible. DER located on the distribution system - whether by the utility, a third party working with the utility, or a customer placing DER on his premises - can reduce the need for both transmission and distribution upgrades and will likewise increase the utilization of these assets. A utility can use this knowledge to conduct a strategic review of its transmission and distribution system and identify key feeders and substations with fast-growing load or poor utilization that would benefit from DER deployment.

\section{C.3 Distribution System Reliability}

DG can have a positive effect on system and local distribution reliability. For a transmission and distribution utility (T\&D) the primary economic effect of poor reliability is increased expenditures for emergency maintenance. An analysis of applicant loads and local reliability data would allow a T\&D to identify locations where DER could have the best effect on reliability improvement. Where T\&Ds cannot own or operate DER, they can work strategically with energy service companies, vendors, and customers to contract for DER in places where reliability enhancement is desired.

Qualitative DG reliability benefits include faster restoration times and improved feeder reliability because of reduced stress and overloading of feeder equipment. Other hard-toquantify benefits include customer good will, customer retention, and avoided damage claims and/or lawsuits. 


\section{C.4 Risk Transfer}

Regulators have assigned to the T\&D the full responsibility for the safe and effective delivery of power to all customers on its distribution system. It has the responsibility to design and operate the distribution system to meet voltage and frequency limits and power quality metrics set by the standard practices in the T\&D. The advent of customer-owned and operated DER in the system adds complexity and uncertainty to the operation of the distribution system and shifts some of the responsibility for power delivery from the utility to the DER-using customer.

Where a customer has installed DER, the T\&D has four options regarding future nearby wire upgrades:

1. Ignore the presence of the DER unit and invest in wires as if the DER did not exist (implicitly discounting the unit's peak load reduction effects).

2. Include the likelihood that the unit will be on during feeder peak times (implicitly anticipating that the unit will reduce feeder peak loads).

3. Establish formal agreements and incentives by contract with the DER owner to encourage DER operations at peak and reduce the T\&D's responsibility for delivery at peak to that customer.

4. Account for the existence of any customer-owned DER on the distribution system by planning to handle the composite, statistical net (of DER) customer loads on feeders and substations.

Using the first approach, the T\&D will continue to plan and finance "lumps" of distribution capacity to accommodate the expected load growth over a specified planning horizon. Not only is most of the new capacity not used in the early years of the upgrade, but also, if the load does not grow as forecast, the investment decision becomes (retrospectively) a poor one. Not accounting for customer DER can lead to over-investment in unneeded capacity.

Using the second approach, the utility will defer its own capital investment because of the capital investment of the customer in the DG unit. In essence, the T\&D has chosen to "lean" on the customer's DER. Note that the logic would be the same in the case of the T\&D requesting load reductions by some of the customers on the feeder and trusting that the load reductions will be available during the distribution system peak.

But the utility is also assuming that the DER will operate during critical peak times as designed, with high availability and good power quality. If either of these operational assumptions is false, especially during severe peak feeder load periods, the utility will have to shed customer load, risk physical damage to the wires, or risk experiencing electrical parameters outside of normal specifications. In this sense, the utility has increased its risk in exchange for the right to lean on the customer DER. 
Assuming that the customer owning the DER has not been compensated for the "leaning rights," the customer is under no obligation to the T\&D to operate the DER in the way anticipated by the T\&D. Using the third approach, in which the utility and the customer have signed a performance contract, the customer's compensation should be affected by his failure to supply those services. A utility that designs and builds to accommodate installed DER should also have contractual assurance that the customer's load is shed first if the DER is tripped off line.

The magnitude of the savings from relying on customer-owned and operated DER to defer T\&D investments can be substantial, essentially equivalent to a permanent deferral of all anticipated reinforcements, including land acquisition, new substation equipment, etc.

The fourth approach uses the measured loads on feeders for planning purposes, unadjusted for known DER on the distribution feeder. Only a modest amount of risk is placed on the $T \& D$ in this case. The DER on the feeder are seen essentially as load reduction and are smoothed out statistically. If multiple DER are in place, their unreliability is probably smoothed out also.

An important case of very large benefit to the T\&D is relying on the customer DER to hedge the risk of planning for uncertain "block" loads. These are loads that represent a significant quantum increase in feeder load in a single year, such as a commercial or industrial facility coming on line. If the load is delayed or fails to materialize as planned, any investments the utility may have made in wires upgrades to accommodate the load will become negative financial investments. Using DER to hedge such load growth uncertainty can be valuable.

\section{C.5 T\&D Costs of Accommodating DER}

The T\&D's accommodation of customer DER will have some adverse effects on the T\&D.

- The T\&D pays for needed hardware upgrades (e.g., DER-compatible breakers, reverse power relays, sensors, instrumentation, communication devices, and meters) to the distribution system to accommodate DER (to the extent that the costs for such upgrades are allocated to the T\&D and not the customer).

- To the extent that the T\&D relies on the DER to support the grid, the T\&D assumes additional risk because the DER may not be as reliable as the wires investments it displaced or deferred.

- The T\&D must pay for some engineering staff time and study costs.

- The T\&D must provide training to its staff to anticipate and understand the implications of customer-owned and operated DER.

However, most of these costs are no different from the costs of planning, owning, and operating a T\&D system with full risk and responsibility for high-reliability electric distribution service. 


\section{C.6 Customer Benefits and Costs}

\section{C.6.1. Bill Reduction: Avoided Energy Costs and Demand Charges}

A customer's bill consists of two categories of charges: energy and demand.

Energy is the commodity purchased from the utility or retail electric provider and is measured in kilowatt-hours. The price charged per kilowatt-hour may be higher as more energy is used (e.g., one price may be charged for up to $1,000 \mathrm{kWh}$, and a higher price may be charge for every kilowatt-hour above that threshold). Energy can also be more expensive during certain times, such as system peaks. This is called time-of-use pricing.

Peaking energy prices can be high at certain times in today's market. When system peaks occur and supplies are tight, spot energy prices can skyrocket, although they may be subject to caps by regulation or ISO rules. DER can be used as insurance against the risk of high energy prices and as a means of energy price management.

Demand charges (for commercial and industrial customers) are fixed monthly charges based on the highest instantaneous load the customer may have during the month, although the specific terms may vary under different customer contracts or tariffs. For example, if the customer's peak load is $10 \mathrm{~kW}$ - even if it is only for one hour - he is charged a monthly fee based on that $10 \mathrm{~kW}$. Thus, by producing power at peak times, a DER can help a customer reduce both energy and demand charges. Peak periods may include relatively few hours per month but represent a significant percentage of a customer's total bill.

To justify using a DER in baseload operation, a careful analysis of the customer's processes and economics is needed. Low-cost fuel must be available, allowing the customer to produce power for less than the utility would charge. DER suitable for baseload use tend to be more efficient and require less operation and maintenance than peaking units. Using CHP typically increases overall economic efficiency substantially, thus increasing the probability that baseload DER operation will be economic for the customer.

Calculation of the estimated cost savings from a DER is relatively straightforward. A review of the energy consumption and demand charges recorded on the customer's recent billing statements will reveal how much energy is used during which time periods and what the costs are. DER size is matched to the peak load reduction desired, or the full customer load if baseload operation is desired, and hours of operation are determined. Total monthly costsall fixed and variable costs of running the DER in the desired mode plus energy and demand charges for whatever portion of customer requirements are not met by the DER-are computed. The cost of the DER itself must also be included using suitable financial parameters. The difference between the no-DER situation and the with-DER case is the projected cost savings of using the DER.

The cost of energy, whether purchased from the utility or generated on site, is the product of power (in kilowatts) times the number of hours of operation times the cost per kilowatt-hour:

Energy cost $=(\mathrm{kW}) *($ hours $) *(\$ / \mathrm{kWh})$. 
Both power level and energy cost are variable with time. Typically, energy costs are computed on an hourly basis, summing the results to a monthly total. Energy cost savings because of DER use are computed by first calculating total energy costs the customer would have paid absent the DER and then subtracting the total energy costs paid with the DER.

The demand charge from the utility is the product of the customer's peak power demand during the month (in kilowatts) times the monthly charge per kilowatt of peak demand:

Demand charge per month $=($ peak $\mathrm{kW}) *(\$ / \mathrm{kW} /$ month $)$.

The demand charge savings of using a DER for peak reduction is the product of the customer's peak power demand reduction (equal to the size of the DER) times the charge per kilowatt-hour:

Demand charge savings per month $=(\mathrm{kW}$ of DER $) *(\$ / \mathrm{kW} /$ month $)$. 


\section{Example Calculation}

Demand charge savings per month $=(\mathrm{kW}$ of DER $) *(\$ / \mathrm{kW} / \mathrm{month})$

Consider the case in which:

- The utility charges $\$ 0.03 / \mathrm{kWh}$ off peak and $\$ 0.12 / \mathrm{kWh}$ on peak

- Utility demand charges are $\$ 10 / \mathrm{kW} / \mathrm{month}$

- The customer's load is $2,000 \mathrm{~kW}$ during peak periods for 6 hours/day, 20 days/ month; all other times, the load is $1,000 \mathrm{~kW}$

- The customer owns a $1,000-\mathrm{kW}$ gas turbine that operates at a cost of $\$ 0.06 / \mathrm{kWh}$, inclusive of fuel and all operations and maintenance.

The customer operates the gas turbine to cut load during peak periods; the customer generates $1,000 \mathrm{~kW}$ and buys $1,000 \mathrm{~kW}$ from the utility. (Off-peak utility use won't change because it is cheaper to buy than generate during off-peak.) For peak periods, on a per-month basis:

$$
\begin{aligned}
& \text { Energy cost, no DER }=(2,000 \mathrm{~kW}) *(6 \mathrm{hrs} / \text { day }) *(20 \text { days } / \text { month }) *(\$ 0.12 / \mathrm{kWh}) \\
& =\$ 28,800 / \text { month } \\
& \begin{aligned}
\text { Energy cost, with DER }=(1,000 \mathrm{~kW}) *(6 \mathrm{hrs} / \text { day }) *(20 \text { days } / \text { month }) *(\$ 0.12 / \mathrm{kWh})+ \\
(1,000 \mathrm{~kW}) *(6 \mathrm{hrs} / \text { day }) *(20 \text { days } / \text { month }) *(\$ 0.06 / \mathrm{kWh}) \\
=(\$ 14,400+\$ 7,200) / \text { month } \\
=\$ 21,600 / \text { month }
\end{aligned}
\end{aligned}
$$

Energy cost savings $=\$ 28,800-\$ 21,600 /$ month

$=\$ 7,200 /$ month

Demand charge savings $=(1,000 \mathrm{~kW}) *(\$ 10 / \mathrm{kW} /$ month $)$

$=\$ 10,000 /$ month

The customer's total savings $=\$ 17,200 /$ month 


\section{C.6.2. On-Site Reliability}

To serve critical loads during sustained T\&D outages, a customer would use a DER capable of starting up in a matter of minutes and operating for the duration of the outage. The cost of purchasing, maintaining, and operating a DER for reliability enhancement would need to be cost-justified based on the expected number and duration of T\&D outages and the estimated costs of those outages to the customer.

A customer's "value of service" (VOS) will vary according to the situation and may be subjective to some degree. Residential customers experience inconvenience but usually do not suffer significant economic losses from outages, which normally last only a few minutes to a few hours. Research has determined that residential VOS is in the vicinity of $\$ 1 / \mathrm{kWh}$.

For commercial and industrial customers, the VOS can be much greater, depending on the process that is interrupted. Product and equipment can be damaged, revenue lost, and labor forces idled until power is restored. Research has estimated the VOS for these customer classes to be in the range of $\$ 10 / \mathrm{kWh}$ to $\$ 70 / \mathrm{kWh}^{2}$

Note: Operating a DER to serve customer load when the T\&D supply is interrupted requires "islanded" operation, i.e., there is no live connection between the customer and the T\&D at the point of common coupling, and the DER operates only to serve local load.

Interconnection rules will specify the protection equipment that must be installed to prevent the DER from reconnecting with the T\&D until T\&D service is restored.

Assuming that the costs to a DER owner are proportional to the length of the outage, the VOS interruptions on a yearly basis can be calculated from the following equation:

Benefit, $\$ /$ year $=(\mathrm{kW}$ of load $) *((\mathrm{SAIDI}, \mathrm{min} / \mathrm{yr}) / 60) *(\mathrm{VOS}, \$ / \mathrm{kWh})$

Where SAIDI for the feeder supplying the customer = system average interruption duration index (minutes/year).

Alternatively, there may be fixed costs associated with an outage, regardless of its length. In this case, the value is the fixed cost times the number of times a year the interruption occurs:

Benefit, \$/year $=($ SAIFI, outages/yr $) *(F C, \$$ outage $)$

Where SAIFI for the feeder supplying the customer = system average interruption frequency index (outages/year).

\footnotetext{
${ }^{1}$ Pupp, Roger, and Woo, C.K. Costs of Service Disruptions to Electricity Customers. The Analysis Group Inc., January 1991.

${ }^{2}$ Ibid.
} 
The total benefit to the customer may be a combination of these two values.

\section{Example Calculation}

Consider the case in which:

Customer load $=1,000 \mathrm{~kW}$

$\mathrm{SAIDI}=90 \mathrm{~min} /$ year

SAIFI $=1.25$ outages/year

$\mathrm{VOS}=\$ 50 / \mathrm{kWh}$

$\mathrm{FC}=\$ 5,000$

For this situation, installing a DER that is capable of providing standby service provides the DER owner an estimated yearly reliability benefit of:

$$
\begin{gathered}
\text { Benefit, } \$ \text { year }=(1,000 \mathrm{~kW}) *((90 \mathrm{~min} / \mathrm{yr}) / 60) *(\$ 50 / \mathrm{kWh}) \\
+(1.25 \text { outages } / \mathrm{yr}) *(\$ 5,000 / \text { outage }) \\
=(\$ 75,000+\$ 6,250) / \text { year } \\
=\$ 81,250 / \text { year }
\end{gathered}
$$

\section{C.6.3. Power Quality Improvement}

Power quality (PQ) is related to reliability in some ways, and the potential solutions can be similar to those for reliability. In general, PQ problems tend to be short in duration and small in magnitude but frequent or constant in occurrence. They may include voltage sags or spikes, switching transients, harmonics (frequencies other than $60 \mathrm{~Hz}$ ), noise, and momentary outages (less than 5 minutes, according to the definition in IEEE Reliability Standard 1366; there is no similar standard for PQ).

Customers can experience many of the same consequences from poor power quality as they would from poor reliability. For many industrial and commercial customers, a momentary outage is just as bad as a sustained outage because production processes or electronic equipment and records may be disrupted in either case. If so, benefits may be computed according to the same VOS principles as described in the section on reliability.

Resolving PQ issues can be difficult because the problems may have their origin in the T\&D system, the customer's equipment, the equipment of other customers on the feeder, or an interaction of any combination of these systems. The proliferation of solid-state electronics, in customer as well as T\&D equipment, is frequently the source of PQ anomalies.

Because many PQ symptoms are low-energy or short-term phenomena, distributed storage (e.g., batteries or flywheels) linked to the customer's most sensitive loads may be an economic solution, relative to the expense and effort of a distributed generation system. Power conditioning systems (power electronics-based converter systems) or isolation transformers may be economical alternatives as well. Whatever system is used, the approach is to interpose the system between the customer and the T\&D to filter or smooth out PQ anomalies. 


\section{C.7 Other Benefits and Costs}

This category of benefits and costs arising from the installation and operation of DER cannot, at this time, be directly allocated to any particular stakeholder or participant in the DER market. Before electric industry restructuring occurred, these effects would have been included in an integrated utility's analysis of total benefit and cost effects of DER. In the current evolution of industry restructuring, it may be worthwhile to analyze these effects and evaluate how they may be allocated in the future.

\section{C.7.1. Line Losses}

When transmitting electric energy through T\&D systems, the impedance (electrical resistance) of wires and transformers causes resistive or "I ${ }^{2} \mathrm{R}$ " losses, where I is the current in the line in amperes, and $\mathrm{R}$ is its resistance in ohms. These losses are typically on the order of $4 \%$ to $7 \%$ systemwide; that is, about that much of the total energy generated is lost in transit from generation sources to loads. This energy must be generated or purchased just like any other energy the T\&D requires.

DER can reduce line losses by providing supply locally rather than through T\&D lines. This benefit is more likely to be quantified on radial distribution lines than on networked distribution or transmission lines. The reduction in line loading because of DG can be seen directly on a distribution feeder, but the effect on a network is spread over multiple lines.

If the system or T\&D-specific average losses are known, then the average line loss reduction can be calculated as a simple percentage of the DER capacity. This data would need to be compiled from a combination of transmission data (from the ISO), Federal Energy Regulatory Commission filed data, or other sources. If, for example, an average T\&D line loss is $7 \%$ (this is comparable with other T\&D utilities nationwide), then approximately $1.075 \mathrm{MW}$ of energy is required to serve $1 \mathrm{MW}$ of actual load. Therefore, every $1 \mathrm{MW}$ of DER can be considered to result in an average benefit of $75 \mathrm{~kW}$ of avoided line losses during the time it operates. This approach takes advantage of known system characteristics to attribute total line loss savings to a specified DER amount.

This reduction also has implications for capacity requirements. A 7.5\% reduction in energy losses from DER use at the point of customer load translates into that much less generation, transmission, and distribution capacity that would otherwise have to be built to produce and transport that energy.

\section{C.7.2. Reserve Margin}

Reserve margin is the capacity cushion (denominated in megawatts) a power region requires as a safety margin at extremely high load times. This extra capacity allows the system generation controllers or operators to dispatch plants with an additional surety that the system will not collapse if an outage of a single transmission line or generating plant occurs. The reserve margin takes into account the instantaneous status of all available generation and transmission assets.

At this time, DER are not sufficiently proven or prevalent in the electric system to warrant explicit and separate inclusion in reserve margin calculations. Once a significant amount of DER is installed and exporting to the electric grid, and concomitant experience with 
operating DER, future DER can be included in reserve margin calculations. For now, customer load served by on-site DER is included in calculations of reserve margin requirements, but the DER is not counted as a generation resource.

Most system peak loads occur in only a few hours per year (fewer than 300 or so). Reserve margin plants do not usually have high efficiency or low emissions because of their very low capacity factor. Customer units, such as standby generators configured for remote dispatch on demand, might be excellent candidates for consideration as reserve margin status and benefits. However, DER capacity will be included in calculations of installed generation capacity for purposes of market share calculations.

Small increments of DER can be added as the load grows. The DER can be sized to accommodate the load that exceeds the capacity limit. This contrasts with typical capacity additions, which are large, "lumpy" capital investments. DER can therefore be more costeffective, flexible, and a less risky way to meet load growth.

If DER are connected to the transmission system, they can displace the need for incremental generation capacity and may reduce transmission line losses.

Reserve margin capacity costs are quantified in terms of dollars per kilowatt per year $(\$ / \mathrm{kW}$ yr) and can apply to generation or transmission capacity. The benefit of DER installation is calculated by evaluating the present worth of the kilowatts deferred. A present worth calculation assumes a certain number of megawatts installed each year, referred back to the present year.

Benefit $(\$)=$ Present Worth $\{(\#$ of $\mathrm{kW}) *(\$ / \mathrm{kW}-\mathrm{yr}) *(\#$ of years $)\}$

\section{Example Calculation}

Consider the case in which generation capacity planned for the next 10 years is $1,000 \mathrm{MW}$ at a budget of $\$ 500$ million. Assume the capacity would be installed in equal increments of $100 \mathrm{MW}$ each year.

Installing $100 \mathrm{MW}$ of DER this year can defer $100 \mathrm{MW}$ of capacity for one year:

$$
\begin{gathered}
\text { Capacity cost, } \$ / \mathrm{kW}-\mathrm{yr}=\left(\begin{array}{c}
\$ 500,000,000) /((1,000,000 \mathrm{~kW}) *(10 \text { years })) \\
=\$ 50 / \mathrm{kW}-\mathrm{yr}
\end{array}\right. \\
\text { Benefit }(\$)=(100,000 \mathrm{~kW}) *(\$ 50 / \mathrm{kW}-\mathrm{yr}) *(1 \text { year }) \\
=\$ 5,000,000
\end{gathered}
$$




\section{C.7.3. Ancillary Services}

Ancillary services comprise a number of valuable electrical attributes that are required for the safe, reliable, and efficient operation of a power system. Typically provided by large central plants for economy and simplicity of operation, several types of ancillary services can also be provided by distributed generators. In fact, given that many DER technologies are nearly as efficient as new central generation, they may actually be more efficient in delivering ancillary services, especially when locational advantages are considered (as with line losses). It is anticipated that there will be markets for ancillary services just as there are for bulk generation; the buyer(s) of the services might be the generators, qualified scheduling entities, or the ISO. The identification of beneficiaries and development of economic accounting tools for ancillary services are key unresolved issues of utility restructuring.

Logistically, ancillary services could be procured from DER that are directly controlled and dispatched by a qualified scheduling entity or the ISO; that is, the DER would have communication and control equipment installed so that they could be monitored and dispatched. Alternatively, the ISO could contract with DER to operate at certain times and with specified performance requirements, with economic penalties for non-performance.

Examples of ancillary services are presented in the following sections.

\section{C.7.3.1. Volt/NAR Control}

DER can be used in lieu of capacitors or other devices to provide the reactive power (kVAR) needed to improve or control voltage profiles on distribution feeders and to generally improve overall system voltage. Capacity values of $\$ / \mathrm{kVAR}$ should be readily available from the T\&D utility for each voltage level in the system, representing the equipment cost of capacitors that the T\&D utility would purchase for voltage correction. Improvement in system voltage profile contributes to increased stability margin as well because the system is less susceptible to voltage collapse during contingencies.

\section{C.7.3.2. Reliability Must Run}

DER are located and operated in specific areas and for specific times to relieve transmission constraints.

\section{C.7.3.3. Spinning Reserve}

The DER operates at reduced load but is ready to pick up additional load if another generator (or generators) in a specified area is forced out of service.

\section{C.7.3.4. Load Frequency Control}

The DER acts as a "swing bus": it adjusts its output to compensate for normal variations in customer load to keep system frequency constant.

\section{C.7.3.5. Load Following}

The DER "tracks" a particular load, i.e., it adjusts its output so that the load has a minimal effect on the rest of the system. 


\section{C.7.3.6. Scheduling and Unit Commitment}

Large generating plants can be uneconomical to use for cycling duty or for reliability-mustrun applications in which the capacity needs are small or the hours of operation are few. Using DER can be more economical than committing a large plant for these purposes.

\section{C.7.3.7. Black Start Capability}

After a T\&D outage, a DER can bring up local loads (forming a "microgrid") and eventually resynchronize with the grid, easing the difficulty of system restoration. 


\section{Appendix D. Bibliography}

\section{D.1 Background}

1. Anderson, P.M. Analysis of Faulted Power Systems. IEEE Press, 1995.

2. Bower, Joseph L.; Christensen, Clayton M. "Disruptive Technologies: Catching the Wave." Harvard Business Review, January/February 1995.

3. California Alliance for Distributed Energy Resources - Collaborative Report and Action Agenda, January 1998.

4. Chapel, Stephen W. "Future Role of IPPs and Distributed Generation." Proceedings of the Twenty-First Annual Illinois Energy Conference: The Role of Natural Gas in Our Electric Future, University of Illinois at Chicago, 1993.

5. Electric Distribution Systems Engineering Handbook. Third Edition, McGraw-Hill, 1994.

6. Electricity Pricing for a Competitive Market. EPRI report \#TR-105226, June 1995.

7. Grainger, J.J.; Stevenson, W. D. Power System Analysis. McGraw-Hill International Editions, 1994.

8. Iannucci, Joseph J. Improved Asset Utilization With the Distributed Utility, EPRI Strategic Resource Planning and Asset Management Forum, St. Petersburg Beach, FL, December 1993.

9. Iannucci, Joseph J.; Coles, Lynn; Bloom, Jeremy. The Distributed Utility - Is This the Future? Sixth International Conference and Exhibition for the Power Generating Industries (POWER-GEN'93), November 1993.

10. Iannucci, Joseph J.; Eyer, James M. Assessing Market Acceptance and Penetration for Distributed Generation in the United States. Report to the United States Department of Energy, Energy Information Administration, June 1999.

11. Iannucci, Joseph J.; Horgan, Susan A.; Eyer, James M. Distributed Utility Opportunities in a Competitive Electricity Market. Presented at the 10th International Conference and Exhibition for the Power Generating Industries (POWER-GEN '97), November 1997.

12. Iannucci, Joseph J.; Horgan, Susan A.; Eyer, James M. "The Distributed Future.” Electric Perspectives, May/June 1998.

13. Iannucci, Joseph J.; Pupp, Roger; Bautista, Paul. Gas Industry Distributed Utility Market Analysis. Gas Research Institute report \#GRI-96/0029. Presented at the 9th International Conference and Exhibition for the Power Generating Industries (POWER-GEN '96), November 1996.

14. Iannucci, Joseph J.; Pupp, Roger; Hamm, G.; Graves, F.; Taylor, A. Strategic Market Assessment of Distributed Resources. EPRI report \#TR-106055, 1996.

15. Jenkins, et. al. Embedded Generation. Institution of Electrical Engineers (IEE), 2000. 
16. Kirby, Brendan; Kueck, John. Review of the Structure of Bulk Power Markets. Oak Ridge National Laboratory report \#ORNL/TM-2000/41. Consortium for Electric Reliability Technology Solutions, December 1999.

17. Kobayashi, Hiromu. Concepts of a New Power Network System for Demand Area, Central Research Institute of Electric Power Industry, Tokyo, Japan.

18. Krause, P.C.; et. al. Analysis of Electric Machinery. IEEE Press, 1994.

19. Kundur, P. Power System Stability and Control. McGraw-Hill, 1994.

20. Künneke, Rolf W. “Electricity Networks: How 'Natural' is the Monopoly?” Utilities Policy, 1999.

21. Lamarre, Leslie. “The Vision of Distributed Generation.” EPRI Journal, April/May 1993.

22. Morse, Jay. The Distributed Generation Utility - A Restructured Perspective, Second Annual EPRI Distributed Resources Conference, Vancouver, B.C., 1996.

23. New Service Opportunities for Electric Utilities. EPRI report \#TR-104345, July 1994.

24. ONSITE Energy Corp. Chemical Industry On-Site Power Market Assessment. Report to the US DOE and the Gas Research Institute, September 1997.

25. ONSITE SYCOM Energy Corp. Gas Turbine Power Generation Combined Heat and Power - Environmental Analysis and Policy Considerations. Report to the US DOE and the Gas Research Institute, November 1998.

26. ONSITE SYCOM Energy Corp. Market Assessment of Combined Heat and Power in the State of California. Report to the California Energy Commission, September 1999.

27. ONSITE SYCOM Energy Corp. The Market and Technical Potential for Combined Heat and Power in the Commercial/Institutional Sector. Report to the Energy Information Administration, January 2000.

28. Orans, Ren; Feinstein, Charles D.; Chapel, Stephen W. "The Distributed Utility: A New Electric Utility Planning and Pricing Paradigm." Annual Review of Energy and the Environment, Vol. 22, 1997.

29. Schoenung, Susan M.; Iannucci, Joseph J.; Horgan, Susan A.; Eyer, James M. "Energy Storage for a Competitive Power Market." Annual Review of Energy and the Environment, Vol. 21, 1996.

30. Staff Report on Electric Retail Markets and Distribution Services. California Public Utilities Commission Order Instituting Rulemaking into Distributed Generation R. 99-10025, April 2000.

31. Structural Change and Futures for Electric Utility Industry. EPRI report \#TR-105144, June 1995.

32. Swisher, J.; Orans, R. “A New Utility DSM Strategy Using Intensive Campaigns Based on Area-Specific Costs." Utilities Policy, 1996. 
33. Van Cutsem, T.; Vournas, C. Voltage Stability of Electric Power Systems. Kluwer Academic Press, 1998.

34. Weinberg, Carl J.; Iannucci, Joseph J.; Reading, Melissa L. "The Distributed Utility: Technology, Customer, and Public Policy Changes Shaping the Electrical Utility of Tomorrow." Energy Systems and Policy, Vol. 15, No. 4, 1993.

\section{D.2 Technical Issues}

1. Advancements in Integrating DSM and Distributed Generation and Storage into $T \& D$ Planning: Proceedings from the 3rd Annual Workshop. EPRI report \#TR-104255, September 1994.

2. Allgood, Glenn O.; Anderson, Richard L.; McIntyre, Timothy J.; Kirby, Brendan. An Intelligent Agent Infrastructure for Monitoring and Control That Will Support Distributed Energy Resources in a Restructured Electric Power Industry. Oak Ridge National Laboratory, January 2001.

3. Barker, P.; Leskan, T.; Zaininger, H.; Smith, D. Integration of Distributed Resources in Electric Utility Systems: Current Interconnection Practice and Unified Approach. EPRI report \#TR-111489, November 1998.

4. Barnes, P.R.; Van Dyke, J.W.; Tesche, F.M.; Zaininger, H.W. The Integration of Renewable Energy Sources into Electric Power Distribution Systems. Oak Ridge National Laboratory report \#ORNL-6775, 1994.

5. Best Current Practices in Integrating DSM into T\&D Planning: Proceedings from the Second Annual Workshop. EPRI report \#TR-102955, December 1993.

6. Budhraja, Vikram; Martinez, Carlos; Dyer, Jim; Kundgagunta, Mohan. Interconnection and Controls for Reliable, Large Scale Integration of Distributed Energy Resources. Lawrence Berkeley National Laboratory report \#LBNL-45274. December 1999.

7. Cardell, Judith B.; Ilić, Marija D.; Tabors, Richard D. Integrating Small Scale Distributed Generation into a Deregulated Market: Control Strategies and Price Feedback. MIT-EL 98-001. Massachusetts Institute of Technology Energy Laboratory, April 1998.

8. Davis, Murray, et. al. Edison Electric Institute Distributed Resources Task Force Interconnection Study. Edison Electric Institute, June 2000.

9. Dispersed System Impacts: Survey and Requirements Study. EPRI report \#TR-103337, July 1994.

10. Distributed Generation Primer: Building the Factual Foundation. Arthur D. Little, October 1999.

11. Distribution System Operations and Planning Workshop Report. California Public Utilities Commission Order Instituting Rulemaking into Distributed Generation R. 99-10025, April 2000. 
12. Donnelly, M.K.; Dagle, J.E.; Trudnowski, D.J.; Rogers, G. J. "Impacts of the Distributed Utility on Transmission System Stability." IEEE Transaction on Power Systems, Vol. 11, No. 2, May 1996.

13. Integrating Dispersed Storage and Generation into Power System Control. EPRI report \#EL-4957, March 1987.

14. Jenkins, N.; Allan, R.; Crossley, P.; Kirschen, D.; Strbac, G. Embedded Generation. Institution of Electrical Engineers, 2000.

15. Jewell, T.; Rizy, T. Interconnection Problems Associated With Small Dispersed Generators and Inverter Devices. Fourteenth Annual Pittsburgh Conference on Modeling and Simulation, 1983.

16. Kobayashi, Hiromu. Multiple Inverter Configuration. Central Research Institute of Electric Power Industry, Tokyo, Japan.

17. Kobayashi, H.; Cakigawa, K; Hashimoto, E.; Kitamura, A.; Matsuda, H. "Method of Preventing Islanding Phenomena on Utility Grid With a Number of Small Scale PV Systems." Proceedings of the 22nd IEEE PV Specialists Conference. October 1991.

18. Koepfinger, J.L. Barrier to Interconnection of Distributed Generation and Other Issues. EEI Workshop on Distributed Resources, June 1998.

19. Longrigg, Paul. Effects on Electrical Distribution Networks of Dispersed Power Generation at High Levels of Penetration. Solar Energy Research Institute paper \#SERI/TP-214-2008, July 1983.

20. Minutes of Utility Workshop on Integrating DSM into T\&D Planning. San Francisco, CA: EPRI, June 1992.

21. Nanahara, Toshiya. Islanding Detection - Japanese Practice. Central Research Institute of Electric Power Industry, Tokyo, Japan.

22. Nichols, D.; Key, T. Compatibility Testing of Grid-Connected Distributed Resources. EPRI Power Quality Applications 2000 Conference, Memphis, TN, June 2000.

23. Recommendation Regarding Distributed Generation Interconnection Rules. California Energy Commission staff report \#P700-00-006, for California Public Utilities Commission Order Instituting Rulemaking into Distributed Generation R. 99-10-025, April 2000.

24. Review of Utility Interconnections, Tariff, and Contract Provisions for Distributed Generation. National Association of Regulatory Utility Commissioners, http://www.naruc.org, January 2000.

25. Rogers, W.S J. Impact of Embedded Generation on Design, Operation, and Protection of Distribution Networks. IEE Colloquium on the Impact of Embedded Generation on Distribution Networks, October 15, 1996. 
26. Salman, S.K. The Impact of Embedded Generation on Voltage Regulation and Losses of Distribution Networks. IEE Colloquium on the Impact of Embedded Generation on Distribution Networks, October 15, 1996.

27. Wasynczuk, Oleg. Integration of Dispersed PV Generation into Utility Distribution Systems: Stability, Interaction, and Fault Tolerance. Nineteenth Intersociety Energy Conversion Engineering Conference, August 1984.

28. Workshop Report on Distributed Generation CEQA and Permit Streamlining. California Energy Commission staff report \#P700-00-003, for California Public Utilities Commission Order Instituting Rulemaking into Distributed Generation R. 99-10-025, April 2000.

29. Workshop Report on Distributed Generation Interconnection Rules. California Energy Commission staff report \#P700-00-005, for California Public Utilities Commission Order Instituting Rulemaking into Distributed Generation R. 99-10-025, June 2000.

30. Zavadil, Robert M., et. al. Utility Integration of Photovoltaic Systems. EPRI Research Project 3179-01. Work performed by Electrotek Concepts Inc. for the Electric Power Research Institute, 1995.

\section{D.3 Benefits, Calculations, Measurement}

1. 20-kW Fuel Cell Monitoring and Evaluation Program. Final Report \#97-3. New York State Energy Research and Development Authority, February 1997.

2. Alderfer, R.B.; Starrs, T.J.; Eldridge, M. M. Making Connections: Case Studies of Interconnection Barriers and Their Impacts on Distributed Power Projects. NREL/SR200-28053. National Renewable Energy Laboratory, http://www.eren.doe.gov/distributedpower/, May 2000.

3. Analysis of the Economic and Environmental Benefits of Market Penetration of Distributed Generation. Oak Ridge National Laboratory and the Environmental Protection Agency, April 1999.

4. Assessment of the Benefits of Distributed Fuel Cell Generators in the Service Areas of Central and South West Services Inc. EPRI report \#TR-102468. October 1993.

5. Begovic, M.; Ropp, M.; Rohatgi, A.; Progelj, A. Determining the Sufficiency of Standard Protective Relaying for Islanding Prevention in Grid-Connected PV Systems.

Proceedings of the 2nd World Conference on Photovoltaic Solar Energy Conversion, Vienna, Austria, July 1998.

6. Cardell, J.; et. al. Integrating Small Scale Generation into a Deregulated Market: Control Strategies and Price Feedback. Massachusetts Institute of Technology, 1998.

7. Chapel, Stephen W.; Feinstein, Charles D.; Coles, Lynn R.; Iannucci, Joseph J. An Introduction to the Distributed Utility Valuation Project Monograph. EPRI report \#TR102461. Sponsored by the Electric Power Research Institute, National Renewable Energy Laboratory, and Pacific Gas and Electric Co., July 1993. 
8. Chapel, Stephen W.; Pupp, Roger; Coles, Lynn R.; Iannucci, Joseph J. Distributed Utility Valuation Project Monograph. EPRI report \#TR-102807. Sponsored by the Electric Power Research Institute, National Renewable Energy Laboratory, and Pacific Gas and Electric Co., July 1993.

9. Chapel, Stephen W.; Richardson, D. New T\&D Planning Methodology. EPRI report \#IN105750. 1996.

10. Coles, Lynn R.; Iannucci, Joseph J.; Chapel, Stephen W. Valuation of Modular Generation, Storage, and Targeted Demand-Side Management. Paper \#94 SM 366-5 EC. IEEE Power Engineering Society 1994 Summer Meeting, San Francisco, CA, July 1994.

11. Cost-Benefit Analysis of Power System Reliability: Determination of Interruption Cost. EPRI report \#EL-6791. April 1990.

12. Customer Backup Generation: Demand-Side Management Benefits for Utilities and Customers. EPRI report \#CU-7316. July 1991.

13. "Demand-Side Management Impacts on the Transmission and Distribution System." IEEE Transactions on Power Systems, Vol. 15, No. 2, May 1989.

14. DERWorkstation Version 1.0. Software product \#AP-111900-CD. Prepared by Electrotek Concepts Inc. for the Electric Power Research Institute. February 1999.

15. Distributed Generation Assessment for Azienda Energetica Municipale of the City of Milan, Phase I: Siting and Technology Screening for High Value Applications. EPRI report \#TR-10408. July 1994.

16. Distributed Generation Assessment Guidelines - A Market-Based Framework for Evaluating High-Value Applications, Vol. 1: Executive Summary. EPRI report \#TR102532 V-1. December 1993.

17. Distributed Generation Assessment Guidelines - A Market-Based Framework for Evaluating High-Value Applications, Vol. 2: Process, Methodology and Procedures. EPRI report \#TR-102532 V-2. 1995.

18. Distributed Generation Characterization and Assessment for San Diego Gas and Electric. EPRI report \#TR-104405. October 1994.

19. Distributed Resources Assessment in the Service Territory of ANZA Electric Cooperative. EPRI report \#TR-104153. October 1994.

20. DSM: Transmission and Distribution Impacts, Volume 1: Analysis Framework and Test Case. EPRI report \#CU-6924. August 1990.

21. DSM: Transmission and Distribution Impacts, Volume 2: Application on Spatial Frequency Analysis. EPRI report \#CU-6924. August 1990.

22. Engineering Methods for Estimating DSM Impacts, Vol. 1: Fundamentals of Engineering Simulations for Residential and Commercial End Uses. EPRI report \#TR-100984. July 1992. 
23. EPRI Investment Strategies Project, Volume 1: Value of Flexibility and Modularity of Distributed Generation. Report \#TR-104171, October 1994.

24. Firor, Kay; Vigotti, Roberto; Iannucci, Joseph J. "Utility Field Experience With Photovoltaic Systems." Renewable Energy. Island Press, 1993.

25. Geographically Targeted Industrial Interruptible/Curtailable Rates for T\&D Benefits. EPRI Technical Brief TB-104500. November 1994.

26. Graf, J.D.; Häeberlin, H. Photovoltaic Research Program - Quality Assurance of Photovoltaic Systems Final Report. Commissioned by the Swiss Federal Office of Energy, July 2000 (in German).

27. Hoff, Tom. Does Kerman Provide Local Utility Value? - Kerman Local Systems Benefits. PVUSA Grid-Support Photovoltaics Workshop, June 1994.

28. Hoff, Tom; Wenger, Howard. Reliability, Environmental, and Modularity Value: Finding the Right Approach. PVUSA Grid-Support Photovoltaics Workshop, June 1994.

29. Iannucci, Joseph J.; Eyer, James M. Analysis of the Economic and Environmental Benefits of Market Penetration of Distributed Generation. DOE (OIT), Oak Ridge National Laboratory, and US Environmental Protection Agency, Spring 1999.

30. Iannucci, Joseph J.; Eyer, James M. Introduction to Distributed Utility Associates' Proprietary DUVal Methodology for Estimating Market Potential for Distributed Electric Resources. Distributed Utility Associates, Fall 1998.

31. Iannucci, Joseph J.; Eyer, James M. Market Potential for Distributed Solar Dish-Stirling Power Plants in the Southwestern U. S., Operated in Solar-Only and Solar/Natural Gas Hybrid Modes. US Department of Energy/National Renewable Energy Laboratory, December 1998.

32. Ignacio Substation Natural Gas Fired Mobile Engine Generator for Distributed Peaking Generation. PG\&E R\&D Update.

33. Integration of Distributed Resources in Electric Utility Systems: Current Interconnection Practice and a Unified Approach. EPRI Report TR-111489.

34. Ishikawa, Tadao. Review of Technology, Experiences, and Guidelines for GridInterconnection of PV Systems - Japan. Central Research Institute of Electric Power Industry, Tokyo, Japan.

35. Kern, G.; Bonn, R.; Ginn, J.; Gonzalez, S. Results of Sandia National Laboratories' Grid-Tied Inverter Testing, 2nd World Conference on Photovoltaic Solar Energy Conversion, Vienna, Austria, July 1998.

36. Kitamura, Akio. Demonstration Test Results for Grid Interconnected Photovoltaic Power Systems. International Energy Agency report \#IEA-PVPS T5-02:1999. March 1999.

37. Lineweber, D.; McNulty, S.; Iannucci, J.; Horgan, S.; Eyer, J. Markets for Distributed Resources: Business Cases for DER Applications. EPRI report \# TR-109234-V2. November 1997. 
38. Lineweber, D.; McNulty, S.; Iannucci, J.; Horgan, S.; Eyer, J. Quantifying the Market for Distributed Resource Technologies; Profiles of the Chemical, Food Processing, Electronics, and Hotel Industries. EPRI report \# TR-111962. November 1998.

39. Lineweber, D.; McNulty, S.; Iannucci, J.; Horgan, S.; Eyer, J. Understanding Customer Needs and Markets for Distributed Resources. EPRI report \# TR-109234-V1. November 1997.

40. Methods for Analyzing Demand-Side Management Impacts on T\&D Systems. EPRI Technical Brief \#TB-101353. December 1992.

41. "Mini-SMES Device Demonstrated." PG\&E Research Reporter. Published by PG\&E Research and Development Department. San Ramon, CA, Winter 1991.

42. Model Energy Communities Program: Delta Project 1991-1994 Evaluation Report. PG\&E Marketing Department, San Francisco, CA, July 1994.

43. Modular Generation Test Facility. PG\&E Research and Development Department technology flier. San Ramon, CA, May 1991.

44. "Modular Generation Test Facility: Testing Ground for the Future." Currents. Published by the PG\&E Technology Center, San Ramon, CA. May 1991.

45. Molten Carbonate Fuel Cells as Distributed Generation Resources: Case Studies for the Los Angeles Department of Water and Power. EPRI report \#TR-100686. May 1992.

46. Orans, Ren. Area Specific Marginal Costing for Electric Utilities: A Case Study of Marginal Transmission and Distribution Costs. Ph. D. dissertation, Civil Engineering Dept., Stanford University, 1989.

47. Orans, Ren; Woo, Chi-Keung; Horii, Brian. "Case Study: Targeting Demand-Side Management for Electricity Transmission and Distribution Benefits." Managerial and Decision Economics, Vol. 15, 1994.

48. Photovoltaic Generation Effects on Distribution Feeders: Analysis Methods and Results. EPRI RP2838-1 Final Report, Vol. 2. New England Public Service Co., October 1993.

49. Photovoltaic Generation Effects on Distribution Feeders: Description of the Gardner, Massachusetts, Twenty-First Century PV Community and Research Program. EPRI RP2838-1 Final Report, Vol. 1. New England Public Service Co., March 1990.

50. Photovoltaic Generation Effects on Distribution Feeders: Monitoring Results From the Gardner, Massachusetts, PV Community. EPRI report \#EL-6754, Vol. 3. New England Power Service Co., January 1992.

51. Proceedings of the Distributed Utility Valuation Project: Institutional Issues Workshop; November 12, 1993, Golden, CO. DOE/CH1 0093-2 83 [DE94000296]. Golden, CO: National Renewable Energy Laboratory, 1994.

52. Proceedings of the Distributed Utility Valuation Project: Research Results and Utility Experience Workshop; March 15-16, 1994, Golden, CO. NREL/CP-463-6829. Golden, CO: National Renewable Energy Laboratory, June 1994. 
53. Pupp, Roger; Woo, C.K. Costs of Service Disruptions to Electricity Customers. The Analysis Group Inc., January 1991.

54. Shugar, Daniel S.; EI-Gasseir, M.; Jones, A.; Orans, R. Benefits of Distributed Generation in PG\&E's T\&D System: A Case Study of Photovoltaics Serving Kerman Substation. Pacific Gas and Electric Co. R\&D report, 1991.

55. Shugar, Daniel S.; Hoff, Thomas E. "Grid-Support Photovoltaics: Evaluation of Criteria and Methods to Assess Empirically the Local and System Benefits to Electric Utilities." Progress in Photovoltaics and Applications, Vol.1, 1993.

56. Stevens, J. Utility Intertied Photovoltaic System Islanding Experiments. Proceedings of the 19th IEEE PV Specialists Conference, New Orleans, LA, 1987.

57. T\&D Benefits of Direct Load Control: Seattle City Light and Snohomish PUD Pilot Project Evaluation. EPRI report \#TR-103993. November 1993.

58. Targeting DSM for Transmission and Distribution Benefits: A Case Study of PG\&E's Delta District. EPRI report \#TR-100487. April 1992.

59. Utility Benefits From Targeting Demand-Side Management Programs at Specific Distribution Areas. EPRI report \#EM-4771. August 1986.

60. Wenger, Howard. Does Kerman Provide Traditional Utility Value? - Kerman Performance \& Bulk Systems Benefits. PVUSA Grid-Support Photovoltaics Workshop, June 1994.

61. Wenger, Howard J.; Hoff, Thomas E. The Value of Photovoltaics in the Distribution System - The Kerman Grid-Support Project. DOE/AL/82993-20. PVUSA project report, May 1995.

62. Wenger, Howard J.; Hoff, Thomas E.; Farmer, Brian K. Measuring the Value of Distributed Photovoltaic Generation: Final Results of the Kerman Grid-Support Project. First World Conference on Photovoltaic Energy Conversion, Waikoloa, HI, December 1994.

63. Wenger, Howard J.; Hoff, Thomas E.; Shugar, Daniel S.; Farmer, Brian K. PVUSA 500kW Grid-Support Photovoltaic Project: Interim Results on Value. Presented at Soltech ' 94 Conference, Ponte Vedga Beach, FL, March 1994, and at the 12th European Photovoltaic Conference, Amsterdam, Holland, April 1994.

64. Whitaker, Charles M.; Farmer, Brian K.; Gough, E. James, et. al. Design, Construction, and Performance of the PVUSA Kerman 500-kW Photovoltaic Power Plant. Presented at the IEA Implementing Agreement on Photovoltaics Task IV Workshop, Paestum, Italy, July 1994.

65. Zaininger, H.W.; Clark, H.K.; Brownell, G.C. Potential Economic Benefits of Battery Storage to Electrical Transmission and Distribution Systems. EPRI report \#GS-6687. 1990. 


\section{D.4 Codes and Standards}

1. 1999 National Electrical Code. National Fire Protection Association, NFPA 70.

2. American National Standard for Electric Power Systems and Equipment Ratings (60 Hertz). ANSI Standard C84.1-1989.

3. American National Standard for Rotating Electrical Machinery-Cylindrical-Rotor Synchronous Generators. ANSI Standard C50.13-1989.

4. American National Standard for Rotating Electrical Machinery-Synchronous Machines. ANSI Standard C50.10-1990.

5. DeBlasio, Richard. Status Update: IEEE SCC21 Activities. Presentation on behalf of the Institute of Electrical and Electronics Engineers Standards Coordinating Committee 21 (SCC 21). April 2000.

6. Electricity Association. Engineering Recommendation G74: Procedure to Meet the Requirements of IEC 909 for the Calculation of Short Circuit Currents in Three-Phase AC Power Systems. 1992.

7. Electromagnetic Compatibility, Part 3: Limits; Section 7: Assessment of Emission Limits for Fluctuating Loads in MV and HV Power Systems. IEC Standard 61000-3-7.

8. Electromagnetic Compatibility, Part 4: Testing and Measuring Techniques; Section 15: Flickermeter - Functional and Design Specifications. International Electrotechnical Commission Standard 61000-4-15.

9. IEEE Guide for Interfacing Dispersed Generation and Storage Facilities With Electric Systems. ANSI/IEEE Standard 1001-1988 (obsolete/withdrawn).

10. IEEE Guide for Service to Equipment Sensitive to Momentary Voltage Disturbances. IEEE Standard 1250-1995.

11. IEEE Guide on Surge Testing for Equipment Connected to Low-Voltage AC Power Circuits. IEEE Standard C62.45-1992 (R1998).

12. IEEE Guide: Test Procedures for Synchronous Machines, Part I-Acceptance and Performance Testing. IEEE Standard 115-1995.

13. IEEE Guide: Test Procedures for Synchronous Machines, Part II - Test Procedures and Parameter Determination for Dynamic Analysis. IEEE Standard 115-1995.

14. IEEE Recommended Practice for Monitoring Electric Power Quality. IEEE Standard 1159-1995.

15. IEEE Recommended Practice for Utility Interface of Photovoltaic (PV) Systems. IEEE Standard 929-2000.

16. IEEE Recommended Practice on Surge Voltages in Low Voltage AC Power Circuits. IEEE Standard C62.41-1980 (R1995). 
17. IEEE Recommended Practice: Test Procedure for Utility Interconnected Static Power Converters. ANSI/IEEE Standard 1035-1989 (obsolete/withdrawn).

18. IEEE Recommended Practices and Requirements for Harmonic Control in Electric Power Systems. IEEE Standard 519-1992.

19. IEEE Standard C37.63-1997: IEEE Standard Requirements for Overhead, Pad-Mounted, Dry-Vault, and Submersible Automatic Line Sectionalizers for AC Systems.

20. IEEE Standard P1547 (Draft 07) for Distributed Resources Interconnected With Electric Power Systems. IEEE Standards Coordinating Committee 21, February 2001.

21. IEEE Standard Test Procedure for Polyphase Induction Motors and Generators. IEEE Standard 112-1996.

22. International Electrotechnical Commission. IEC 909: Short Circuit Calculation for Three-Phase AC Systems, 1988.

23. Inverters, Converters, and Controllers for Use in Independent Power Systems. Underwriters Laboratories Standard UL 1741, Revised January 2001.

24. Pacific Gas and Electric Co. Supplemental Filing Revising Rule 21, Generating Facilities Interconnection. January 2001.

25. Siting Committee Supplemental Recommendation on Distributed Generation Interconnection Rules. California Public Utilities Commission Order Instituting Rulemaking into Distributed Generation R. 99-10-025, October 2000.

26. Southern California Edison Co. Supplemental Filing Revising Rule 21, Generating Facilities Interconnection. January 2001.

27. Standard for Safety: Stationary Engine Generator Assemblies. UL 2200.

28. Standard for the Installation and Use of Stationary Combustion Engines and Gas Turbines. NFPA-37.

29. Standard Interconnection Requirements. New York State Public Service Commission, http://www.dps.state.ny.us/94e0952_11152000.pdf. November 2000.

30. Substantive Rules Chapter 25, Applicable to Electric Service Providers. Public Utility Commission of Texas, http://www.puc.state.tx.us/rules/subrules/electric/index.cfm.

31. Surge Withstand Capability Tests for Protective Relays and Relay Systems. IEEE Standard C37.90.1-1989 (R1994).

32. Type Tested and Approved Equipment. New York State Public Service Commission, http://www.dps.state.ny.us/SIRDevices.pdf. November 2000.

33. Withstand Capability of Relay Systems to Radiated Electromagnetic Interference from Transceivers. IEEE Standard C37.90.2. 


\section{Appendix E. Technology Vendors}

\begin{tabular}{|c|c|}
\hline \multicolumn{2}{|c|}{ Distributed Power Equipment and Services Vendors } \\
\hline \multicolumn{2}{|l|}{ Energy Storage } \\
\hline Liebert & http://www.liebert.com/ \\
\hline Exide & http://www.exide.com/ \\
\hline Electrosource & http://www.electrosource.com/ \\
\hline Williams & http://www.williams.com/ \\
\hline Beacon Power & http://www.beaconpower.com/ \\
\hline Active Power & http://www.activepower.com/ \\
\hline American Superconductor & http://www.amsuper.com/ \\
\hline International Computer Power & http://www.rotoups.com/ \\
\hline Piller & http://www.piller.com/ \\
\hline Maxwell & http://www.maxwell.com/ \\
\hline PEAC & http://www.epri-peac.com/ \\
\hline \multicolumn{2}{|l|}{ Fuel Cells } \\
\hline Ballard Power Systems & http://www.ballard.com \\
\hline DCH Technology & http://www.dch-technology.com \\
\hline Dais Analytic & http://www.daisanalytic.com \\
\hline FuelCell Energy & http://www.fce.com \\
\hline GE MicroGeneration & http://www.gemicrogen.com \\
\hline H Power Corp. & http://www.hpower.com \\
\hline IdaTech (Northwest Power Systems) & http://www.idatech.com \\
\hline International Fuel Cells (United Technologies) & http://www.internationalfuelcells.com \\
\hline NuPower (Energy Partners Inc.) & http://www.energypartners.org \\
\hline Plug Power & http://www.plugpower.com \\
\hline Proton Energy Systems & http://www.protonenergy.com \\
\hline GE (GE Power) & $\begin{array}{l}\text { http://www.gepower.com/microgen/homegen_prod_d } \\
\text { esc.html }\end{array}$ \\
\hline Sure Power & http://www.hi-availability.com \\
\hline FCE (Fuel Cell Energy) & http://www.fce.com/ \\
\hline \multicolumn{2}{|l|}{ Microturbines } \\
\hline AeroVironment & http://www.aerovironment.com/ \\
\hline Capstone & http://www.capstoneturbine.com \\
\hline Elliott Energy Systems/MagneTek & http://www.magnatek.com/ \\
\hline GE Power Systems & http://www.ge.com \\
\hline Honeywell Parallon Power Systems & http://www.parallon75.com/ \\
\hline Ingersoll-Rand Energy Systems & http://www.ingersoll-rand.com/energystystems \\
\hline \multicolumn{2}{|l|}{ Solo Energy Corp. } \\
\hline \multicolumn{2}{|l|}{ Turbec AB } \\
\hline PowerPac (Elliot Microturbine Systems) & http://www.powerpac.com/turbine.html \\
\hline Williams Distributed Power Services & http://www.williamsgen.com \\
\hline
\end{tabular}




\begin{tabular}{|c|c|}
\hline Photovoltaics & \\
\hline Amonix & http://www.amonix.com/ \\
\hline ASE Americas & http://www.asepv.com \\
\hline AstroPower & http://www.astropower.com \\
\hline Atlantis Solar & \\
\hline BP Solar & http://www.bpsolar.com \\
\hline Ebara Solar & http://www.ebarasolar.com \\
\hline Energy Photovoltaics Inc. & http://www.epv.net \\
\hline Entech Inc. & http://www.entechsolar.com \\
\hline Evergreen Solar & http://www.evergreensolar.com \\
\hline First Solar & http://www.firstsolar.com \\
\hline Kyocera Solar & http://www.kyocerasolar.com \\
\hline Matrix Solar Technologies & http://www.matrixsolar.com \\
\hline Midway Labs & \\
\hline PowerLight & http://www.powerlight.com/ \\
\hline Siemens Solar/Shell & http://www.siemenssolar.com \\
\hline Solec & \\
\hline Spire Corp & http://www.spiresolar.com/ \\
\hline SunPower Corp & http://www.sunpowercorp.com/ \\
\hline United Solar Systems Corp. & http://ovonic.com/unisolar/ \\
\hline Internal Combustion Engines & \\
\hline Caterpillar & http://www.cat.com \\
\hline Cooper Energy Services & http://www.cooperenergy.com \\
\hline Cummins Energy Company & http://www.cummins.com \\
\hline Detroit Diesel & http://www.detroitdiesel.com \\
\hline Electryon & http://www.electryon.com \\
\hline Honda & http://www.honda.com \\
\hline Jenbacher Energie-Systeme AG & http://www.jenbacher.com \\
\hline Kohler Generators & http://www.kohlergenerators.com \\
\hline MAN B\&W Diesel & http://www.manbw.dk \\
\hline SenerTec & http://www.senertec.de \\
\hline Wartsila Diesel & http://www.wartsila-nsd.com \\
\hline Waukesha Engine & http://www.waukeshaengine.com \\
\hline Stirling Engines & \\
\hline BG Technology & http://www.bgtech.co.uk \\
\hline SIG Swiss Industrial Company & http://www.sig-group.com \\
\hline Sigma Elektroteknisk A.S. & http://www.sigma-el.com \\
\hline Solo Kleinmotoren $\mathrm{GmbH}$ & http://www.solo-germany.com \\
\hline Stirling Technology Company & http://www.stirlingtech.com \\
\hline Stirling Technology Inc. & http://www.stirling-tech.com \\
\hline Sunpower Inc. & http://www.sunpower.com \\
\hline Tamin Enterprises & http://www.tamin.com \\
\hline Whisper Tech Ltd. & http://www.whispertech.co.nz \\
\hline
\end{tabular}




\begin{tabular}{|c|c|}
\hline Wind Turbines & \\
\hline Bergey WindPower & http://www.bergey.com \\
\hline Bonus Energy A/S & http://www.bonus.dk \\
\hline Dewind Technik & http://www.dewind.de \\
\hline Ecotecnia & http://www.icaen.es/icaendee/ent/ecotech.htm \\
\hline Enercon & http://www.enercon.de \\
\hline Enron Wind & http://www.wind.eneron.com \\
\hline Gamesa Eolica & http://www.gamesa.es \\
\hline Mitsubishi Heavy Industries & http://www.mhi.co.jp \\
\hline NEG Micon & http://www.neg-micon.dk \\
\hline Nordex & http://www.nordex.dk \\
\hline Nordic Windpower & http://www.nwp.se \\
\hline Vesta Wind Systems A/S & http://www.vestas.com \\
\hline Controls & \\
\hline ASCO Controls & http://www.asco.com/ \\
\hline Encorp & http://www.encorp.com/ \\
\hline GE Zenith Controls & http://www.zenithcontrols.com/ \\
\hline Woodward Industrial Controls & http://www.woodward.com/ \\
\hline Schweitzer & http:/www.scheitzer.com \\
\hline Combined Heat and Power & \\
\hline Asea Brown Boveri & http://www.abb.com \\
\hline Inverters and Power Conditioning Systems & \\
\hline Advanced Energy Systems & http://www.advancedenergy.com/ \\
\hline AeroVironment & http://www.aerovironment.com/ \\
\hline $\begin{array}{l}\text { Xantrex (Includes Trace Engineering, Trace } \\
\text { Technologies, Heart Interface, and Statpower) }\end{array}$ & $\begin{array}{l}\text { http://www.xantrex.com; } \\
\text { http://www.traceengineering.com } \\
\text { http:///www.tracetechnologies.com/ } \\
\text { http://www.heartinterface.com/ }\end{array}$ \\
\hline $\begin{array}{l}\text { S\&C Electric Company (Formerly Omnion Power } \\
\text { Engineering) }\end{array}$ & http://www.omnion.com \\
\hline Vanner & http://www.vanner.com \\
\hline SMA America & http://www.sma.de/en/solartechnik \\
\hline $\begin{array}{l}\text { California Energy Commission Inverter Buy- } \\
\text { Down Program }\end{array}$ & $\begin{array}{l}\text { http://www.energy.ca.gov/greengrid/certified_inverter } \\
\text { s.html }\end{array}$ \\
\hline Organizations & \\
\hline Distributed Power Coalition of America & http://www.dpc.org/ \\
\hline
\end{tabular}




\section{REPORT DOCUMENTATION PAGE}

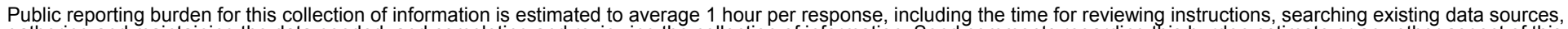

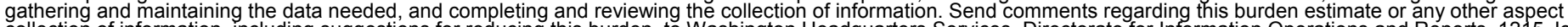

collection of information, including suggestions for reducing this burden, to Washington Headquarters Services, Directorate for Information Operations and R

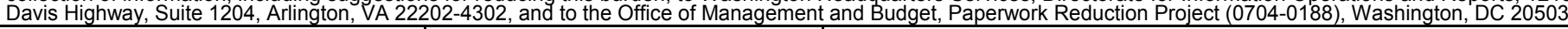

\begin{tabular}{|l|l|l|}
\hline 1. AGENCY USE ONLY (Leave blank) & $\begin{array}{l}\text { 2. REPORT DATE } \\
\text { August } 2003\end{array}$ & $\begin{array}{l}\text { 3. REPORT TYPE AND DATES COVERED } \\
\text { Subcontract }\end{array}$ \\
\hline
\end{tabular}

4. TITLE AND SUBTITLE

DUIT: Distributed Utility Integration Test
5. FUNDING NUMBERS

DP03.1001

AAD-0-30605-05

Distributed Utility Associates

8. PERFORMING ORGANIZATION

REPORT NUMBER

7. PERFORMING ORGANIZATION NAME(S) AND ADDRESS(ES)

Distributed Utility Associates

P.I. Susan Horgan

1062 Concannon Blvd.

Livermore, CA 94550

9. SPONSORING/MONITORING AGENCY NAME(S) AND ADDRESS(ES)

National Renewable Energy Laboratory

1617 Cole Blvd.

Golden, CO 80401-3393

10. SPONSORING/MONITORING AGENCY REPORT NUMBER

NREL/SR-560-34389

11. SUPPLEMENTARY NOTES

NREL Technical Monitor: Ben Kroposki

12a. DISTRIBUTION/AVAILABILITY STATEMENT

National Technical Information Service

U.S. Department of Commerce

5285 Port Royal Road

Springfield, VA 22161

13. ABSTRACT (Maximum 200 words)

The Distributed Utility Integration Test (DUIT) is a proposed test of the electrical implications of deep and diverse penetration of distributed energy resources into distribution systems.

14. SUBJECT TERMS distributed utility integration test; distribution; EPS; penetration; distributed power; distributed energy; distributed resources; DER; interconnection; National Renewable Energy Laboratory; NREL

17. SECURITY CLASSIFICATION OF REPORT Unclassified

18. SECURITY CLASSIFICATION OF THIS PAGE Unclassified
19. SECURITY CLASSIFICATION OF ABSTRACT Unclassified 12b. DISTRIBUTION CODE 